\title{
Reactor Materials Program - Baseline Material Property Handbook - Mechanical Properties of 1950's Vintage Stainless Steel Weldment Components, Task Number 89-23-A-1
}

by

K. J. Stoner

Westinghouse Savannah River Company

Savannah River Site

Aiken, South Carolina 29808

R. L. Sindelar

G. R. Caskey, Jr.

This paper was prepared in connection with work done under the above contract number with the U.S. Department of Energy. By acceptance of this paper, the publisher and/or recipient acknowledges the U.S. Government's right to retain a nonexclusive, royalty-free license in and to any copyright covering this paper, along with the right to reproduce and to authorize others to reproduce all or part of the copyrighted paper. 


\section{DISCLAIMER}

This report was prepared as an account of work sponsored by an agency of the United States Government. Neither the United States Government nor any agency thereof, nor any of their employees, makes any warranty, express or implied; or assumes any legal liability or responsibility for the accuracy, completeness, or usefulness of any information, apparatus, product, or process disclosed, or represents that its use would not infringe privately owned rights. Reference herein to any specific commercial product, process, or service by trade name, trademark, manufacturer, or otherwise does not necessarily constitute or imply its endorsement, recommendation, or favoring by the United States Government or any agency thereof. The views and opinions of authors expressed herein do not necessarily state or reflect those of the United States Government or any agency thereof.

This report has been reproduced directly from the best available copy.

Available to DOE and DOE contractors from the Office of Scientific and Technical Information, P.O. Box 62, Oak Ridge, TN 37831; prices available from (615) 576-8401.

Available to the public from the National Technical Information Service, U.S. Department of Commerce, 5285 Port Royal Road, Springfield, VA 22161. 


\section{DISCLAIMER}

Portions of this document may be illegible in electronic image products. Images are produced from the best available original document. 


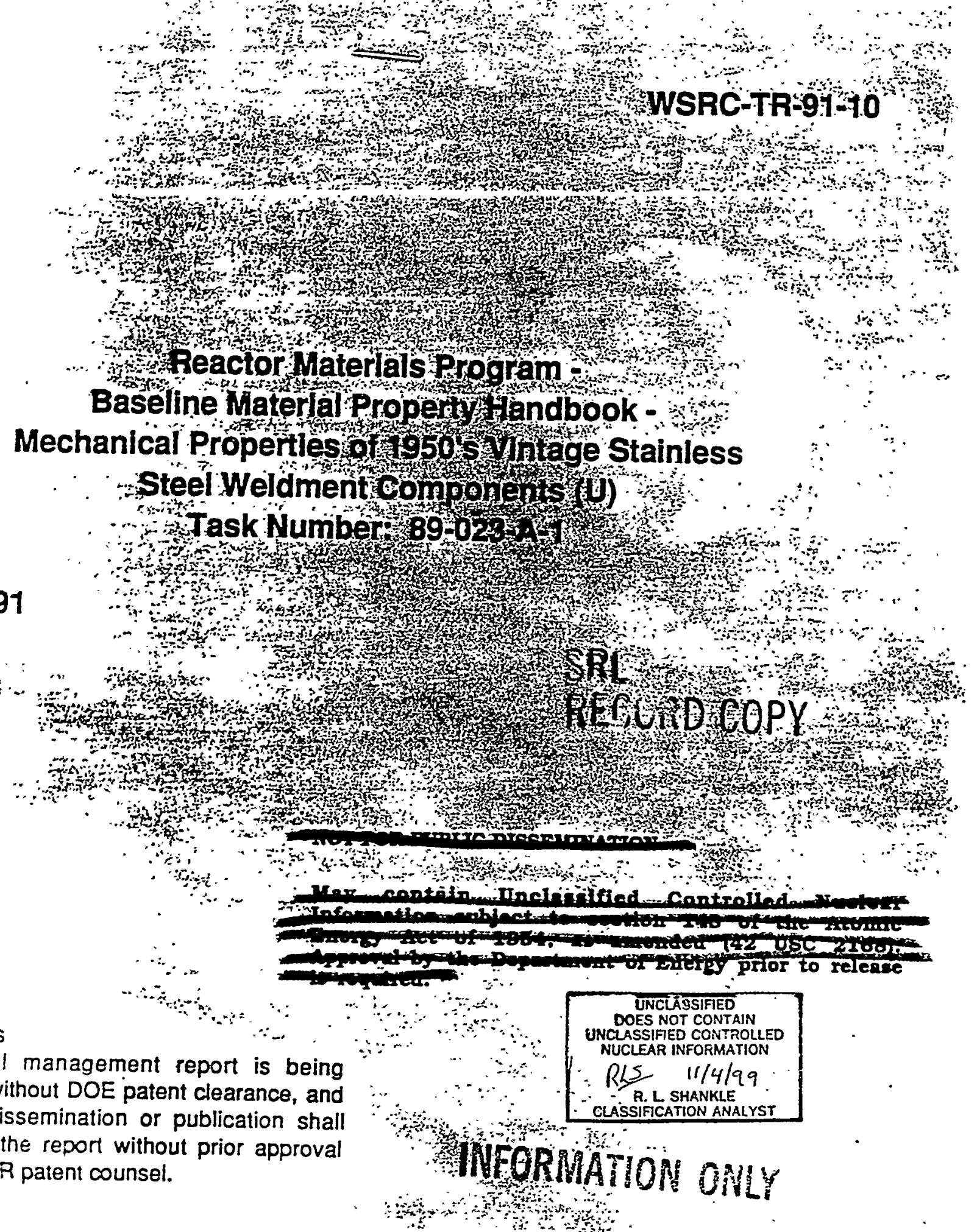

Patent Status

This interna! management report is being transmitted without DOE patent clearance, and no further dissemination or publication shall be made of the report without prior approval of ine DOE.SR patent counsel.

Westinghouse Savannah River Company

P. O. Box 616

Aiken, SC 29802 
WSRC-TR-91-10

\section{NRTSC}

NUCLEAR REACTOR TECHNOLOGY

AND SCIENTIFIC COMPUTATIONS

Keywords: Corrosion

Stainless Steol

Reactor

PTERM

CAMEL

Retention - Permanent

\section{Reactor Materials Prógram - Baseline Material Property Handbook - Mechanical Properties of 1950's Vintage Stainless Steel Weldment Components (U) \\ Task Number: 89-023-A-1}

By

K. J. Stoner utseres

R.L. Sindelar Rzfindelar

G.R. Caskey, Jr.ju Casky, 8 ,

ISSUED: April 1, 1991 
PROJECT: REACTOR MATERIALS PROGRAM

DOCUMENT: WSRC-TR-91-10

TITLE: Reactor Materials Program -

Baseline Material Property Handbook -

Mechanical Properties of 1950's Vintage

Stainless Steel Weldment Components (U)

TASK: $\quad$ Measure Mechanical Properties of Moderator Piping, Task 89-023-A-1.

APPROVALS

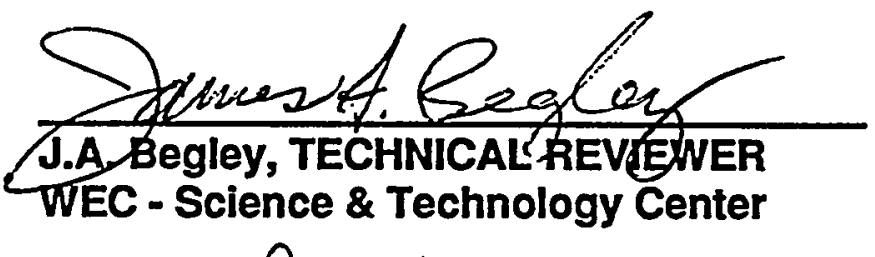

DATE: $3 / 28 / 91$

N.G.-Awadalla

DATE: M/ay 29,1991

N. G. Awadalla, MANAGER

MATERIALS TECHNOLOGY 。

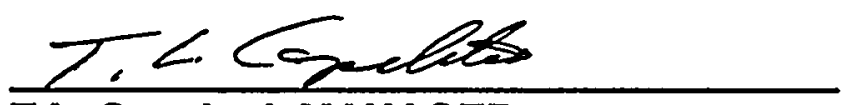

DATE: $3 / 30 / 5 /$

T.L. Capeletti, MANAGER

MATERIALS TECHNOLOGY
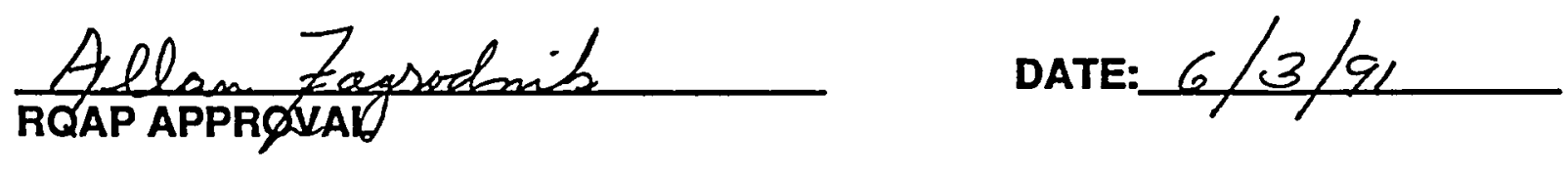


\section{Table of Contents}

Section

Page

1.0 INTRODUCTION................................................... 1-1

2.0 MATERIALS SOURCE AND CHARACTERIZATION................... 2-1

3.0 MATERIALS TESTING

3.1 Charpy Impact Testing................................................ 3-1

3.2 Tensile Testing....................................................... 3-1

3.3 Compact Tension Testing................................................ 3-2

4.0 ANALYSIS OF DATA

4.1 Static J-R Curve Data Analysis Procedures............................. 4-1

4.1.1 Overview.................................................... 4-1

4.1.2 Crack Length Evaluation-Compliance Method................................................. 4-1

4.1.3 J Integral Evaluation-JD and JM........................... 4-3

4.1.4 J-R Curve Evaluation....................................... 4-4

4.2 Dynamic J-角 Curve Data Analysis Procedures.......................... 4-4

4.2.1 Overview................................................... 4-4

4.2.2 DCPD: Theory and Measurement

Procedures....................................................... 4-5

4.2.3 Initiation and Plasticity........................................ 4-5

4.2.4 Multiple Specimen Data Analysis............................... 4-6

4.3 Static Tensile Data Analysis Procedures................................ 4-6

4.3.1 Engineering Stress/Strain.................................. 4-6

4.3.2 True Stress/Strain......................................... 4-6

4.4 Dynamic Tensile Data Analysis Procedures............................. . 4-8

4.5 Charpy Data Analysis.............................................. 4-8

4.6 Specimen Design Studies............................................ 4-8

4.6.1 Compact Tension Specimen Design

Selection................................................... 4-8

4.6.1.1 Overview........................................ 4-8

4.6.1.2 Approach....................................... 4-9

4.6.1.3 Results and Conclusions......................... 4-10

4.6.2 Compact Tension Side-Grove Study........................... 4-11

4.6.2.1 Overview......................................... 4-11

4.6.2.2 Results...................................... 4-12

4.6.2.3 Conclusions............................................. 4-13 
Table of Contents (cont'd)

Section

Page

5.0 MECHANICAL TESTING RESULTS AND DISCUSSION

5.1 Tensile Data Results................................................. 5-1

5.2 Charpy Data Results............................................... 5-2

5.3 Compact Tension Data Results........................................ 5-2

5.4 Specimen Orientation............................................... 5-2

5.5 Specimen Size Effects................................................. 5-3

5.6 Fractography........................................................ 5-3

6.0 PIPING MECHANICAL PROPERTIES: ENGINEERING STRUCTURAL ANALYSES

6.1 Overview........................................................... 6-1

6.1.1 PWS Construction Specifications and Materials of

Construction.................................................... 6-1

6.1.2 Mechanical Properties for Structural Design and AnalysisSummary................................................. 6-1

6.1.3 Tensile Properties for Structural Analysis-Summary..... 6-2

6.1.4 Fracture Toughness Properties for Structural AnalysisSummary..................................................... 6-2

6.1.5 Baseline Properties for Irradiation Effects StudiesSummary.............................................. 6-2

-2 :

6.2 Tensile Properties....................................................... 6-3

6.2.1 Handbook Data-Temperature Dependence.................. 6-3

6.2.2 ASME B31.1 and B31.1; ASME BPV Code Required Properties..................................................... 6-3

6.3 Charpy V-Notch Impact Energy....................................... 6-3

6.4 Fracture Toughness-CT Specimens.................................. 6-4.

7.0 MECHANICAL PROPERTIES: APPLICATION TO PIPING FRACTURE ANALYSES

7.1 Introduction................................................... 7-1

7.2 SRS Piping Fracture Analysis...................................... 7-1

7.2.1 Modified Limit Load Analysis: Allowable Flaw Sizes... 7-1

7.2.1.1 Flow Stress Evaluation......................... 7-2

7.2.1.2 Circumferential Flaw Size Evaluation.......... 7-2

7.2.1.3 Longitudinal Flaw Size Evaluation............. 7-3

7.2.2 Elastic-Plastic Fracture Analysis.............................. 7-5

8.0 CORRELATION OF NOTCH DUCTILITY (CHARPY V-NOTCH ABSORBED ENERGY) and FRACTURE TOUGHNESS PARAMETERS

8.1 Overview............................................................ 8-1

8.2 Results........................................................... 8-1

8.3 Conclusions............................................................... 8-2 
Table of Contents (cont'd)

Section

Page

9.0 FUTURE STUDIES................................................. 9-1

10.0 REFERENCES.................................................... 10-1

ATTACHMENT 1: BASELINE MECHANICAL PROPERTY TEST RESULTS

ATTACHMENT 2: MECHANICAL TEST DATA - DIGITIZED PLOTS

$=\pi \quad-x$

) 


\section{EXECUTIVE SUMMARY}

The Process Water System (primary coolant) piping of the nuclear production reactors constructed in the 1950's at Savannah River Site is comprised primarily of Type 304 stainless steel with Type 308 stainless steel weld filler. A program to measure the mechanical properties of archival PWS piping and weld materials (having approximately six years of service at temperatures between 25 and $100^{\circ} \mathrm{C}$ ) has been completed. An extensive data base of mechanical properties has been produced for applications to piping structural analyses. Included is the development of fracture toughness properties for applications to piping fracture analyses and flaw specific evaluations. The data base also serves to provide baseline or unirradiated properties for companion irradiated specimen testing for evaluation of the material properties of the SRS reactor tanks. Tensile properties, Charpy-V notch toughness, and elastic-plastic fracture toughness were measured for base metal, weld metal and weld heat-affected-zone (HAZ) materials. A total of 375 mechanical specimens representing ASTM L-C and C-L orientations were tested at temperatures of 25,75 , or $125^{\circ} \mathrm{C}$, bounding reactor service temperatures. Dynamic testing to simulate seismic loading of the piping was also performed to evaluate the tensile and fracture toughness property response to a simulated seismic event.

The tensile properties of the archival piping material were found typical of recently-produced commercial melts of Type 304 stainless steel piping and are equivalent or superior to the ASME Code Section III commerciâl nuclear design values (Division 1, Appendix I). The fracture toughness properties of the original weld and weld heat-affected-zone materials, were found similar to the base material, yielding a high fracture resistance. It was also found that the high fracture toughness and tensile properties were not diminished at the dynamic loading conditions.

The results from the mechanical testing has been synthesized to provide a mechanical properties data base for structural analyses of the SRS piping. Specific analyses which include piping flaw evaluation through fracture mechanics, including elastic-plastic analysis, are illustrated. The testing results show a marked difference in fracture resistance between the fracture plane parallel versus perpendicular to the pipe axis or rolling direction of the original Type 304 stainless steel plate; the material properties developed for piping flaw stability analyses reflect this directionality effect. 


\subsection{INTRODUCTION}

The production reactors at Savannah River Site (SRS) were constructed and began operation in the 1950's. The material of construction of the primary coolant piping was American Iron and Steel Institute (AISI) Type 304 stainless steel welded by inert-gas-shielded arc-welding with Type 308 stainless steel filler wire. Archival piping materials were obtained for mechanical testing as part of an experimental program of the Reactor Materials Program at the Savannah River Laboratory (SRL) [1,2]. Program studies include measurement of baseline mechanical/corrosion and irradiated mechanical/corrosion properties. The machining and testing of the mechanical test specimens was performed by Materials Engineering Associates (MEA) in Lanham, Maryland under the direction of SRL $[3,4]$. This report covers the mechanical testing details, results, and applications of properties to piping analyses.

Section 2 contains a brief description of the materials source for the mechanical testing program. Details of the mechanical testing procedures are provided in Section 3. The mechanical test specimens were tensile $(T)$, Charpy V-notch $\left(\mathrm{C}_{\mathrm{V}}\right)$, and compact tension (CT) specimens machined from the three different weldment components: base material; weld heat-affected-zone (HAZ) material; and weld metal. The test temperatures $\left(25,75\right.$ and $\left.125^{\circ} \mathrm{C}\right)$ bounded the primary piping operating temperatures. The test specimens were machined in the ASTM C-L and L-C orientations to allow comparison of the mechanical response for the cases of piping flaws oriented parallel and perpendicular, fespectively, to the pipe axis or rolling direction of the original plate. The testing program included studies [5] to optimize and validate a CT specimen design for the SRS reactor piping in the RMP experimental programs. In addition, dynamic $\mathrm{T}$ and $C T$ testing was performed to evaluate the material response of the piping to simulated seismic loading conditions. The test data analysis procedures and a discussion of the test results are provided in Sections 4 and 5 respectively.

Mechanical properties for structural engineering analyses, including fracture mechanics analyses of the SRS Process Water System (PWS) piping, are provided in Sections 5 - 7. From the test parameters of temperature $\left(25\right.$ and $\left.125^{\circ} \mathrm{C}\right)$, orientation $(\mathrm{L}-\mathrm{C}$ and $\mathrm{C}-\mathrm{L})$ and weldment component (base, HAZ and weld), twelve different sets of properties are defined (as shown schematically in Figure 1-1). A 95\% confidence interval of the average properties for each data set are developed through statistical analysis of the mechanical test results. The results from the specimen set exhibiting the lowest strength, toughness or impact energy from the twelve data sets is identified as the lower bound material property. The mechanical test results from the data sets are compared to evaluate mechanical response dependency on testing condition. The response to dynamic loading was evaluated as a subset of several of the test sets shown in Figure 1-1. The material data set also includes the test results from a reference heat (F50) of Type 304L stainless steel, also tested as part of the program [2]. A discussion of mechanical properties of Type 304L, the piping replacement material for the SRS PWS piping [6], is also included. A comparison of the property results to engineering design handbook values, including commercial nuclear design values is provided in Section 6 . The development of fracture toughness properties and fracture mechanics applications to evaluate piping flaw stability are provided in Section 7. Section 8 suggests a potential correlation between Charpy notch ductility and fracture toughness. Future RMP studies related to the characterization of mechanical properties for the SRS process water system are discussed in Section 9. Mechanical property test results for the individual mechanical specimens are listed in Attachment 1. Digitized curves summarizing the full mechanical test response are provided in Attachment 2. 
In addition to providing a database of archival engineering material properties, these tests also provide a baseline to which irradiated material properties can be compared. Similar to the mechanical baseline properties developed in this report for the PWS piping, irradiated mechanical property results [7] provide material data for an elastic-plastic fracture analysis for the reactor tanks.

The data collected by Materials Engineering Associates and evaluated in this report have been qualified for critical application as part of the Qualification of LOCA Definition Project [71-74].

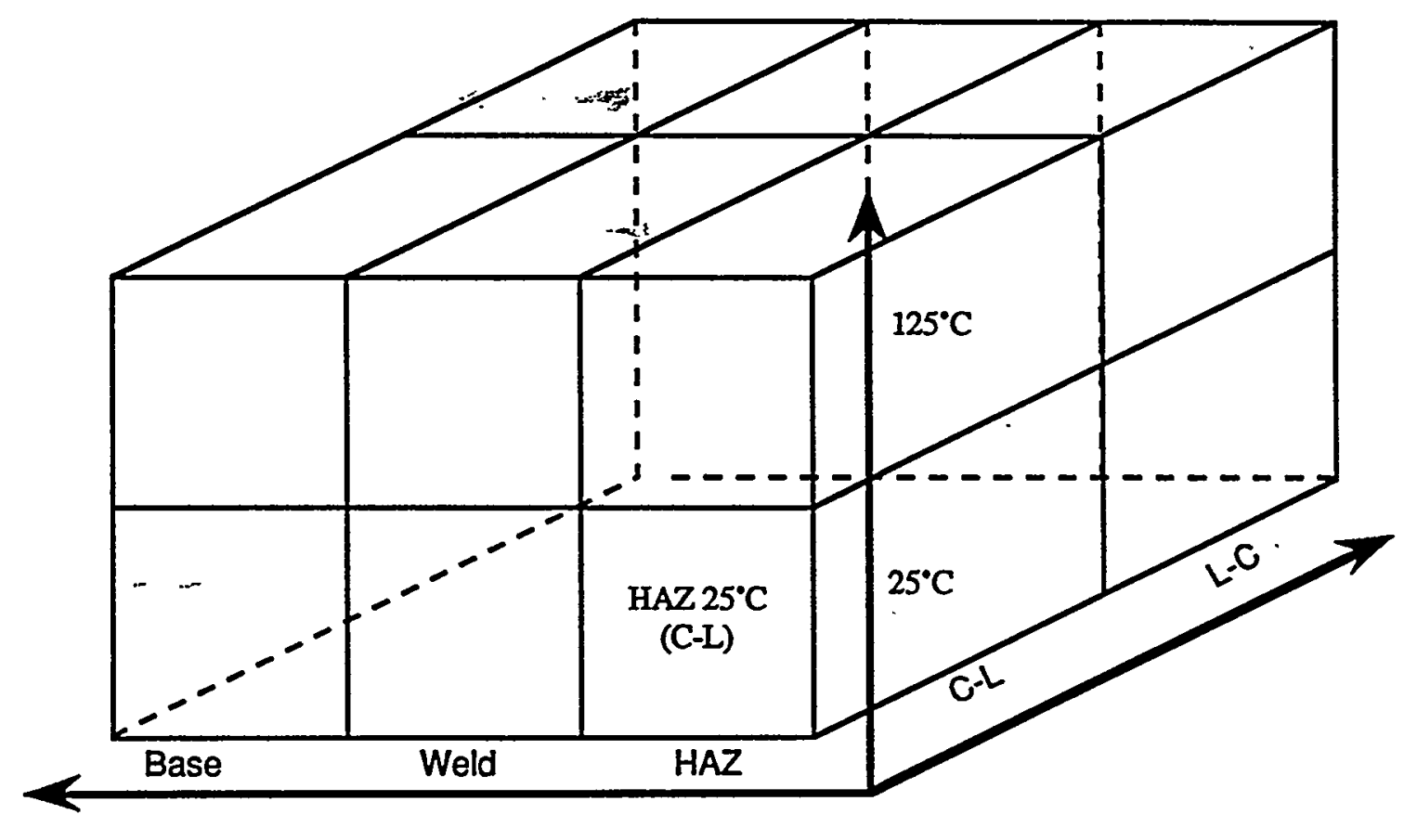

Figure 1-1: Schematic of the mechanical test parameter categories illustrating the twelve sets defined for tensile, Charpy V-notch toughness, and fracture toughness properties for various

- Material, Temperature and Flaw Orientation combinations. The testing included static loading for all twelve sets and dynamic loading for several of the sets. 


\subsection{MATERIALS SOURCE and CHARACTERIZATION}

The test materials were 1950's vintage, rolled and welded Type 304 stainless steel pipe sections having a 16 inch (406 mm) outer diameter (OD) and a nominal wall thickness of 0.5 inch (12.7 $\mathrm{mm}$ ). A total of eight pipe sections with approximately six years of service each were removed from the decommissioned R-Reactor as the archival materials source for the mechanical testing programs [8]. In this report, the individual materials are referenced to the arbitrarily assigned pipe ring number (1 through 8). These pipe sections were located either between the pump and the heat exchanger or between the heat exchanger and the inlet plenum to the reactor [8]. Service temperatures during historical full power operation for these two sections were approximately 95 and $40^{\circ} \mathrm{C}$, respectively [9].

Each pipe section contained a circumferential butt weld made by the Metal Inert Gas (MIG) welding process and one or more mill-annealed longitudinal welds. This provides the potential for having base metals representing up to 16 different melts of steel. The mechanical properties of the circumferential welds, associated heat affected zones, and base metal regions were measured in this study. The circumferential weld joint was a single Vee; the joint preparation contained a small land on the inner diameter (ID) side to aid preweld fitup. Figure $2-1$ shows an etched cross section of a typical weld joint from ring \#1. The joint was filled from the OD side using several weld passes; a root pass made from the ID side is also visible in most joints.

The chemical compositions of the different base and weld metals for the eight pipe rings are given in Tables 2-1 and 2-2. Note that the base and weld metal compositions indicate different source melts. With minor exception, the base material compositions are within the range specified by ASTM for Type 304 stainless steel: $\max 0.08 \mathrm{wt} \%$ carbon, $\max 2.0 \mathrm{wt} \%$ manganese, $\max 0.045$ wt\% phosphorous, $\max 0.03$ wt\% sulfur, $\max 0.75 \mathrm{wt} \%$ silicon, $8-11$ wt\% nickel and 18-20 wt\% chromium [10]. These materials provide a basis for statistical evaluation of mechanical properties of weldments produced in the 1950's.

Delta-ferrite measurements were taken along the outer surface of the circumferential weld metal around each of the eight pipe sections. The weld filler metal for the SRS reactor process water system piping consists of a delta-ferrite forming Type 308 stainless steel. The ferrite level in specific piping welds is one property that can be used to establish uniformity of welding conditions among different reactor systems throughout the plant. The ferrite measurement results (logbook DPSTN-4321, Copy Series E37276) using an Autotest Model Fe measuring probe are summarized in Table 2-3. This range of 10 to 15 percent ferrite is consistent with commercial piping weldments [11].

As an altemate to direct measurement, the percent ferrite level can be derived using a variation of the Schaeffler Diagram, shown in Figure 2-2 [12]. From Reference 13, the nominal compositional ranges for Type 308 stainless steel are max $0.08 \mathrm{wt} \%$ carbon, 1.0-2.5 wt\% manganese, $\max 0.03 \mathrm{wt} \%$ phosphorous, $\max 0.03 \mathrm{wt} \%$ sulfur, $0.30-0.65 \mathrm{wt} \%$ silicon, $9-11$ wt\% nickel and 19.5-22.0 wt\% chromium. This corresponds to a predicted ferrite range of 0 to 18 percent [14] as shown in Figure 2-2.

The pipe sections were decontaminated by electropolishing in a concentrated Manganese-

- Phospholene (MP-\#7) bath prior to shipment to MEA. Approximately 1000 mechanical and corrosion test specimens were machined for testing as part of the RMP materials program [8]. From the stock of test specimens, 375 mechanical specimens were tested for the baseline material property study. 
Table 2-1: Base metal chemical compositions (wt\%)

\begin{tabular}{|c|c|c|c|c|c|c|c|c|c|c|c|c|c|}
\hline & & & \multicolumn{11}{|c|}{ Composition (wt-\%) } \\
\hline & & C & Mn & Si & $\mathbf{P}$ & $\mathbf{S}$ & $\mathbf{N i}$ & $\mathrm{Cr}$ & Mo & B & $\mathrm{Co}$ & $\mathrm{Cu}$ & $\mathbf{N}$ \\
\hline \multirow[t]{2}{*}{1} & A & 0.079 & 1.60 & 0.79 & 0.031 & 0.011 & 9.36 & 18.79 & 0.41 & 0.001 & 0.11 & 0.29 & 0.047 \\
\hline & B & 0.035 & 1.56 & 0.58 & 0.024 & 0.016 & 9.19 & 18.44 & 0.25 & 0.002 & 0.10 & 0.24 & 0.036 \\
\hline \multirow[t]{2}{*}{2} & A & 0.079 & 1.50 & 0.34 & 0.031 & 0.024 & 9.65 & 18.27 & 0.45 & 0.002 & 0.13 & 0.42 & 0.043 \\
\hline & B & 0.052 & 1.41 & 0.38 & 0.031 & 0.025 & 8.50 & 19.40 & 0.39 & $<0.001$ & 0.15 & 0.42 & 0.036 \\
\hline \multirow[t]{2}{*}{3} & A & 0.063 & 1.30 & 0.31 & 0.028 & 0.024 & .9 .38 & 18.59 & 0.40 & 0.001 & 0.12 & 0.38 & 0.044 \\
\hline & B & 0.048 & 1.33 & 0.39 & 0.027 & 0.025 & 9.13 & 18.67 & 0.36 & 0.002 & 0.13 & 0.39 & 0.034 \\
\hline \multirow[t]{2}{*}{4} & A & 0.053 & 1.81 & 0.33 & 0.026 & 0.017 & 8.75 & 18.97 & 0.35 & 0.002 & 0.11 & 0.28 & 0.033 \\
\hline & B & 0.083 & 1.75 & 0.74 & 0.033 & 0.017 & 9.60 & 18.88 & 0.46 & 0.002 & 0.13 & 0.32 & 0.043 \\
\hline \multirow[t]{2}{*}{5} & A & 0.041 & 1.39 & 0.67 & 0.026 & 0.024 & 9.64 & 19.05 & 0.52 & 0.002 & 0.12 & 0.28 & 0.035 \\
\hline & B & 0.080 & 1.25 & 0.32 & 0.026 & 0.016 & 10.0 & 18.88 & 0.44 & 0.001 & 0.13 & 0.41 & 0.043 \\
\hline \multirow[t]{2}{*}{6} & A & 0.058 & 1.44 & 0.49 & 0.027 & 0.017 & 9.65 & 19.05 & 0.43 & 0.001 & 0.15 & 0.62 & 0.044 \\
\hline & B & $0.046 \ldots$ & 1.46 & 0.66 & 0.026 & 0.024 & 8.48 & 18.88 & 0.22 & 0.001 & 0.13 & 0.17 & 0.034 \\
\hline \multirow[t]{2}{*}{7} & A & 0.052 & 1.30 & 0.55 & 0.028 & 0.016 & 9.35 & 18.65 & 0.38 & 0.002 & 0.12 & 0.26 & 0.039 \\
\hline & B & 0.047 & 1.33 & 0.34 & 0.027 & 0.019 & 9.15 & 18.50 & 0.21 & 0.001 & 0.08 & 0.20 & 0.037 \\
\hline \multirow[t]{2}{*}{8} & A & 0.055 & 1.30 & 0.40 & 0.030 & 0.026 & 8.72 & 19.05 & 0.42 & 0.002 & 0.16 & 0.45 & 0.036 \\
\hline & B & 0.078 & 1.75 & 0.40 & 0.033 & 0.018 & 8.30 & 19.66 & 0.44 & 0.003 & 0.54 & 0.34 & 0.043 \\
\hline
\end{tabular}


Table 2-2: Weld metal chemical compositions (wt\%)

\begin{tabular}{|c|c|c|c|c|c|c|c|c|c|c|c|}
\hline & \multicolumn{11}{|c|}{ Composition (wt-\%) } \\
\hline & $\mathbf{C}$ & $\mathbf{M n}$ & Si & $\mathbf{P}$ & $\mathbf{S}$ & $\mathbf{N i}$ & $\mathrm{Cr}$ & Mo & $\mathbf{B}$ & $\mathrm{Cr}$ & $\mathbf{C u}$ \\
\hline 1 & 0.038 & 1.39 & 0.41 & 0.023 & 0.018 & 9.65 & 20.15 & 0.23 & 0.002 & $\begin{array}{l}0.11 \\
0.11^{\mathrm{a}}\end{array}$ & $\begin{array}{l}0.21 \\
0.20^{\mathrm{a}}\end{array}$ \\
\hline 2 & 0.052 & 1.45 & 0.41 & 0.022 & 0.019 & 10.50 & 19.20 & 0.20 & 0.005 & 0.10 & 0.22 \\
\hline 3 & 0.039 & 1.25 & 0.39 & 0.020 & 0.017 & 10.16 & 19.56 & 0.21 & 0.004 & 0.20 & 0.21 \\
\hline 4 & 0.047 & 1.41 & 0.43 & 0.022 & 0.018 & 10.75 & 19.29 & 0.17 & 0.005 & 0.094 & 0.20 \\
\hline 5 & 0.048 & 1.52 & 0.42 & 0.023 & 0.010 & 10.15 & 19.96 & 0.26 & 0.001 & $\begin{array}{l}0.16 \\
0.17^{a}\end{array}$ & $\begin{array}{l}0.23 \\
0.18^{a}\end{array}$ \\
\hline 6 & 0.050 & 1.56 & 0.49 & $\begin{array}{l}0.024 \\
0.022^{a}\end{array}$ & $\begin{array}{l}0.008 \\
0.010^{\mathrm{a}}\end{array}$ & 10.12 & 19.87 & 0.24 & $<0.001$ & 0.18 & $\begin{array}{l}0.19 \\
0.19^{a}\end{array}$ \\
\hline 7 & 0.042 & 1.47 & 0.43 & 0.020 & 0.009 & 9.88 & 19.47 & 0.24 & 0.003 & 0.15 & 0.21 \\
\hline 8 & 0.045 & 1.52 & 0.37 & 0.022 & 0.018 & 9.70 & 20.15 & 0.21 & 0.002 & 0.22 & $\begin{array}{l}0.18 \\
0.16^{a}\end{array}$ \\
\hline
\end{tabular}

a Duplicate Analysis Using Separate Stock

Table 2-3: Average Ferrite Levels for Weld Material

$\begin{array}{ccc}\text { Ring \# } & \text { Weld Reference } & \text { Ferrite (\%) } \\ 1 & \text { 2PW216W3 } & 13.6 \\ 2 & \text { 6PW1816W3 } & 10.0 \\ 3 & \text { 4PW16W5 } & 15.0 \\ 4 & \text { 1P1W1316W3 } & 10.7 \\ 5 & \text { 2PW1716W2 } & 11.7 \\ 6 & \text { 3PW1516W5 } & 11.2 \\ 7 . & \text { 4PW416W4 } & 14.2 \\ 8 & \text { 2PW216W5 } & 14.3\end{array}$




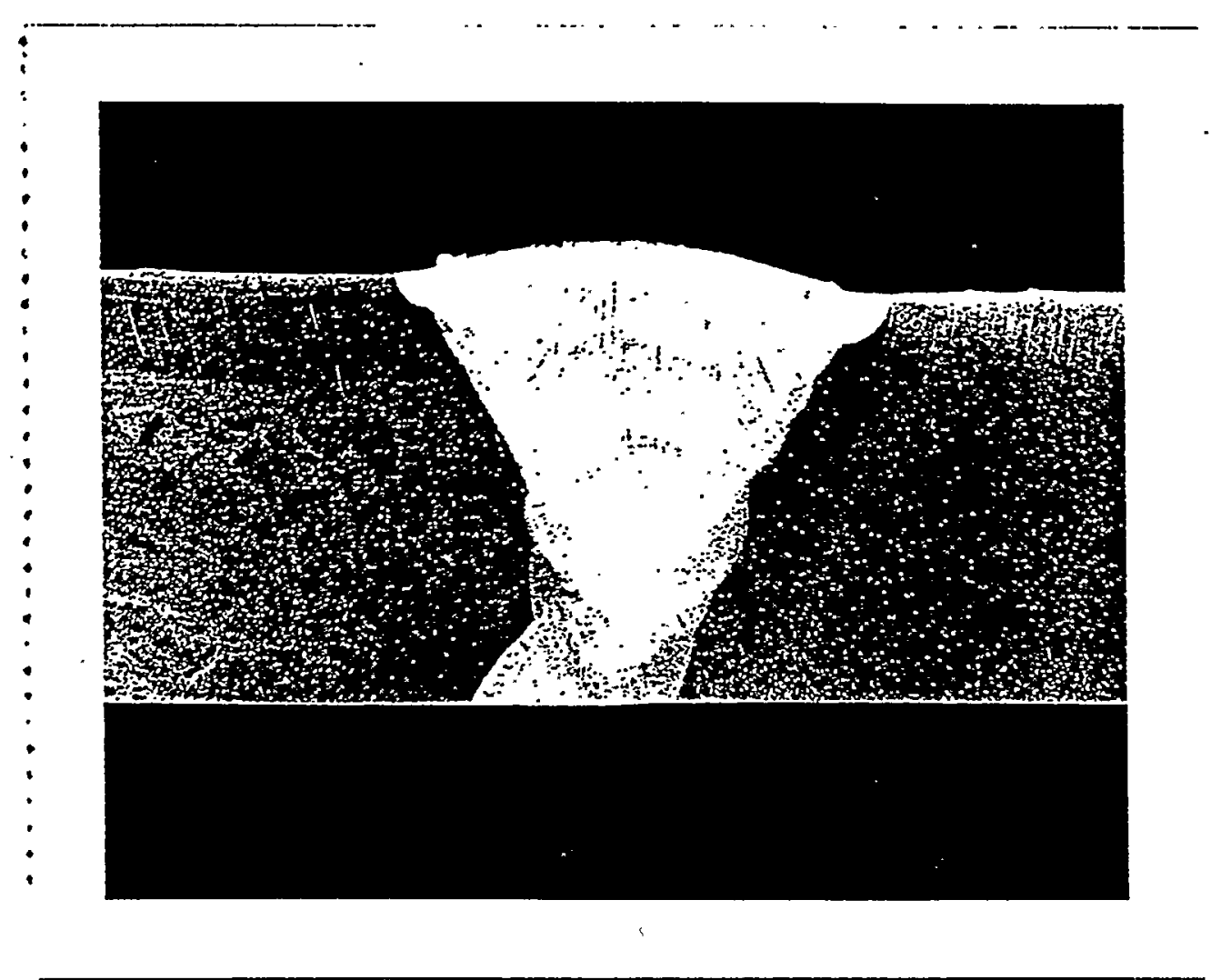

Figure 2-1: Etched cross section of pipe ring \# 1weld (4X) (12.7 mm base plate thickness) 


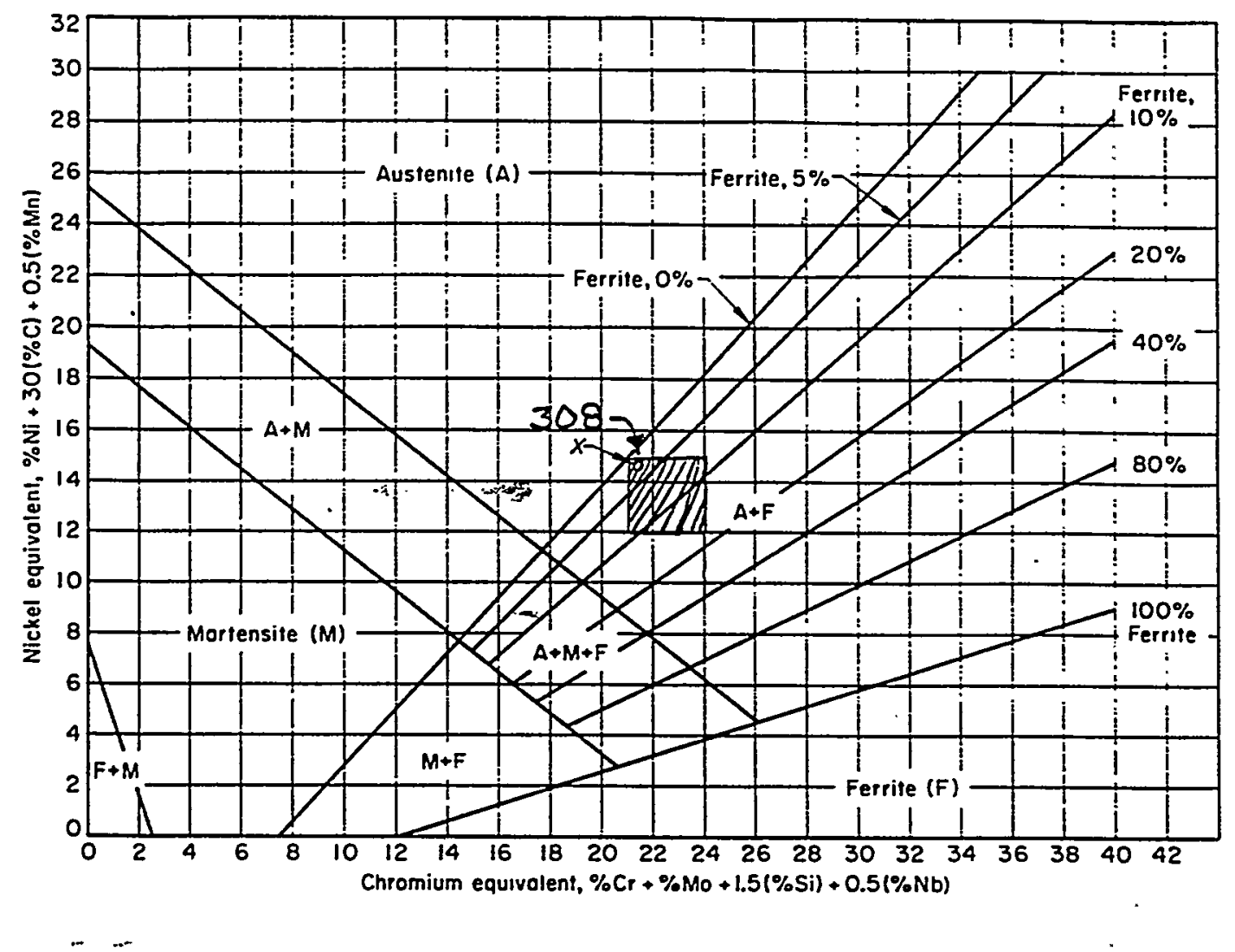

Figure 2-2: Modified Scheaffler Diagram from ASM Metals Handbook [12] 


\subsection{MATERIALS TESTING}

The mechanical and corrosion specimen types chosen by the SRL Reactor Materials Program [1, 2] to measure the properties of Type 304 stainless steel under SRS process water system operating conditions included the Charpy-V notch $\left(\mathrm{C}_{\mathrm{v}}\right)$, tensile $(T)$, compact tension (CT), constant extension rate tensile (CERT) and wedge-opening-loaded (WOL) specimens [8].

The specimens were machined according to applicable ASTM specifications, and assigned a unique identifier number that allowed traceability throughout their testing history, as well as identification of their location and orientation with respect to the original pipe ring section. The first number of this code identifies the pipe ring number, and the adjacent letter indicates the material type ( $\mathrm{W}=$ weld, $\mathrm{B}=$ base, and $\mathrm{H}=$ heat-affected-zone or HAZ). The second letter (applicable to base and HAZ material only) identifies the side with respect to the circumferential weld from which the specimen came from in the pipe ring (side A or side B) as referenced in the cutting diagrams [see Appendix D of Reference 5].

Table 3-1 contains the mechanical specimen test matrix indicating the specimen material origin (ring number), mechanical specimen type, orientation and test temperature. Prior to testing of the matrix, shakedown or design testing was initiated by SRL to document the effects of substandard specimen size and side-groove testing of compact tension specimens. The results of these preliminary tests are described in Section 4 . The test results with the final specimen design are summarized in Section 5.

The subsequent discussion details the baseline specimen design and testing $\left(C_{v}, T\right.$ and $\left.C T\right)$. The tests were conducted at temperatures of 25,75 and $125^{\circ} \mathrm{C}$ controlled to $\pm 5^{\circ} \mathrm{C}$ [5] and included both the ASTM L-C and C-L specimen orientations (see Figure 3-1).

\subsection{Charpy Impact Testing}

The $C_{v}$ specimen design for notch toughness testing is shown in Figure 3-2. The dimensions conform with those of the standard size Type-A specimen identified in ASTM E 23-81, "Standard Methods for Notch Bar Impact Testing of Metallic Materials." The impact tests were conducted.in accordance with this standard. Two different base, weld and HAZ metals were tested in both the L-C and C-L orientations at both 25 and $125^{\circ} \mathrm{C}$. Four additional melts of HAZ and one additional melt of weld were tested at both 25 and $125^{\circ} \mathrm{C}$ in either the L-C or C-L orientation. Several additional melts of base, weld and HAZ metal were also tested at either 25 or $125^{\circ} \mathrm{C}$. The baseline specimen test matrix shown in Table 3-1 lists the number of specimens for each material melt tested at 25 or $125^{\circ} \mathrm{C}$. At the intermediate temperature of $75^{\circ} \mathrm{C}$, two different melts were tested for each of base, weld and HAZ materials. The test results of absorbed energy and lateral expansion for each specimen are contained in Attachment 1.

\subsection{Tensile Testing}

The tensile test specimen design (Figure 3-3) conforms to ASTM standards E8-81 and E21-79. Test results of yield ( $0.2 \%$ offset) and tensile strengths (engineering), uniform elongation, and percent reduction in area at specimen failure for each specimen are contained in Attachment 1.

- All stress-strain curves were recorded over the entire range of load, up to failure and are presented as both engineering and true stress strain curves (Attachment 2). Most of the testing were duplicated, with thirteen different melts or compositions, and four different welds tested at 25 or $125^{\circ} \mathrm{C}$, as indicated in Table 3-1. 
In addition, tensile tests were performed under dynamic conditions simulating the time response of the piping to a seismic event. In each of the dynamic tests, the maximum load was reached in about 80 milliseconds, with a strain rate of approximately $0.05 \mathrm{~s}^{-1}$ for the elastic portion of the test. Two different base metal compositions and three welds were tested.

\subsection{Compact Tension Testing}

Fracture toughness was evaluated by analysis of J-R curves obtained from specimens tested by procedures that were in general conformance to ASTM E 813-81 (also E813-88) and ASTM 1152. Due to piping size constraints, the CT specimens were limited to a 0.4T-CT thickness, that is, a 0.394 -in $(10 \mathrm{~mm})$ thick specimen was the maximum that could be machined from the pipe considering the curvature of the large diameter pipe stock. The diameter and location of the loading holes were modified slightly to produce consistent and conservative J-R curves. All specimens were side-grooved (10\% on each side or $20 \%$ total) to reduce crack tunneling and to provide an even, parallel crack front to assess crack extension. The final specimen design, shown in Figure 3-4, was based upon extensive testing and comparison with specimens of standard design [5].

A conventional load cell was used to measure the applied load to the CT specimen during testing. For static testing, specimen load-line displacement was measured with an outboard clip gage. For dynamic testing, crack extension was measured with the direct current potential drop (DCPD) method. Crack extension was calibrated with single-specimen compliance techniques. $\mathrm{J}$-integral resistance (J-R) curve analysis was performed for both the modified-J $\left(J_{M}\right)$ and deformation- $\mathrm{J}\left(\mathrm{J}_{\mathrm{D}}\right)$ approach from the toad versus crack extension data. Flow stress values, ( $\mathrm{s}_{\mathrm{y}}$ $\left.+s_{u}\right) / 2$ (where $s_{y}$ and $s_{u}$ are the engineering yield and ultimate tensile strengths, respectively) were obtained from corresponding tensile data or from estimated flow stress properties in the cases where no corresponding data existed [5]. A power-law of the form $J=C\left(\Delta a^{n}\right)$ was fit to the data between the exclusion lines (ASTM E 813-81, E 813-88) with the power law toughness corresponding to the onset of stable tearing, $\mathrm{J}_{\mathrm{Ic}}$, defined as the intersection of the power law curve with the $0.15 \mathrm{~mm}$ (0.006 in) exclusion line (see Figures 4-5A and 4-5B). The power law formulation of the J-R curve was employed to facilitate construction of the material J-T curve discussed in section 7. Values for $\mathrm{J}_{\text {Ic }}$ were also obtained as specified in ASTM E813-81 with results similar to those from the power law formulation [5].

Base metal fracture toughness properties were measured on three melts of steel at both test temperatures and on an additional eleven melts at $125^{\circ} \mathrm{C}$. Five different welds were tested. Fracture properties were also measured at 25 and $125^{\circ} \mathrm{C}$ on several $\mathrm{HAZ}$ specimens. Dynamic compact tension specimen testing was performed similar to the tensile specimen testing whereby the time to specimen maximum load was reached in about 80 milliseconds. Base, weld and HAZ specimens were tested in the dynamic loading condition (see Table 3-1). 
Table 3-1: Specimen Test Matrix [Mechanical Test / Direction / Temperature ( $\left.{ }^{\circ} \mathrm{C}\right)$ ]

\begin{tabular}{|c|c|c|c|c|c|c|c|c|c|c|c|c|c|c|c|c|c|c|c|c|c|}
\hline \multirow[b]{2}{*}{$\begin{array}{l}\text { Material } \\
\text { Heat }\end{array}$} & \multicolumn{3}{|c|}{ Tensile -- Static } & \multicolumn{4}{|c|}{ Tensile -- Dyn. } & \multicolumn{6}{|c|}{ Charpy-V Impact Test } & \multicolumn{4}{|c|}{$\begin{array}{c}\text { Toughness - } \\
\text { Static }\end{array}$} & \multicolumn{4}{|c|}{$\begin{array}{c}\text { Toughness -- } \\
\text { Dyn. }\end{array}$} \\
\hline & $\begin{array}{l}\text { L-C } \\
25 \mid 125\end{array}$ & \begin{tabular}{|l|l|}
\multicolumn{2}{|c|}{ C-L } \\
25 & 12 \\
\end{tabular} & & $\frac{\mathrm{L}-\mathrm{C}}{25 / 12}$ & & \begin{tabular}{|l|l|}
\multicolumn{2}{|c|}{ C-L } \\
$25 \mid 12$
\end{tabular} & & & $\begin{array}{l}\mathrm{L}-\mathrm{C} \\
75 \mid 12\end{array}$ & & 25 & $\frac{\text { C-L }}{75 \mid 1}$ & & \begin{tabular}{l|l}
$\mathrm{L}-\mathrm{C}$ \\
25 & 1
\end{tabular} & & & & \begin{tabular}{l|l}
\multicolumn{2}{l}{ L-C } \\
25 & 12
\end{tabular} & & \begin{tabular}{l|l}
\multicolumn{2}{c}{ C-L } \\
$25 \mid 12$
\end{tabular} & \\
\hline $\begin{array}{c}1 \mathrm{BA} \\
1 \mathrm{BB} \\
2 \mathrm{BA} \\
2 \mathrm{BB} \\
3 \mathrm{BA} \\
3 \mathrm{BB} \\
4 \mathrm{BA} \\
4 \mathrm{BB} \\
5 \mathrm{BA} \\
5 \mathrm{BB} \\
6 \mathrm{BA} \\
6 \mathrm{BB} \\
7 \mathrm{BA} \\
7 \mathrm{BB} \\
8 \mathrm{BA} \\
8 \mathrm{BB}\end{array}$ & $\begin{array}{l}- \\
- \\
- \\
- \\
2 \\
2 \\
2 \\
- \\
2 \\
2 \\
2 \\
- \\
- \\
- \\
- \\
-\end{array}$ & $\begin{array}{l}- \\
- \\
- \\
- \\
2 \\
2 \\
2 \\
- \\
2 \\
2 \\
2 \\
- \\
- \\
- \\
- \\
-\end{array}$ & $\begin{array}{l}1 \\
1 \\
- \\
- \\
3 \\
2 \\
1 \\
1 \\
1 \\
1\end{array}$ & $\begin{array}{l}- \\
- \\
- \\
- \\
4 \\
4 \\
- \\
- \\
- \\
- \\
- \\
- \\
- \\
- \\
- \\
-\end{array}$ & $\begin{array}{l}- \\
- \\
- \\
- \\
4 \\
4 \\
- \\
- \\
- \\
- \\
- \\
- \\
- \\
- \\
- \\
-\end{array}$ & $\begin{array}{l}- \\
- \\
- \\
- \\
4 \\
4 \\
- \\
- \\
- \\
- \\
- \\
- \\
- \\
- \\
- \\
-\end{array}$ & $\begin{array}{l}- \\
- \\
- \\
- \\
4 \\
4 \\
- \\
- \\
- \\
- \\
- \\
- \\
- \\
- \\
-\end{array}$ & $\begin{array}{l}- \\
- \\
- \\
- \\
3 \\
- \\
3 \\
- \\
- \\
- \\
- \\
- \\
- \\
- \\
- \\
-\end{array}$ & $\begin{array}{l}- \\
- \\
- \\
- \\
3 \\
- \\
3 \\
- \\
- \\
- \\
- \\
- \\
- \\
- \\
- \\
-\end{array}$ & $\begin{array}{l}1 \\
1 \\
- \\
- \\
4 \\
1 \\
4 \\
- \\
- \\
1 \\
- \\
1 \\
1 \\
1 \\
1 \\
2\end{array}$ & $\begin{array}{l}- \\
- \\
- \\
- \\
2 \\
- \\
2 \\
- \\
- \\
- \\
- \\
- \\
- \\
- \\
- \\
-\end{array}$ & $\begin{array}{l}- \\
- \\
- \\
- \\
- \\
- \\
- \\
- \\
- \\
- \\
- \\
- \\
- \\
- \\
- \\
-\end{array}$ & $\begin{array}{l}- \\
1 \\
1 \\
- \\
3 \\
1 \\
3 \\
1 \\
- \\
1 \\
1 \\
1 \\
1 \\
1 \\
1 \\
2\end{array}$ & $\begin{array}{l}- \\
- \\
- \\
- \\
- \\
- \\
3 \\
- \\
- \\
- \\
3 \\
- \\
- \\
- \\
- \\
5\end{array}$ & $\begin{array}{l}2 \\
3 \\
- \\
- \\
1 \\
1 \\
4 \\
- \\
1 \\
1 \\
3 \\
1 \\
1 \\
- \\
1 \\
3\end{array}$ & $\begin{array}{l}- \\
- \\
- \\
- \\
- \\
- \\
3 \\
- \\
- \\
- \\
3 \\
- \\
- \\
- \\
- \\
-\end{array}$ & $\begin{array}{l}2 \\
3 \\
- \\
- \\
1 \\
1 \\
4 \\
1 \\
1 \\
1 \\
3 \\
1 \\
1 \\
2 \\
1 \\
2\end{array}$ & $\begin{array}{l}- \\
- \\
- \\
- \\
- \\
- \\
3 \\
- \\
- \\
- \\
3 \\
- \\
- \\
- \\
- \\
-\end{array}$ & $\begin{array}{l}- \\
- \\
- \\
- \\
- \\
- \\
3 \\
- \\
- \\
- \\
2 \\
- \\
- \\
- \\
- \\
-\end{array}$ & $\begin{array}{l}- \\
- \\
- \\
- \\
- \\
- \\
3 \\
- \\
- \\
- \\
3 \\
- \\
- \\
- \\
- \\
-\end{array}$ & $\begin{array}{l}- \\
- \\
- \\
- \\
- \\
- \\
3 \\
- \\
- \\
- \\
4 \\
- \\
- \\
- \\
- \\
-\end{array}$ \\
\hline $\begin{array}{l}1 \mathrm{HA} \\
1 \mathrm{HB} \\
2 \mathrm{HA} \\
2 \mathrm{HB} \\
3 \mathrm{HA} \\
3 \mathrm{HB} \\
4 \mathrm{HA} \\
4 \mathrm{HB} \\
5 \mathrm{HA} \\
5 \mathrm{HB} \\
6 \mathrm{HA} \\
6 \mathrm{HB} \\
7 \mathrm{HA} \\
7 \mathrm{HB} \\
8 \mathrm{HA} \\
8 \mathrm{HB}\end{array}$ & $\begin{array}{l}- \\
- \\
- \\
- \\
- \\
- \\
- \\
- \\
- \\
- \\
- \\
- \\
- \\
- \\
- \\
-\end{array}$ & $\begin{array}{l}- \\
- \\
- \\
- \\
2 \\
2 \\
- \\
- \\
- \\
- \\
- \\
- \\
- \\
- \\
- \\
-\end{array}$ & $\begin{array}{l}- \\
- \\
- \\
- \\
- \\
1 \\
- \\
- \\
- \\
- \\
- \\
- \\
- \\
- \\
- \\
-\end{array}$ & $\begin{array}{l}- \\
- \\
- \\
- \\
- \\
- \\
- \\
- \\
- \\
- \\
- \\
- \\
- \\
- \\
- \\
-\end{array}$ & $\begin{array}{l}- \\
- \\
- \\
- \\
- \\
- \\
- \\
- \\
- \\
- \\
- \\
- \\
- \\
- \\
- \\
-\end{array}$ & $\begin{array}{l}- \\
- \\
- \\
- \\
- \\
2 \\
- \\
- \\
- \\
- \\
- \\
- \\
- \\
- \\
- \\
-\end{array}$ & $\begin{array}{l}- \\
- \\
- \\
- \\
- \\
1 \\
- \\
- \\
- \\
- \\
- \\
- \\
- \\
- \\
- \\
-\end{array}$ & $\begin{array}{l}2 \\
2 \\
3 \\
3 \\
3 \\
- \\
3 \\
3 \\
3 \\
2 \\
3 \\
2 \\
- \\
- \\
- \\
-\end{array}$ & $\begin{array}{l}- \\
- \\
- \\
- \\
- \\
- \\
3 \\
- \\
- \\
- \\
- \\
- \\
2 \\
- \\
- \\
-\end{array}$ & $\begin{array}{l}2 \\
- \\
- \\
- \\
2 \\
- \\
3 \\
- \\
- \\
- \\
1 \\
- \\
- \\
- \\
- \\
-\end{array}$ & $\begin{array}{l}- \\
- \\
- \\
- \\
2 \\
2 \\
2 \\
2 \\
- \\
- \\
- \\
- \\
- \\
- \\
- \\
-\end{array}$ & $\begin{array}{l}- \\
- \\
- \\
- \\
- \\
- \\
- \\
- \\
- \\
- \\
- \\
- \\
- \\
- \\
- \\
-\end{array}$ & $\begin{array}{l}- \\
- \\
- \\
-\end{array}$ & $\begin{array}{l}- \\
- \\
- \\
- \\
- \\
- \\
2 \\
- \\
- \\
- \\
2 \\
- \\
- \\
- \\
- \\
-\end{array}$ & $\begin{array}{l}- \\
- \\
- \\
- \\
- \\
- \\
2 \\
- \\
- \\
- \\
- \\
2 \\
- \\
- \\
- \\
-\end{array}$ & $\begin{array}{l}- \\
- \\
- \\
- \\
- \\
- \\
2 \\
- \\
- \\
- \\
2 \\
- \\
- \\
- \\
- \\
-\end{array}$ & $\begin{array}{l}- \\
- \\
- \\
- \\
- \\
- \\
- \\
- \\
- \\
- \\
1 \\
1 \\
- \\
-\end{array}$ & $\begin{array}{l}- \\
- \\
- \\
- \\
- \\
- \\
3 \\
- \\
- \\
- \\
2 \\
- \\
- \\
- \\
- \\
-\end{array}$ & $\begin{array}{l}- \\
- \\
- \\
- \\
- \\
- \\
- \\
- \\
- \\
- \\
- \\
- \\
- \\
- \\
- \\
-\end{array}$ & $\begin{array}{l} \\
- \\
- \\
- \\
- \\
- \\
- \\
- \\
- \\
- \\
- \\
- \\
- \\
- \\
- \\
-\end{array}$ & $\begin{array}{l}- \\
- \\
- \\
- \\
- \\
- \\
-\end{array}$ \\
\hline $\begin{array}{l}1 W \\
2 W \\
3 W \\
4 W \\
5 W \\
6 W \\
7 W \\
8 W\end{array}$ & $\begin{array}{l}- \\
- \\
- \\
- \\
2 \\
2 \\
- \\
-\end{array}$ & $\begin{array}{l}- \\
- \\
- \\
- \\
2 \\
- \\
- \\
2\end{array}$ & $\begin{array}{l}- \\
- \\
- \\
- \\
- \\
-\end{array}$ & $\begin{array}{l}- \\
- \\
- \\
- \\
- \\
2 \\
- \\
-\end{array}$ & $\begin{array}{l}- \\
- \\
- \\
- \\
- \\
- \\
2 \\
-\end{array}$ & $\begin{array}{l}- \\
- \\
- \\
- \\
1 \\
- \\
- \\
2\end{array}$ & $\begin{array}{l}- \\
- \\
- \\
- \\
- \\
- \\
- \\
-\end{array}$ & $\begin{array}{l}3 \\
3 \\
3 \\
3 \\
3 \\
3 \\
- \\
-\end{array}$ & $\begin{array}{l}3 \\
3 \\
- \\
- \\
- \\
- \\
- \\
-\end{array}$ & $\begin{array}{l}3 \\
3 \\
- \\
- \\
- \\
1 \\
- \\
-\end{array}$ & $\begin{array}{l}2 \\
2 \\
- \\
- \\
- \\
- \\
- \\
-\end{array}$ & $\begin{array}{l}- \\
- \\
- \\
- \\
- \\
- \\
-\end{array}$ & $\begin{array}{l}\text { - } \\
- \\
- \\
-\end{array}$ & $\begin{array}{l}- \\
2 \\
- \\
- \\
- \\
- \\
1 \\
-\end{array}$ & $\begin{array}{l}- \\
2 \\
- \\
- \\
2 \\
- \\
-\end{array}$ & \begin{tabular}{c|}
- \\
2 \\
- \\
- \\
1 \\
- \\
2 \\
-
\end{tabular} & $\begin{array}{l}1 \\
- \\
- \\
- \\
-\end{array}$ & $\begin{array}{l} \\
2 \\
- \\
- \\
1 \\
- \\
1 \\
-\end{array}$ & $\begin{array}{l}- \\
1 \\
- \\
- \\
2 \\
- \\
- \\
-\end{array}$ & $\begin{array}{l}- \\
- \\
- \\
- \\
- \\
- \\
- \\
-\end{array}$ & \\
\hline
\end{tabular}




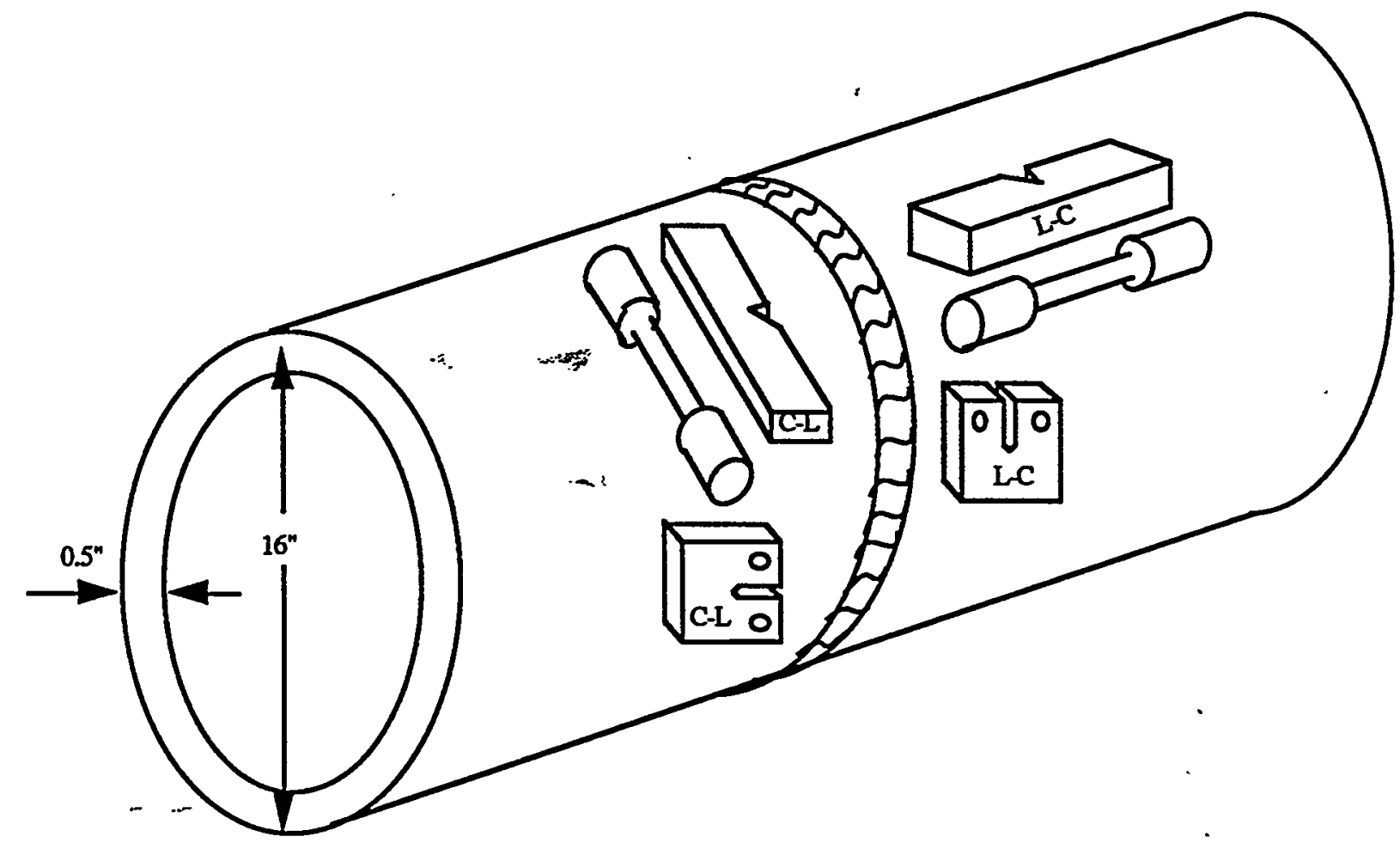

FIGURE 3-1: Schematic illustration of specimen orientation in the pipe ring 


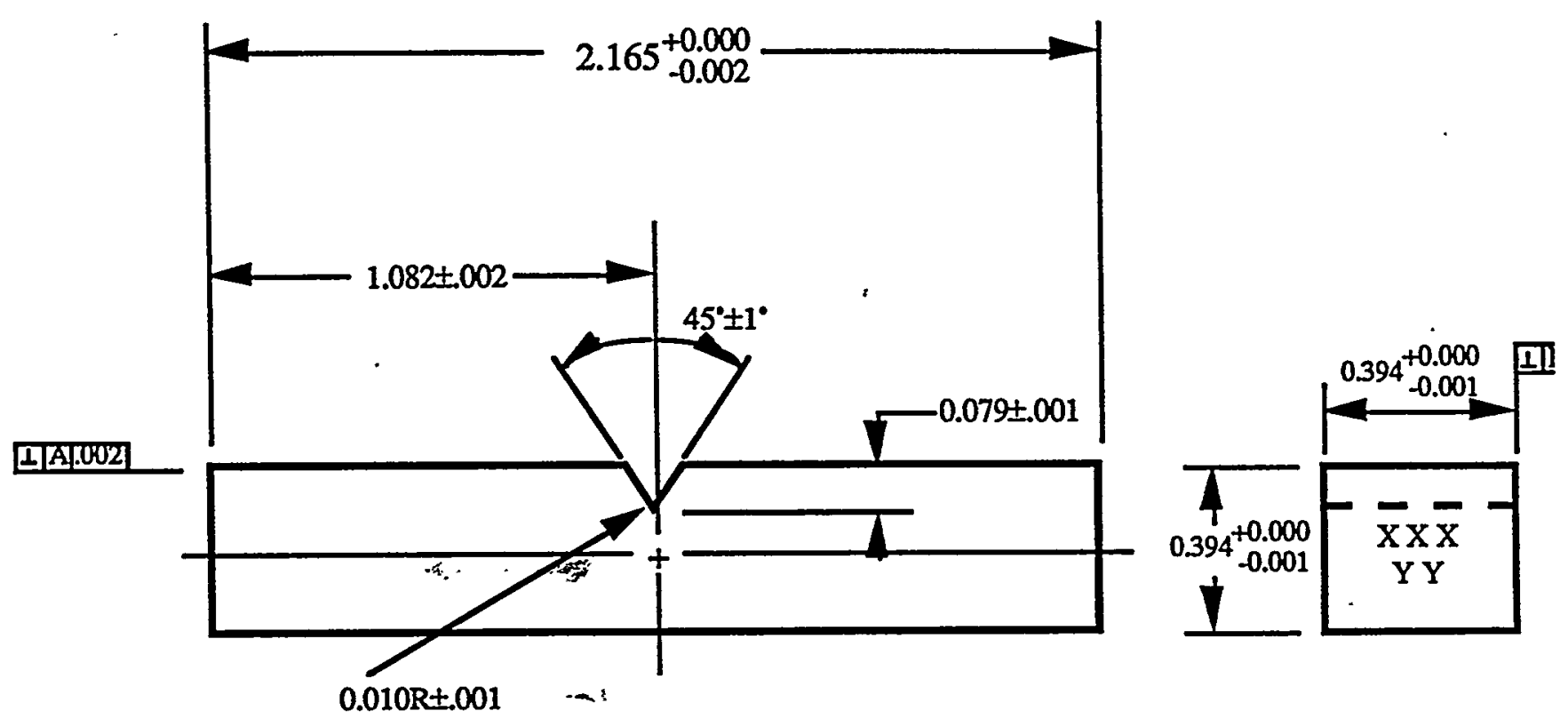

FIGURE 3-2: Charpy Impact Specimen Dimensions

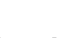




\begin{tabular}{|c|c|c|}
\hline Type & DIM "A" & DIM "B" \\
\hline 1 & $7 / 16-14$ UNC & 0.340 TYP \\
2 & $5 / 16-18$ UNF & 0.235 TYP \\
\hline
\end{tabular}

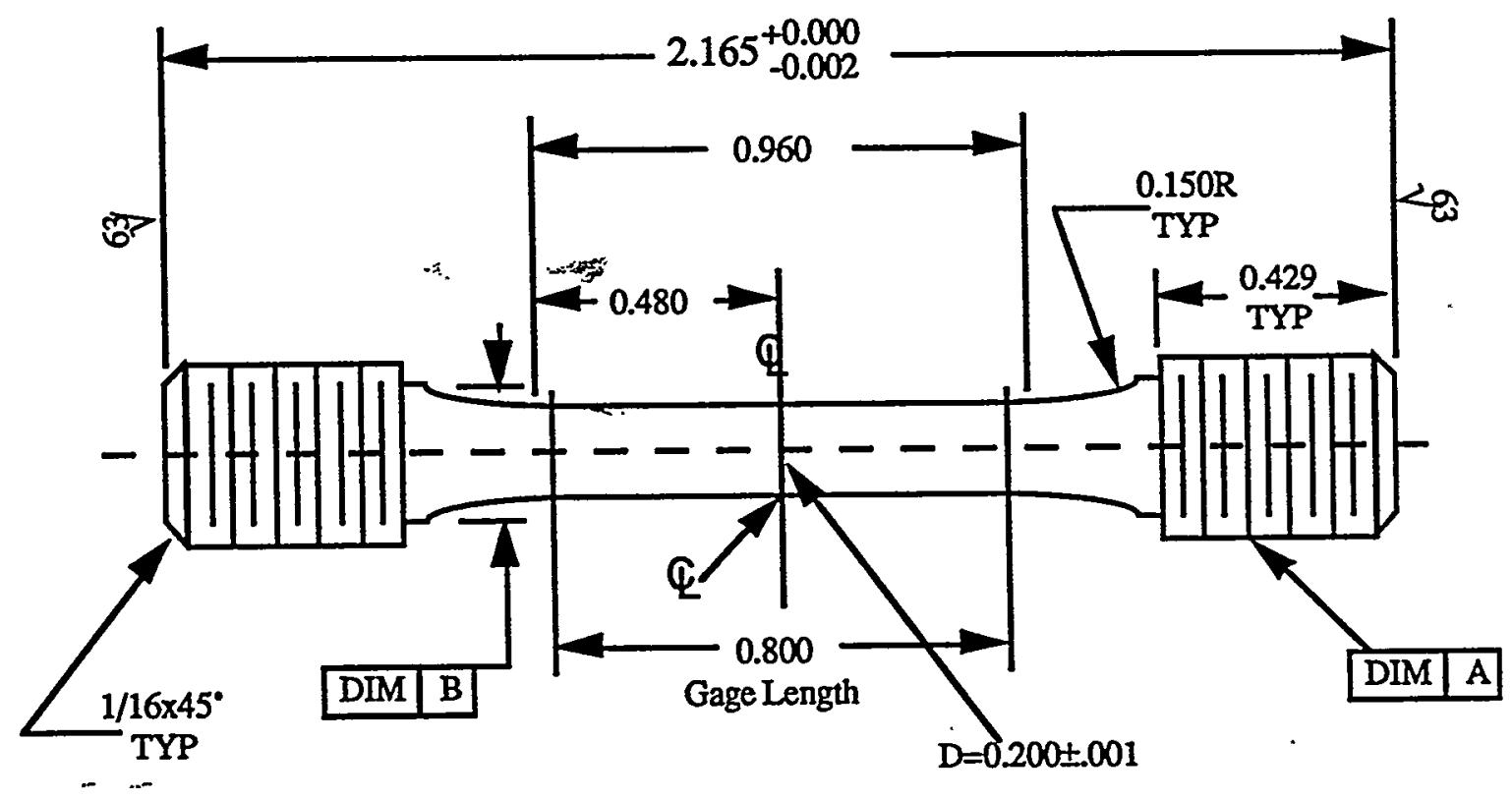

FIGURE 3-3: Tensile Specimen Dimensions 

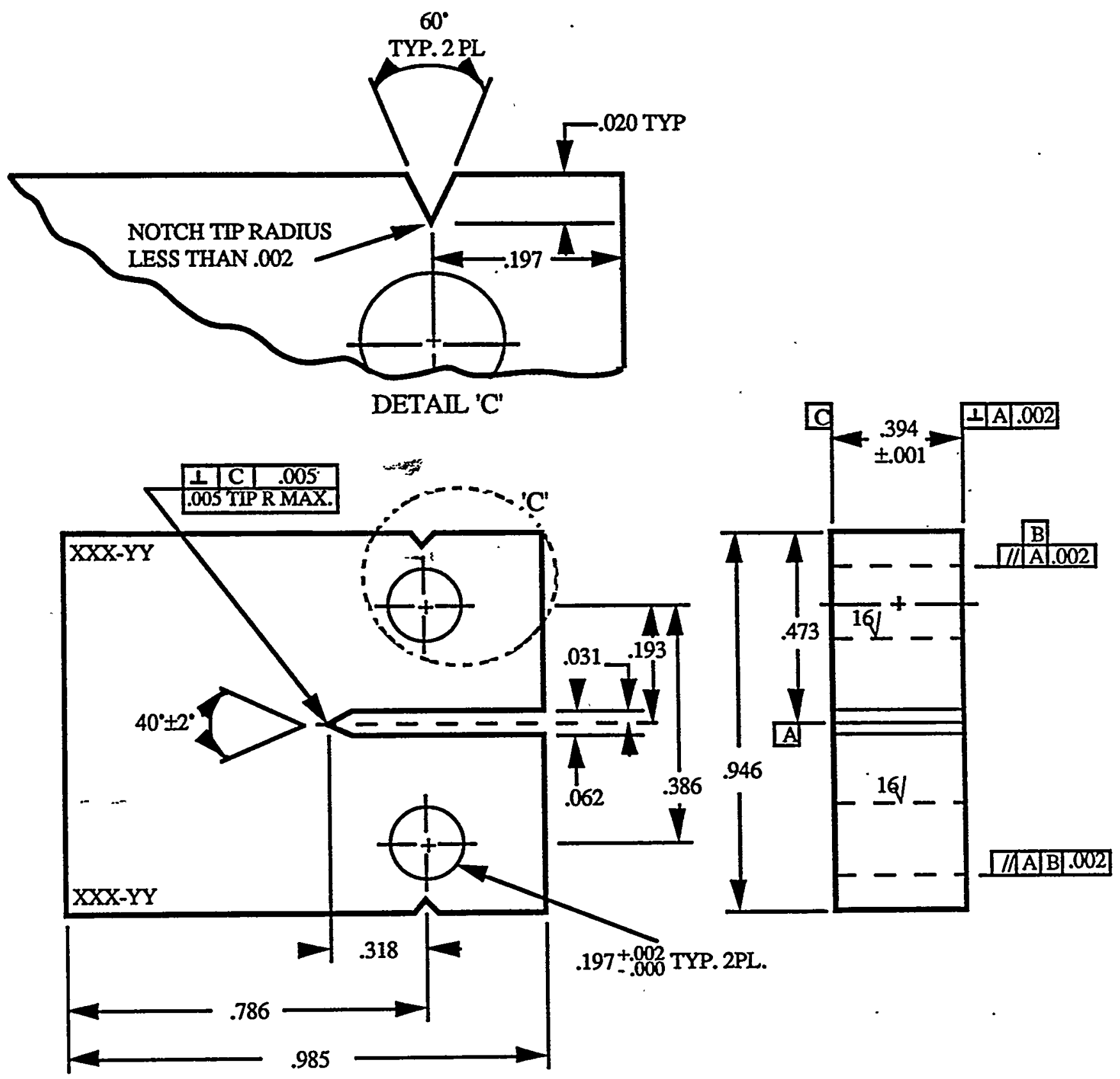

FIGURE 3-4: Compact Tension Specimen Dimensions. The final specimen design included $20 \%$ (10\% each side) sidegrooving of the notch plane. 


\subsection{ANALYSIS OF DATA and SPECIMEN DESIGN}

\subsection{Static J-R Curve Data Analysis Procedures}

\subsubsection{Qverview}

Measurements of applied load, load-line displacement and crack length for the compact tension test specimen are required to calculate $J$ and construct the material fracture resistance curve or J-R curve. Load and displacement are readily determined using a load cell and a clip gage, respectively. Instantaneous crack length change generally is not directly measurable. Typically, it is inferred by evaluations of some other parameter in collaboration with equations relating that parameter to the crack length. For static loading conditions, crack length is normally evaluated by the single specimen compliance (SSC) method, also called the unloading compliance method, and hence the J-R curve can be obtained from a single test specimen. This method, described below, is not suitable for rapid (dynamic) loading conditions. Instead, crack growth is evaluated by the direct current potential drop (DCPD) method. The mechanical test results are given in Section 5.

\subsubsection{Crack Length Evaluation - Compliance Method}

The compliance method reliês on the sping-like nature of the CT specimen (as given by the slope of the elastic load-displacement record) to establish crack length. As illustrated in Figure 4-1, the load-displacement record for a J-R curve test has a linear elastic portion at the beginning of the record, followed by plasticity formation up to maximum load, with decreasing load accompanying increased displacement thereafter. The sloped lines at various points on the record in Figure 4-1 represent compliance measurements made during the test. These compliance unloadings represent a decrease in load of $\approx 10 \%$ of the maximum load, then a reloading to the previous load value. The result, shown in Figure 4-2, is a linear record of load $(\Delta \mathrm{P})$ versus displacement $(\Delta \delta)$. It is seen in Figure 4-2 that the compliance (slope) changes from the initial crack length conditions at the right $(\mathrm{a} / \mathrm{W} \approx 0.52)$ to the final crack length conditions at the left $(\mathrm{a} / \mathrm{W} \approx 0.78)$, where the parameters a and $W$ are defined in Figure 4-3. The $(\Delta \delta / \Delta P)$, is combined with other terms to give [15]:

$$
\mathrm{U}_{\mathrm{LL}}=\frac{1}{\left\{\sqrt{\left.\frac{\mathrm{B}_{\mathrm{e}} \mathrm{E} \Delta \delta}{\Delta \mathrm{P}}\right]}+1\right\}}
$$

where: $\mathrm{U}_{\mathrm{LL}}=$ Load Line measurement of $\mathrm{a} / \mathrm{W}$

$$
\begin{aligned}
& \mathrm{B}_{\mathrm{e}}=\mathrm{B}-\left(\mathrm{B}-\mathrm{B}_{\mathrm{N}}\right)^{2} / \mathrm{B} \\
& \mathrm{B}=\text { gross specimen thickness } \\
& \mathrm{B}_{\mathrm{N}}=\text { net specimen thickness } \\
& \mathrm{E}=\text { modulus of elasticity }
\end{aligned}
$$

The crack length for a load-line mounted clip gage is given by the calibration equation of Hudak-

- Saxena [15]:

$$
\begin{aligned}
\mathrm{a} / \mathrm{W}= & 1.00196-4.06319 \mathrm{U}_{\mathrm{LL}}+11.242 \mathrm{U}_{\mathrm{LL}}{ }^{2}-106.043 \mathrm{U}_{\mathrm{LL}}{ }^{3} \\
& +464.355 \mathrm{U}_{\mathrm{LL}}{ }^{4}-650.677 \mathrm{U}_{\mathrm{LL}}{ }^{5}
\end{aligned}
$$


Two corrections to the compliance crack lengths are made: a rotation correction and a modulus correction. The calibration equation (Eqn. 4-2) was determined from elastic specimens which had not been plastically deformed. Since these J-R curve tests result in significant plastic deformation, a "rotation" correction must be applied to the measured slope values. The rotationcorrected compliance , $\mathrm{C}_{\mathrm{c}}$, is then evaluated from [16]:

$$
C_{c}=\frac{C_{m}}{\left\{\left[\frac{H^{*}(\sin \theta-\cos \theta)}{R}\right]\left[\frac{D(\sin \theta-\cos \theta)}{R}\right]\right\}}
$$

where (Figure 4-3):

$$
\begin{aligned}
& \mathrm{C}_{\mathrm{c}}=\text { compliance corrected for rotation of the specimen } \\
& \mathrm{C}_{\mathrm{m}}=\text { measured compliance }(=\Delta \delta / \Delta \mathrm{P}) \\
& \mathrm{H}^{*}=\text { initial half span of the load points (center of pin holes) } \\
& \mathrm{R}=\text { radius of rotation of the crack centerline, }(\mathrm{W}+\mathrm{a}) / 2 \\
& \text { where "a" is the current crack length } \\
& \mathrm{D}=\text { one-half of the initial distance between the displacement } \\
& \text { measured points }
\end{aligned}
$$

The modulus correction is used to provide a consistent starting point (initial crack length) for the compliance measurement and the initial crack length as determined by optical measurement. The match modulus (matches the compliance and optical initial crack lengths) is evaluated from Equations 4-1 and 4-2 in an iterative manner by first determining the proper $U_{L L}$ to give the optically-measured initial (pre-test) crack length. Using an initial (pre-test) compliance value, $\mathrm{C}_{0}$, the match modulus, $\mathrm{E}_{\mathrm{M}}$, is determined by inverting Equation 4-1.

$$
E_{M}=\frac{\left[\left(\frac{1}{U_{\tilde{L}}}\right)-1\right]^{2}}{\left(B_{e} C_{d}\right.}
$$

Combining these two corrections, a corrected definition of Equation 4-1 results:

$$
\mathrm{U}_{L L, C}=\frac{1}{\left\{\sqrt{\mathrm{Be}_{\mathrm{M}} \mathrm{C}_{\mathrm{c}}}+1\right\}}
$$

- This corrected value of $U_{L L, C}$ is then used with Equation 4-2 to determine the crack length, and after subtracting the initial crack length, the crack growth for the specimen. These crack growth values are referred to as "predicted" crack growth values. 


\subsubsection{J Integral Evaluation - $\mathrm{J}_{D}$ and $\mathrm{J}_{M}$}

Both the deformation theory $\left(\mathrm{J}_{\mathrm{D}}\right)$ and modified theory $\left(\mathrm{J}_{\mathrm{M}}\right)$ forms of the J-integral were analyzed by MEA and are discussed below for completeness. The values of $J_{D}$ and $J_{M}$ are calculated by the following equations [17]:

$$
J_{D i+1}=\left\{\left(J_{D_{i}}+\left[\left(\frac{\eta}{b}\right)_{i} \frac{A_{i, i+1}}{B_{N}}\right]\right\}\left\{1-\left(\frac{\eta}{b}\right)_{i}\left(a_{i+1}-a_{i}\right)\right\}\right.
$$

where: $\eta=2+0.52(\mathrm{~b} / \mathrm{W})$

$\gamma=1+0.76(\mathrm{~b} / \mathrm{W})$

$\mathrm{b}=$ unbroken ligament $(=\mathrm{W}-\mathrm{a})$

$\mathrm{W}=$ specimen width

$\mathrm{A}=$ area under load-loadline displacement record

$\mathrm{a}=$ crack length.

$\mathrm{J}_{\mathrm{M}}=\mathrm{J}_{\mathrm{D}^{-}} \int_{\mathrm{a}_{\mathrm{o}}}^{\mathrm{a}} \frac{\partial\left[\mathrm{J}_{\mathrm{D}^{-}}-\mathrm{G}\right]}{\partial \mathrm{a}} \mid \delta_{\mathrm{pl}} \mathrm{da}$

where: $\begin{array}{ll}\mathrm{J}_{\mathrm{D}} & =\text { deformation theory } \mathrm{J} \\ \mathrm{G} & =\text { Griffith linear elastic release rate }\end{array}$

$$
=\mathrm{K}_{\mathrm{I}}^{2}\left(1-v^{2}\right) / \mathrm{E}
$$

$\mathrm{a}_{\mathrm{O}} \quad=$ initial crack length

$\mathrm{J}_{\mathrm{D}^{-}} \mathrm{G}=\mathrm{J}_{\mathrm{pl}}$, the plastic portion of the deformation theory $\mathrm{J}$

$v \quad=$ Poisson's ratio

and,

$\mathrm{K}_{\mathrm{I}} \quad=\mathrm{Pf}(\mathrm{a} / \mathrm{W})\left(\mathrm{WBB}_{\mathrm{N}}\right)^{-0.5}$

where $P$ is the hold load at a partial unloading, $f(a / W)$ is given in ASTM standard E 399 [18], and $W, B$ and $B_{N}$ are the specimen width, thickness and net thickness respectively.

Although both $\mathrm{J}$ theories (deformation and modified) were calculated by MEA in the post-test analysis, deformation- $J$ results are presented in detail in this report and are recommended for use in the structural integrity determinations. This is the formulation of the $J$ integral specified for use in the ASTM standards E 813-81 [19] and E 1152 [20]. At crack extensions greater than a few millimeters, deformation-J theory also results in a J-R curve lying below the J-R curve for the modified-J formulation as shown in Figure 4-4. Thus, application of the deformation-J material toughness in the piping fracture analysis (see Section 7) would yield conservative (shorter) stable flaw lengths compared to analysis with the modified-J toughness. 
It is mentioned, however, that the modified-J formulation proposed by Ernst (17) as appropriate in the evaluation of the J-R curve is essentially independent of CT planform size. Furthermore, crack extension in J-controlled growth is apparently allowed even for crack growth where $\omega$ (see Section 5.5) is approximately zero.

\subsubsection{J-R Curve Evaluation}

A typical J-R curve is illustrated in Figure 4-5. The J-R curve format is in accordance with that of ASTM E 813-81, with the line emanating from the origin called the blunting line, as given by $\mathrm{J}=2 \sigma_{\mathrm{f}} \Delta \mathrm{a}$, where $\sigma_{\mathrm{f}}$ is the flow strength; the average of the $0.2 \%$ offset yield strength and the ultimate strength. The exclusion lines are parallel to the blunting line, but offset by $0.15 \mathrm{~mm}$ (0.006 inch) and $1.5 \mathrm{~mm}(0.06 \mathrm{inch})$.

In ASTM E 813-81, a straight line is fit to the data points between the 0.15 and $1.5 \mathrm{~mm}$ exclusion lines. This line is extrapolated back to the blunting line, with the intersection termed $\mathrm{J}_{\mathrm{Q}}$. $\mathrm{J}_{\mathrm{Ic}}$ equals $\mathrm{J}_{\mathrm{Q}}$ when various validity criteria are satisfied. With Types 304 and $304 \mathrm{~L}$ stainless steels, the specified specimen sizes $\left(0.4 \mathrm{~T}\right.$ planform) preclude determination of valid $\mathrm{J}_{\text {Ic }}$ values per ASTM E 813-81.

In the power law evaluation of the I-R curve data, an equation of the form $J=C(\Delta a)^{n}$ is fit to the data between the exclusion lines. The power law $\mathrm{J}_{\mathrm{Ic}}$ is then evaluated as the intersection of the power law equation with the $0.15 \mathrm{~mm}$ exclusion line. This power law methodology to determine $\mathrm{J}_{\text {Ic }}$ yields values nearly equivalent to the values developed by applying the ASTM E 813-81 methodology (see Figures 4-5 $\widehat{A}$ and 4-5B).

The tearing modulus, $T_{M}$, characterizes the tearing resistance of the material and is given by:

$$
T_{M}=\frac{E}{\left(\sigma_{f}\right)^{2}} \frac{d J}{d a}
$$

with (dJ / da) being the slope of the J-R curve. Since the J-R curve is well defined by a power law, $T_{M}^{-}$changes with crack growth. For comparison purposes, average values of $T_{M}$, termed $\mathrm{T}_{\text {avg, have been defined. The ASTM } \mathrm{T}_{\text {avg }} \text { value is taken as the slope (dJ/da) of the linear }}$ regression fit to the data between the exclusion lines; the power law $T_{\text {avg }}$ value is taken from a linear fit to the power law curve whereby an average slope is defined in a closed form [21].

\subsection{Dynamic J-R Curve Data Analysis Procedures}

\subsubsection{Overview}

For J-R curve evaluation under dynamic or rapid-load conditions, crack length estimation cannot be accomplished by the unloading compliance method used for the static specimen test J-R curve determination. The direct current potential drop or DCPD method can be applied as an alternative for dynamic testing conditions. The subsequent sections describe the DCPD method as it applies

- to the dynamic compact tension (CT) specimen tests, including the data analysis procedures used. 


\subsubsection{DCPD: Theory and Measurement Procedures}

The DCPD method involves the application of a direct current (DC) across the CT specimen as illustrated in Figure 4-6. The output voltage is measured across the crack, in this case at points in the specimen front face. As the crack is lengthened, the electrical resistance across the crack increases due to the reduced cross-section of the unbroken ligament. For the case of a constant applied current, the increased resistance to current flow results in an increase in the measured voltage across the crack according to Ohm's Law. Recognizing this, Johnson [22] developed calibration equations relating measured potential drop (PD) and crack length. The calibration positions used by Johnson for input and output leads are those given in Figure 4-6. Johnson's equation is:

$$
a=\frac{2 W}{\pi} \cos ^{-1}\left\{\frac{\cosh \left(\frac{\pi y}{2 W}\right)}{\cosh \left(\frac{U}{U_{0}}\right) \cosh ^{-1}\left[\frac{\cosh \left(\frac{\pi y}{2 W}\right)}{\cos \left(\frac{\pi a_{0}}{2 W}\right)}\right]}\right\}
$$

where $U_{o}$ and $a_{o}$ are the initial potential drop and crack length, respectively, and $U$ and $a$ are the instantaneous values of these quantities.

\subsubsection{Initiation and Plasticity}

As with the unloading compliance method, Johnson's calibration equations were derived without consideration of the plasticity which is present in all J-R curve tests and without consideration of cross-section shape changes which typically occur under conditions of gross plasticity. The creation of non-parallel crack fronts was found in the testing of the 0.4T planform Type 304 stainless steel specimens in this program due to the limited constraint provided by the thickness of the specimens. The specimen design studies to control this effect are discussed in subsequent sections. --

The primary drawback of the DCPD method is plasticity. Prior to the initiation of crack growth in the specimens, plasticity causes a large increase in the measured potential drop. As illustrated in Figure 4-7, the plasticity-induced increase in potential drop is linearly-related to displacement in the potential drop blunting line. Unlike the compliance method, however, determination of crack growth $(\Delta \mathrm{a})$ values in the blunting region using appropriate calibration equations does not give results which follow the J-R curve blunting line $\left(J=2 \sigma_{f} \Delta a\right)$. Many researchers have concluded that departure from this linear trend is associated with the initiation of crack growth. Due to the gross plasticity observed in these stainless steel tests, the initiation point is difficult to determine from a plot of potential drop versus displacement. Also, there are no set of guidelines as to the $\Delta \mathrm{a}$ value which should be assigned to the initiation data point, for conformance with compliance-based J-R curve evaluations. Current practice by many researchers is to subtract - from all potential drop measurements the difference between $U_{o}$ and $U$ at initiation as an attempt to correct for plasticity. An alternate method for handling this problem, suggested by multiple specimen results, is discussed below. [As stated, crack growth measurements for the dynamic CT testing were performed bt DCPD (Section 4.2.2). Section 4.2.4 below is provided for information only]. 


\subsubsection{Multiple Specimen Data Analysis}

Historically, the multiple specimen approach was the initial ASTM recommended method for evaluating the J-R curve for structural materials. The approach involves the preparation of a group of identical specimens, in terms of material melt, crack-plane orientation and specimen configuration. Each of the specimens is instrumented with a clip gage and then loaded to a specific displacement. The specimen is subsequently fractured or fatigued to failure, with the amount of crack growth $(\Delta a)$ determined from optical measurements of the fracture surface. The $\mathrm{J}$ value is determined from the load-displacement record. The result is a single datum of $(\mathrm{J}, \Delta \mathrm{a})$. for the material. The duplicate specimens are used to obtain a range of $\Delta \mathrm{a}$ increments for the material, and thereby establish the crack growth behavior. Since many specimens are required to obtain a single J-R curve, the development of procedures for J-R curve development from a single specimen greatly improves the economics of fracture toughness evaluation.

The multiple specimen dynamic test series results have been evaluated using the Merkle-Corten corrected form of the $\mathrm{J}$ integral as given by:

$$
J_{M-C}=\left(\frac{A}{b_{0} B_{N}}\right) f\left(\frac{a}{w}\right)
$$

$$
\text { where } \begin{array}{ll}
\mathrm{b}_{\mathrm{o}} & =\text { the initial unbroken ligament }\left(=\mathrm{W}-\mathrm{a}_{\mathrm{o}}\right) \\
\mathrm{B}_{\mathrm{N}} & =\text { the net specimen thickness }(=\mathrm{B}(1-\% \mathrm{SG})) \\
f(\mathrm{a} / \mathrm{W}) & =2(1+\alpha) /\left(1+\alpha^{2}\right) \\
\alpha & =\left\{\left(2 \mathrm{a}_{\mathrm{o}} / \mathrm{b}_{\mathrm{o}}\right)^{2}+2\left(2 \mathrm{a}_{\mathrm{o}} / \mathrm{b}_{\mathrm{o}}\right)+2\right\} 0.5-\left(2 \mathrm{a}_{\mathrm{o}} / \mathrm{b}_{\mathrm{o}}+1\right) \\
\mathrm{a}_{\mathrm{o}} & =\text { optically measured initial (pre-test) crack length }
\end{array}
$$

\subsection{Static Tensile Data Analysis Procedures}

The engineering and true stress-strain values were calculated from the measurements of applied load $(\mathrm{P})$ and axial displacement $(\Delta \mathrm{L})$, together with the initial specimen dimensions, shown in Figure 3-2a.

\subsubsection{Engineering Stress/Strain}

Engineering stress $\left(\sigma_{\mathrm{E}}\right)$ and strain $\left(\varepsilon_{\mathrm{E}}\right)$ were calculated from the respective relationships:

$$
\begin{aligned}
& \sigma_{\mathrm{E}}=\mathrm{P} / \mathrm{A}_{\mathrm{O}} \\
& \varepsilon_{\mathrm{E}}=\Delta \mathrm{L} / \mathrm{L}_{\mathrm{O}}
\end{aligned}
$$

where $L_{O}$ is the initial (extensometer) gage length and $A_{0}$ is the gage section area by $\pi r_{0}{ }^{2}$, where

- $r_{0}$ is the initial gage section radius. 


\subsubsection{True Stress/Strain}

Because of necking, the true stress-strain values are calculated from measured load and extensometer displacement up to maximum load only; the final gage diameter and radius of curvature (of the necked region) are used to obtain values of true stress-strain at fracture. Up to maximum load, true strain $\left(\varepsilon_{\mathrm{T}}\right)$ is calculated from:

$$
\varepsilon_{\mathrm{T}}=\mathrm{LOG}_{\mathrm{e}}\left(\varepsilon_{\mathrm{E}}+1\right)
$$

while true stress $\left(\sigma_{\mathrm{T}}\right)$ is calculated from:

$$
\sigma_{\mathrm{T}}=\sigma_{\mathrm{E}}\left(\varepsilon_{\mathrm{E}}+1\right)
$$

based on assumptions of constant volume and a homogeneous distribution of strain along the gage length.

The true strain at fracture $\left(\varepsilon_{\mathrm{Tf}}\right)$ is calculated from:

$$
\varepsilon_{\mathrm{Tf}}=\operatorname{LOG}_{\mathrm{e}}\left(\mathrm{A}_{0} \mathrm{Af}_{\mathrm{f}}\right)
$$

where $A_{f}$, the final gage area, is given by $\pi \mathrm{r}_{f}{ }^{2}$. Dimension $\mathrm{r}_{\mathrm{f}}$ is the measured final gage section radius.

The true stress at fracture $\left(\sigma_{\mathrm{Tf}}\right)$ is calculated using a Bridgman correction [24]:

$$
\sigma_{\mathrm{Tf}}=\frac{\mathrm{P}_{\mathrm{f}}}{\left[\mathrm{A}_{\mathrm{f}}\left(1+\frac{2 \mathrm{R}}{\mathrm{I}_{\mathrm{f}}}\right) \log _{\mathrm{e}}\left(1+\frac{\mathrm{r}_{\mathrm{f}}}{2 \mathrm{R}}\right)\right]}
$$

where $\mathrm{P}_{\mathrm{f}}$ is the load at fracture and $R$ is the measured radius of curvature of the necked region. This correction, from a mathematical analysis, adjusts the average axial stress to account for the introduction of transverse stresses. The following assumptions were made in the formulation of the Bridgman correction:

1) The contour of the neck is approximated by the arc of a circle.

2) The cross section of the necked region remains circular throughout the test.

3) The von Mises' criterion for yielding applies.

4) The strains are constant over the cross section of the necked region.

The stress-strain values were computed by MEA from paired load-displacement points. Since the true stress-strain values cannot be derived in a like manner beyond maximum load, no true stress-strain values are listed for points between maximum load and the point of fracture.

- Attachment 1 contains the strength and ductility results for each of the tensile specimens. Section 5 summarizes the static tensile testing results. 


\subsection{Dynamic Tensile Data Analysis Procedures}

The main matrix dynamic tensile test results were developed with an LVDT-type extensometer chosen for its extended-range measuring capability and its good adaptability to hot cell operation. Subsequent problems with the LVDT circuitry led MEA to change-over to a direct mount, strain gage-type extensometer (MTS) and to evaluate a "second" specimen set.

Strain gages were applied to the specimen gage sections to verify the accuracy of the MTS extensometer yield strength values. Although the strain gages provided a yield strength that was consistently lower than that obtained by the axial extensometer, in all cases the resultant values were within $2 \mathrm{ksi}$. This agreement between the strain gage and MTS extensometer yield strength values gives good general confidence in the MTS data [Appendix O of Reference 5].

Following completion of the "second" set of dynamic tests, attention was given to redefining the data from the main matrix ("first" set) tests. This re-evaluation of the stress-stroke data was made by reference to the stress-stroke data from the second set of specimens [25], the results of which are contained in Attachment 1 and summarized in Section 5.

\subsection{Charpy Data Analysis}

The charpy specimens were tested with an instrumented specimen striker (tup), equipped with a Dynatup Instrumentation System. This system records applied load versus time-of-fracture and integrates energy absorbed versus time-to-fracture. An example of the Dynatup record produced by the system is given in Figure 4-8. Each record presents two traces; applied load versus timeto-fracture and energy absorbed versus time. Both traces are in analog form (voltage versus time). In the first (load), one volt is equal to $1000 \mathrm{lbs}$-force. In the second (energy), one volt is equal to $20 \mathrm{ft}-1 \mathrm{~b}$ energy absorption plus a standard Dynatup correction factor [Appendix $\mathrm{L}$ of Reference 5]:

For the traces in Figure 8, the hand written entries refer to specific points on the curve. Each entry gives (a) the instantaneous time (in microseconds), (b) the applied load (in volts) and (c) the integrated energy absorption (in volts).

\subsection{Specimen Design Studies}

In addition to the standard test matrix (Table 3-1), several series of "shakedown" tests were initiated to verify that the results for the substandard specimen designs were consistent with those produced by standard specimen designs. The most important of these, the effect of the substandard compact specimen planform ( $0.4 \mathrm{~T}$ versus $1 \mathrm{~T})$, is discussed in Section $5-5$. In addition, compact tension side-groove and load hole studies were conducted. The results of these studies are given in the subsequent sections.

\subsubsection{Compact Tension Specimen Design Selection}

\subsubsection{Overview}

Prior to machining any baséline main test matrix specimens (Table 3-1) compact tension (CT) specimens, a study was made to identify a suitable CT specimen design for determining the elastic-plastic fracture toughness of the SRS stainless steel piping materials. These materials, Types 304 and 308 stainless steel, have low-to-medium strength and high resistance to fracture. 
For the SRS piping materials, no standardized test method exists for fracture toughness evaluation. The American Society for Testing and Materials (ASTM) fracture toughness standards E 399 and E 813 would require a specimen thickness of several inches to obtain valid measurements for the materials at expected (high) toughness levels. The thickness of the SRS piping materials, in contrast, is only 0.5 -inch and sets the largest "full-size" specimen obtainable: a 0.4T-CT specimen (0.394-inch thick planform).

In addition to the specimen size restrictions, other constraints impact the choice of a suitable specimen design. Some specimens were designed for irradiation in the Oak Ridge National Laboratory (ORNL) High Flux Intensity Reactor (HFIR) in direct contact with the coolant, raising concerns that the razor knife edges attached to the CT specimen for transducer (clip gage) mounting would corrode. Alternatives to the usual test procedure would be attachment of the blades to the specimen after irradiation, or use another method for displacement measurement.

A second concern was specimen deformation in the loading arms. From past work with high toughness materials, the ASTM Standard E 813 specimen design was found to have a tendency toward substantial plastic deformation in the region of the loading pin holes. Such deformation is highly undesirable from the standpoints of transducer measurement errors and problems in removing the specimens from the test fixtures.

The following Section describes the series of tests undertaken to provide a workable compact tension specimen design for the SRS revactor piping materials [Appendix B of Reference 5].

\subsubsection{Approach}

The primary criterion for selecting a final specimen design was the ability to produce consistent and conservative J-R curves and thus fracture toughness properties. Six compact tension specimen designs were considered. These include the ASTM standard E 399 and E 813 specimens, as well as variations on these configurations which incorporated smaller-thanstandard pin-hole diameters and smaller-than-standard pin-hole center-to-center spacing. Table 4-1 lists the various specimen types, the identification numbers of the specimen types and the respective specimen drawing numbers. Machining dimensions for all six specimen types are gives in Figures 4-9 through 4-14.

Each specimen type is identified in Table 5-6 with by a two letter suffix, identifying its conformance or nonconformance with the applicable ASTM standard. The first letter refers to the pin-hole size, the seconds to pin-hole spacing. An "S" indicates no change from the ASTM standard; an " $R$ " indicates a reduction in pin-hole diameter or spacing. For example, an $E$ 399SS specimen (Figure 4-9) is the ASTM E 399 design, including the standard pin-hole diameter and standard spacing between pin holes. An E 399-RR specimen (Figure 4-10) is the E 399 design, but with both pin-hole size and spacing reduced. An E 399-SR specimen (Figure 4-11) is the E 399 design but with pin-hole spacing only reduced.

One beneficial aspect of the E 399 designs compared to the ASTM E 813 design, is substantially more metal provided around the pin holes; that is, the absence of an expanded notch for load-line razor blade attachment. This additional load-bearing metal inherently reduces plastic deformation at the pin-holes. Reducing the pin-hole diameter and spacing in the nonstandard versions of the - E 399 and the E 813 specimen design also serves to reduce stress levels in the pin-hole region.

With the MEA-modified E 399 designs (Figures 4-9 through 4-12), a shallow notch is machined above the pin holes on the load line. Load-line deflection is measured by placing an "outboard" clip gage having integral razor edges in these notches. This effectively eliminates a need for 
attaching razor knife edges to the test specimen itself. This modified configuration was validated in a multi-laboratory round-robin using specimens from low alloy (reactor pressure vessel) steel [26]. Plastic deformation above the loading pin holes should be negligible in these designs as well. Again, the concern is that plastic deformation above the pin holes could introduce extraneous deflection measurements in the load-line clip gage, resulting in an improper elevation of of the J-R curve. Another consideration of the various specimen designs was the degree of bulging under the clip gage notches.

A third source of error in J-R curve assessment is the plastic bending of the specimen "arms". This phenomenon would be present in both the E 813 and E399 designs regardless of the pinhole size or spacing, and is symptomatic of low yield strength materials.

\subsubsection{Results and Conclusions}

A total of 17 plane-sided (i.e., $0 \%$ side grooved) compact tension specimens were tested and evaluated for three types of plastic deformation (see Figure 5-14):

- bulging above the pin holes;

- plastic arm bending; and

- shear displacement of the end of the arm (in the E 813 designs).

Measurements made on each deformation type are given in Table 4-2 for each specimen, with the following observations:

- Bulging is negligible in comparison to plastic arm bending. (Direct measurement of bulging was not possible for the E 813 specimens.) Since bulging is negligible, outputs from a clip gage mounted "outboard" above the pin holes would not be perturbed.

- Shear displacement occurs in the E 813 designs but not in the E 399 designs. Shear displacement contributions in the E 813 designs are small (not important) if displacements are measured between the pin holes (i.e., "inboard").

- "Plastic arm bending is "approximately" the same for all specimen designs evaluated.

The plastic arm bending phenomenon will introduce an error into all J-R curves. This source of error can not be eliminated with the low yield strength materials of this investigation. The induced error by plastic arm bending however, should evolve only up to the point of maximum specimen load $\left(\mathrm{P}_{\max }\right)$. Crack initiation is believed to occur close to $\mathrm{P}_{\max }$; accordingly, the error probably affects only crack initiation $\left(\mathrm{J}_{\mathrm{Ic}}\right)$ and not the tearing modulus $(\mathrm{T})$. The magnitude of this error is estimated to be less than $15 \%$, and will change slightly as the material yield strength varies (weld versus base metal).

A summary of the results (all specimen types) is illustrated in Figure 4-16. Results comparing the $E 813$ and $E 399$ designs are given in Figures 4-17 to 4-19. Conclusions from the specimen

- design evaluations are:

- The $\mathrm{E} 813$ design is unacceptable. The "outboard" clip gage cannot be used due to shear displacements in the specimen arms. This design requires the 
use of an "inboard" clip gage mounted on razor blades. However, the razor blades are unacceptable for irradiation in the HFIR and in the SRS surveillance program.

- The E 399 design variations are acceptable, they avoid the need for razor blade attachments.

- The E 399-RR design has strong advantages over the other E 399 designs (SS, SR and RS) because it retains more metal above the loading pin-holes via use of a reduced pin-hole diameter and a reduced pin-hole spacing.

One consideration against the E 399-RR specimen design is the relatively small diameter of the pins used for loading the specimen. Since irradiated specimens could have an ultimate strength up to $120 \mathrm{ksi}$, pins suitable for this design were subjected to a load approximating the maximum load expected for this material in the irradiated condition. The finding was excessively high pin bending which would preclude testing. This indicated that the standard size pins must be used, as they are capable of carrying the loads expected from the irradiated material condition. The E 399-SR specimen design (Figure 4-11) accordingly was chosen for the main matrix tests.

The E 399-SR design was modified to include small, drilled holes for attachment of electrical leads required for monitoring of crack growth by the Direct Current Potential Drop (DCPD) technique. The DCPD techñique wass planned for dynamic testing only (see Section 4.2). To prove that the metal removed by these holes would not influence the J-R curve, several specimens were machined according to Figure 4-20 (with DCPD holes) and tested. The results of these tests are compared to previous tests of E 399-SR specimens in Figure 4-21. The data indicate no effect of the special holes on J-R curve behavior.

While the E 399-SR design is judged to be the best design for the material test program, the inability to eliminate the plastic arm bending (in plane-sided specimens) must be addressed. Bending will result in errors in the computed $J$ values. This error is believed to be less than $15 \%$, but will depend on the amount of arm bending (a function of the material yield strength). The subsequent study on side grooving indicated that $20 \%$ side grooves, as used in the main program tests, significantly reduce this bending. Results of this side-groove study are given in the next section.

\subsubsection{Compact Tension Side-Groove Study}

\subsubsection{Overview}

The objective of this investigation, performed prior to testing the main specimen matrix, was to identify the degree of side grooving required for determining the elastic-plastic fracture toughness of the SRS piping materials (Types 304 and 308 stainless steel). For such materials, no standardized procedure existed to determine the proper amount of side grooving [Appendix $\mathrm{C}$ of Reference 5].

For low alloy steels, side grooving has been used to assure lower bound J-R curve development, to increase crack extension prediction capabilities (using the compliance technique) and to reduce

- crack-front tunneling. These criteria were also used to determine the proper side-groove depth in this study. For low alloy steels, $20 \%$ side grooves (10\% of the specimen thickness on each side) have frequently been used. 
Three side-groove depths were considered: 0,10 and 20 percent. A minimum of two weld and two base metal specimens having each side-groove depth were tested using the E 399 SR specimen design (see previous section). Side grooves machined in each specimen were centered on and parallel to the crack plane and were cut using a wheel cutter having a $45^{\circ}$ included angle and a 0.010-in. tip radius. This cutter design has been widely used in other studies [Appendix C of Reference 5].

\subsubsection{Results}

J-R curve results for the base metal and weld materials are illustrated in Figures 4-22 and 4-23. In each case, the data for $0 \%$ versus $10 \%$ side-grooved specimens are in good agreement; an observable lowering of the J-R curve (more conservative fracture toughness prediction) resulted with $20 \%$ side grooving.

Specimen fracture surfaces for the tests are illustrated in Figure 4-24. The amount of crack front tunneling is directly related to the side-groove depth for both the base and weld metal specimens. With 20\% side-grooves, the crack front is essentially straight for base metal specimens; the weld specimen crack fronts are slightly reverse-tunneled. From the standpoint of minimizing crackfront tunneling, $20 \%$ side grooves produced the best results.

Referring to Figure 4-24, side grooving would appear to accentuate material flaws. This observation is particularly true for the $20 \%$ side-grooved plate specimens, where large vertical cracks perpendicular to the fracture plane are evident for the base material. These cracks are probably metallurgical inhomogeneities that have been opened up by the transverse constraint in the specimen under load. Since this constraint is relatively low in the $0 \%$ side-grooved specimens, these flaws are not as apparent in the $0 \%$ side-grooved specimens as in the $20 \%$ sidegrooved specimens.

A further observation is that the crack plane was not always coincident with the bottom of the side groove (20\% side-grooved case). This resulted in a net specimen thickness $\left(\mathrm{B}_{\mathrm{N}}\right)$ that is somewhat larger than that assumed for the J calculations; this would artificially elevate the J-R curve by a few percent $(\approx 3-5 \%)$. This phenomenon could also attribute to the degree of scatter for the $20 \%$ side-grooved specimens, compared to results for the $0 \%$ and $10 \%$ side-grooved specimens-(Figures 4-22 and 4-23).

In the preliminary specimen design study, plastic bending of the specimen arms occurred in the plain-sided (i.e., $0 \%$ side-grooved) specimens of the type used in that study. Because $20 \%$ side grooving reduces the specimens load carrying capacity, virtually zero plastic arm bending was noted here. This potential source of error is thus eliminated for the main program tests.

The effect of side grooving on crack extension prediction accuracy is illustrated in Figure 4-25. The crack growth prediction error tends to decrease with increasing side-groove depth. This result was expected since the compliance curve used for crack growth prediction is based on a straight crack front, i.e., that which is most closely associated with $20 \%$ side grooves.

For a structural integrity analysis based on tearing instability concepts, the slope of the J-R curve, $\mathrm{dJ} / \mathrm{da}$, is of primary interest. Therefore, knowledge of the effect of side grooving on J-R

- curve slope is important. To illustrate this, an average slope was calculated for a range of $\approx 0.5$ to $2.8 \mathrm{~mm}$. The results, shown in Figure 4-26, indicate that there is no appreciable effect due to side-grooving depth. This trend is different from that observed with reactor pressure vessel (RPV) steels (e.g., A 533-B plate). With the latter, the J-R curve slope decreases appreciably with increasing side-groove depth in the range of 0 to $20 \%$. 


\subsubsection{Conclusions}

The $20 \%$ side-grooved geometry was recommended for the baseline testing program for the following reasons:

(1) J-R curves obtained with $20 \%$ side-grooved specimens are slightly lower and thus more conservative than curves developed with $0 \%$ and $10 \%$ side-grooved specimens.

(2) The crack growth prediction errors are lowest with the $20 \%$ side-grooved specimens, implying that the J-R curves from the $20 \%$ side-grooved specimens are more accurate.

(3) The use of $20 \%$ side grooves virtually eliminated the plastic arm bending and crack tunneling observed with the $0 \%$ side-grooved specimens. In turn, errors in the J-R curve which result from these phenomena are precluded.

(4) Side grooving has no discernible effect on the slope of the J-R curve for the stainless steels of interest (Types 304 and 308).

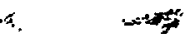


Table 4-1: Compact Tension 0.394T Specimen Design Test Matrix ${ }^{a}$

\begin{tabular}{|l|c|c|c|c|c|c|}
\hline $\begin{array}{c}\text { Specimen } \\
\text { Type }\end{array}$ & $\begin{array}{c}\text { Number } \\
\text { of Tests }\end{array}$ & $\begin{array}{c}\text { Specimen } \\
\text { Number }\end{array}$ & $\begin{array}{c}\text { Hole c } \\
\text { Diameter }\end{array}$ & $\begin{array}{c}\text { Holed } \\
\text { Spacing }\end{array}$ & $\begin{array}{c}\text { Dimensional } \\
\text { Drawing \# }\end{array}$ & Figure \\
\hline E 399 (SS) & 3 & $6,29,34$ & Std & Std & $447-A O-5004$ & $4-9$ \\
E 399 (RR) & 3 & $7,17,19$ & R & R & $447-A O-5005$ & $4-10$ \\
E 399 (SR) & $3(2)$ & $26,31,33$ & Std & R & $447-A O-5003$ & $4-11$ \\
& & $(20,37)$ & & & & \\
E 399.(RS) & 1 & 5 & R & Std & $447-A O-5008$ & $4-12$ \\
E 813 (RR) & 2 & 8,30 & R & R & $447-A O-5007$ & $4-13$ \\
E 813 (SS) & 3 & $25,28,35$ & Std & Std & $447-A O-5006$ & $4-14$ \\
\hline
\end{tabular}
a All specimens have standard 0.394T-CT planer dimensions with a thickness of
0.394 -in.

b ASTM E 399 or E 318 notch type, first and second letter in parentheses refer to pinhole size and spacing, respectively: $(S=$ Standard, $R=$ Reduced $)$.

c $S t d=$ Standard ASTM E 399 or E 813 pin-hole diameter $\mathrm{R}=$ Reduced pin-hole spacing

d Std $=$ Standard ASTM E 399 or E 813 pin-hole center-to-center spacing $\mathrm{R}=$ Reduced pin-hole spacing

e Number in parentheses refers to additional tests with tapped holes for DCPD . checkout 
Table 4-2: Plastic Deformation in CT Design Specimens

\begin{tabular}{|c|c|cc|cc|cc|}
\hline $\begin{array}{c}\text { Specimen } \\
\text { Type }\end{array}$ & \multirow{2}{*}{$\begin{array}{c}\text { Number } \\
\text { of Tests }\end{array}$} & \multicolumn{2}{|c|}{ Bulging } & \multicolumn{2}{|c|}{$\begin{array}{c}\text { Plastic Arm Bending } \\
\text { (Each Arm) }\end{array}$} & \multicolumn{2}{|c|}{$\begin{array}{c}\text { Shear Displacement } \\
\text { E 813 Specification } \\
\text { (Each Arm) }\end{array}$} \\
\cline { 2 - 9 } & & $\begin{array}{c}\text { Range } \\
\text { (mil) }\end{array}$ & $\begin{array}{c}\text { Mean } \\
\text { (mil) }\end{array}$ & $\begin{array}{c}\text { Range } \\
\text { (mil) }\end{array}$ & $\begin{array}{c}\text { Mean } \\
\text { (mil) }\end{array}$ & $\begin{array}{c}\text { Range } \\
\text { (mil) }\end{array}$ & $\begin{array}{c}\text { Mean } \\
\text { (mil) }\end{array}$ \\
\hline E 813 (RR) & 2 & $\mathrm{a}$ & $\mathrm{a}$ & $12-17^{\mathrm{b}}$ & $14^{\mathrm{b}}$ & $8-14$ & 11 \\
E 813 (SS) & 3 & $\mathrm{a}$ & $\mathrm{a}$ & $10-16^{\mathrm{b}}$ & $12^{\mathrm{b}}$ & $16-19$ & 17 \\
E 399 (RR) & 3 & $0.2-0.6$ & 0.4 & $9-13$ & 11 & - & - \\
E 399 (RS) & 1 & -- & 0.4 & -- & 16 & - & - \\
E 399 (SR) & 3 & $0.2-0.4$ & 0.26 & $10-21$ & 15 & -- & - \\
E 399 (SS) & 4 & $0.6-2.0$ & 1.0 & $7-25$ & 16 & -- & - \\
\hline
\end{tabular}
a Unable to establish
$\because$
b Includes bulging 


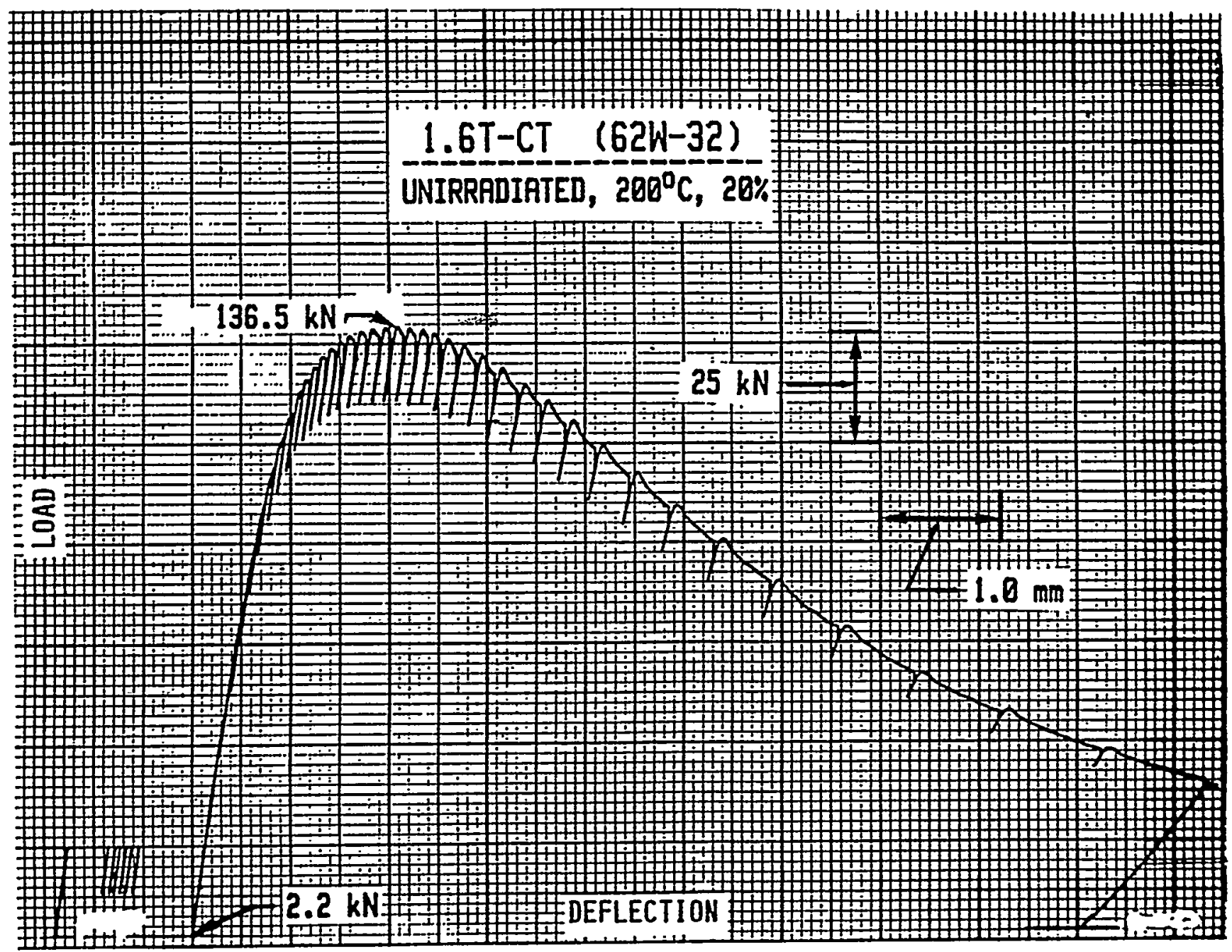

Figure 4-1: Typical load-displacement record for a J-R curve test. 


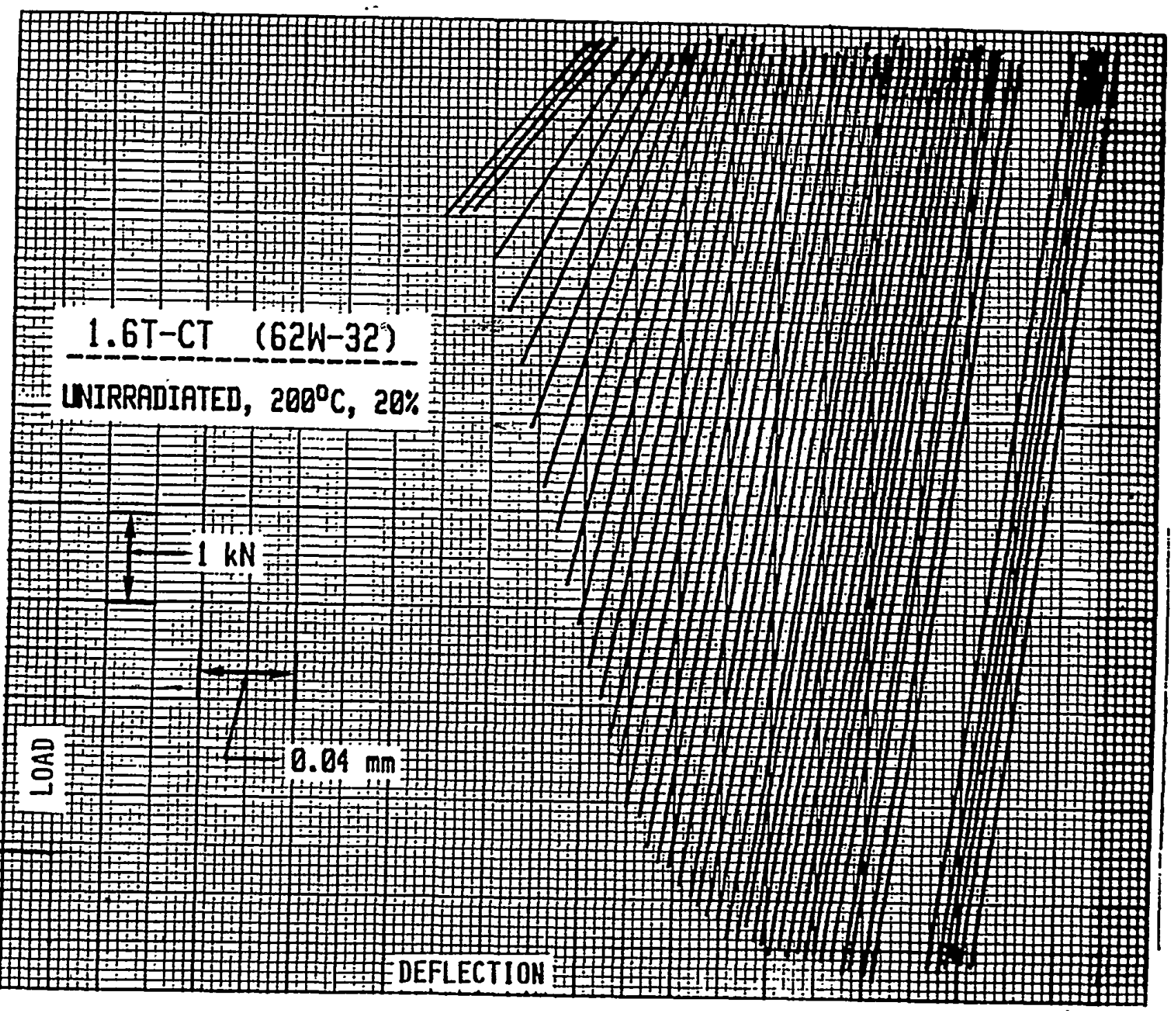

Figure 4-2: Unloading compliance traces for the J-R curve test in Figure 4-1. A decrease in slope is apparent (increased compliance) as crack extension increases from left to right. 

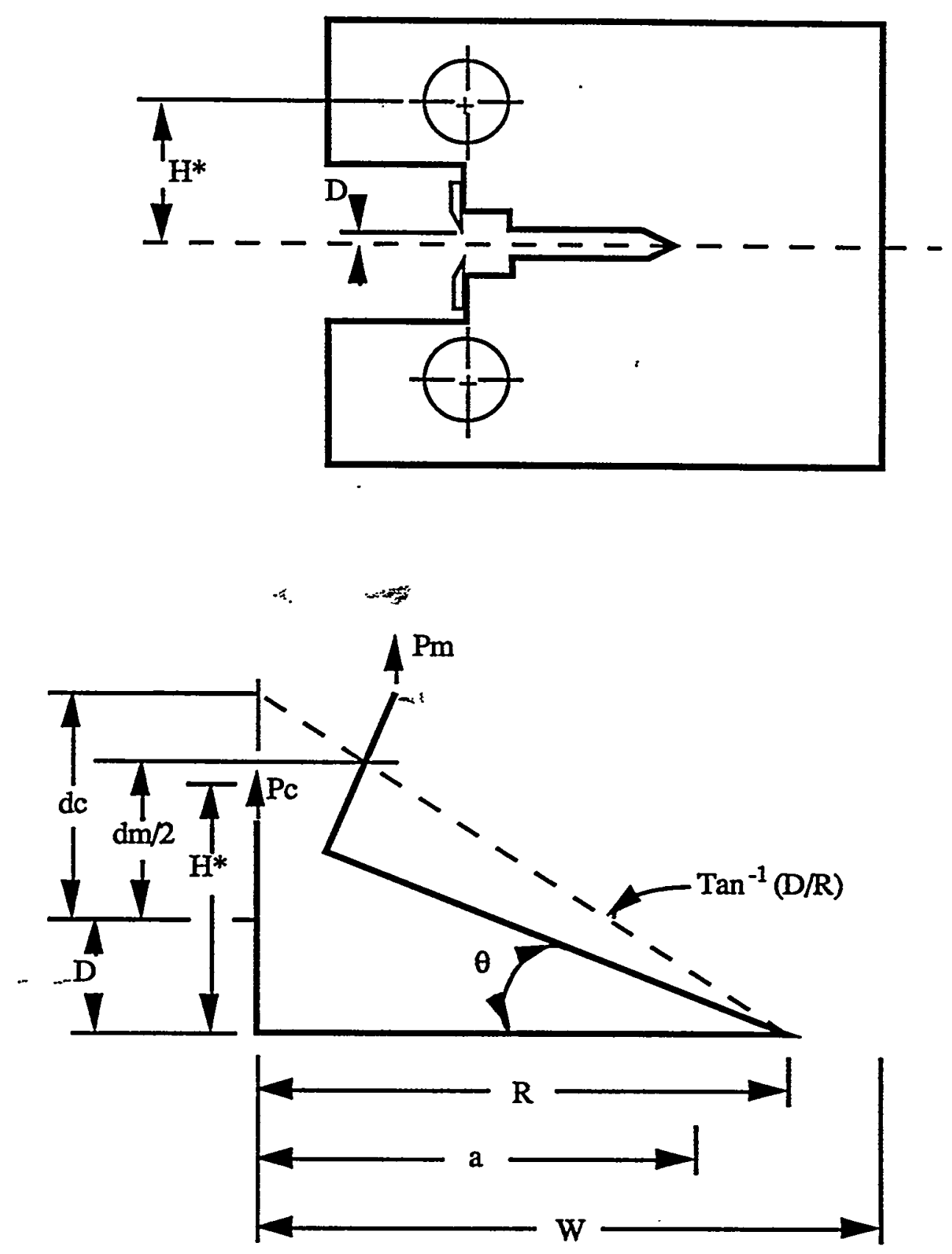

Figure 4-3: Elastic compliance correction for the E813 compact tension specimen rotation

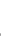




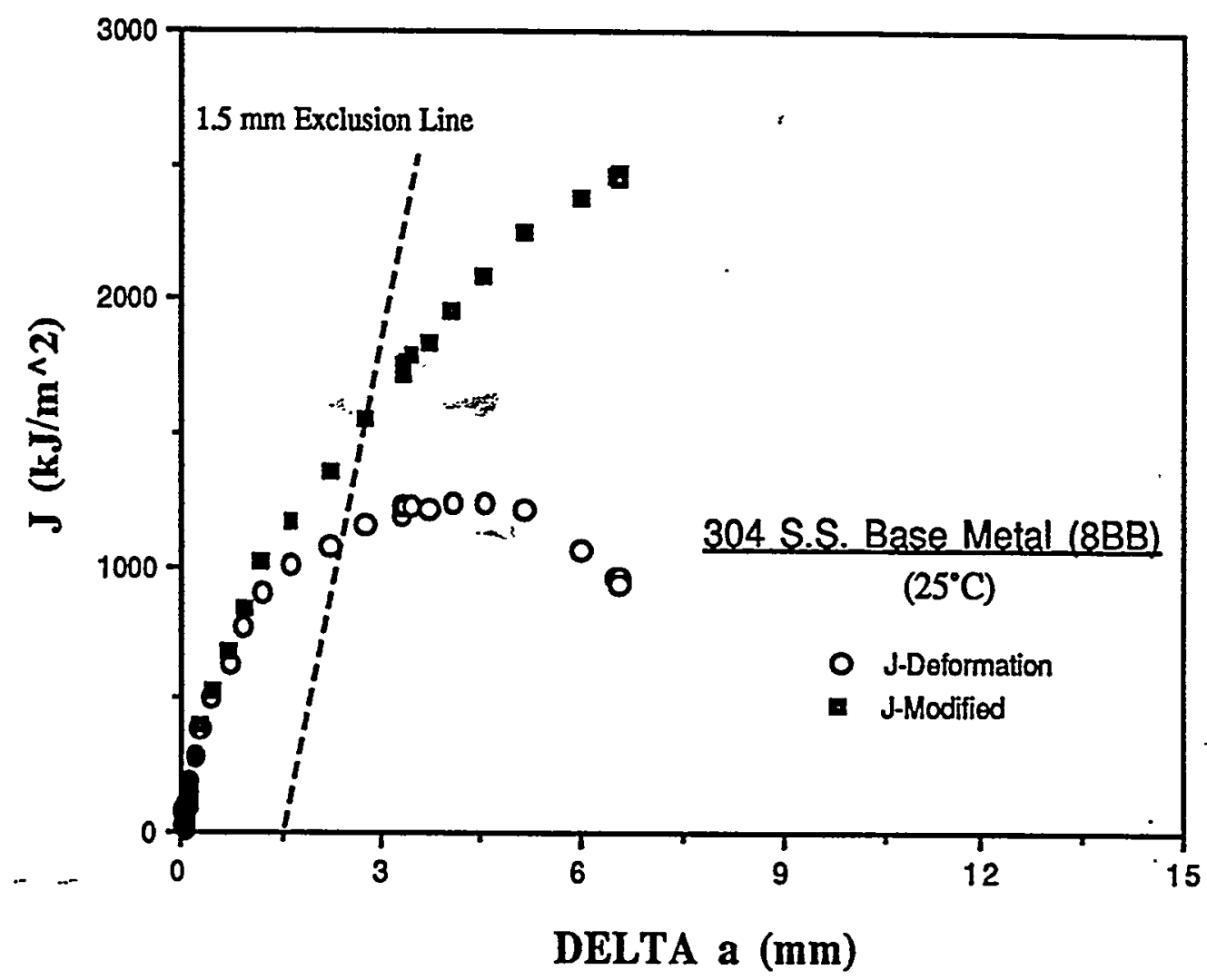

Figure 4-4: Plot of J-R curves developed for both Deformation-J and Modified-J theories applied to the load-displacement data of a Ring \#8 base material specimen. 


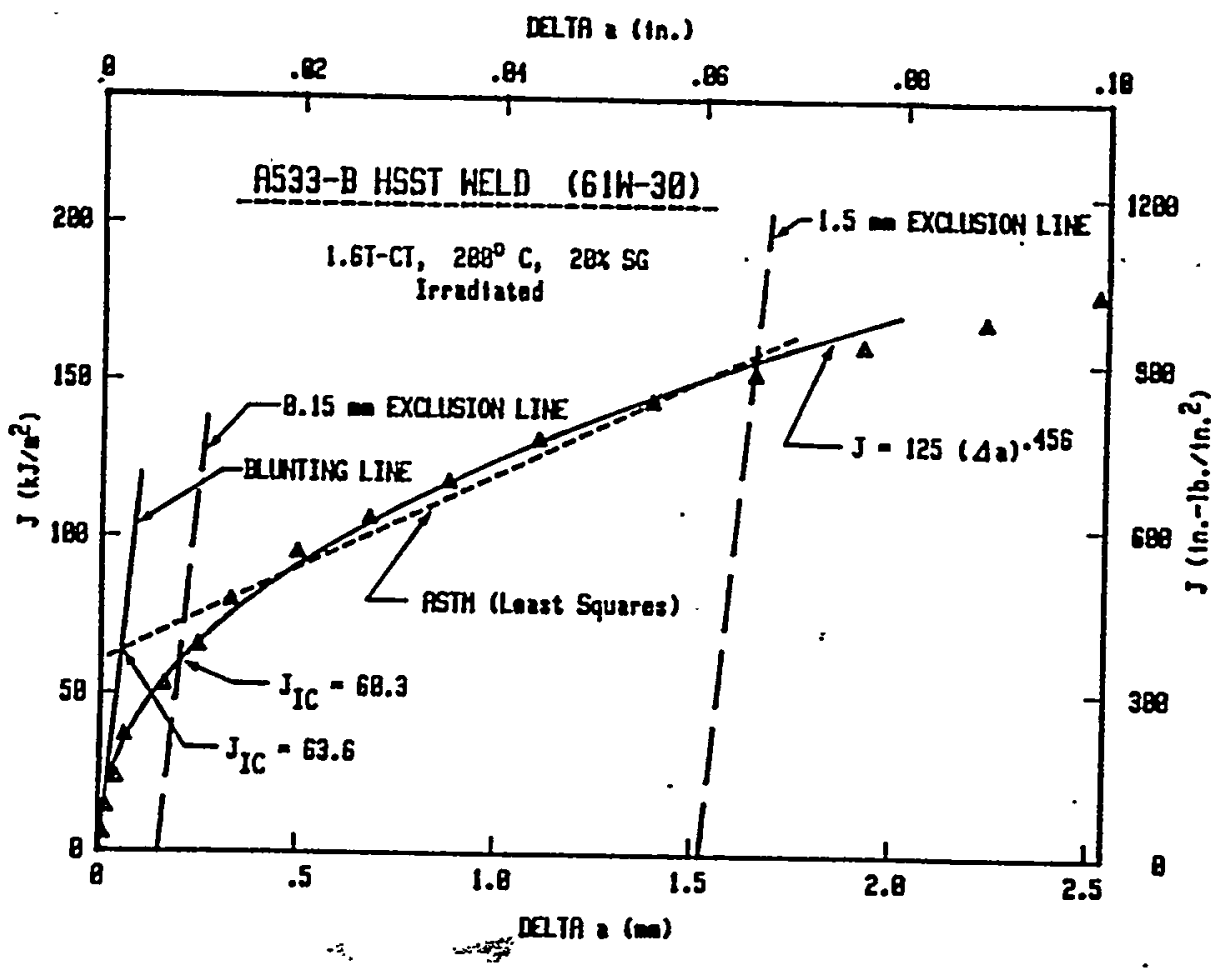

Figure 4-5A: Example of a typical J-R curve. The ASTM E 813-81 format is used in these cases.

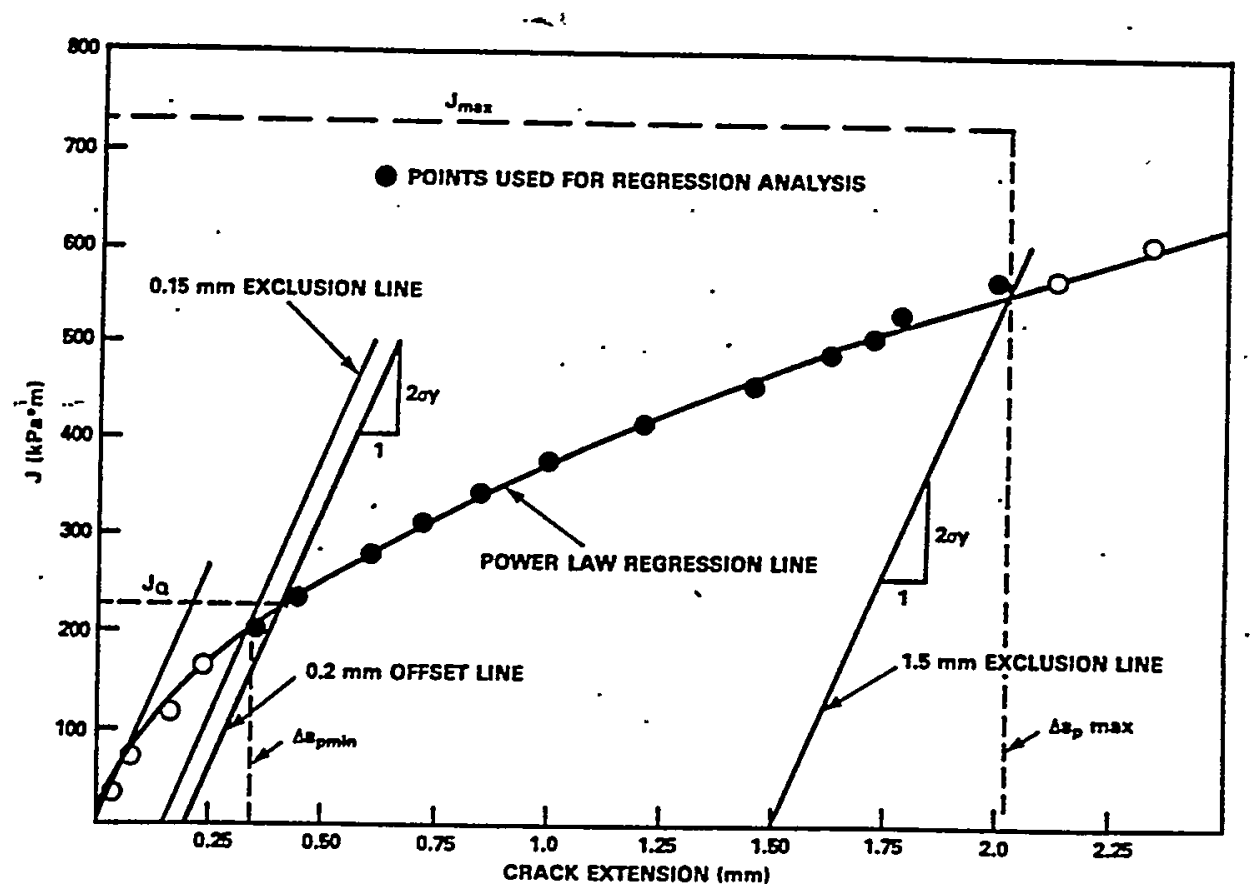

Definitions for Data Qualification

Figure 4-5B: ASTM E 813-88 method for determination of JC (JO). The JC reported for the baseline data (Section 5) determined by the MEA power law method, corresponds to the intersection of the power law fit with the exclusion line $(0.15 \mathrm{~mm}$ offset) of Figure $4-5 \mathrm{~A}$ and thereby yields the lowest JC of the three methods (ASTM E 813-81, -88, and the MEA power law) to calculate JIC (JQ). 


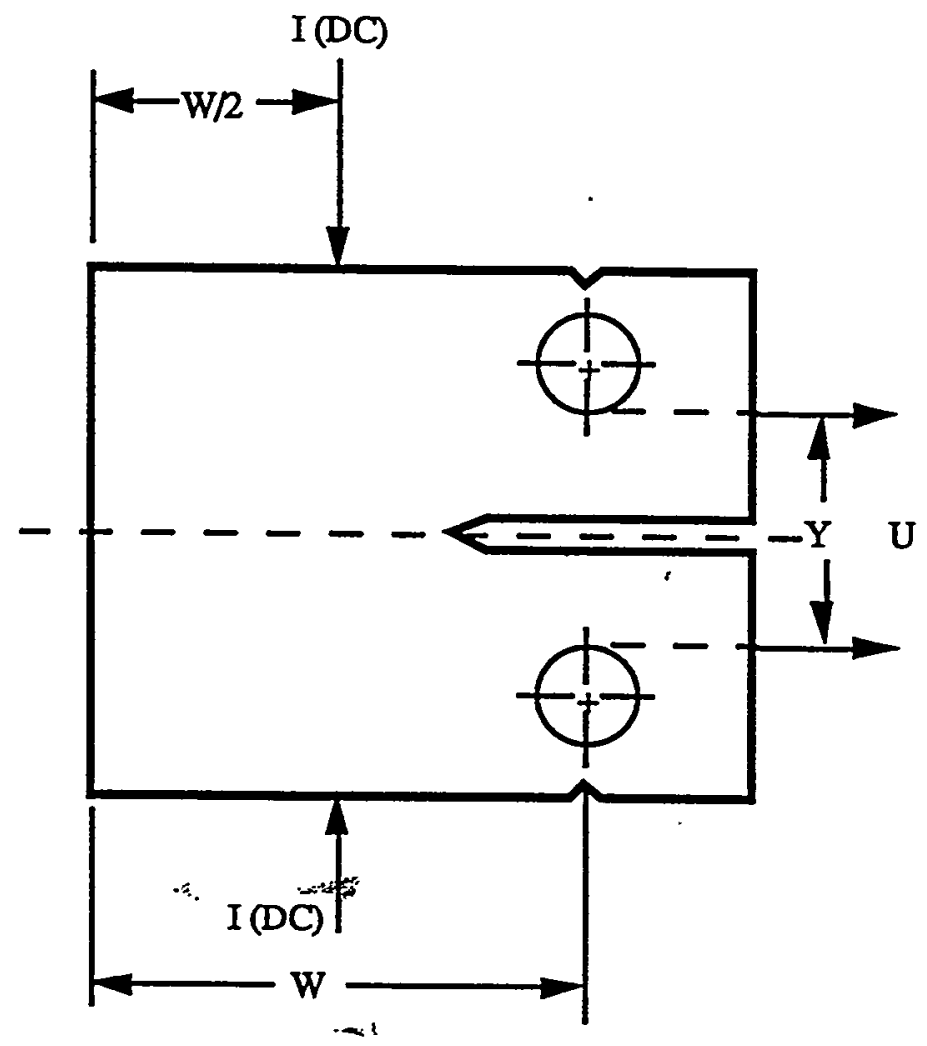

Figure 4-6: The DCPD method uses a direct current (DC) applied to the E399 CT specimen, as shown, and output leads mounted across the crack at a distance " $Y$ ", apart. The input lead location corresponds to the calibration point from Reference 22.

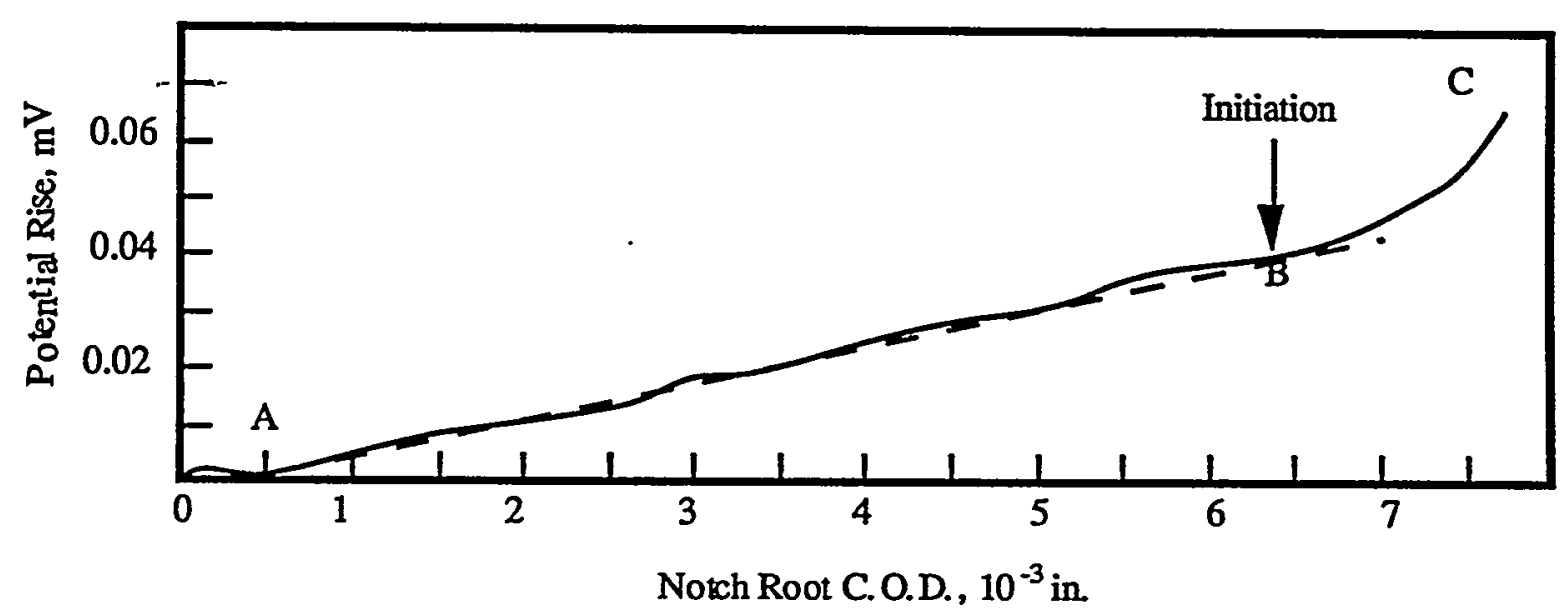

Figure 4-7: A typical DCPD ("potential rise") versus displacement ("Notch root COD") record for a J-R curve test [23]. The "initiation" point is denoted above by "B". 


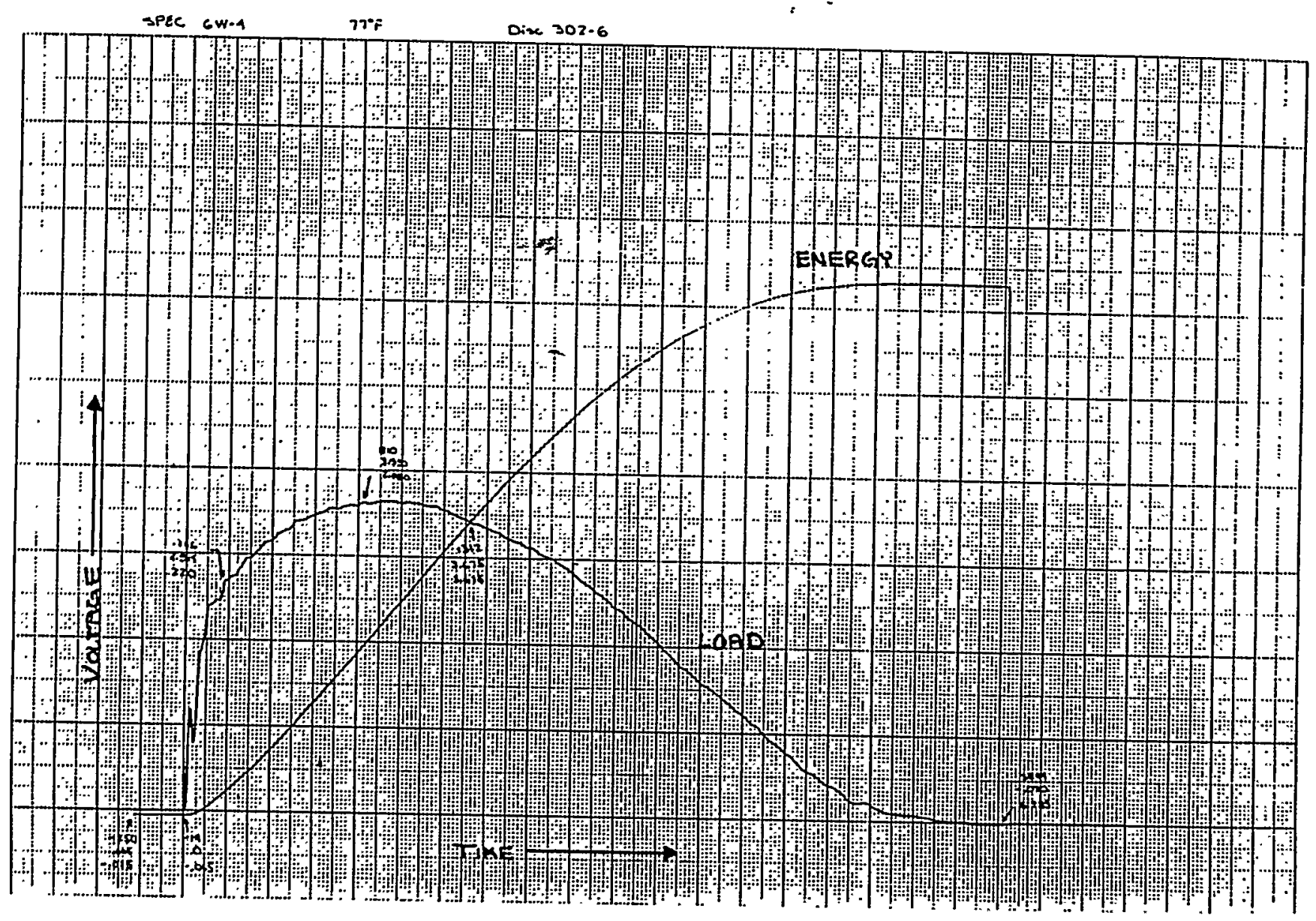

Figure 4-8: Example of load and energy versus time record from standard $C_{V}$ test. 


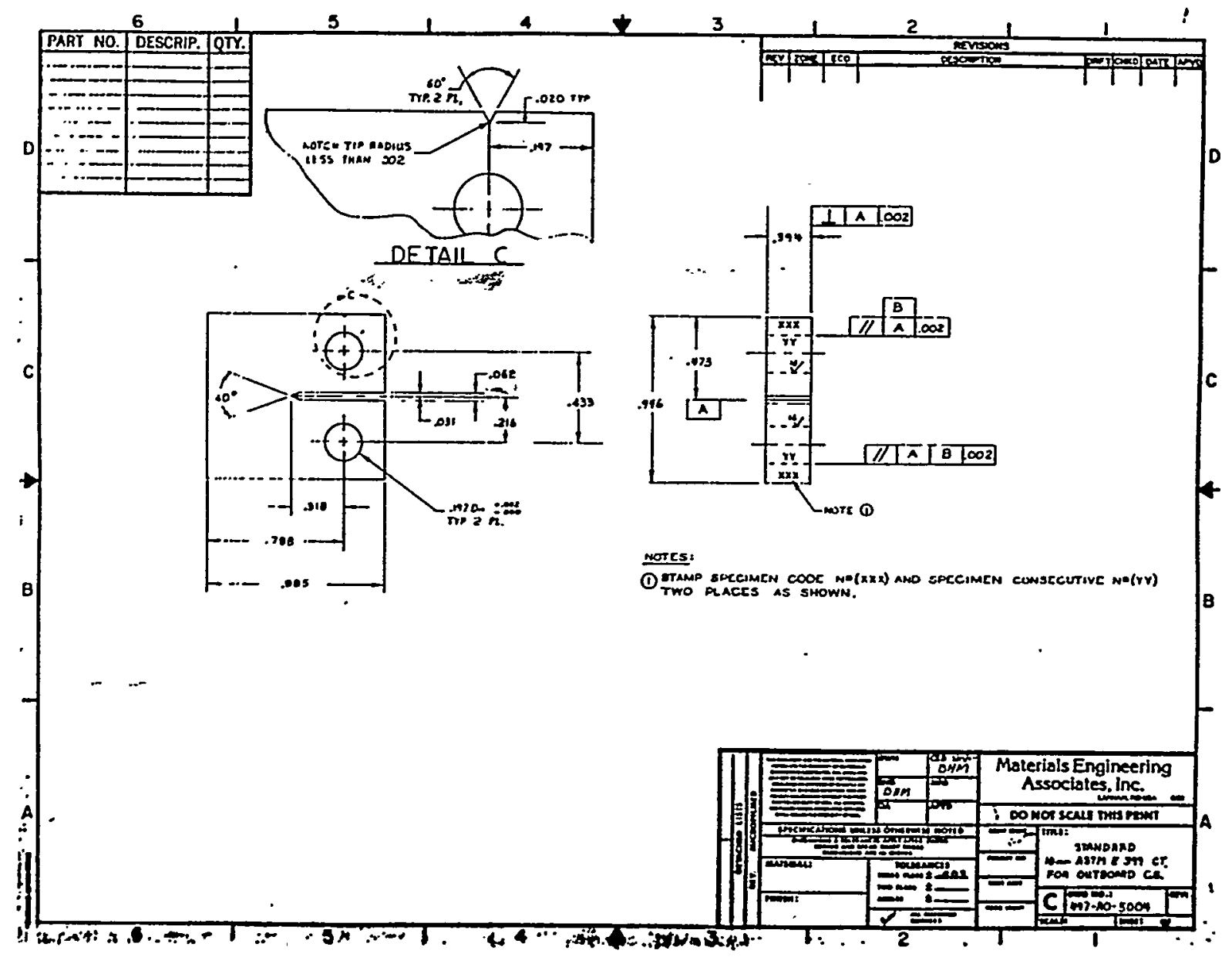

Figure 4-9: Dimensional machining drawing for the E 399-SS specimen 


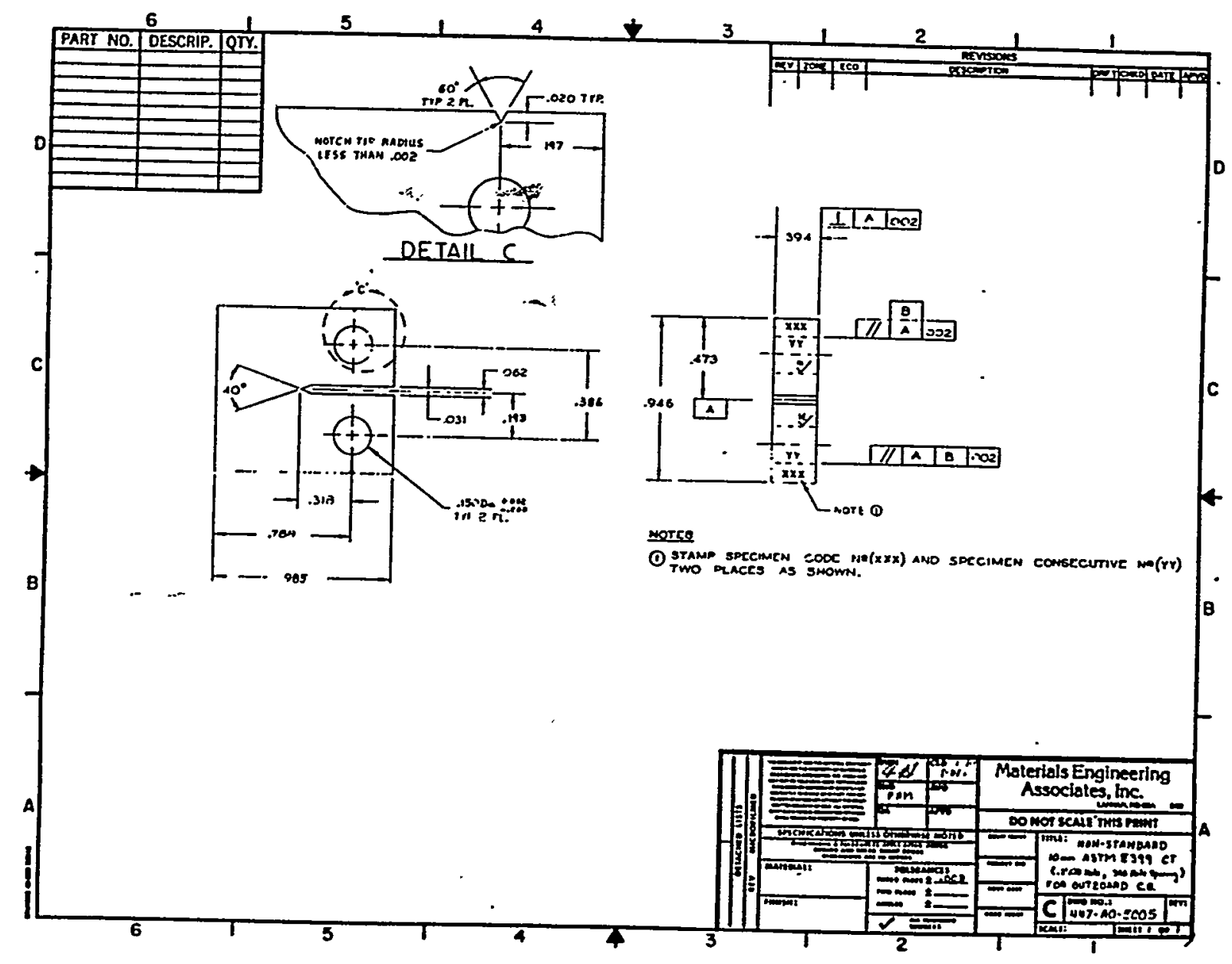

- Figure 4-10: Dimensional machining drawing for the E 399-RR specimen 


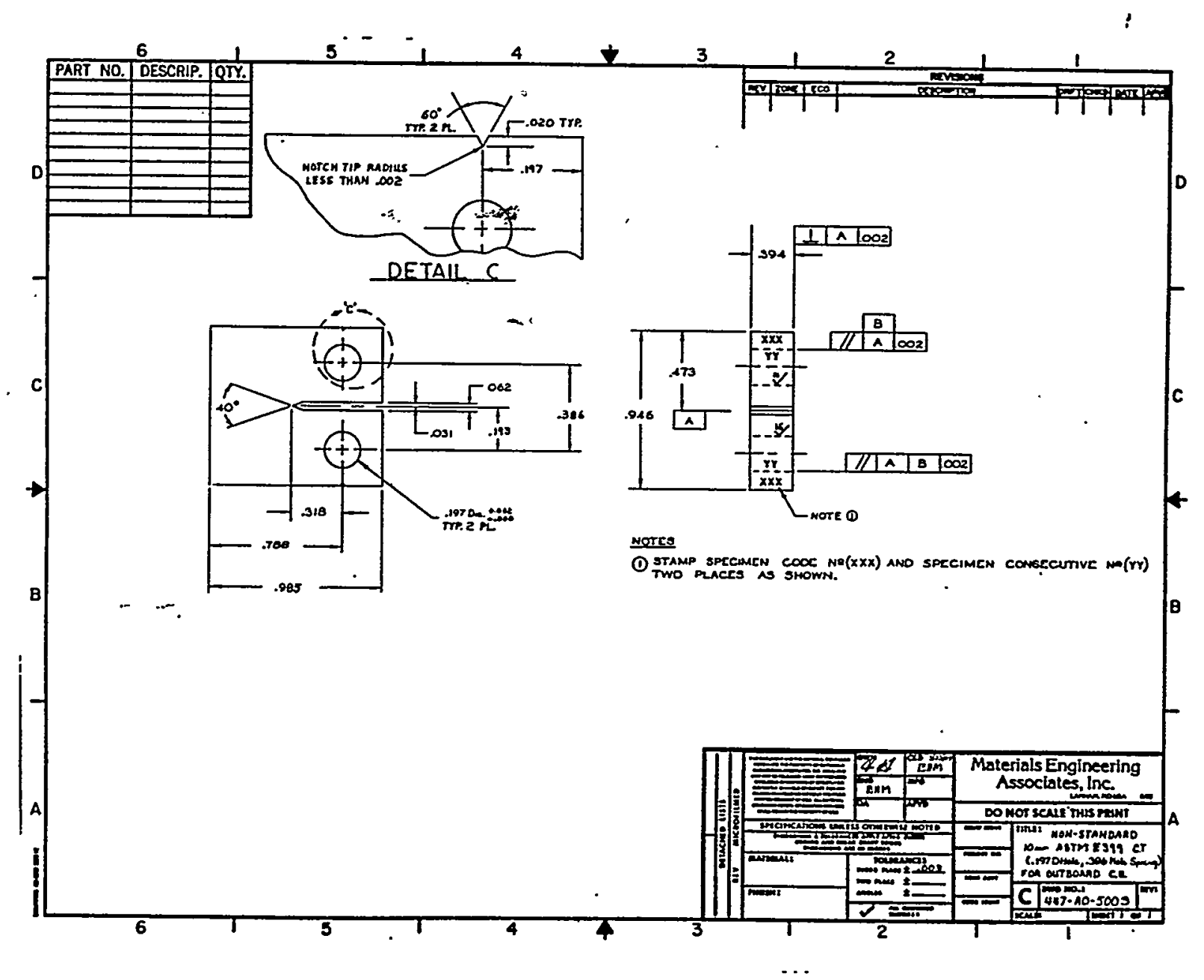

- Figure 4-11: Dimensional machining drawing for the E 399-SR specimen 


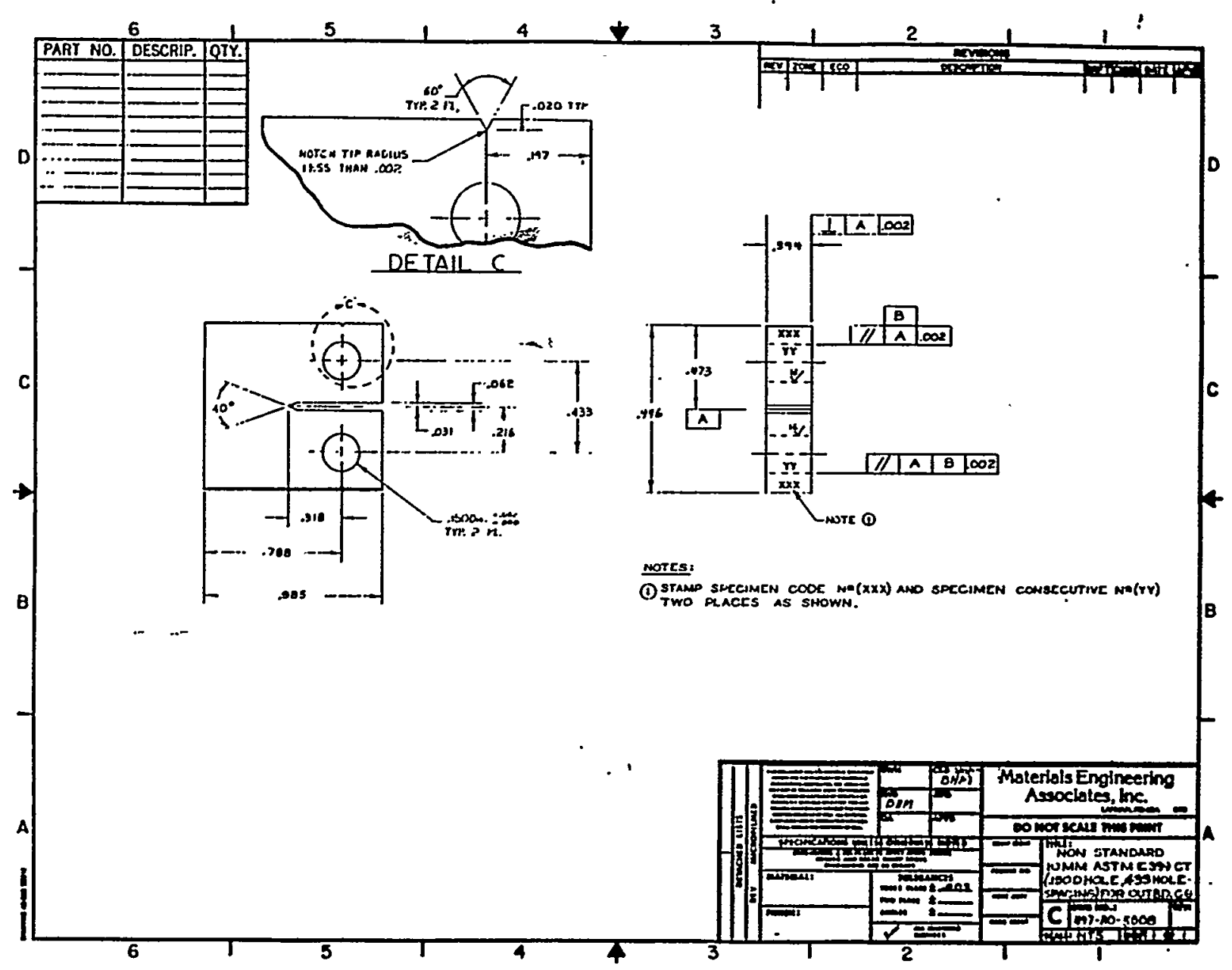

- Figure 4-12: Dimensional machining drawing for the E 399-RS specimen 


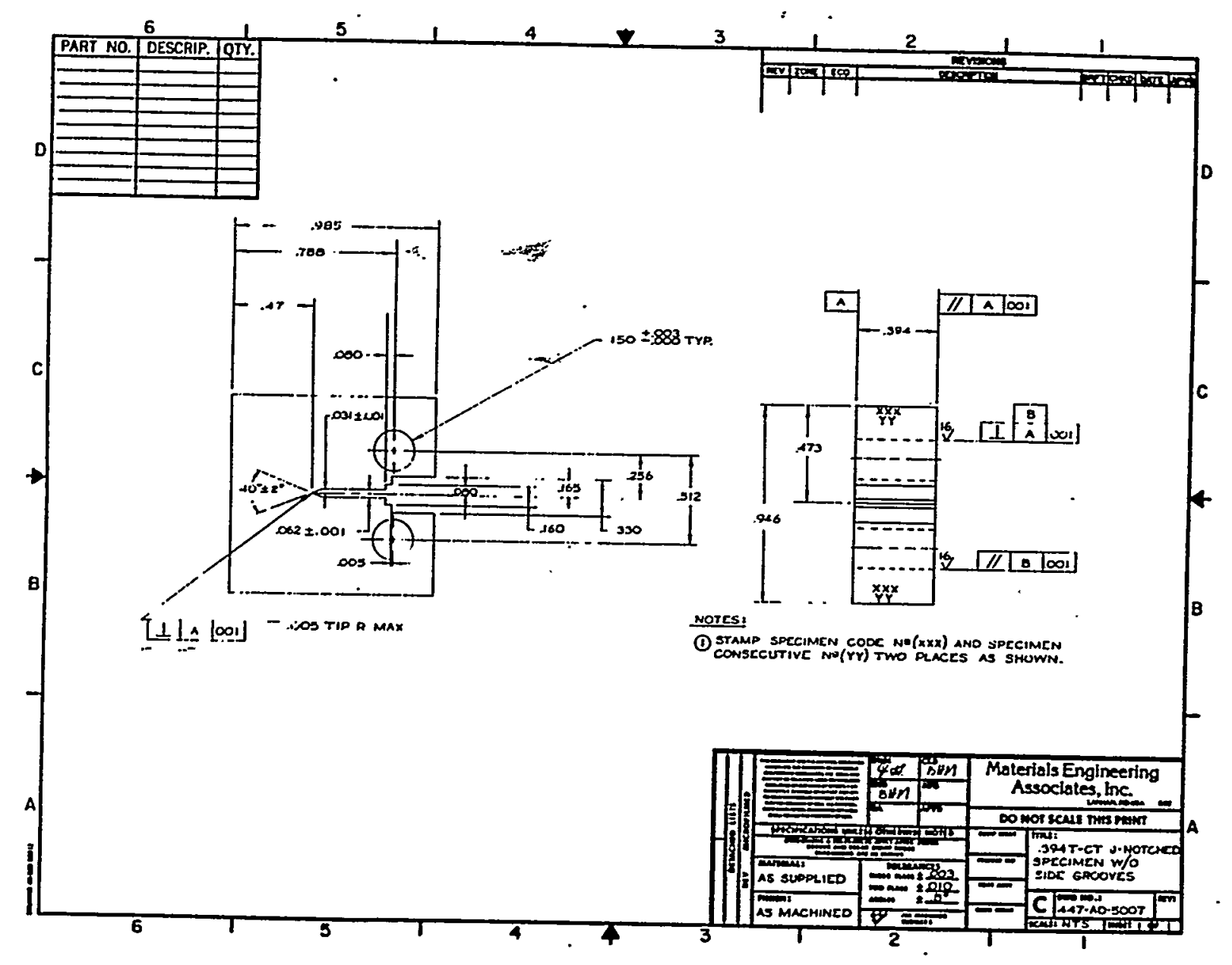

- Figure 4-13: Dimenșional machining drawing for the E 813-RR specimen

) 


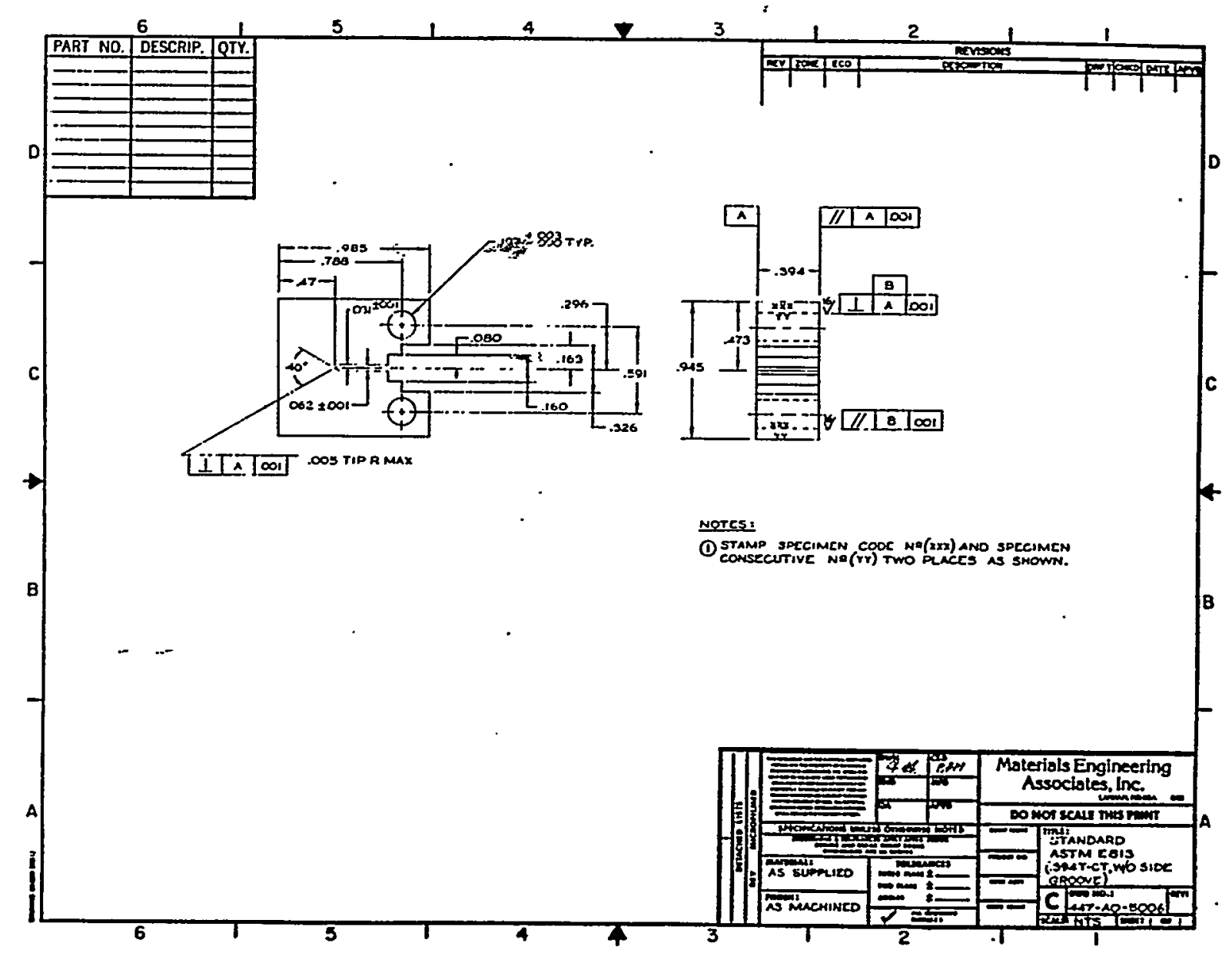

- Figure 4-14: Dimensional machining drawing for the E 813-SS specimen

) 

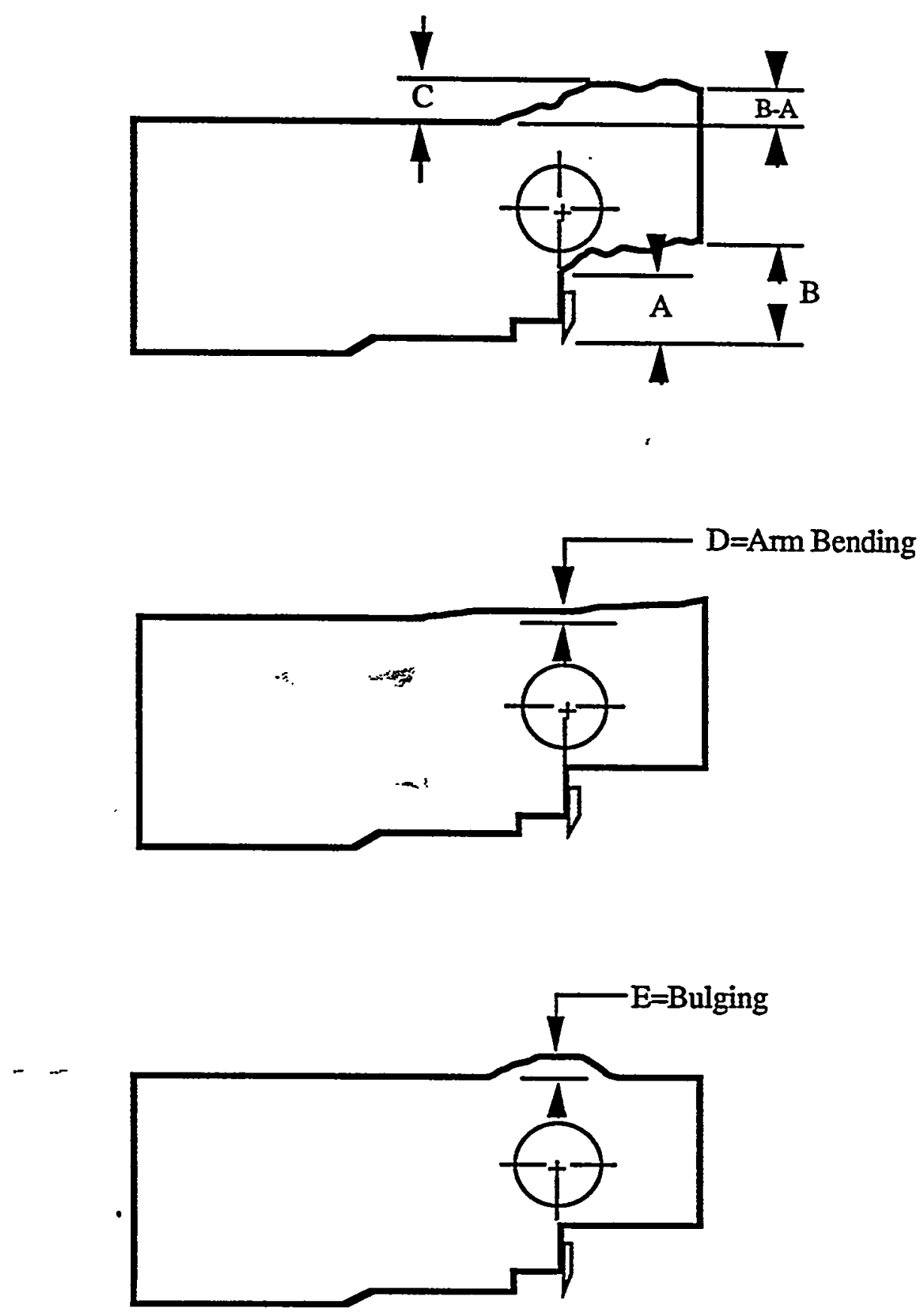

$$
\begin{aligned}
\mathrm{A}-\mathrm{B} & =\text { Shear Deflection } \\
\mathrm{C} & =\text { Shear Deflection+Arm Bending }+ \text { Bulging } \\
& =(\mathrm{B}-\mathrm{A})+\mathrm{D}+\mathrm{E}
\end{aligned}
$$

Figure 4-15: Schematic illustration of the plastic displacements exhibited by $0.394 T-C T$ specimens machined from SRS piping materials. 


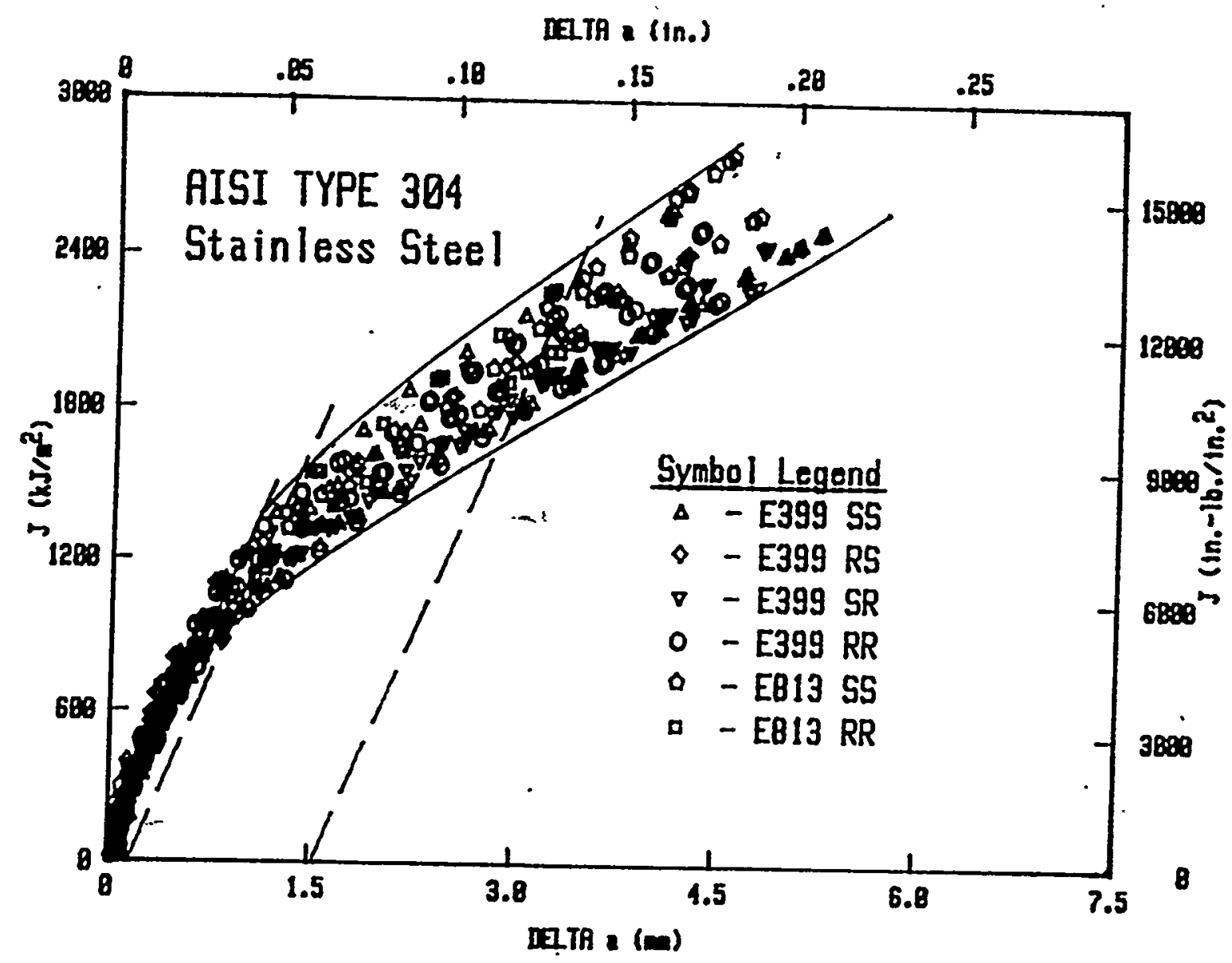

Figure 4-16: Summary plot illustrating all J-R curve data obtained from the various $0.394 \mathrm{~T}$ CT specimen types. All tests were conducted at ambient temperature.

E 399 specimens tested with an "outboard" clip gage; E 813 specimens had an "inboard" clip gage. 


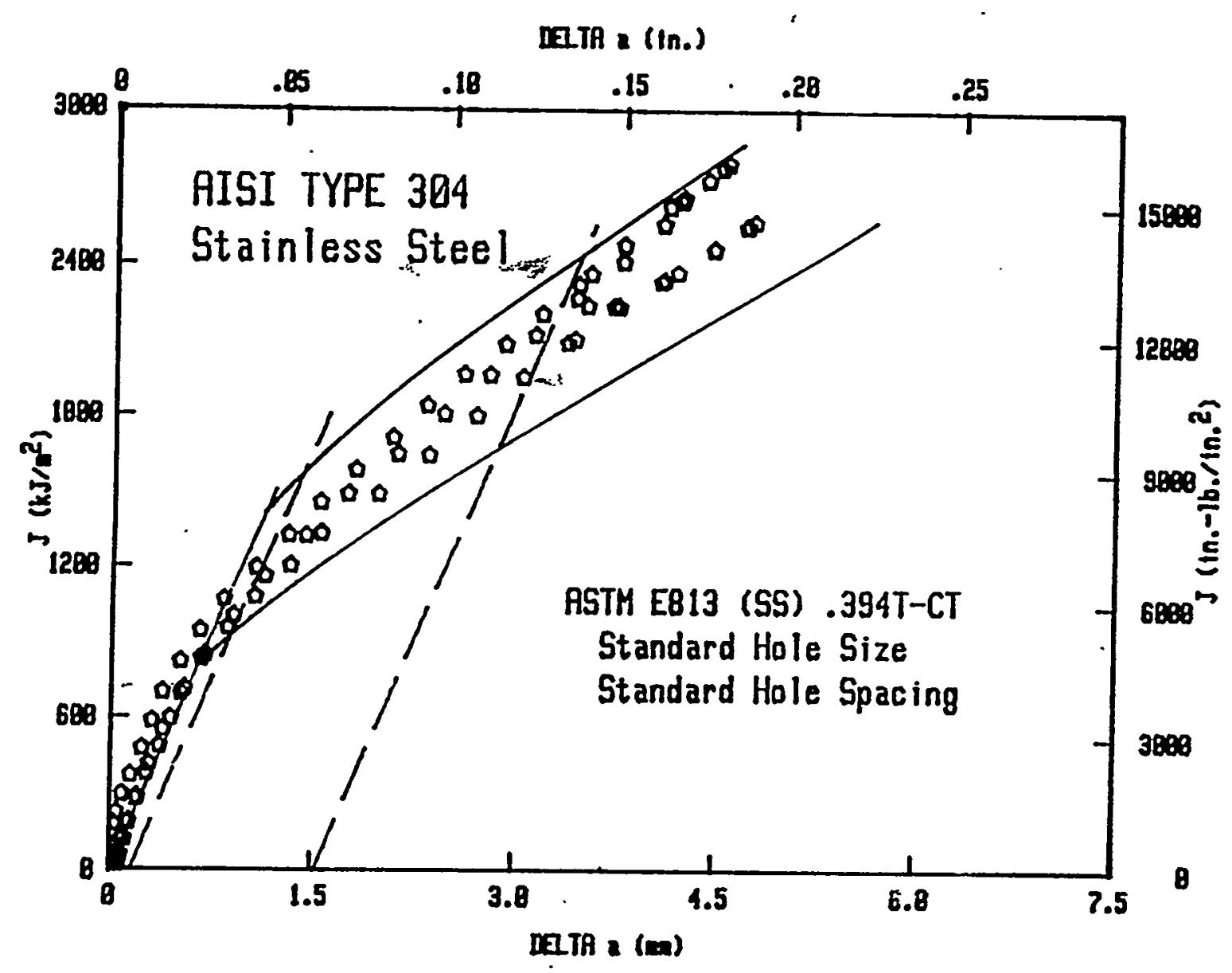

-Figure 4-17: Illustration of the J-R curves obtained with three E 813-SS specimens having a load-line deflection measuring clip gage mounted on the integral specimen knife edges. The trend band is that from Figure 5-15. 


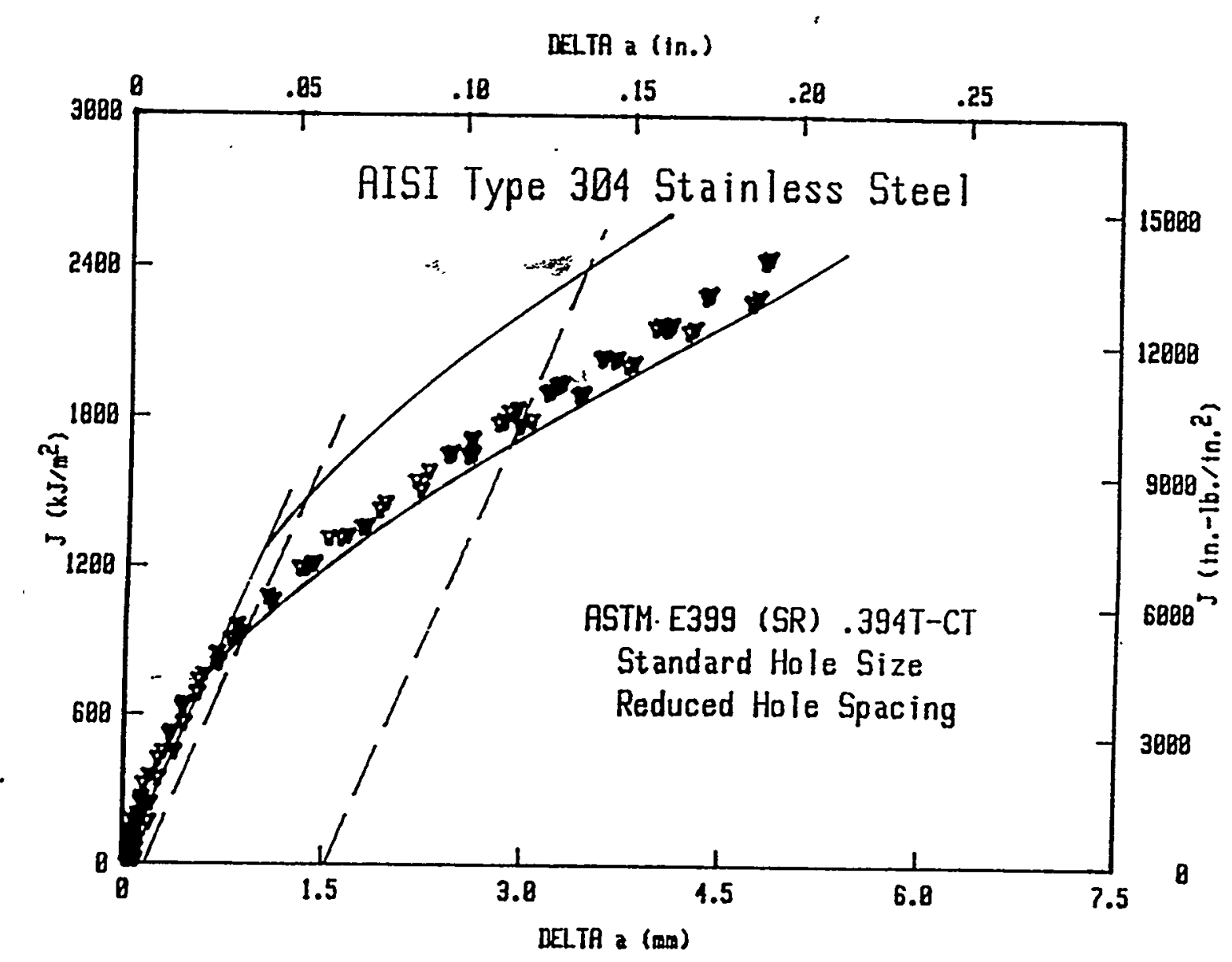

- Figure 4-18: Illustration of the J-R curves obtained from three E 399-SR test specimens. note that all data lie in the lower part of the trend band from Figure 5-15. 


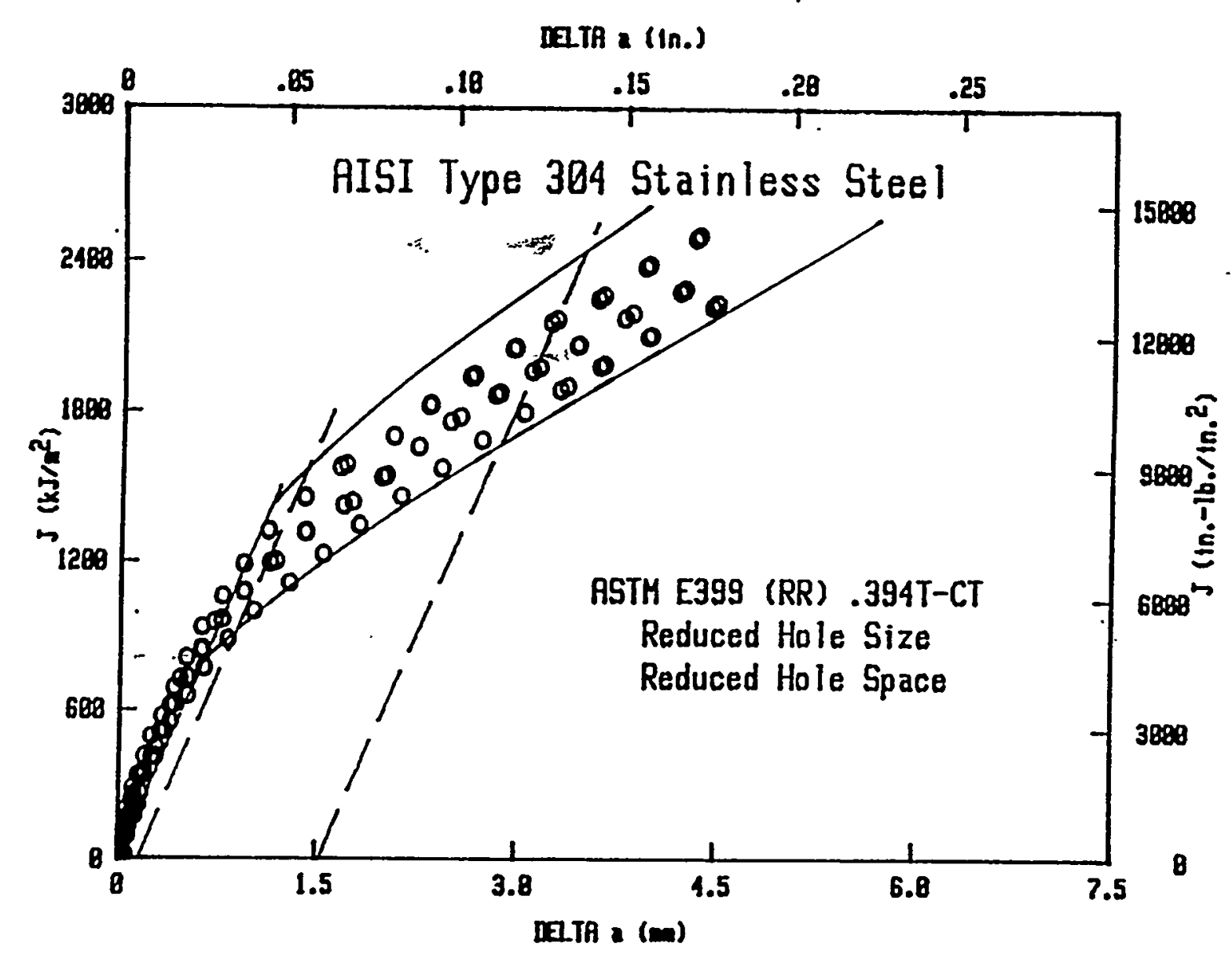

- Figure 4-19: Illustration of the J-R curves obtained from three E 399-RR specimens. The trend band shown is that form Figure 5-15. 


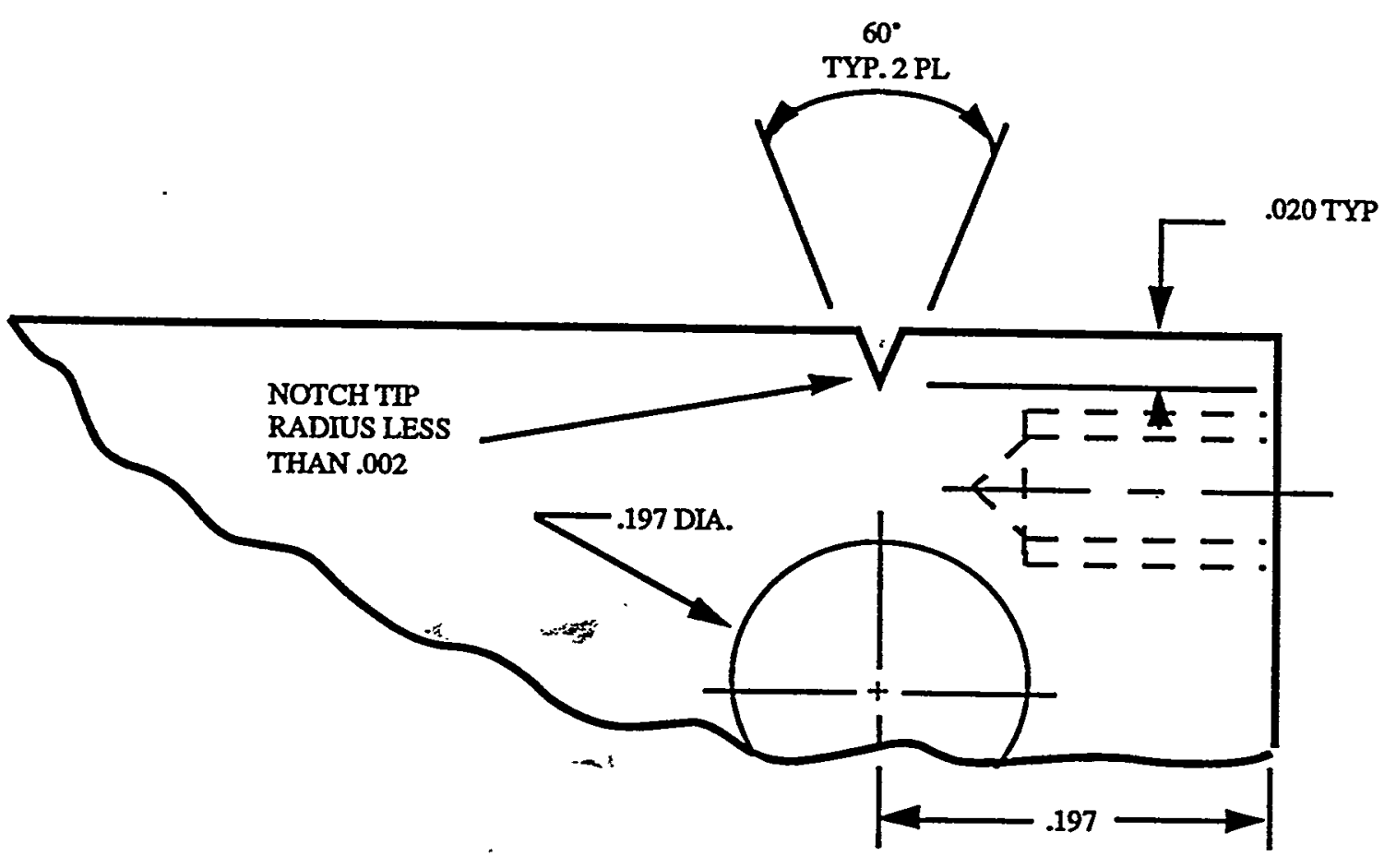

E399 SR COMPACT

Figure 4-20: Illustration of the position of the DCPD screw holes required for the CT specimen. 


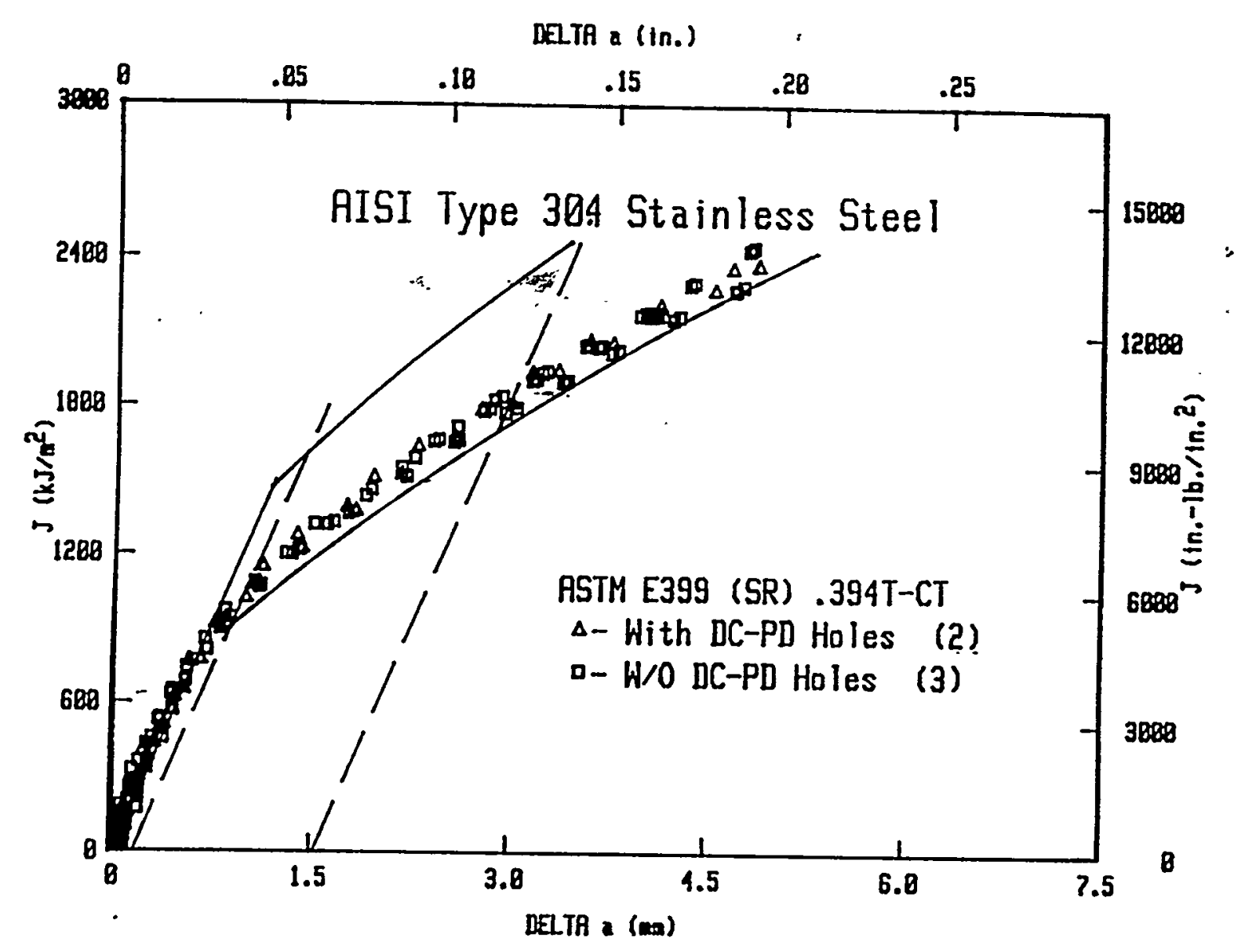

Figure 4-21: Comparison of 0.394T-CT J-R curves developed with and without DCPD holes. 


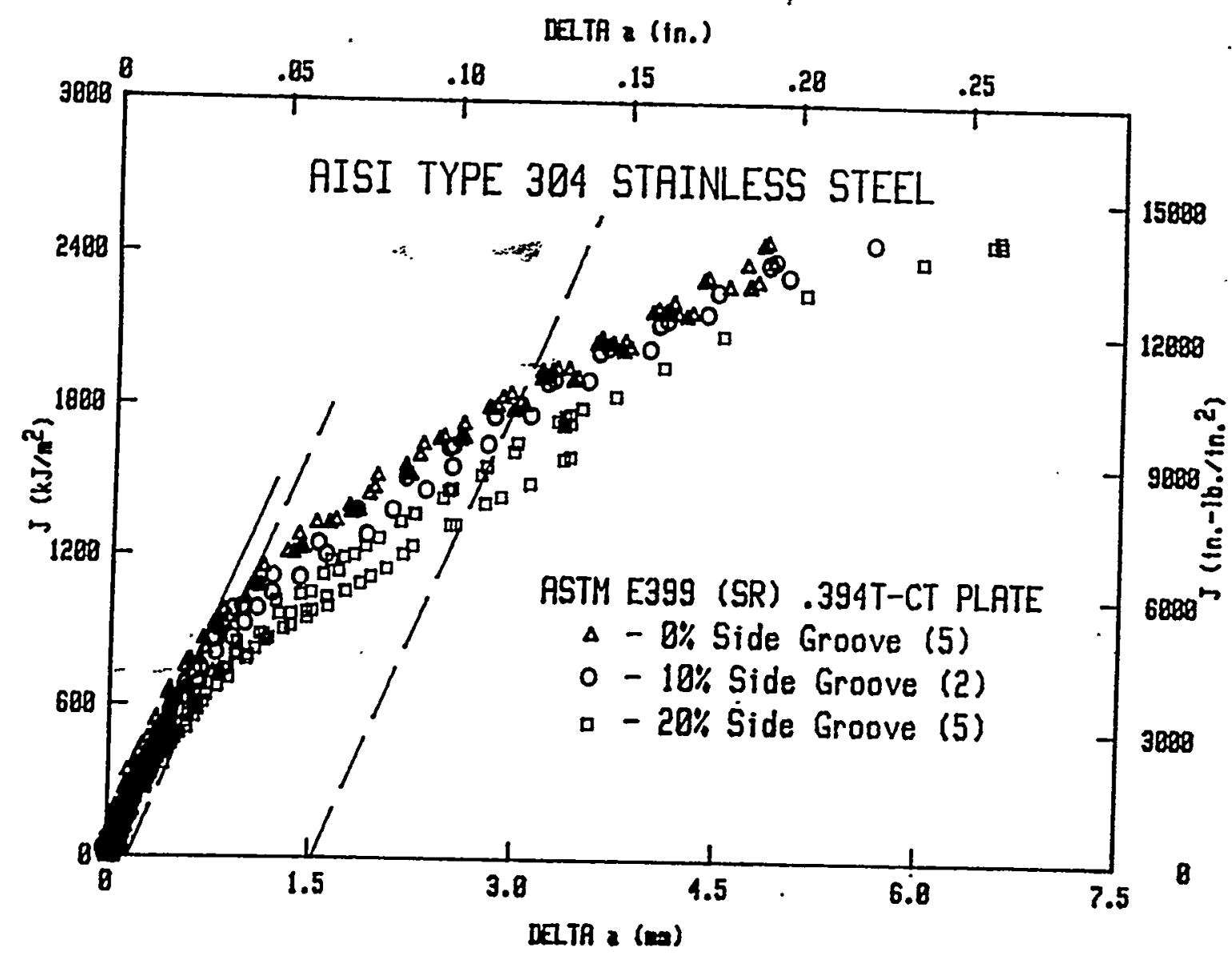

- Figure 4-22: Illustration of the J-R curves resulting from 0,10 and $20 \%$ side-grooved specimen tests of base material. Numbers in parentheses indicate the number of specimens of each type tested. 
DEITh a (In.)

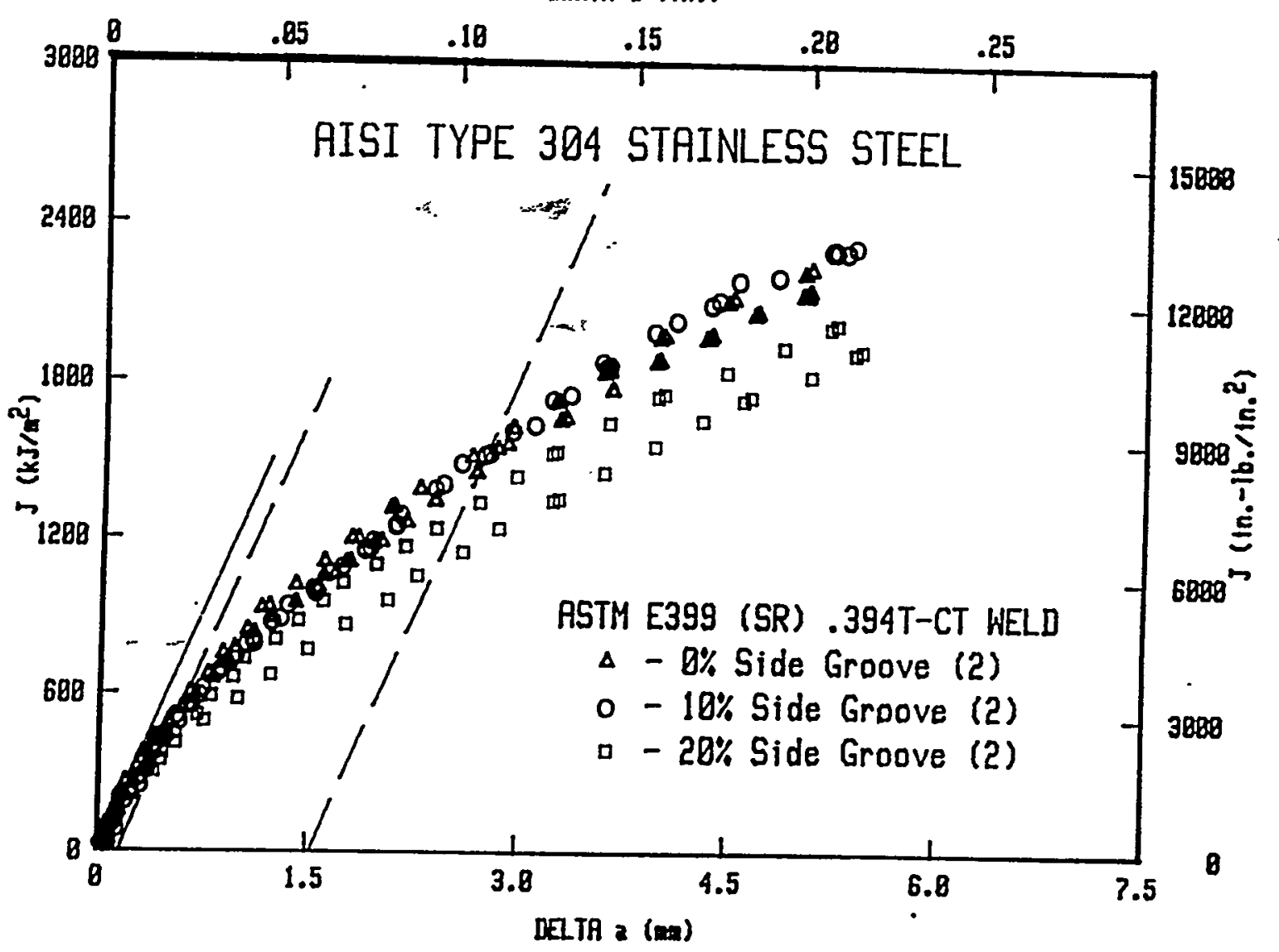

- Figure 4-23: Illustration of the J-R curves resulting from 0,10 and $20 \%$ side-grooved specimen tests of weld material. Two specimens of each type were tested. 


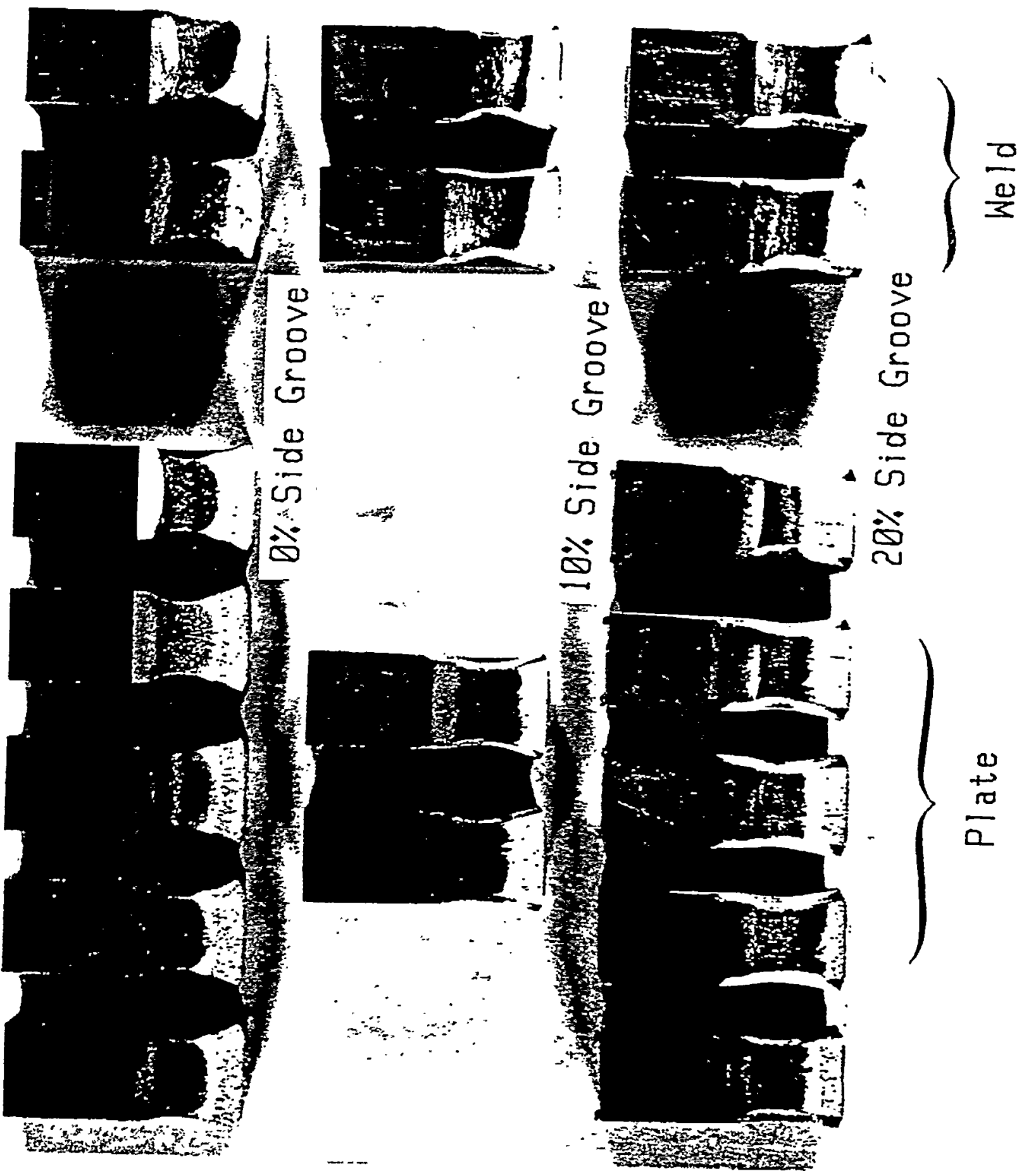

Figure 4-24: Fracture surfaces from specimens tested in the side-groove study. 


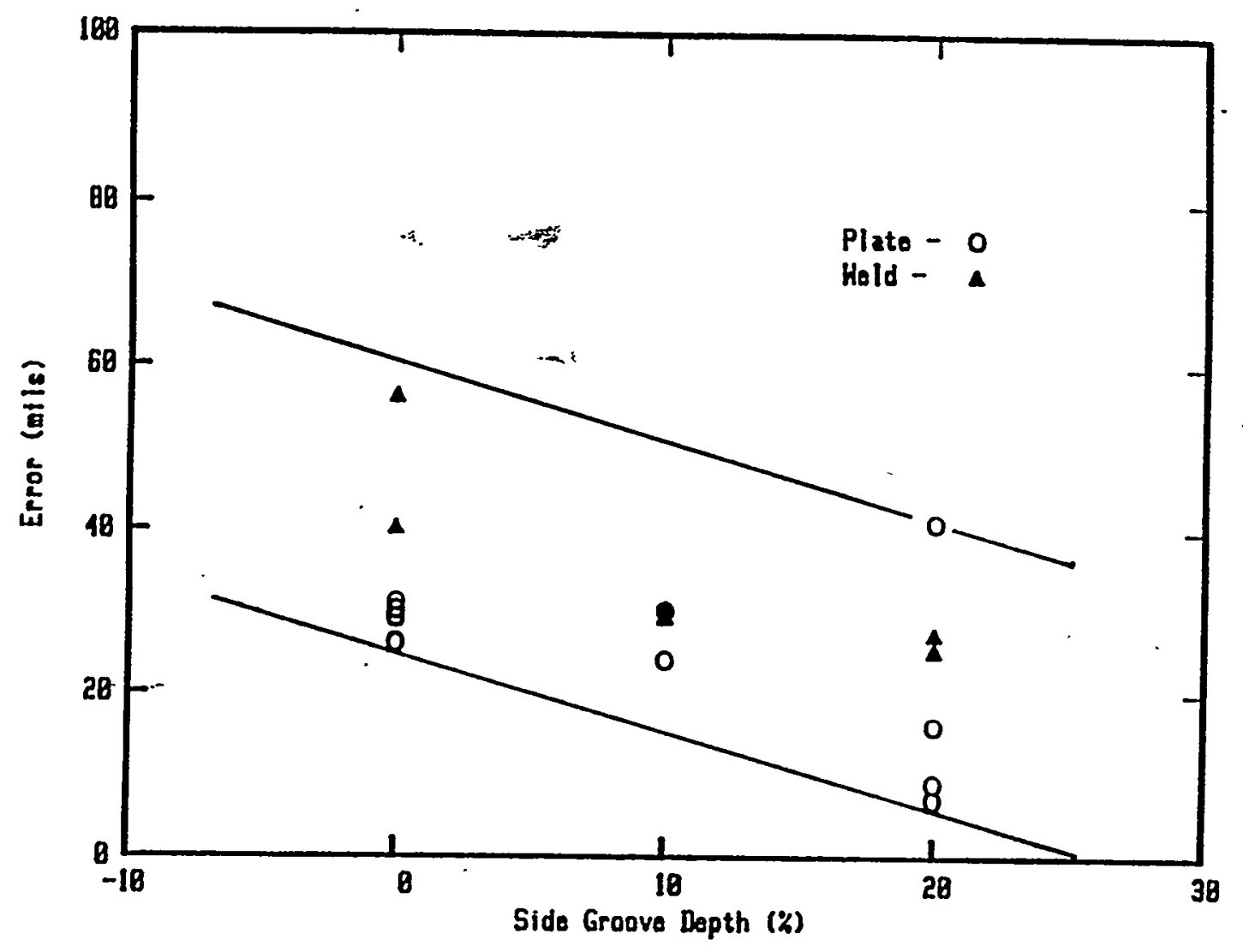

- Figure 4-25: Illustration of the effect of side-groove depth on crack extension prediction.

) 
)

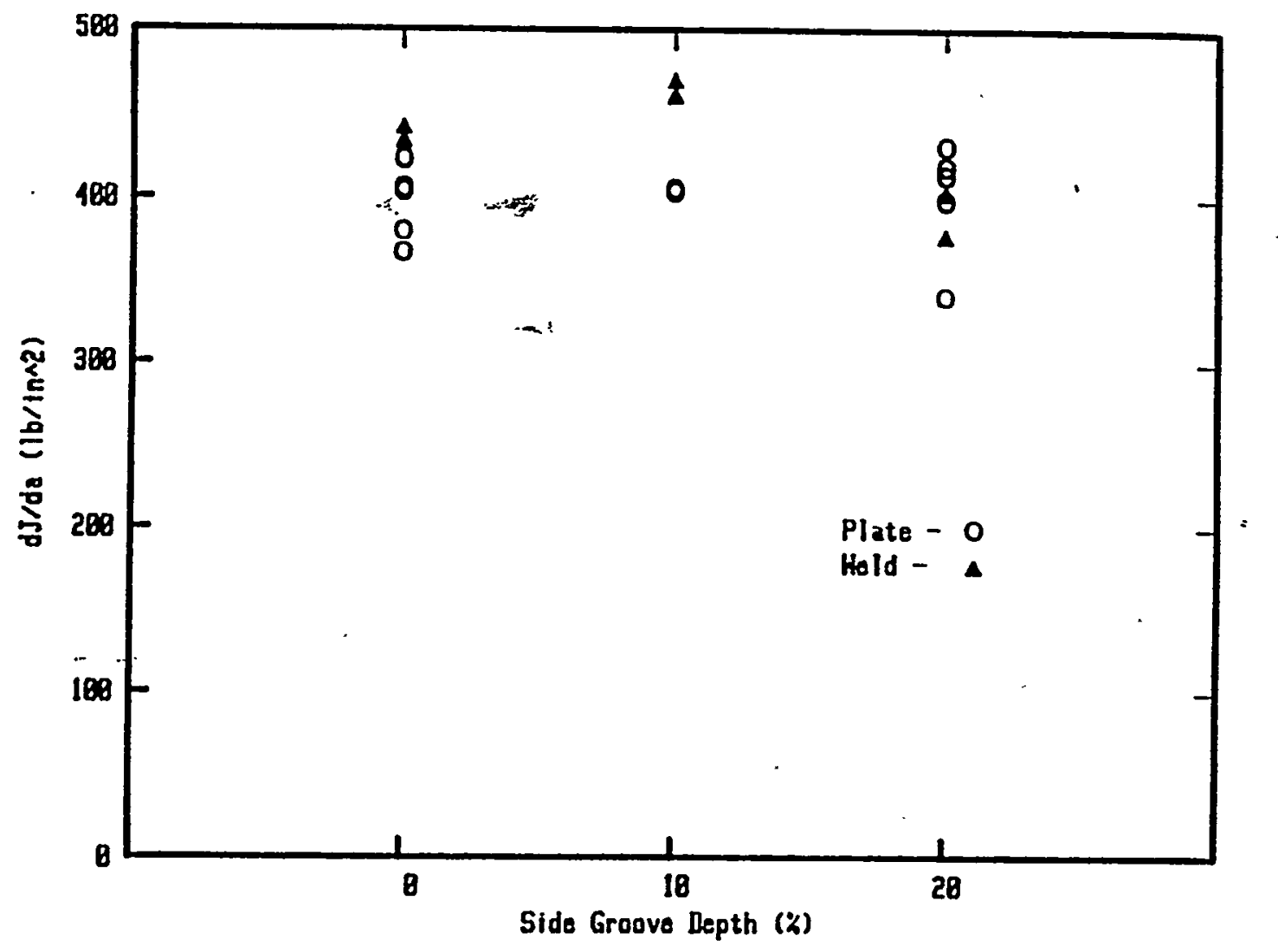

- Figure 4-26: Illustration of the variation of the average J-R curve slope with side-groove depth.

)

$$
4-40
$$




\subsection{MECHANICAL TESTING RESULTS and DISCUSSION}

The average tensile, fracture toughness and impact mechanical properties measured at the test conditions discussed above are listed in Tables 5-1 through 5-5. The average properties in these tables were obtained from the baseline material testing results listed in Attachment 1. A statistical analysis was performed to provide a basis for the comparison of mechanical properties. The data were grouped to form twelve separate data sets defined by. common test parameters of test temperature $\left(25\right.$ or $125^{\circ} \mathrm{C}$ ), weldment type (base, weld or weld heat-affected-zone) and specimen orientation (L-C or C-L) as shown schematically in Figure 1-1. The mechanical properties of the potentially different melts of material were thus averaged into each of the twelve common sets. The effect of material composition on the mechanical response was not evaluated statistically due to the limited number of specimens tested for a given material melt (see Table 3-1). The difference in material composition is insignificant in terms of effect on the mechanical response compared to the other test parameters in this investigation.

Listed along with the average mechanical properties in Tables 5-1 through 5-5 is the 95\% confidence interval for the sample mean. The interval is calculated by the following equation [27] (RMP Calculation Set \#91-03, Part 1):

$$
\begin{aligned}
& \text { Confidence interval for sample mean = Average sample property } \pm \frac{t s}{\sqrt{n}}, \\
& \text { where } \begin{aligned}
n= & \text { number. of speeirfens in the sample } \\
\mathrm{s}= & \text { sample standard deviation based on } n-1 \\
& \text { degrees of freedom } \\
\mathrm{t}= & \begin{array}{l}
\text { Students } t \text {-distribution multiplier for } \mathrm{n}-1 \\
\text { degrees of freedom and chosen } \\
\text { for a confidence interval of } 95 \%
\end{array}
\end{aligned}
\end{aligned}
$$

Statistically, the confidence interval for a particular sample mean can be compared to the confidence interval for a different sample mean to assess the difference in the average results. An overlap in intervals indicates no significant difference in the mean value of the measured sample property. The standard deviation for the mean of small sample sizes ( 2 to 4 specimens) was generally high $(\geq 100)$ due to a large "t" multiplier based on sample size. The confidence interval for these sample means is not reported. Figures 5-1 and 5-2 show the extent of this variability over the matêrial data range for both tensile and J-R curves respectively.

\subsection{Tensile Data Results}

Tensile results from each tensile specimen are listed in Attachment 1 and shown graphically in Attachment 2. A summary of the average test data obtained under static loading conditions is provided in Table 5-1. As expected for Type 304 stainless steel, strength properties at the higher test temperature $\left(125^{\circ} \mathrm{C}\right)$ were slightly lower than the strength properties at the lower temperature $\left(25^{\circ} \mathrm{C}\right)$. No orientation effect on material tensile properties was observed for the $\mathrm{L}-\mathrm{C}$ and $\mathrm{C}-\mathrm{L}$ test directions. The room temperature $\left(25^{\circ} \mathrm{C}\right)$ measured tensile property data are superior to the ASME Section II required values of $70 \mathrm{ksi}$ for tensile strength, and $30 \mathrm{ksi}$ for yield strength with longitudinal $(\mathrm{L}-\mathrm{C})$ and transverse ( $\mathrm{C}-\mathrm{L}$ ) elongations exceeding 35 and 25\%, respectively.

The dynamic average and lower bound test results are summarized in Table 5-2. The average dynamic yield strength results show an increase between 15 to $50 \%$ over the static results. The ultimate strengths, however, were similar for both static and dynamic loading. This effect of static versus dynamic loading on the tensile behavior of Type 304 stainless steel is shown in Figure 5-3 for Ring \#3, side A, base material. 


\subsection{Charpy Data Results}

Test results for each Charpy specimen are listed in Attachment 1. Table 5-3 summarizes the average Charpy impact energy data. The average energy absorption exceeded $90 \mathrm{ft}-1 \mathrm{bs}$ for base metal, weld metal and HAZ material. These impact test results corroborate the high toughness of Type 304 stainless steel for the temperature range of operation for all three process water system weldment components, and both ASTM specimen orientations.

\subsection{Compact Tension Data Results}

Test results from each compact tension specimen are listed in Attachment 1 and shown graphically in Attachment 2. Average fracture toughness properties for the three weldments (base, weld and HAZ) are shown in Tables 5-4 and 5-5 for static and dynamic testing respectively. The deformation-J values shown in Tables 5-4 and 5-5 were derived using a power law fit to the J-R curve data between the exclusion lines. A linear analysis per the requirements of ASTM E 813-81 would yield similar results [5].

No significant effect of loading rate (dynamic versus static) on the J-R curve results ( $\mathrm{J}_{\mathrm{IC}}, \mathrm{T}$ ) was observed. The fracture toughness behavior under both static and dynamic loading conditions is shown in Figure 5-4 for Ring \#4, side A, base material. A comparison of the static and dynamic toughness results of JIc and T summarized in Tables 5-4 and 5-5 indicate no consistent trend of $\mathrm{J}_{\mathrm{Ic}}$ response to dynamic loading. The âverage tearing modulus, $\mathrm{T}$, was consistently lower under dynamic loading; however, the tearing modulus remained high (141 to 203) and the confidence intervals of the static and dynamic results overlapped. A strong directional dependence is observed from Table 5-4 for the base and HAZ material, and for base material in Table 5-5. This observation is discussed in detail below.

\subsection{Specimen Orientation}

A comparison of the average notch toughness results for the L-C and C-L specimen orientations shows a marked difference in the influence of crack orientation on the Charpy impact energies and the $\mathrm{J}_{\mathrm{Ic}}$ values for the base material and weld heat-affected-zone material. The absorbed energy is 28 and $79 \%$ greater for the base material L-C direction compared to the C-L direction for the test temperatures of 25 and $125^{\circ} \mathrm{C}$, respectively. Similarly, the absorbed energy for the weld heat-affected-zone is 43 and $86 \%$ greater for the L-C direction compared to the C-L direction for the test temperatures of 25 and $125^{\circ} \mathrm{C}$, respectively. The average fracture toughness results given by $\mathrm{J}_{\mathrm{Ic}}$ as shown in Table 5-4 also exhibits a strong dependence on crack orientation. The toughness is 60 and $71 \%$ greater for the L-C direction compared to the C-L direction for base material at test temperatures of 25 and $125^{\circ} \mathrm{C}$, respectively. The toughness is 58 and $145 \%$ greater for the $L-C$ direction compared to the C-L direction for the weld heataffected-zone material at test temperatures of 25 and $125^{\circ} \mathrm{C}$, respectively. This orientation effect on fracture toughness behavior is illustrated in Figure 5-5, for Ring \#1, sides A and B base material.

The difference in mechanical response between $C-L$ versus $L-C$ orientations is attributed to the microstructural variation in the pipe due to the thermomechanical processing. Figure 5-6 is an optical micrograph of the pipe material showing delta ferrite stringers parallel to the pipe axis or

- rolling direction of the plate material. Non-metallic inclusions are generally spherical in shape as seen in Figure 5-7. Fracture along directions parallel to the stringers results in a reduced fracture toughness compared to the fracture perpendicular to the axis of the stringers. For this reason, an evaluation of flaw stability for a postulated planar flaw along the pipe axis in the piping would 
require application of the C-L material data. Likewise, application of the $\mathrm{L}-\mathrm{C}$ material data is appropriate for postulated planar flaw along the circumferential direction of the piping.

Unlike the base and heat-affected-zone material, the weld metal microstructure is essentially isotropic, and shows no preferred orientation effects on toughness properties. The fracture toughness and $\mathrm{J}_{\mathrm{Ic}}$ values for the weld deposit material are equivalent within the confidence interval for the sample mean (see equation 5-1) for both test temperatures (25 and $125^{\circ} \mathrm{C}$ ).

\subsection{Specimen Size Effects}

The design of the CT specimens was based on a size effect variation study performed by Hanford Engineering Development Laboratory (HEDL) [28] and geometry studies (specimen planform variance) conducted by MEA $[29,30]$. The pipe material stock from which the specimens were cut was nominal 0.5 inch thick large diameter piping. Allowing for the curvature of the pipe and machining the faces of the specimens, the maximum possible specimen thickness was 0.4 inches; a $0.394 \mathrm{in}$. $(10 \mathrm{~mm})$ specimen thickness was chosen. This results in insufficient thickness to satisfy the ASTM E 813 size requirements. Studies were conducted at HEDL [28] and MEA $[29,30]$ to investigate the effects of variation in planform dimensions on the fracture toughness. A decrease in the planform dimensions while holding the thickness constant tends to give greater toughness ( $\mathrm{J}_{\mathrm{IC}}$ ) values; the $0.4 \mathrm{~T}$ planform specimen tends to yield higher J-R data with a higher $\mathrm{J}_{\mathrm{Ic}}$ than a 0.4T $\times 1 \mathrm{~T}$ planform specimen for the J-modified formulation. A comparison of the J-R curves (see Figure 5-7) for the J-deformation formulation yields the opposite conclusion.

The J-R curve in Figure 5-7 shows this size effect on deformation-J for 0.4T and 0.4T x 1T-CT specimens from 8BB (ring 8, Base material, side B) material stock. The different specimen sizes show nearly equivalent $J$ values for crack extension up to the intersection of the $1.5-\mathrm{mm}$ blunting line. After that, the small specimen size (0.394T) shows a lower J-R curve [30]. Significant departure between the J-R curves in Figure 5-7 is seen at $\Delta$ a values greater than $4 \mathrm{~mm}$. A cut-off to the J-R curve data is suggested at a departure point of the $0.4 \mathrm{~T}$ data from the $1 \mathrm{~T}$ data. This point occurs approximately at $3 \mathrm{~mm}$ of crack extension. J-controlled crack growth theory specifies that the outer boundary of the J-dominated region be less than the specimen ligament. The extension $(\Delta \mathrm{a}=3 \mathrm{~mm})$ is suggested to be a candidate to the limit of J-controlled growth in the 0.4T planform specimens (see Section 7). Furthermore, this conclusion serves to validate the application of the results of the small planform (0.394T) to an elastic-plastic analysis. As discussed in Section 7, J-controlled crack extension is dependent on the parameter $\omega$, where:

$$
\omega=\left(\frac{\mathrm{dJ}}{\mathrm{da}}\right)\left(\frac{\mathrm{b}}{\mathrm{J}}\right)
$$

The $0.4 \mathrm{~T} \times 1 \mathrm{~T}$ vs. $0.4 \mathrm{~T}$ planform specimen test results indicate $\mathrm{J}$-controlled growth is valid up to $\omega=1(\Delta \mathrm{a}=3 \mathrm{~mm}$ ) (see RMP Calculation Set \#91-03, Part 2). The results from the large planform specimen thus validate this criterion for J-controlled growth for the small planform specimens.

Side grooving, applied to the CT specimens to provide a even, parallel crack front to assess crack extension after precracking, tends to reduce toughness values. No study was done to correlate small side-grooved specimens ( $0.4 \mathrm{~T}$ planform) with the large (1T) planform specimens; however, a study with single-edge-notch cantilever specimens [31] determined no significant effect of thickness ( 0.3 to 1.0 inches) on fatigue crack propagation rates in Type 304 stainless steel at temperatures from $25^{\circ} \mathrm{C}$ to $600^{\circ} \mathrm{C}$. All results contained in this report are comparable within the same proportional configuration (thickness, planform and depth of side groove). 


\subsection{Fractography}

Fracture surfaces of several Charpy impact and compact-tension specimens were examined by scanning electron microscopy. Base, weld, and heat-affected-zone (HAZ) materials were selected from among specimens tested at 25 and $125^{\circ} \mathrm{C}$.

All test specimens and all three material types exhibited ductile rupture behavior at both test temperatures. Large pits or dimples with associated inclusions characteristic of microvoid coalescence were seen in base, weld and HAZ specimens (see Figure 5-8). In addition, secondary cracking was observed in the base material for both $\mathrm{C}_{\mathrm{V}}$ and $\mathrm{CT}$ specimens, Figure 59. The cracks appear to be associated with inclusion stringers or short bands of segregation leading to weakened areas aligned parallel to the surfaces during forming. Energy dispersive Xray spectroscopy was applied to obtain a chemical assay of selected precipitates. The analysis suggests the precipitates to be chromium and titanium carbides, calcium-aluminum silicates and manganese sulfides. The stringers were concluded to be delta-ferrite which formed as a result of the thermomechanical processing [5]. 


\section{Table 5-1: Static Tensile Data}

\begin{tabular}{|c|c|c|c|c|c|c|}
\hline Material & $\begin{array}{c}\text { Test } \\
\text { Temperature } \\
\text { ('C) }\end{array}$ & $\begin{array}{c}\text { Sample } \\
\text { ASTM } \\
\text { Orientation }\end{array}$ & $\begin{array}{c}\text { Yield } \\
\text { Strength (ksi) }\end{array}$ & $\begin{array}{c}\text { Tensile } \\
\text { Strength (ksi) }\end{array}$ & $\begin{array}{l}\text { Elongation* } \\
\text { (\%) }\end{array}$ & $\begin{array}{l}\text { Reduction } \\
\text { in } \\
\text { Area (\%) }\end{array}$ \\
\hline \multirow[t]{4}{*}{ Base } & 25 & L-C & $38( \pm 2)^{* * *}$ & $91( \pm 3)$ & $88( \pm 6)$ & $73( \pm 0)$ \\
\hline & & C-L & $38( \pm 2)$ & $92( \pm 3)$ & $85( \pm 8)$ & $71( \pm 5)$ \\
\hline & 125 & L-C & $29( \pm 2)$ & $70( \pm 2)$ & $61( \pm 3)$ & $77( \pm 1)$ \\
\hline & & C-L & $29( \pm 2)$ & $71( \pm 1)$ & $62( \pm 3)$ & $73( \pm 1)$ \\
\hline \multirow[t]{4}{*}{ HAZ } & 25 & L-C & - & - & - & - \\
\hline & & C-L & $51( \pm 2)$ & $95( \pm 3)$ & $86( \pm 2)$ & $71( \pm 2)$ \\
\hline & 125 & L-C & - & - & - & - \\
\hline & & C-L & $43\left({ }^{* *}\right)$ & $74(* *)$ & $60\left(^{* *}\right)$ & $67(* *)$ \\
\hline \multirow[t]{4}{*}{ Weld } & 25 & L-C & $55( \pm 6)$ & $90( \pm 5)$ & $48( \pm 10)$ & $64( \pm 8)$ \\
\hline & & C-L & $57( \pm 8)$ & $90( \pm 2)$ & $58( \pm 30)$ & $57( \pm 22)$ \\
\hline & 125 & L-C & $46( \pm 2)$ & $72( \pm 2)$ & $37( \pm 5)$ & $68( \pm 12)$ \\
\hline & & $C-L$ & - & - & - & - \\
\hline
\end{tabular}

*: Gage length $=0.80$ inch

$\cdots$

**: High standard deviation of the sample mean $(\geq 100)$ noted due to small sample size

***: Number in parenthesis represents confidence interval for sample mean (see eqn. 5-1) 
Table 5-2: Dynamic Tensile Data

\begin{tabular}{|c|c|c|c|c|c|c|}
\hline Material & $\begin{array}{l}\text { Test } \\
\text { Temperature } \\
\text { ("C) }\end{array}$ & $\begin{array}{c}\text { Sample } \\
\text { ASTM } \\
\text { Orientation }\end{array}$ & $\begin{array}{c}\text { Yield } \\
\text { Strength (ksi) }\end{array}$ & $\begin{array}{c}\text { Tensile } \\
\text { Strength (ksi) }\end{array}$ & $\begin{array}{l}\text { Elongation* } \\
\text { (\%) }\end{array}$ & $\begin{array}{l}\text { Reduction } \\
\text { in } \\
\text { Area (\%) }\end{array}$ \\
\hline \multirow[t]{4}{*}{ Base } & 25 & L-C & $47( \pm 1)$ & $94( \pm 1)$ & $63( \pm 5)$ & $68( \pm 1)$ \\
\hline & & C-L & $47( \pm 1)$ & $=93( \pm 1)$ & $62( \pm 5)$ & $65( \pm 2)$ \\
\hline & 125 & L-C & $36( \pm 1)$ & $79( \pm 1)$ & $52( \pm 5)$ & $70( \pm 2)$ \\
\hline & & C-L & $36( \pm 1)$ & $78( \pm 1)$ & $57( \pm 5)$ & $66( \pm 1)$ \\
\hline \multirow[t]{4}{*}{ HAZ } & 25 & L-C & - & $=$ & - & - \\
\hline & & C-L & $63( \pm 9)$ & $63( \pm 9)$ & $63( \pm 18)$ & $62( \pm 9)$ \\
\hline & 125 & L-C & - & - & - & - \\
\hline & & C-L & $49^{(* *)}$ & $79(* *)$ & $60\left({ }^{* *}\right)$ & $65(* *)$ \\
\hline \multirow[t]{4}{*}{ Weld } & 25 & $L-C^{\circ}$ & $66( \pm 9)$ & $93( \pm 18)$ & $39( \pm 27)$ & $58( \pm 13)$ \\
\hline & & $C-L$ & $70( \pm 7)$ & $97( \pm 2)$ & $35( \pm 25)$ & $50( \pm 37)$ \\
\hline & 125 & L-C & $64( \pm 9)$ & $95( \pm 9)$ & $28( \pm 27)$ & $68( \pm 13)$ \\
\hline & & C-L $\cdots$ & - & - & - & - \\
\hline
\end{tabular}

*: . Gage length $=0.80$ inch

**: High standard deviation of the sample mean $(\geq 100)$ noted due to small sample size

***: Number in parenthesis represents confidence interval for sample mean (see eqn. 5-1) 
Table 5-3: Charpy Impact Data

\begin{tabular}{ccccc} 
Material & $\begin{array}{c}\text { Test Temperature } \\
\left({ }^{\circ} \mathrm{C}\right)\end{array}$ & $\begin{array}{c}\text { Sample } \\
\text { ASTM } \\
\text { Orientation }\end{array}$ & $\begin{array}{c}\text { Energy Absorption } \\
(\mathrm{ft}-\mathrm{lbs})\end{array}$ & $\begin{array}{c}\text { Lateral Expansion } \\
(\text { mils })\end{array}$ \\
\hline \multirow{2}{*}{ Base } & 25 & L-C & $149( \pm 7)^{* * * *}$ & $80( \pm 4)$ \\
& 125 & C-L & $116( \pm 5)$ & $83( \pm 5)$ \\
& 25 & L-C & $229( \pm 14)$ & $87( \pm 2)$ \\
HAZ & $25-L$ & $128( \pm 11)$ & $77( \pm 2)$ \\
& 125 & L-C & $136( \pm 8)$ & $80( \pm 2)$ \\
& 25 & C-L & $95( \pm 13)$ & $73( \pm 6)$ \\
Weld & & L-C & $188( \pm 33)$ & $85( \pm 3)$ \\
& 125 & C-L & $101( \pm 12)$ & $81( \pm 2)$ \\
& & L-C & $113( \pm 7)$ & $84( \pm 7)$ \\
& & C-L & $118( \pm 27)$ & $85( \pm 3)$ \\
& & - $-C$ & $158( \pm 39)$ & $79( \pm 6)$ \\
& & C-L & $175( \pm 16)$ & $83( \pm 2)$
\end{tabular}

***: Number in parenthesis represents confidence interval for sample mean (see eqn. 5-1) 


\section{Table 5-4: Static Fracture Toughness Data (Deformation-J, Power law)}

\begin{tabular}{cccccc} 
Material & $\begin{array}{c}\text { Test } \\
\text { Temperature } \\
\left({ }^{\circ} \mathrm{C}\right)\end{array}$ & $\begin{array}{c}\text { Sample } \\
\text { ASTM } \\
\text { Orientation }\end{array}$ & $\begin{array}{c}\mathrm{J}_{\mathrm{Ic}}-\text { Deformation } \\
\left(\mathrm{kJ} / \mathrm{m}^{2}\right)\end{array}$ & $\begin{array}{c}\mathrm{K}_{\mathrm{Ic}}-\text { Deformation } \\
(\mathrm{MPa} \sqrt{\mathrm{m}})\end{array}$ & $\begin{array}{c}\text { Tearing } \\
\text { Modulus } \\
(\mathrm{T})\end{array}$ \\
\hline \multirow{2}{*}{ Base } & 25 & L-C & $680( \pm 79)^{* * *}$ & $373( \pm 23)$ & $218( \pm 23)$ \\
& 125 & C-L & $424( \pm 29)$ & $295( \pm 24)$ & $186( \pm 21)$ \\
& & L-C & $579( \pm 54)$ & $339( \pm 15)$ & $254( \pm 21)$ \\
HAZ & 25 & C-L & $338( \pm 33)$ & $258( \pm 13)$ & $218( \pm 17)$ \\
& & L-C & $497( \pm 78)$ & $320( \pm 25)$ & $178( \pm 27)$ \\
& 125 & C-L & $314( \pm 52)$ & $254( \pm 21)$ & $151( \pm 35)$ \\
Weld & L-C & $536(* *)$ & $326( \pm 60)$ & $190( \pm 21)$ \\
& 25 & C-L & $219(* *)$ & $207(* *)$ & $155(* *)$ \\
& 125 & L-C & $417( \pm 73)$ & $292( \pm 25)$ & $244( \pm 48)$ \\
& & C-L & $399(* *)$ & $286(* *)$ & $181(* *)$ \\
& & L-C & $486(* *)$ & $308( \pm 70)$ & $300( \pm 70)$ \\
& & C-L & $538(* *)$ & $323(* *)$ & $253( \pm 97)$ \\
\hline
\end{tabular}

**: High standard deviation of the sample mean $(\geq 100)$ noted due to small sample size ***: Number in parenthesis represents confidence interval for sample mean (see eqn. 5-1) 


\section{Table 5-5: Dynamic Fracture Toughness Data} (Deformation-J, Power law)

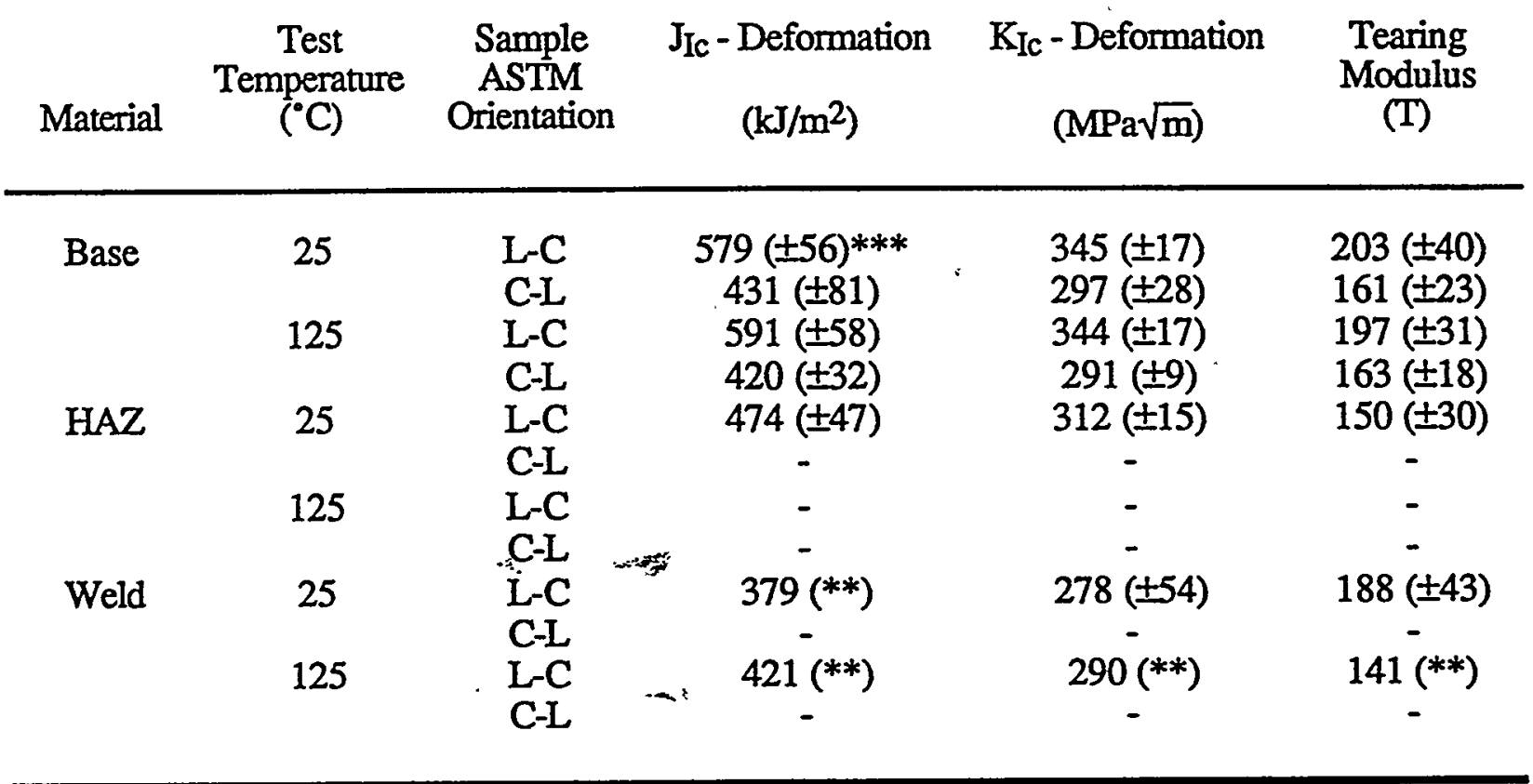

**: High standard deviation of the sample mean $(\geq 100)$ noted due to small sample size

***: Number in parenthesis represents confidence interval for sample mean (see eqn. 5-1) 


\section{$\frac{\text { Type } 304 \text { Stainless Steel - Base Metal }}{\text { Static Tensile, } 125^{\circ} \mathrm{C}}$}

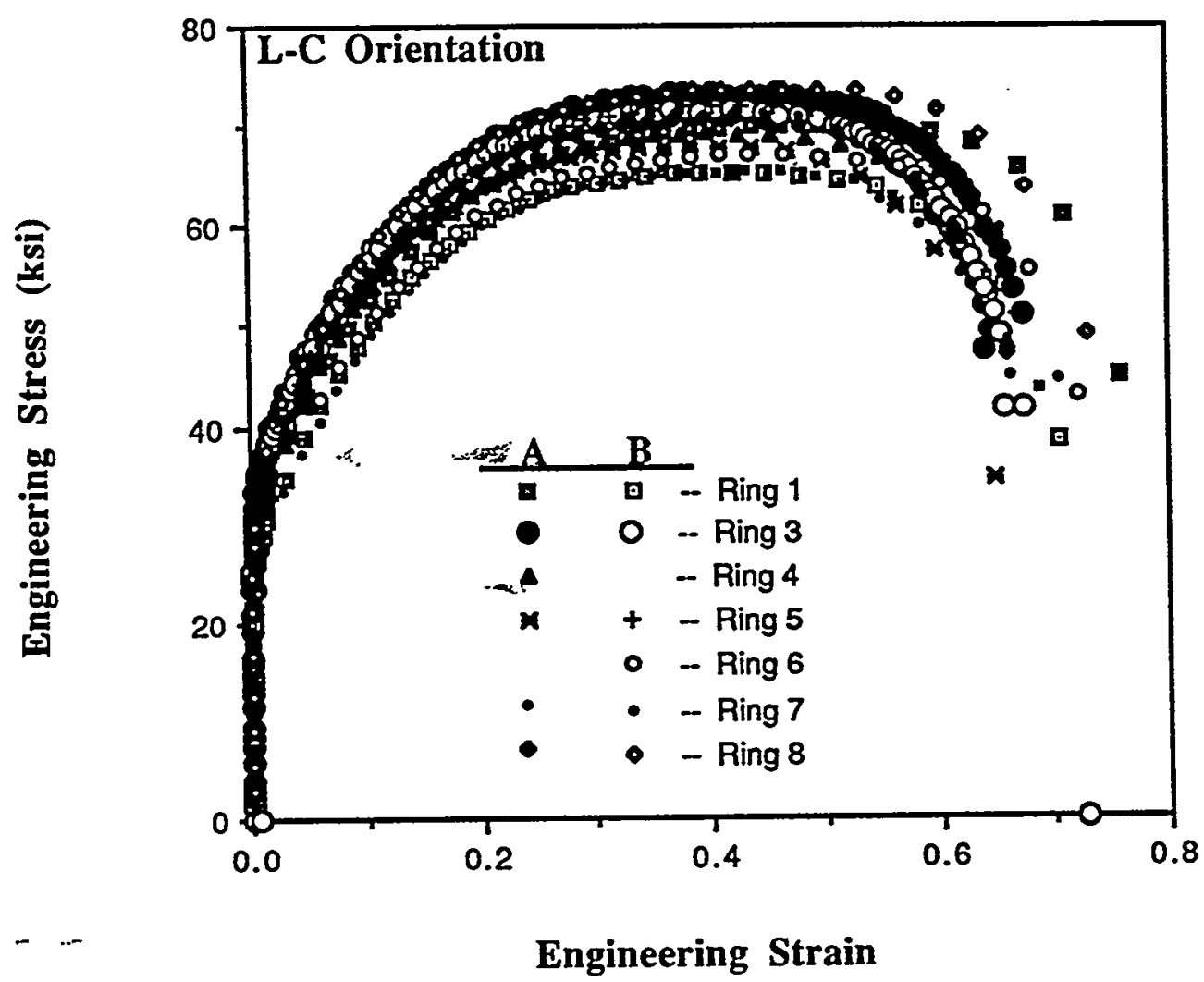

Figure 5-1: Effect of material variability on Tensile behavior for the L-C orientation of base metals 


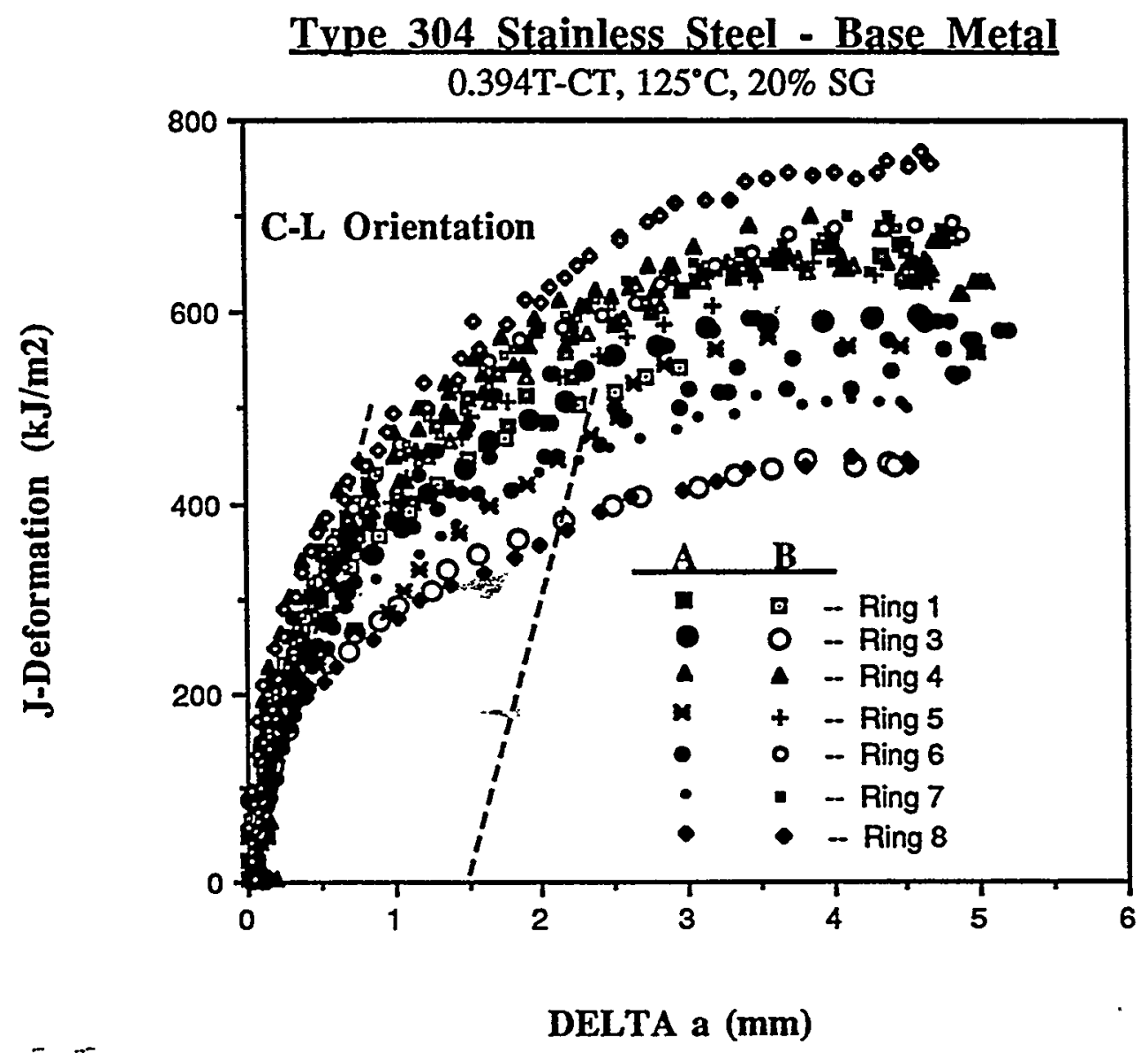

Figure 5-2: Effect of material variability on Fracture Toughness behavior for the C-L orientation of base metals (Deformation-J) 


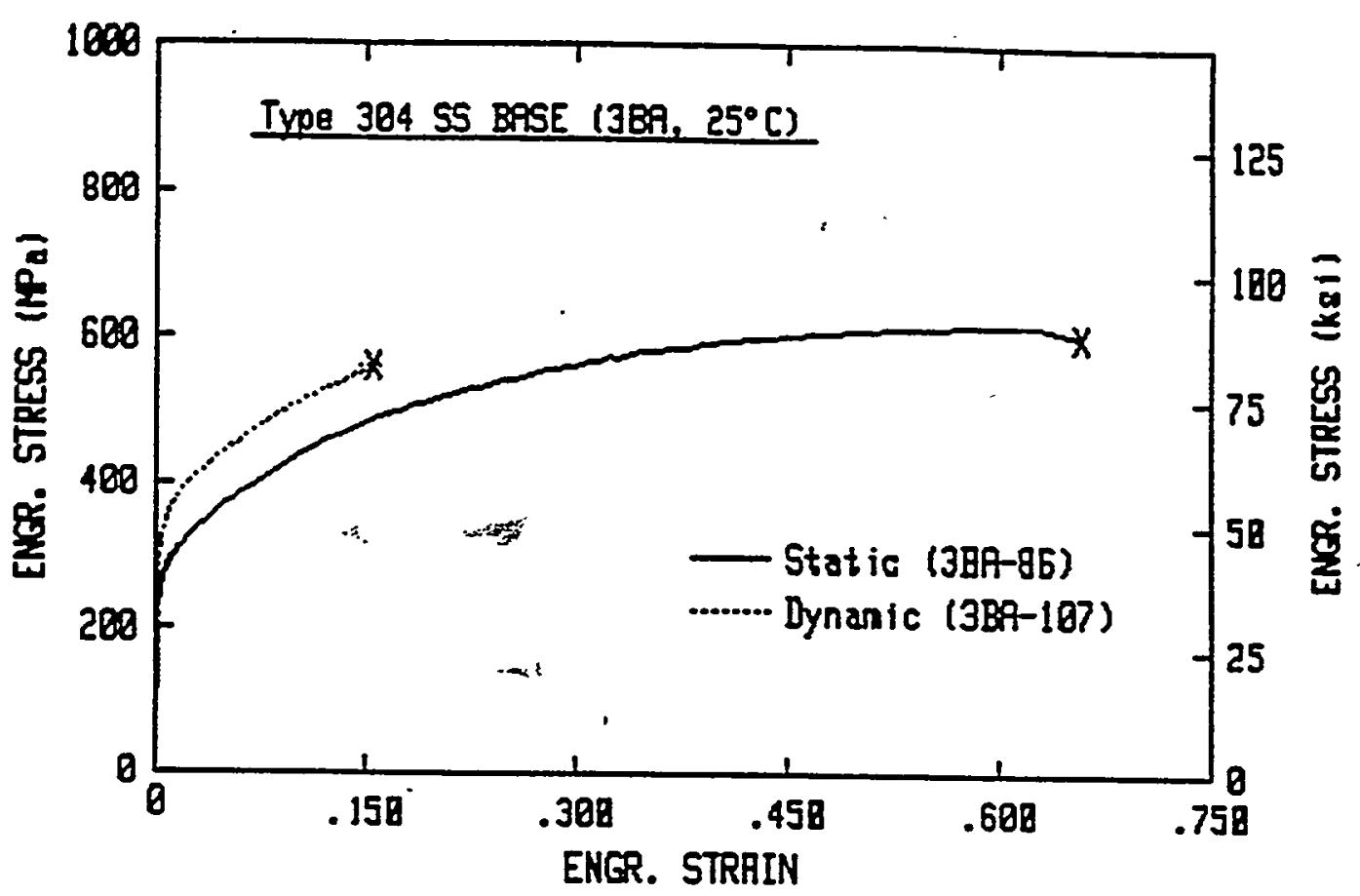

Figure 5-3: Effect of Static versus Dynamic loading on Tensile behavior (specimen 3BA). The dynamic-loading curve terminates prematurely because the strain extensometer reached its measurement capacity. 


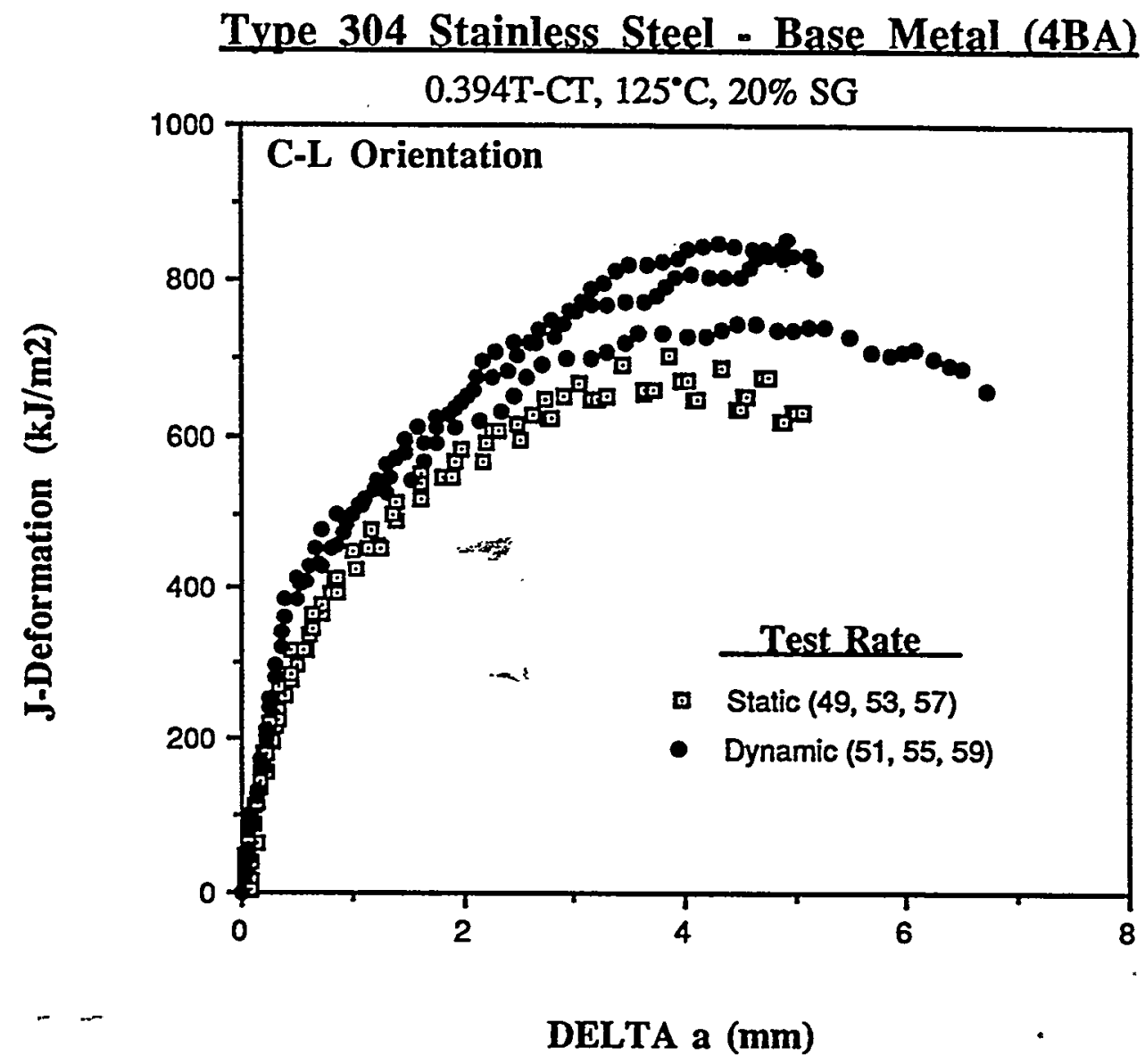

Figure 5-4: Effect of Static versus Dynamic loading on Fracture Toughness behavior 


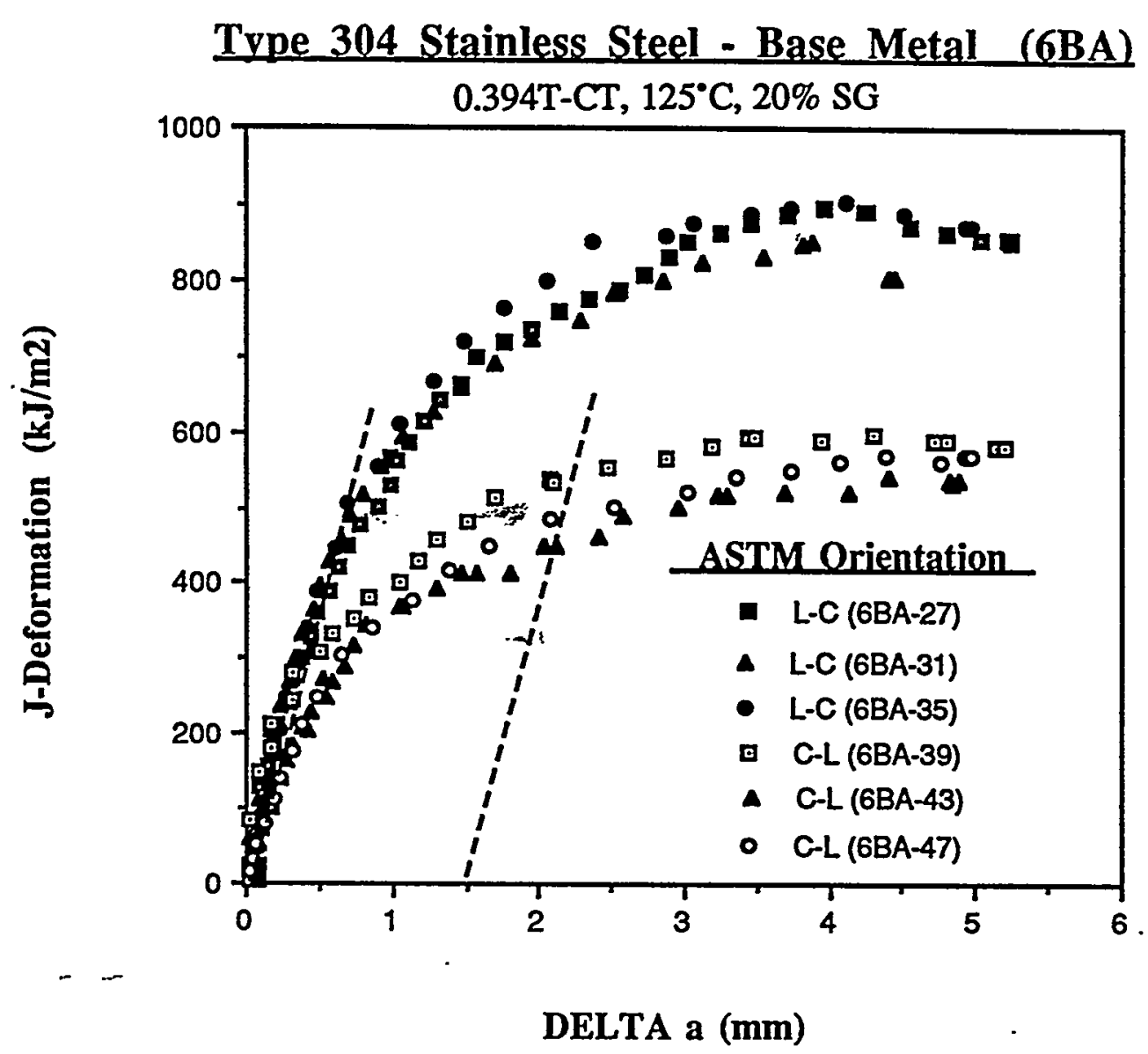

Figure 5-5: Specimen orientation effects; Decreased fracture toughness observed for cracking parallel to the rolling direction (C-L) compared to pipe circumnferential (L-C) direction. 


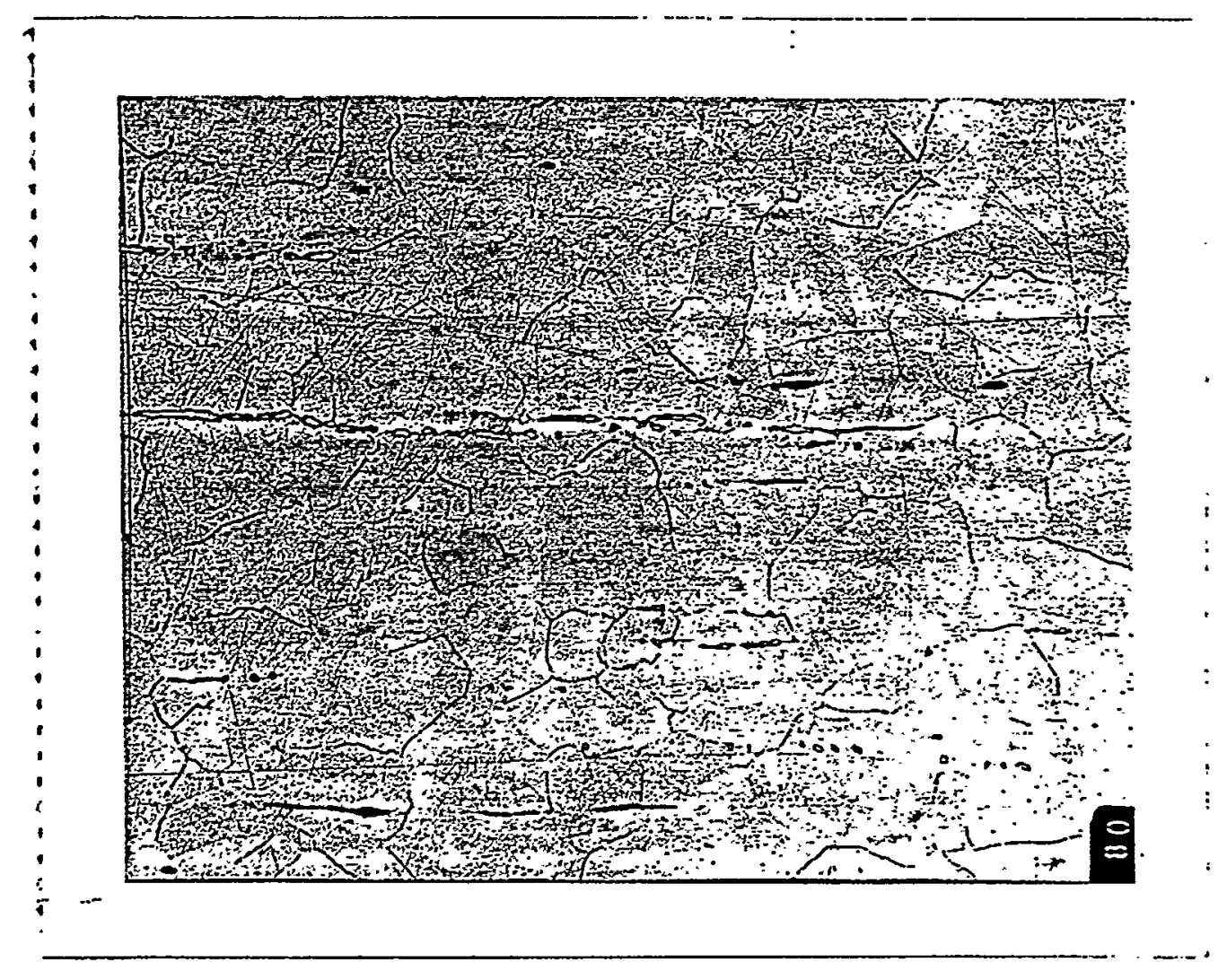

Figure 5-6: Optical metallograph of pipe HAZ material with delta ferrite stringers (specimen 7HA12 - 250x). 


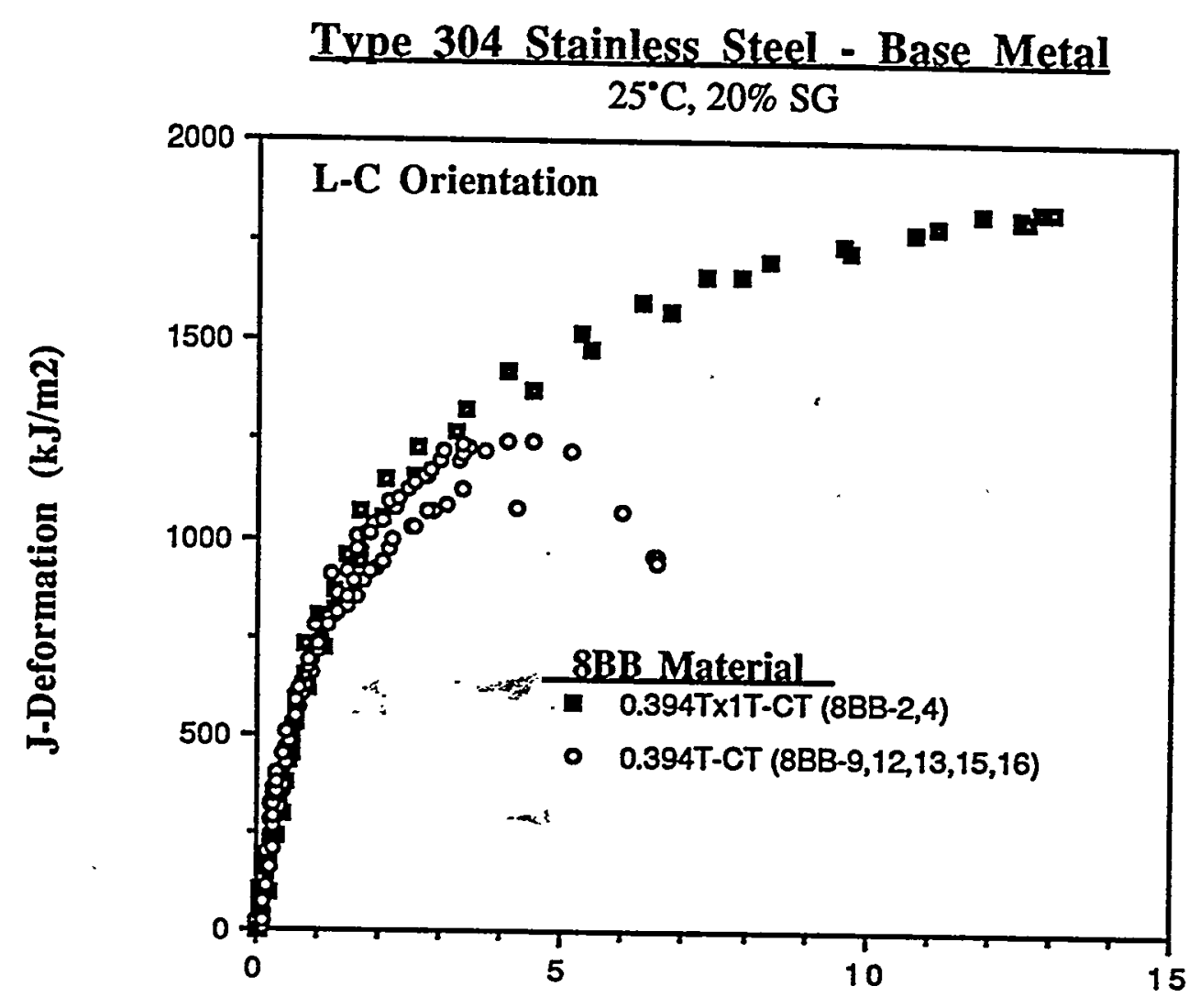

DELTA a (mm)

Figure 5-7: J-R curves for 8BB material developed with five 0.394T and two $0.394 \mathrm{~T} \times 1 \mathrm{~T}$ plan form CT specimens (Deformation-J formulation) 


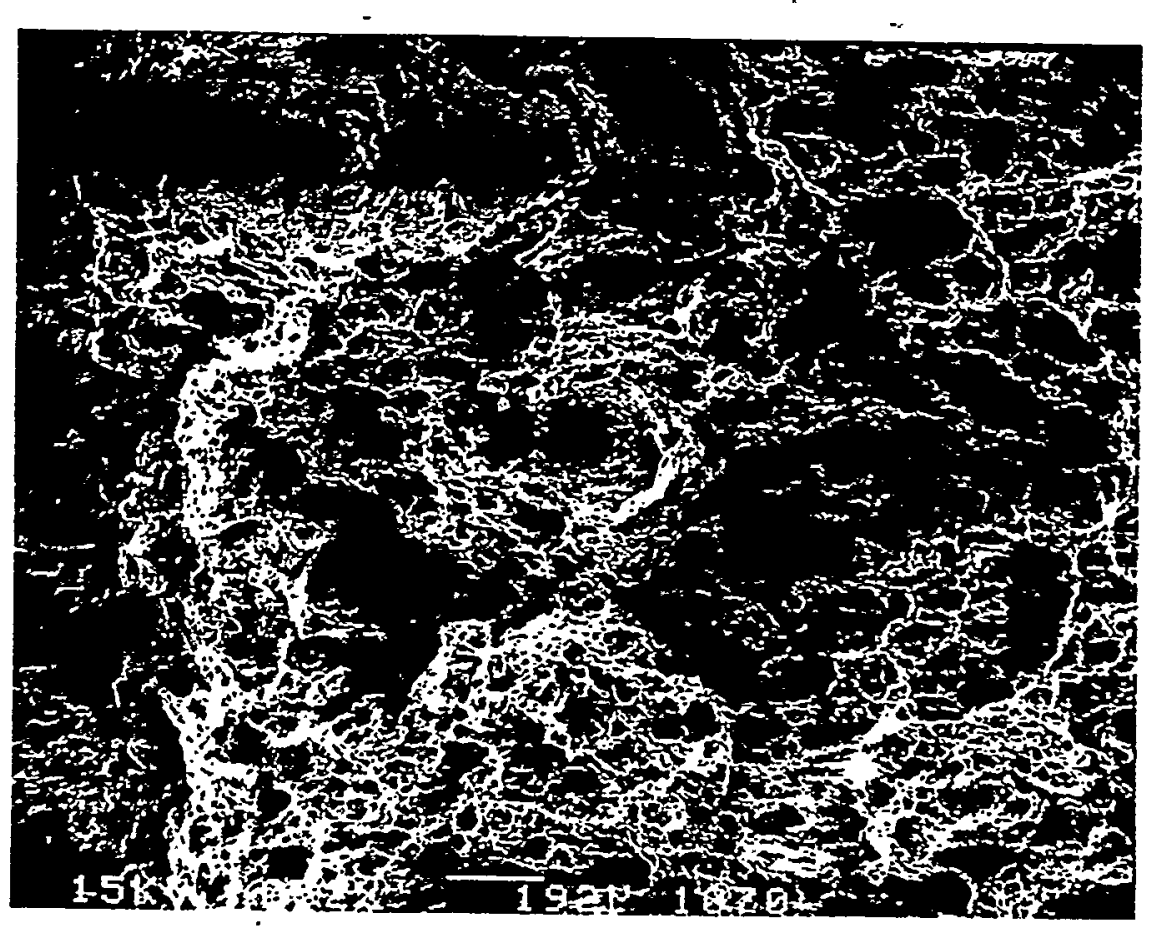

Figure 5-8: Typical ductile fracture of Type 304 stainless steel (specimen 4BA-12; $\mathrm{C}_{\mathrm{V}}, 125^{\circ} \mathrm{C}$, ASTM C-L) 
(a)

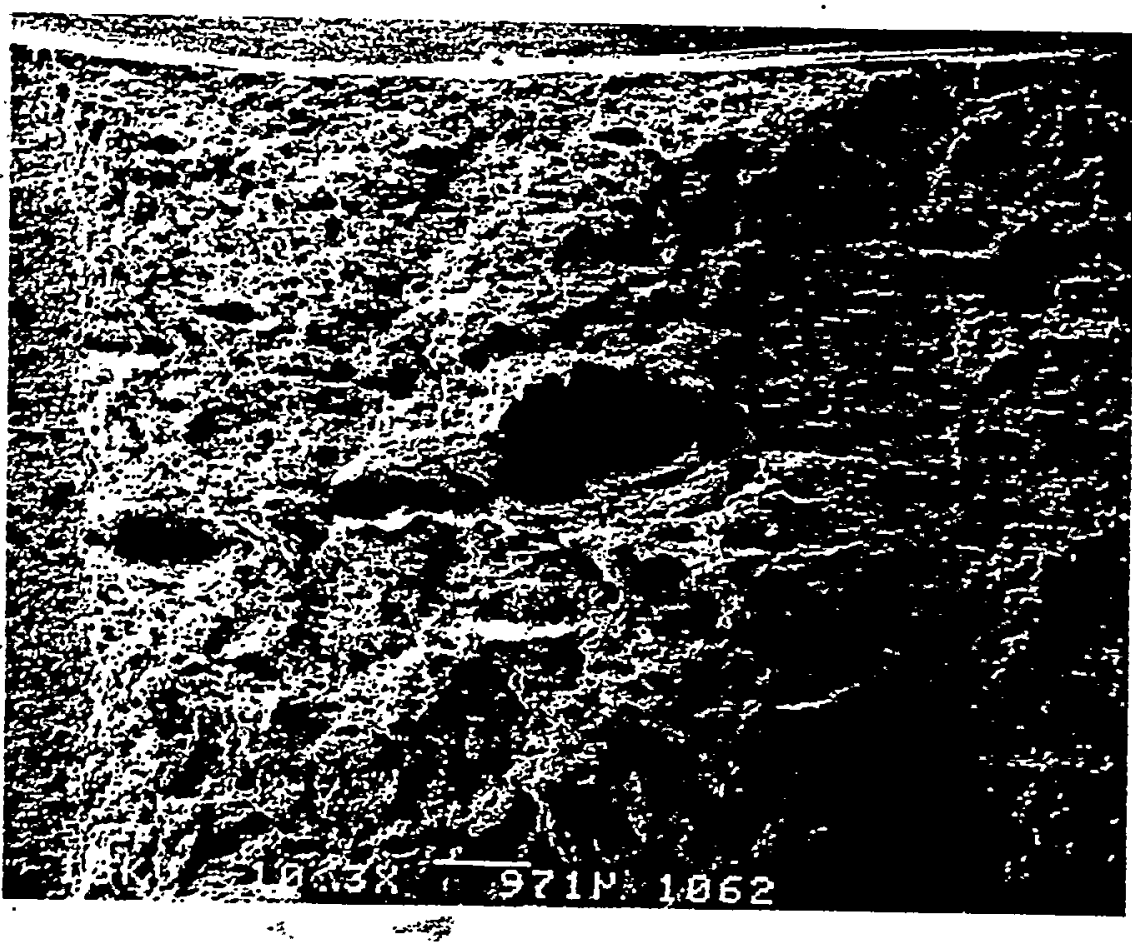

(b)

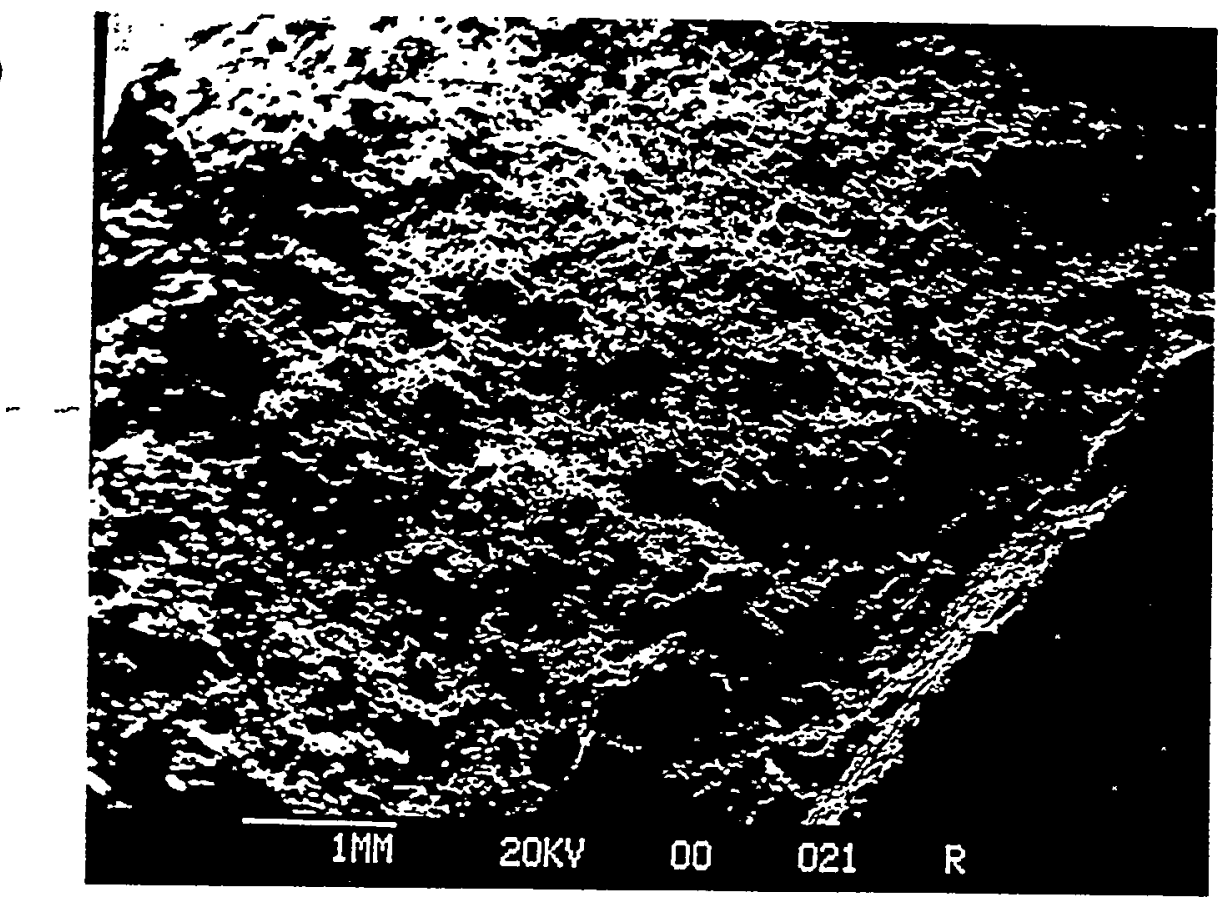

Figure 5-9: Secondary cracking observed in (a) Compact Tension [4BA72; ASTM L-C] and (b) Charpy [3BA49; ASTM L-C] specimens 


\subsection{PIPING MECHANICAL PROPERTIES: ENGINEERING STRUCTURAL ANALYSES}

\subsection{Overview}

\subsubsection{PWS Construction Specifications and Materials of Construction}

The original construction piping and the replacement piping of the reactor Process Water System were fabricated per site specifications governing the manufacturing and installation of the piping. The majority of the piping in the K, L, and P reactor PWS is original installation (1958 upgrade), 1950's vintage Type 304 stainless steel. Since 1986, several sections of piping containing IGSCC flaws have been replaced with IGSCC-resistant Type 304L stainless steel [32].

All piping contacting the heavy water moderator was fabricated originally from Type 304 stainless steel per Du Pont Specification SW 304M (Grade 304) as listed in Specification 3018, P39.010 and P39.020, issued November 11, 1951 with latest revision January 24, 1957. The original construction design code of record was American National Standards Institute (ANSI) B31.1. General specifications for process piping components were covered in Specification 3069 issued March 14, 1952 and revised December 18, 1952. Seamless pipe was to be manufactured to ASTM Specification A-269-47 (Grade chromium-nickel) and welded pipe was to be fabricated to ASTM A-312-48T"(Grade chromium-nickel).

The original piping specifications were replaced in August 1973 by Specification 4482, Codes P45 and P46. Codes P45 and P46, for the low (150 psig design) and high (400 psig design) pressure piping, respectively, specify Type 304L stainless steel as the replacement piping under construction code ASME B31.3. Welded replacement piping is required to be fabricated to ASTM A312 or A358. Seamless piping may be substituted and is required to be fabricated to ASTM A312 or A376. All replacement pipe is required to be evaluated to Specification 4498.

The site specifications also cover the weldments. All original construction welds were made by inert-gas-shielded arc-welding with Type 308 bare welding wire or tungsten arc. The codes P45 and P46 (Revision 2) require GTAW 2-T or 6-T (helium) or GMAW 51-M, 53-M, or 59-M procedures.with helium shielding gas (in 105-buildings) for all stainless steel welds. These procedures specify Type 308L filler wire for Type 304L stainless steel piping.

Each reactor process water system contains six 16-inch by 12-inch reducing " $Y$ " fittings and six 16-inch by 12-inch "T fittings that are made of cast stainless steel. Grade CF-8, which is the cast equivalent to wrought Type 304 stainless steel, was specified for this service, per Du Pont specification SW $300 \mathrm{M}$.

\subsubsection{Mechanical Properties for Structural Design and Analysis - Summary}

The mechanical property data base generated through the testing program provides site-specific properties representative of wrought Type 304 stainless steel pipe and Type 308 stainless steel weld metal filler, the materials of construction of the SRS Process Water System piping in the late 1950's [8]. These properties are compared to properties from the literature of more recent

- melts to assess any impact of potential differences in the stainless steels (thermomechanical processing or service degradation) which would lead to significant differences in mechanical response. This comparison shows that the mechanical properties from this testing program are equivalent or superior to handbook properties and similar to nominal properties from more recent melts of Type 304 and Type 308 stainless steels. Mechanical properties of Type 304L stainless 
steel, the replacement material for PWS piping [6], and CF-8 castings are included in the comparison. Type 304L stainless steels have less strength and higher fracture toughness compared to Type 304 stainless steels; the CF-8 castings have similar strengths and toughness levels of Type 304 stainless steel.

\subsubsection{Tensile Properties for Structural Analysis - Summary}

The tensile data in this testing program were generated in conformance to ASTM testing specifications and are applicable to engineering analyses. Special dynamic testing (high strain rate) was also performed to evaluate material properties in response to seismic loading conditions (see Section 5). The mechanical results are compared to required values in recent versions of the ASME/ANSI B31.1 (original piping) and B31.3 (replacement piping) design codes and the ASME Boiler and Pressure Vessel code for commercial nuclear structural design. The average piping tensile properties (confidence interval for the mean material strengths for the base, heataffected-zone and weld materials) and elongations are superior to the ASME BPV Section II (Material Specifications) and Section III (Design) values for Type 304 Stainless Steel piping. Similarly, the tensile strengths of the archival weld materials (Type 308 stainless steel) are superior to ASME-required (SA-358) values for welded pipe. It is thus demonstrated that the ASME code tensile property values are conservative to the archival SRS reactor PWS piping values. The ASME code Section III requirements can provide the reference source for material property data in stress analyses for the PWS piping.

\subsubsection{Fracture Toughness Properties for Structural Analysis - Summary}

The ASME (formerly ANSI or ASME/ANSI) B31.1 \& B31.3 construction codes and the ASME BPV code do not specify fracture toughness properties for Type 304 stainless steel piping. The fracture toughness data generated in this study provide site-specific fracture toughness parameters for elastic-plastic fracture analyses of the PWS piping. The testing results from this program have shown a strong dependency of fracture toughness with respect to the pipe axis, or, the rolling direction of the plate material from which the archival piping was fabricated. As suggested in Section 5, this is the result of stringers of delta ferrite and alignment of non-metallic inclusions in the stainless steel matrix along the pipe axis. Fracture analyses of the piping should thus consider directionality effects as related to the material toughness. Lower Bound material JT curves from the archival material data are provided for elastic-plastic fracture mechanics for flaw analysis in the PWS piping for flaws lying parallel to either the pipe circumference or pipe axis.

Fracture toughness data of 304L stainless steel is superior to the archival material. Similarly, literature fracture toughness data of cast CF-8 material is also shown to be equivalent to the SRS Type 304 stainless steel data. Thus the archival SRS data provides a lower bound to the fracture toughness properties of the materials of construction of the SRS PWS piping. The tensile data from the set of properties provided in Section 5 can also be applied with the fracture toughness data in flaw-specific fracture analyses of the PWS piping. [The fracture analysis methodology (J-integral based limit load) of the PWS piping applied in the LBB analysis of the PWS [33] is also discussed in Section 7].

\subsubsection{Baseline Properties for Irradiation Effects Studies - Summary}

Results from the mechanical testing of a single melt (Materials Engineering Associates, code F50) of Type 304L stainless steel in this program were reported along with the archival material data in Section 5. Collectively, these data provide baseline or unirradiated material property data to evaluate the effects of irradiation on the mechanical response for application to structural 
analysis of the SRS reactor tanks [1,2,34 - 38]. A complete review of the irradiated material properties of the archival piping material and the F50 plate material from the Reactor Materials Program irradiation programs will be contained in a future report [7].

\subsection{Tensile Properties}

\subsubsection{Handbook Data - Temperature Dependence}

An extensive literature data base (453 tests) exists $[39,40]$ for tensile properties of mill-annealed or solution-treated tube, pipe and plate Type 304 stainless steel products from the U.S., Japan, and the United Kingdom. Figure 6-1, reproduced from reference [11] shows the temperature dependency of this data (above two references) data. The average yield strengths of the SRS archival piping weldment components at 25 and $125^{\circ} \mathrm{C}$ (see Table 5-1) are equivalent or superior to the average properties of 35 and $30 \mathrm{ksi}$ at these temperatures, respectively, as shown in Figure 6-1a. Similarly, the archival Type 308 results (Table 5-1) are equivalent to the literature values [1] of Type 304 stainless steel as shown in Figure 6-1b. The room temperature properties of Types 304, 304L, and 308 provided by the Committee of Stainless Steel Producers, American Iron and Steel Institute (see for example reference 41) are equivalent to the lower bound properties of the SRS archival piping (Section 5).

\subsubsection{ASME B31.1 and B31.3; ASME BPV Code Required Properties}

The ASME B31.1 [42] and B31.3 [43] specify minimum tensile strengths of Type 304 and 304L stainless steel piping material of 75 and $70 \mathrm{ksi}$, respectively. Weld material specifications (ASME Section II, A358) require the-weld tensile strength (Type 308 or 308L for SRS PWS piping) to be equivalent or superior to the base piping material (Type 304 or 304L). These requirements are met for the SRS piping materials. The ASME Boiler and Pressure Vessel Code, Section II requirements (A312 or A358) for SRS piping materials require yield/tensile strengths of $30 / 75$ and $25 / 70$ for Type 304 and 304L piping, respectively with minimum elongations of 35\% (longitudinal) and 25\% (transverse). The archival piping results (Section 5) exceed these specifications. Replacement piping (Type 304L) is ordered to ASTM standards $\mathrm{A} 312$ or A358; the minimum properties required by these standards would be met.

For stress analysis of the PWS piping, the design values required by ASME BPV code Section III are conservative to the archival results. Figure 6-2 shows the static yield strength results from Table 5.1 along with the Section III design values for Types 304 and 304L piping and CF-8 casting. Figure 6-3 shows the static tensile strength results from Table 5.1 along with the Section III design values for Types 304 and 304L piping and CF-8 casting. Section III material properties may be applied in stress analyses of the PWS piping. Alternatively, the archival material tensile results may be applied for the Type 304 stainless steel portions of the PWS piping. The code allows simple linear interpolation to develop strengths at temperatures other than those specified (room temperature, $100^{\circ} \mathrm{F}, 200^{\circ} \mathrm{F}, \ldots . . ., 1000^{\circ} \mathrm{F}$ ).

\subsection{Charpy V-Notch Impact Energy}

Charpy V-notch data for Type 304 and 304L stainless steels are not required by engineering design codes. A simple evaluation of the effects of processing variables, heat treatment and test - temperature on the toughness of a material type can be made with the impact energy data. The Charpy V-notch testing was ápplied in this study to provide a survey of the piping ring material [8] to compare the base, weld and heat-affected zone weldment material types for the L-C and C$\mathrm{L}$ orientations at test temperatures spanning the operating conditions of the reactor moderator. 
The average results of the Charpy V-notch toughness of the SRS piping material have been previously summarized in listed in Table 5.3. As discussed in Section 5, the Charpy impact energy results were consistant with the fracture toughness results for the base and HAZ components indicting a directional dependency (C-L vs. L-C). The correlation between the Charpy results and the toughness results (developed in Section 8) demonstrate that the Charpy impact testing can be applied to evaluate the-fracture-toughness-response of the SRS archival materials.

\subsection{Fracture Toughness - CT Specimens}

As stated above, the ASME design codes for piping systems do not specify fracture toughness data for austenitic stainless steels in either design or flaw evaluation criteria. Fracture toughness data is developed as part of the Reactor Materials Program [2] for the SRS piping materials to provide site-specific properties. Characterization of the fracture process for the compact tension specimen design in this study is given by an J-R curve to represent the material resistance to fracture. The J-R curve is the proper format since the all the specimens exhibited a ductile fracture mode and the elastic-plastic deformation mode is appropriate for the compact tension specimen design. Lower bound properties for flaw orientation in the piping circumferential (LC) and axial (C-L) directions are provided to reflect the strong orientation dependency of the archival material test results (see Section 5). The development of the material J-T curve from the $\mathrm{J}-\mathrm{R}$ data and the application in a elastic-plastic fracture assessment of the piping is discussed in section 7.0 .

A single value from the J-R curve is selected for comparison of the toughness properties of SRS piping fracture toughness to values reported in the literature. The elastic-plastic toughness pararmeter, $J_{I C}$, which corresponds to the onset of stable tearing [44] is shown for a variety of melts of Type 304 stainless steel in Table 6.1. The SRS piping toughness for the base, weld and HAZ material (Table 5-4) is similar to the respective reported literature values at room temperature.

The fracture toughness of Type 304L (F50 plate) is compared to the archival Type 304 stainless steel piping material in reference [45]. The J-R curves from this comparison are reproduced in Figure 6-4. It is seen that the fracture toughness of the Type 304L stainless steel, tested in an identical specimen configuration to the archival piping, lies above (is tougher than) specimen 6BA-43, an archival Type 304 stainless steel with toughness average to the archival material test results (Section 5). A comparison of CF-8 material to the archival SRS material has also been made previously [46, 47]. The lower bound literature cast toughness results (J-R curve) are similar to nominal archival results. The fracture toughness properties developed for the archival piping (Section 7) thus bound the fracture properties for the materials of construction of the SRS PWS piping. Confirmatory testing of several archival cast CF-8 specimens will be performed as part of the SRL Reactor Materials Program (see Section 9 and ref. 2). 
Table 6-1: Fracture toughness parameters (JIC) reported for Type 304 stainless steel and associated welds (at room temperature)

\begin{tabular}{|c|c|c|c|}
\hline Material & $J \mathrm{Jc}\left(\mathrm{kJ} / \mathrm{m}^{2}\right)$ & $T$ & Reference \\
\hline \multirow[t]{18}{*}{ Base Metal } & 872 & 574 & 48 \\
\hline & 700 & 293 & 48 \\
\hline & 700 & 550 & 48 \\
\hline & 1033 & 509 & 48 \\
\hline & 1138 & 1020 & 49 \\
\hline & 1016 & $220=$ & 49 \\
\hline & 1401 & 230 & 49 \\
\hline & 963 & 87 & 50 \\
\hline & 1296 & 95 & 50 \\
\hline & 928 & 185 & 50 \\
\hline & "ז5 & 230 & 50 \\
\hline & 1401 & 205 & 51 \\
\hline & 1156 & 160 & 51 \\
\hline & 1051 & 100 & 51 \\
\hline & 1016 & 104 & 51 \\
\hline & 779 & 188 & 51 \\
\hline & 1634 & 592 & 28 \\
\hline & 518 & 308 & 28 \\
\hline$-\ldots$ & 456 & 454 & 28 \\
\hline \multirow[t]{3}{*}{ Weld (Inert Gas) } & 405 & 512 & 48 \\
\hline & 516 & 289 & 52 \\
\hline & 392 & 249 & 28 \\
\hline \multirow[t]{3}{*}{$\mathrm{HAZ}$} & 648 & 426 & 48 \\
\hline & 1051 & 553 & 48 \\
\hline & 1578 & 250 & 48 \\
\hline
\end{tabular}


(a)
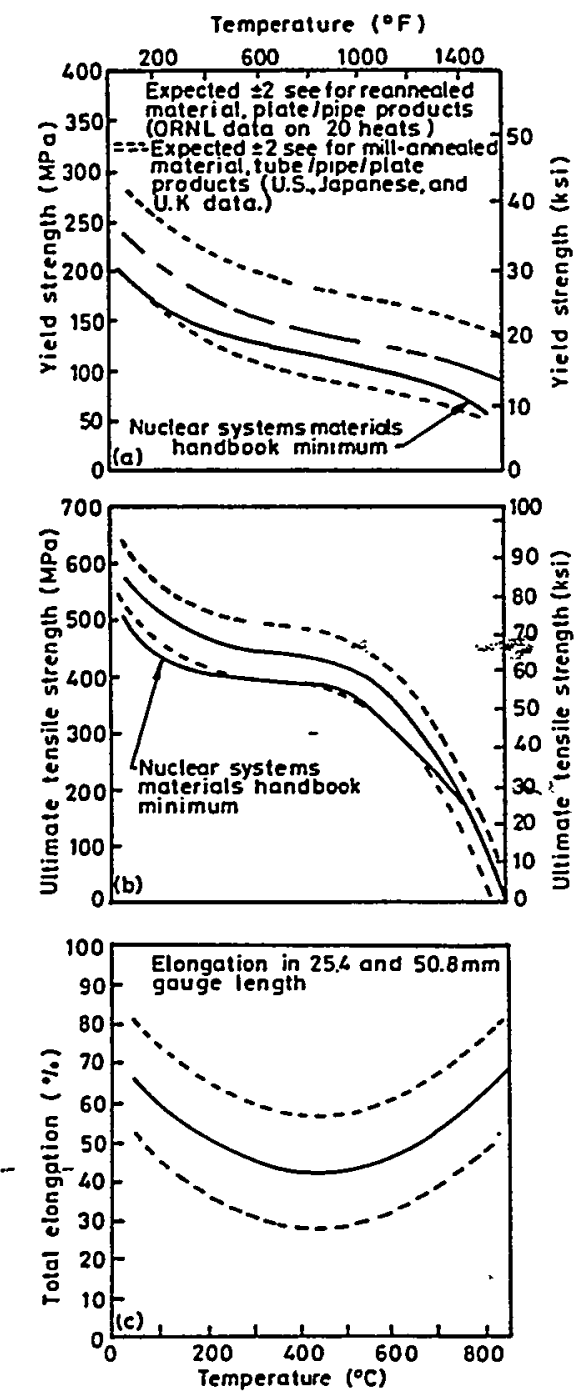

(b)
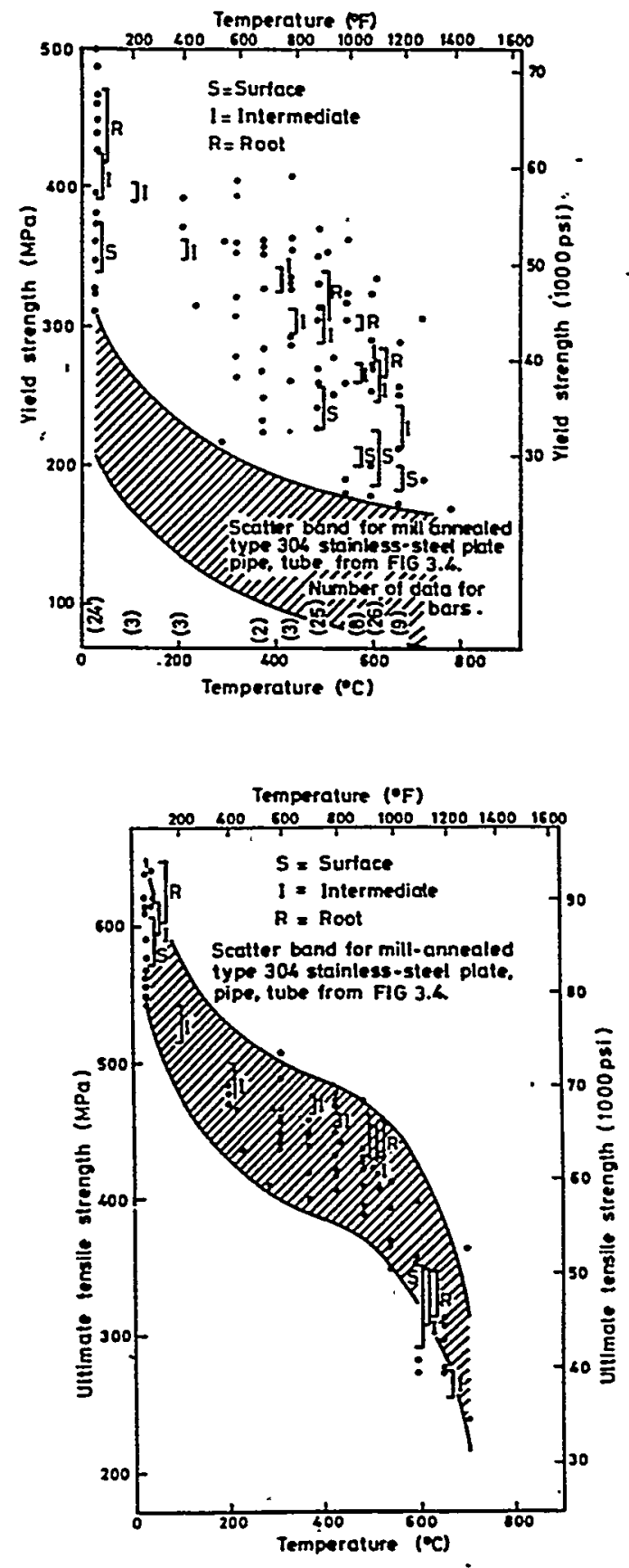

Figure 6-1: Literature Tensile Data [Reproduced from reference 11] (a) Type 304 stainless steel tensile properties for tube / pipe / plate materials. (b) Type 308 stainless steel tensile properties. 
)

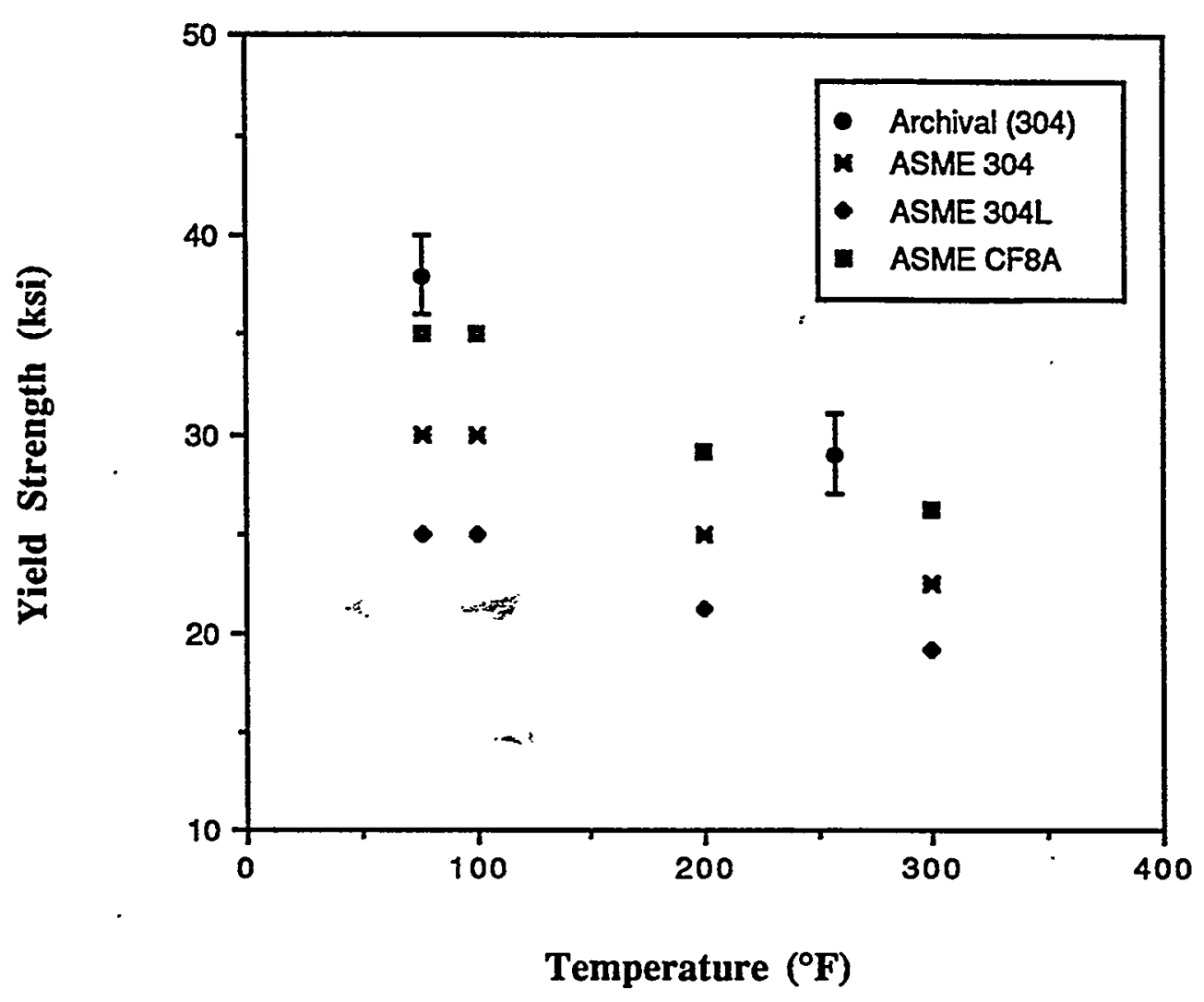

Figure 6-2: Archival SRS piping lower bound yield strength values (Table 5-1) in comparison to the ASME BPV code, Section III, Appendix I, Table I-2.2 values for Types 304 and $304 \mathrm{~L}$ piping and CF8A cast material. 


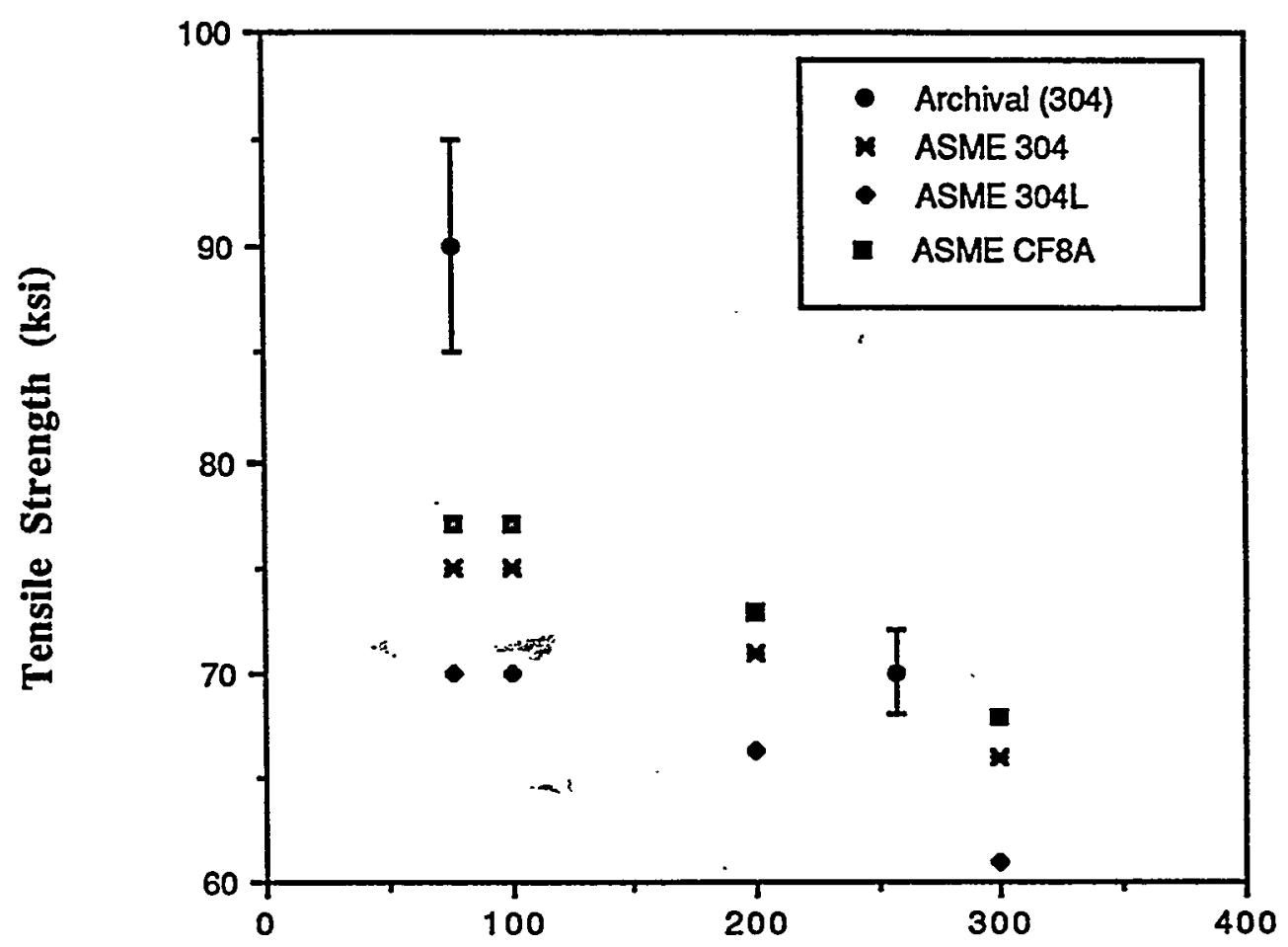

Temperature $\left({ }^{\circ} \mathbf{F}\right)$

Figure 6-3: Archival SRS piping lower bound tensile strength values (Table 5-1) in comparison to the ASME BPV code, Section III, Appendix I, Table I- 2.2 values for Types 304 and 304L piping and CF8A cast material. 


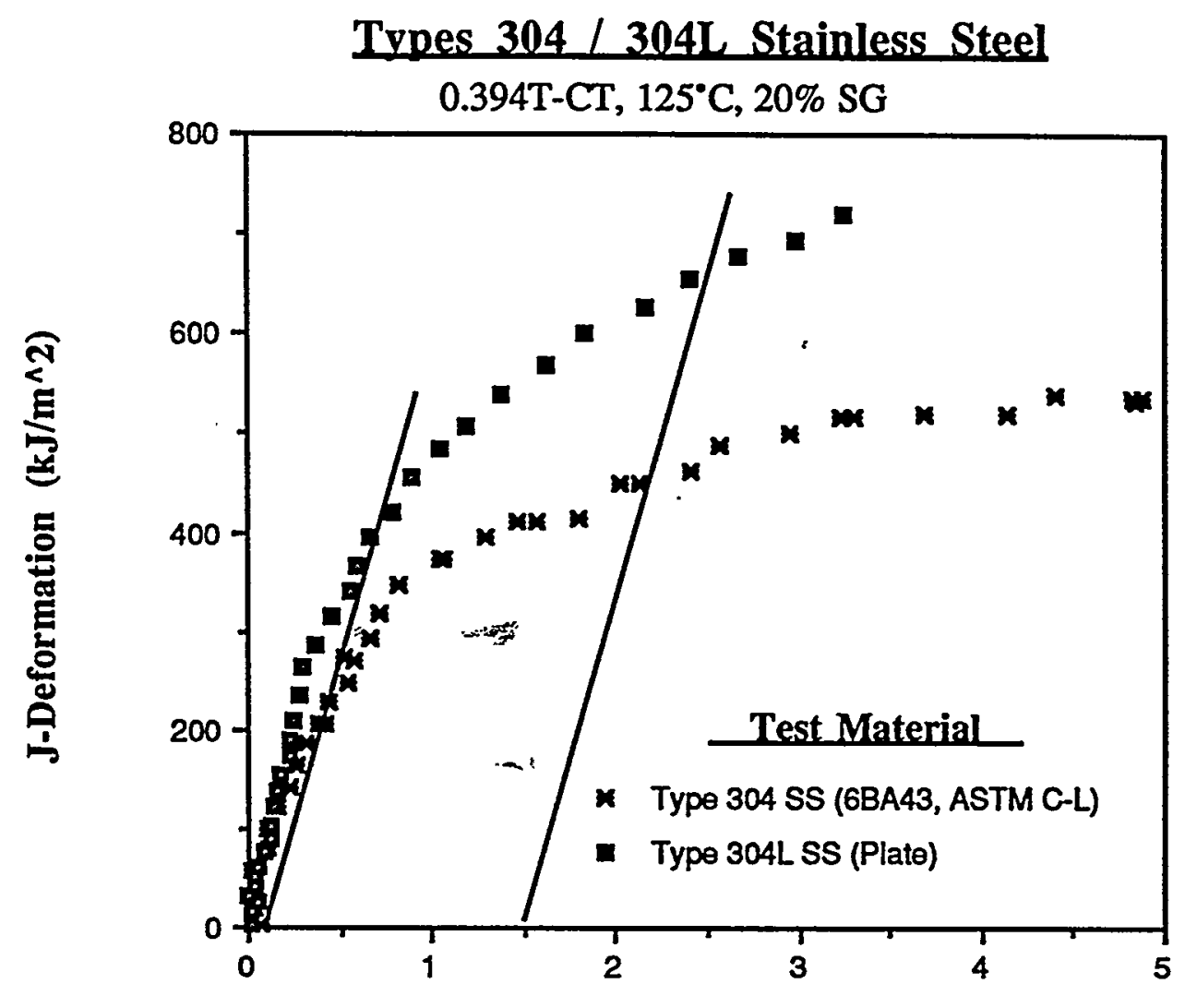

DELTA a (mm)

Figure 6-4: Fracture Toughness Comparison Between Archival Type 304 and F50 Type 304L Stainless Steel Materials.

$$
6-9
$$




\subsection{MEChANICAL PROPERTIES: Application to Piping Fracture Analyses}

\subsection{Introduction}

The materials of fabrication of the SRS piping and piping weldments, Type 304 stainless steel and Type 308 stainless steel filler, respectively, are tough, ductile materials. With increasing load applied to a pre-cracked specimen, the material undergoes significant plastic deformation and crack tip blunting prior to initiation of crack growth by ductile tearing. With this material characteristic, crack growth initiation is followed by stable growth by tearing prior to unstable tearing. Hence, the maximum load that a flawed piping section can carry may be appreciably greater than the load that causes the initiation of flaw growth. Under these conditions, a safety analysis of a degraded component should give explicit consideration to crack tip plasticity and fracture instability after some stable crack growth.

Fracture mechanics can be broadly divided into three general categories, namely linear-elastic (LEFM), elastic-plastic (EPFM), and plastic or limit load analysis. Linear elastic fracture mechanics (LEFM) techniques ignore crack tip plasticity. LEFM methods can take into account a rising crack resistance during stable growth, but its predictions may give misleading estimates of the structure load carrying capability. Clearly, more appropriate fracture techniques are needed to avoid this situation. Several of these approaches have been investigated during the 1970's. Some of these approaches include:

- the J-resistance (J-R) curve (EPFM)

- the crack tip opening angle criterion (EPFM)

- plastic collapse

- other approaches combining features of the above.

\subsection{SRS Piping Fracture Analysis}

A fracture analysis of the SRS piping, applying an ASME-based modified limit load (or plastic collapse) approach, has previously been completed [53-55]. The fracture mechanics approach, termed J-integral based Limit Load Analysis (JiLLA), was used to determine the load capacity of cracked piping and calculate safety margins for postulated flaws in the PWS piping 3 to 24inches in diameter [54,55]. Section 7.2.1 outlines the approach and materials properties applied in the SRS piping fracture analysis as applied in the structural integrity demonstration for the PWS [33].

Section 7.2.2 describes an elastic-plastic fracture mechanics approach for SRS piping. The application of material toughness properties from this testing program to the piping is discussed for the deformation $\mathrm{J}$ material fracture toughness results which bound the modified $\mathrm{J}$ results. The testing results for the modified $\mathrm{J}$ are contained in the final reports by Materials Engineering Associates $[5,56]$.

\subsubsection{Modified Limit Load Analysis: Allowable Flaw Sizes}

The critical crack size for high toughness materials was determined using a net-section plastic - collapse criterion. Plastic collapse failure assumes that at failure the remaining ligament of the cracked section of the pipe is fully plastic prior to any extension of the crack. This criterion implies that the flawed pipe is at the point of incipient failure when the net section in the crack plane first forms a plastic hinge. Failure is assumed to occur at a critical flow stress, $\sigma_{f}$, a 
material tensile property. The flow stress is defined as $\left(\sigma_{\mathrm{y}}+\sigma_{\mathrm{u}}\right) / 2$, where $\sigma_{\mathrm{y}}$ is the 0.2 percent offset yield strength and $\sigma_{\mathrm{u}}$ is the ultimate tensile strength.

The following sections describing the development of flaw evaluation procedures for ductile piping containing either longitudinal or circumferential flaws are abbreviated from the published discussions contained in references $[54,55]$. A margin of safety of three is applied to the normal plus seismic loadings to establish a maximum allowable flaw size. The factor of safety of three on load is required by the ASME code for limit load analyses, and is conservative in this analysis since a modified limit load approach, JiLLA is used [54].

\subsubsection{Flow Stress Evaluation}

The modified limit load approach $[54,55]$ assumes that flow strength at net section collapse is $3 S_{m}$, where $S_{m}$ is the design allowable stress. The basis fór this assumption is a comparison of flow stress determination from experimental results for circumferentially cracked piping and tensile strength properties.

In the work described in Reference 57, tensile test data from plate and piping Type 304 stainless steel materials at elevated temperatures were used to justify use of the empirical approximation:

$\sigma_{f}=1.15\left(\mathrm{~S}_{\mathrm{y}}+\mathrm{S}_{\mathrm{u}}\right) / 2$

to define the flow stress $\left(\sigma_{f}\right)$ as a function of the ASME Code yield $\left(S_{y}\right)$ and ultimate $\left(S_{u}\right)$ strengths for austenitic piping steel [58]:

The mechanical testing of archival Type 304 stainless steel materials has yielded flow stresses values between 60 and $70 \mathrm{ksi}$ (Section 5), conservatively calculated as $\left(S_{y}+S_{u}\right) / 2$. The literature results show that the ASME BPV Code, Section III value for $3 S_{m}$ of $60 \mathrm{ksi}$ is a lower bound to the flow strength calculated for base metal at room temperature, and is a reasonable estimate [53] of the average flow stresses (Section 5) at $125^{\circ} \mathrm{C}$.

\subsubsection{2 - Circumferential Flaw Size Evaluation}

The basis for the flaw evaluation procedure for high toughness austenitic materials has been described previously by Ranganath and co-workers [59] and is based on earlier work by Kanninen et. al. [60]. The relationship between the collapse load and flaw size for a simple crack geometry is obtained by requiring force and moment equilibrium of the pipe section (see Figure 7-2). The crack depth, a, and half angle $\alpha$, at which plastic collapse is predicted is determined from the following equations [60]; for which the neutral axis is located such that $\alpha+$ $B \leq \pi$ :

$$
P_{b}{ }^{\prime}=2 \sigma_{f}[2 \sin \beta-(a / t) \cdot(\sin \alpha)] / \pi
$$

- where

$$
B=\left[(\pi-\alpha a / t)-\left(P_{m} / \sigma_{f}\right) \pi\right] / 2
$$


or if the neutral axis is located such that $\alpha+\beta>\pi$ (assumes crack takes compression), then:

$P_{b}{ }^{\prime}=2 \sigma_{f}[(2-a / t) \cdot \sin B] / \pi$

where,

$B=\pi\left[1-(a / t)-\left(P_{m} / \sigma_{f}\right)\right] /(2-a / t)$

$P_{b}{ }^{\prime}$ in the above equations is equal to:

$P_{b}^{\prime}=\left(P_{b}+P_{m}\right)(S F) M-P_{m}$

where $P_{b}$ and $P_{m}$ are the primary bending and membrane stresses, $S F$ is a safety factor against net section collapse and $M$ is the pipe size multiplier given in Table 3 of ref [54]. $B$ is the angle that defines the location of the neutral axis. The $M$ factor is calculated from an applied $J$ with material Ramberg-Osgood parameters of $a=2$ and $n=5$ [43]. This was based on tensile results from 3BA-83, 3BA-87, 3BB-91, and 3BB-95, which are part of the lower bound tensile data sets (base material, $125^{\circ} \mathrm{C}, \mathrm{L}-\mathrm{C}$ and C-L). Figure II- 1 in Attachment II displays the full specimen data from the lower bound tensile data sets.

Equations (2) and (4) above together define the combinations of $\alpha$ and $\beta$ for which failure by collapse is predicted under the given stresses, $P_{b}$ and $P_{m}$. The flow stress was assumed to be equal to $3 \mathrm{~S}_{\mathrm{m}}$ or $60 \mathrm{ksi}$, as discussed above.

It should be noted that only the stresses due to externally applied loads are considered in evaluating $\mathrm{P}_{\mathrm{b}}$ and $\mathrm{P}_{\mathrm{m}}$. Such loads include pressure, deadweight, thermal and seismic or water hammer. Since thermal loads may result in compressive stresses, multiple loading combinations are used. This combination of both normal operation and accident loading stresses is detailed in Reference 62. The residual stress distributions discussed earlier are excluded from the critical flaw size determination because this stress is relieved at the onset of net-section collapse.

A generic-failure analysis diagram (FAD) is shown in Figure 7-3 [54]. This figure shows schematically, a maximum recommended nondimensional crack depth $(\mathrm{a} / \mathrm{t})$, of approximately $80 \%$ throughwall. This added conservatism was employed, not for safety margin, but for potential interruption in reactor operations because of a throughwall leaking flaw. The recommended $80 \%$ throughwall criteria also accounts for added conservatism due to ultrasonic testing and other uncertainties in predicting throughwall crack growth.

\subsubsection{Longitudinal Flaw Size Evaluation}

The fracture analysis methodology for the SRS piping includes the methodology for axial flaw stability. The incidence of cracking in the SRS piping has been primarily flaws oriented circumferentially. This is due to the fact that intergranular stress corrosion cracking occurs primarily in the sensitized region (heat affected zone) around circumferential welds. All evidence

- supports the conclusion that longitudinal seam welds from SRS's process water piping are solution annealed [63] and would therefore not be subject to IGSCC susceptibiliy. Axial flaws are also not subjected to the bending stresses that dominate the service portions of the loading stresses [62]. 
Short, nominally $<0.5$-inch, axial flaw indications have been detected in the associated HAZ of circumferential butt welds. The fracture analysis for axial flaws, therefore, is included for completeness, to include longitudinal flaws in flame washed areas, and the short axial flaws associated with circumferential butt welds.

An empirical formulation for the hoop stress was developed for pipes with part-throughwall axial flaws [64]:

$$
\sigma_{\mathrm{h}}=\sigma_{f}[(\mathrm{x}-1) /(\mathrm{x}-1 / \mathrm{M})]
$$

where

$$
\begin{aligned}
& M=\left[1+(1.61 / 4 \mathrm{Rt})[2]^{1 / 2}\right. \\
& \mathrm{R}=\text { mean pipe radius } \\
& \mathrm{l}=\text { total axial flaw length (Figure 12) } \\
& \mathrm{t}=\text { pipe wall thickness } \\
& \mathrm{x}=\mathrm{t} / \mathrm{a} . \\
& \mathrm{a}=\text { crack depth }
\end{aligned}
$$

Substututing $\sigma_{f}=3 \mathrm{~S}_{\mathrm{m}}$, and a safety factor (SF), equation (7) is written as:

$$
\sigma_{\mathrm{h}}(\mathrm{SF}) / 3 \mathrm{~S}_{\mathrm{m}}=[(\mathrm{x}-1) /(\mathrm{x}-1 / \mathrm{M})]
$$

Using equation (9), the allowable stress ratio $\sigma_{h} / S_{m}$ can be determined as a function of any specified crack depth and length. The allowable flaw sizes for longitudinal flaws in austenitic piping materials are generated for a margin of 3.0 for normal plus seismic loadings.

Solving for $1 / x($ or $a / t)$ :

$$
\frac{a}{\mathfrak{t}}=\left[\frac{\frac{\sigma_{h}}{S_{m}}-\frac{3}{S F}}{\frac{\sigma_{h}}{S_{m} M}-\frac{3}{S F}}\right]
$$

This equation represents the curve which defines the allowable flaw size for the user specified factor of safety. Net section collapse is given by equation (10), when $S F=1.0$, for part through cracks.

For throughwall cracks the hoop stress at failure [64], is given by:

$$
\sigma_{\mathrm{h}}=\sigma_{f} / \mathrm{M}=3 S_{\mathrm{m}} / \mathrm{M}
$$

Thus, substituting in equation (11) for $M$, the length at which collapse is expected is, 


$$
\mathfrak{C}_{\text {collapse }}^{*}=\frac{\mathfrak{l}}{\sqrt{\mathrm{Rt}}}=\sqrt{\left\{\frac{4\left(\left[\frac{3 \mathrm{~S}_{\mathrm{m}}}{\sigma_{\mathrm{h}}}\right)^{2}-1\right]}{1.61}\right\}}
$$

\subsubsection{Elastic-Plastic Fracture Analysis}

The J-R curves developed in this work serve to define the material toughness for the SRS piping archival Type 304 stainless steel. As demonstrated in Section 6, the fracture toughness (J-R curves) for Type 304L and cast CF-8 materials are equivalent or superior to typical toughnesses for the archival piping. The defined lower bound toughnesses for the archival piping thus bound the material toughnesses for the entire PWS piping materials of construction. The material properties developed herein may therefore be applied in future elastic-plastic analyses of the SRS piping. An elastic-plastic fracture assessment methodology applicable to the SRS piping is discussed next in this chapter.

The elastic-plastic fracture mechanics analysis used to determine instability conditions is based on the J-integral and the associated tearing modulus, $T$, instability criterion $[65,66]$. There are several considerations in the J-T approach to assess flaw stability. The first consideration requires equilibrium between the potential to extend an existing crack, $\mathrm{J}$ applied, and the material resistance to crack extension, $\mathrm{J}$ material. The J-integral is a measure of the elastic-plastic stressstrain field around the crack tip field for any specified crack geometry and loading; the J-integral (J applied) is dependent on the material stress-strain relationship. Expressions for J applied have been developed for various flaw geometries and loadings in structural components [53]. For applied J fracture evaluation, the true stress-strain behavior is characterized in the RambergOsgood format:

$$
\frac{\varepsilon}{\varepsilon_{0}}=\frac{\sigma}{\sigma_{0}}+\alpha\left(\frac{\sigma}{\sigma_{0}}\right)^{\mathrm{n}}
$$

Three region Ramberg-Osgood parameter fits from the tensile test results are contained in Reference 5. A single region set of Ramberg-Osgood values for the lower bound tensile data (base material, $125^{\circ} \mathrm{C}, \mathrm{L}-\mathrm{C}$ and C-L) of $\alpha=2$ and $\mathrm{n}=5$ is shown in the plot of Figure II- 1 of Attachment II.

The J-resistance or J-R curve provides $\mathrm{J}$ material or the material resistance to crack extension. J$R$ curves for each of the $C T$ specimens were generated during the data analysis by MEA. The onset of stable tearing, denoted by $\mathrm{J}_{\mathrm{IC}}$, was calculated from J-deformation formulation. The second consideration in the J-T approach is that proportional loading of the crack tip field must be satisfied during crack growth. The condition for the proportional loading (J-controlled growth) is:

$$
\omega \text { given by }\left(\frac{\mathrm{dJ}}{\mathrm{da}}\right) *\left(\frac{\mathrm{b}}{\mathrm{J}}\right) \gg 1,
$$

where $b$ is the remaining ligament, and $a$ is the crack length. Generally, only small amounts of crack growth are allowed under the strict requirements of J-controlled growth. It has been 
reported that J-controlled growth requirements are satisfied when $\omega$ is greater than 10 [67]. The large (1T) vs. small (0.4T) specimen testing performed in this program (Section 5.5) has -identified a cut-off in the J-R data at $\Delta a=3 \mathrm{~mm}$. Since the crack growth in the large specimen yielded results equivalent to the small specimen up to at least $3 \mathrm{~mm}$, crack extension apparently occurred under J-controlled growth (remaining ligament in the small specimen sufficient to allow J-controlled growth up to $3 \mathrm{~mm}$ ). The $\omega$ at $\Delta \mathrm{a}=3 \mathrm{~mm}$ is 1 (RMP Calculation Set \#91-03, Part 2).

While the previous discussion infers crack growth from the J-R curve of a CT specimen, it does not define stable crack growth in a large structure. Elastic-plastic fracture mechanics analyses are based on correlations between the J-integral crack driving force, which reflects the crack configuration and applied loads, and the crack growth resistance in a given material. An estimation procedure for calculating the $J$ crack driving force for several cracked configurations has been established [68]. The J solutions from complex crack configurations can be calculated using finite element or other numerical analysis methods. By combining the crack driving force solution for a specific crack/structure geometry $\left(\mathrm{J}_{\text {applied }}\right.$ ) with the experimentally determined material J-R curve, it is possible to predict the critical load (or displacement) at which unstable crack propagation occurs. This determines the amount of stable crack growth achievable prior to instability. Specifically, the J-R curve is superimposed on the $J_{\text {applied diagram at the }}$ appropriate initial crack length, $a_{0}$. Equilibrium requires that the $J$ driving force be equal to the material's resistance to crack" growth at each applied load level. Crack instability occurs at the crack length corresponding to the tangency between the applied $J$ and the material $J$ as shown in the diagram at the bottom of Figure 7-1. $\cdots$

This point of instability is expressed by $[65,66]$ :

$\mathrm{J}$ applied $=\mathrm{J}$ material

$\mathrm{T}$ applied $=\mathrm{T}$ material

where $\mathbf{T}$ (nondimensional) is the tearing modulus:

$$
\begin{aligned}
\ldots T_{\text {applied }} & =\frac{E}{\sigma_{0}}\left(\frac{\mathrm{dJ}_{\text {applied }}}{\mathrm{da}}\right) \\
\mathrm{T}_{\text {material }} & =\frac{\mathrm{E}}{\sigma_{\mathrm{o}}}\left(\frac{\mathrm{dJ} \mathrm{J}_{\text {material }}}{\mathrm{da}}\right)
\end{aligned}
$$

and where: $\quad E=$ the elastic modulus, and

$$
\sigma_{0}=\text { flow strength. }
$$

A convenient means to define the margin against instability involves plotting $\mathrm{J}$ versus $\mathrm{T}$ for the applied and material resistance values. A schematic diagram showing crack instability as the intersection of the two curves in given in Figure 7-1. The power-law constants from compact

- tension material J-R data at $125^{\circ} \mathrm{C}$ were averaged and plotted for each material (base, weld and HAZ metal) and specimen orientation (ASTM L-C and C-L) type. Figure 7-4 shows the resultant power-law average curves for crack extension up to 5-millimeters. The power-law average correlates well with the data for crack extension up to about 3-millimeters, as shown in 
Figure 7-5. This deviation of the power-law fit from the J-R curve data at 3-millimeters also correspondes to the limits of J-controlled crack growth, discussed in Section 5-5. Material J-T curves (deformation J) have been generated (Figure 7-6) from the power-law average curves in Figure 7-4 for crack extension between 0.2-millimeter $\left(\approx \mathrm{J}_{\mathrm{IC}}\right)$ and 3-millimeters. .

It is seen in Figure 7-6 that the specimen orientation (ASTM L-C versus C-L) has little effect on toughness for the weld material, but a strong effect in the base and HAZ material. For application to fracture assessment of the piping, the material J-T may be broadly grouped in two sets. The first set contains base (C-L) and HAZ (C-L) material which corresponds to crack extension along the pipe axis or rolling direction of the material. The material toughness designated HAZ (C-L) provides a lower bound toughness for this data set. The second data set contains the remaining J-T material curves in Figure 7-6. The material toughness designated HAZ ( $-C$ - provides a lower bound toughness for this second data set. Attachment II, Figures II-2 and II-3, shows the property average J-R power law formulation for the lower bound material data sets $\left(\mathrm{HAZ}, 125^{\circ} \mathrm{C}, \mathrm{L}-\mathrm{C}\right.$ and $\left.\mathrm{C}-\mathrm{L}\right)$. The data range corresponds to the range of $\mathrm{J}$ controlled crack extension, with the upper range of $\mathrm{J}$ validity taken at the J value at $\Delta \mathrm{a}=3 \mathrm{~mm}$ of crack extension. As discussed in Section 5, the microstructure of the piping containing delta ferrite stringers along the pipe axis, leads to a sensitivity of toughness to test specimen orientation. The marked difference in material toughness between the L-C and C-L orientations should be considered in a flaw stability assessment of the piping. Alternative "cut-off" options are presented schematically in Figure 7-7. 

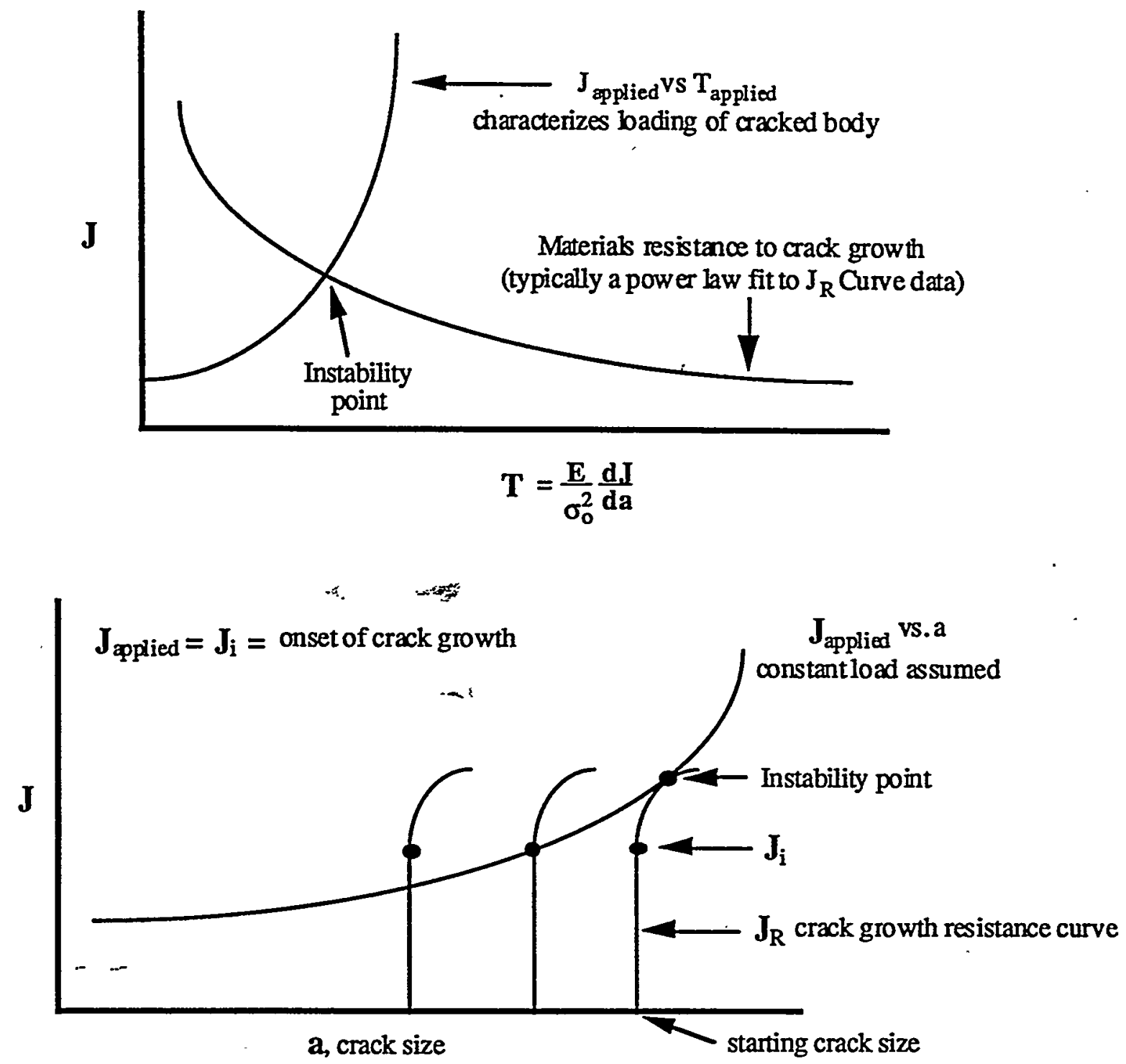

$$
\begin{aligned}
& \text { AT INSTABILITYY } \\
& \mathrm{J}_{\text {applied }}=\mathrm{J}_{\text {material }} \\
& \mathrm{T}_{\text {applied }}=\mathrm{T}_{\text {material }} \\
&\left.\frac{\mathrm{dJ}}{\mathrm{da}}\right|_{\text {applied }}=\left.\frac{\mathrm{d} J}{\mathrm{da}}\right|_{\text {material }}
\end{aligned}
$$

Figure 7-1: Equivalent J-T, J-a Illustrations of Crack Growth Stability [69]. 


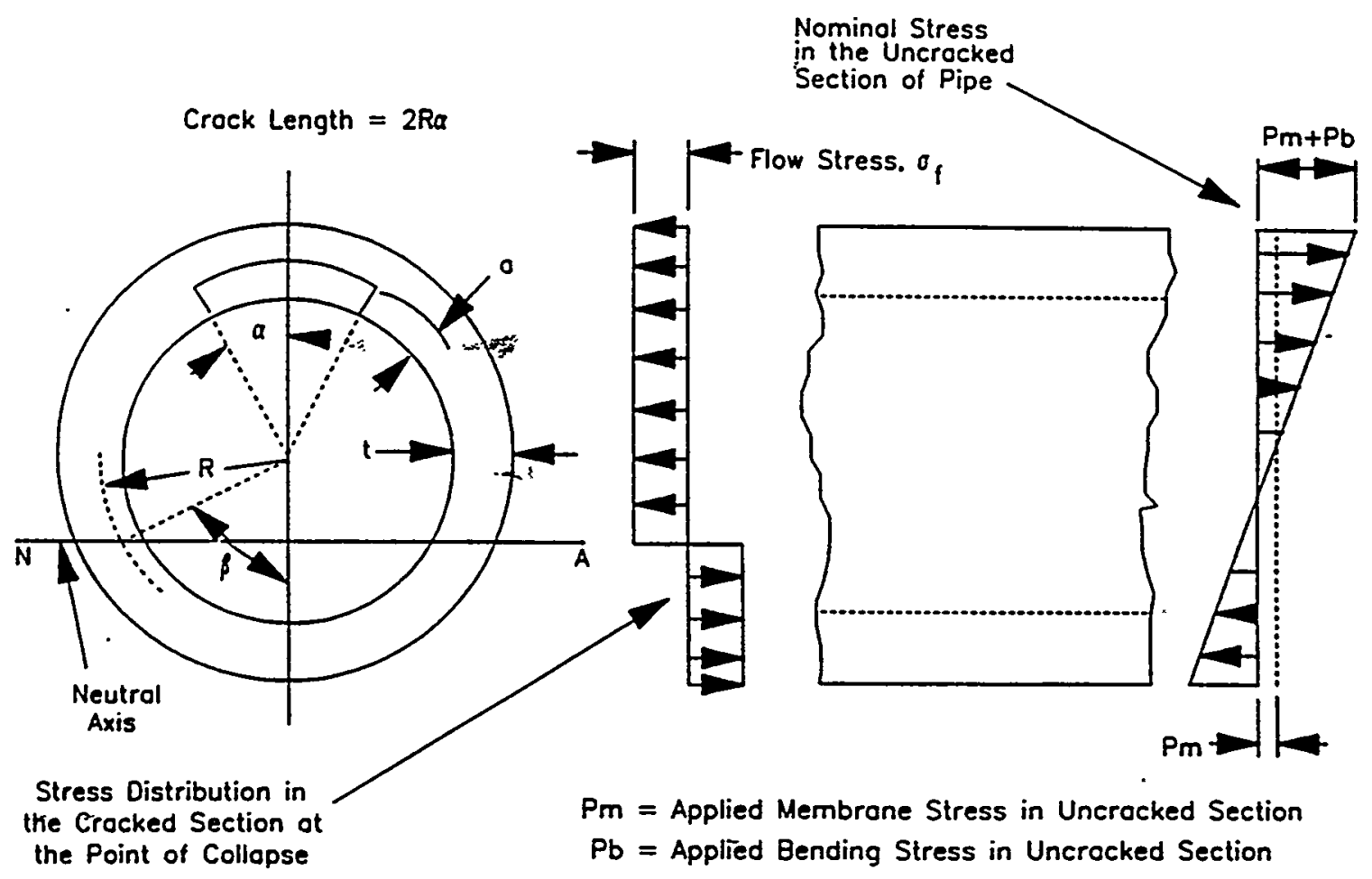

Figure 7-2: Circumferential Surface Flaw Geometry and Assumed Plastic Collapse Stress Distribution 
FAILURE ANALYSIS DIAGRAM

CIRCUMFERENTIAL CRACK GROWTH

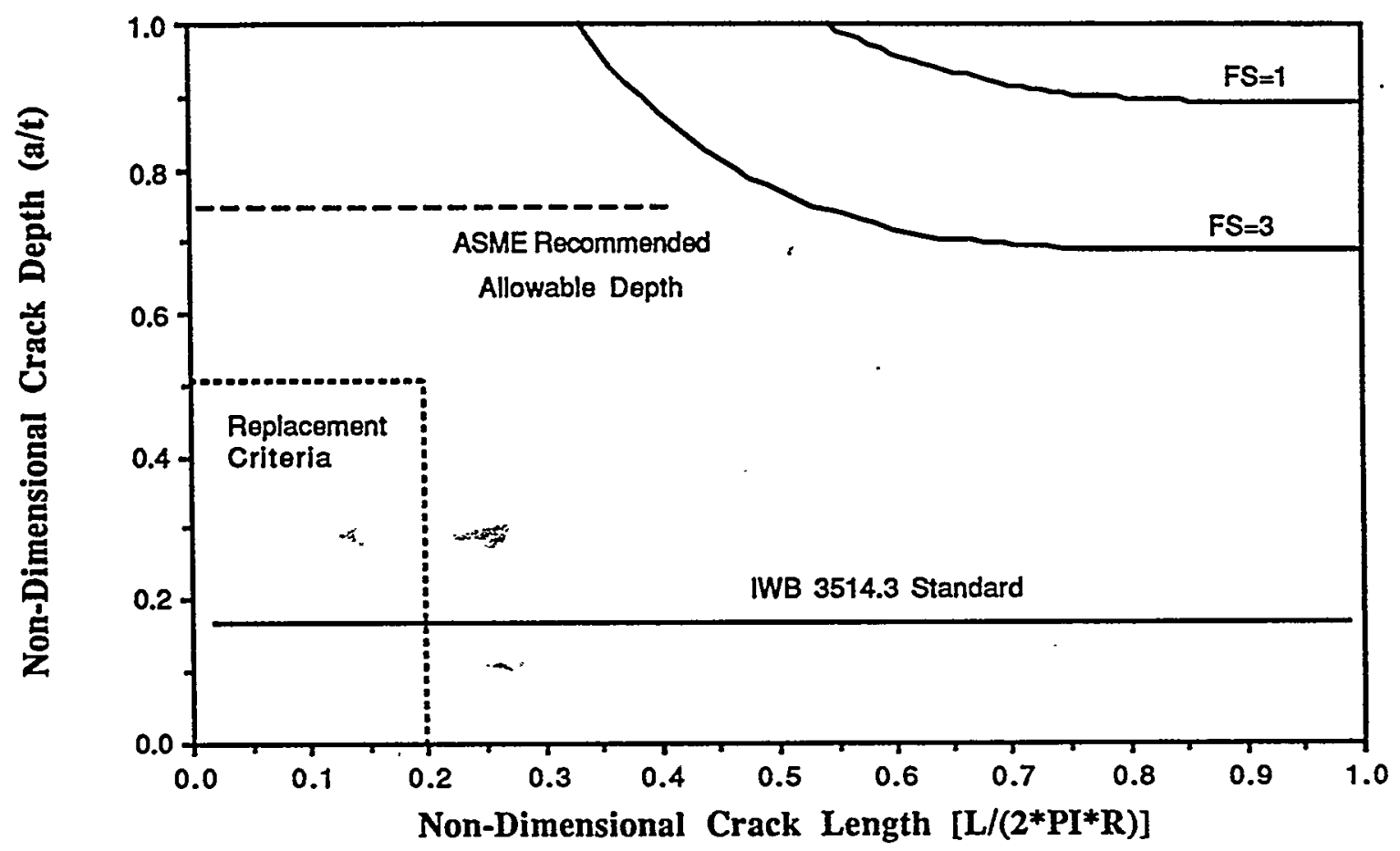

Figure 7-3: Comparison of Typical Computed Allowable Flaw Size with ASME Code Flaw Evaluation Standard, IWB-3514.3 [70] 


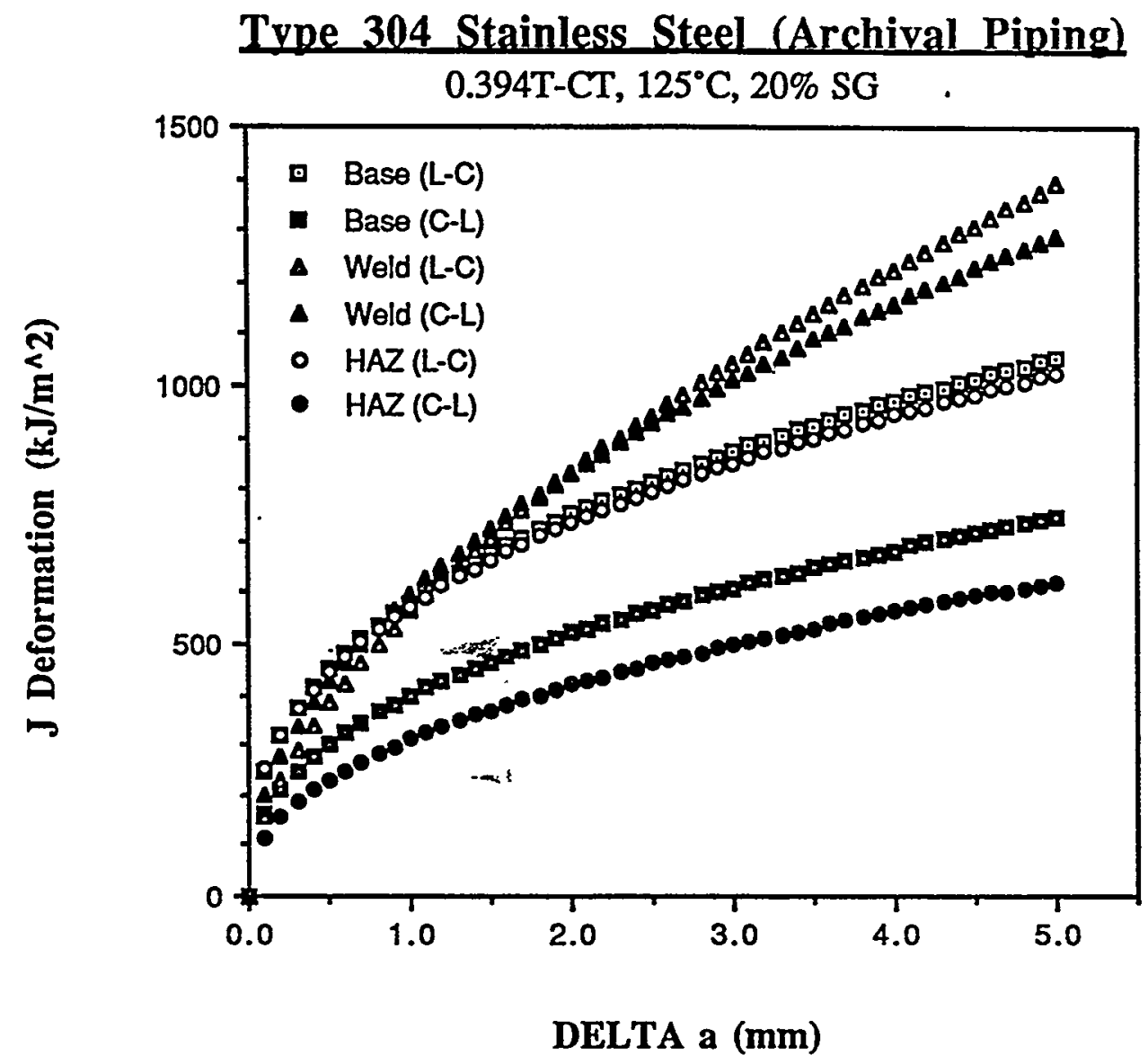

Figure 7-4: Compilation of Mean Material J-R Curves. Plotted from a power-law average of material constants $\left(J=C(\Delta a)^{n}\right)$. 


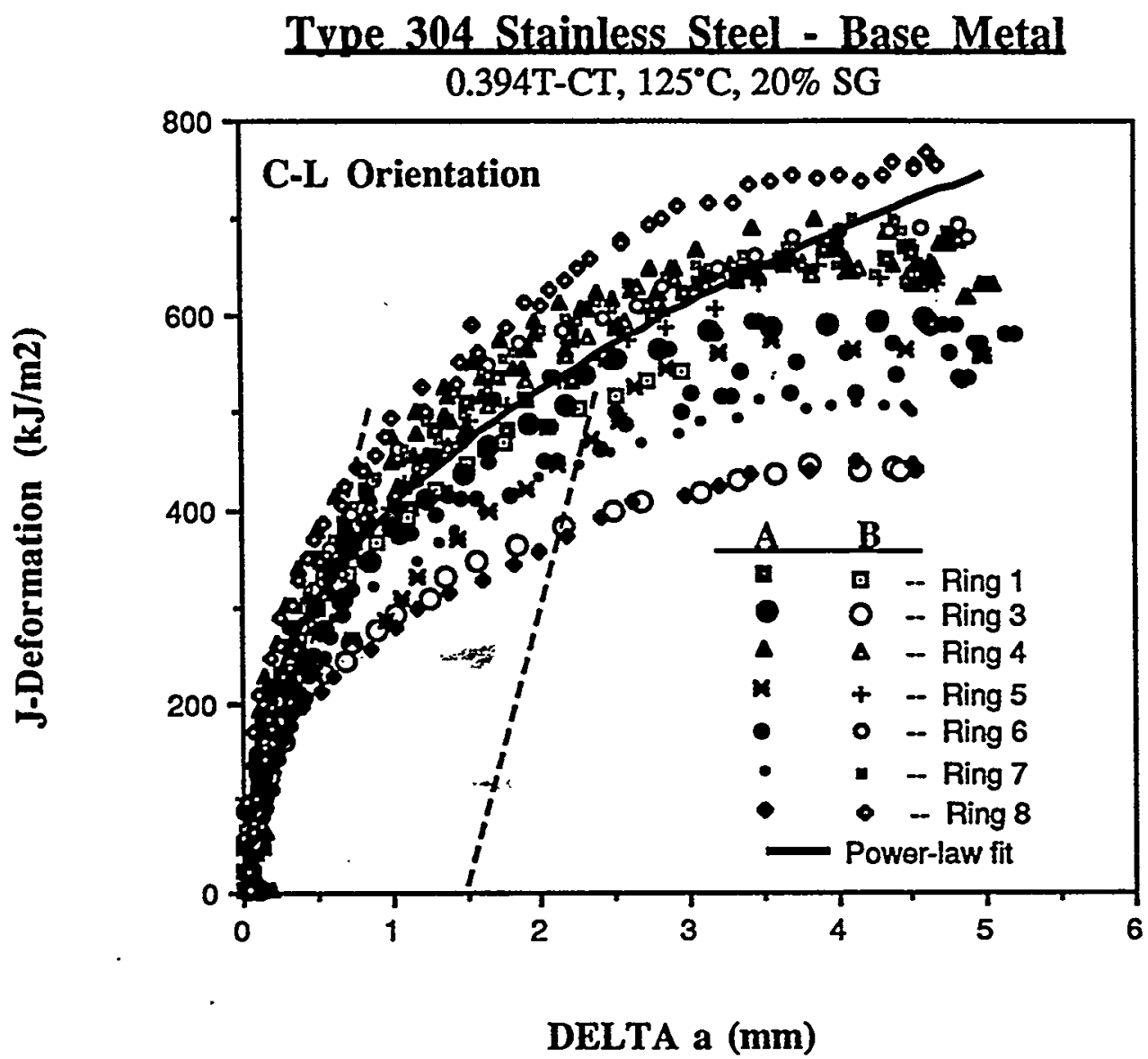

Figure 7-5: Comparison of the power-law average J-R curve (average $C, n$ parameters from the data set) to the J-R curves from the constituent specimens of the data set. Note deviation of powerlaw average curve from the individual curves at $\approx 3$-millimeters. 


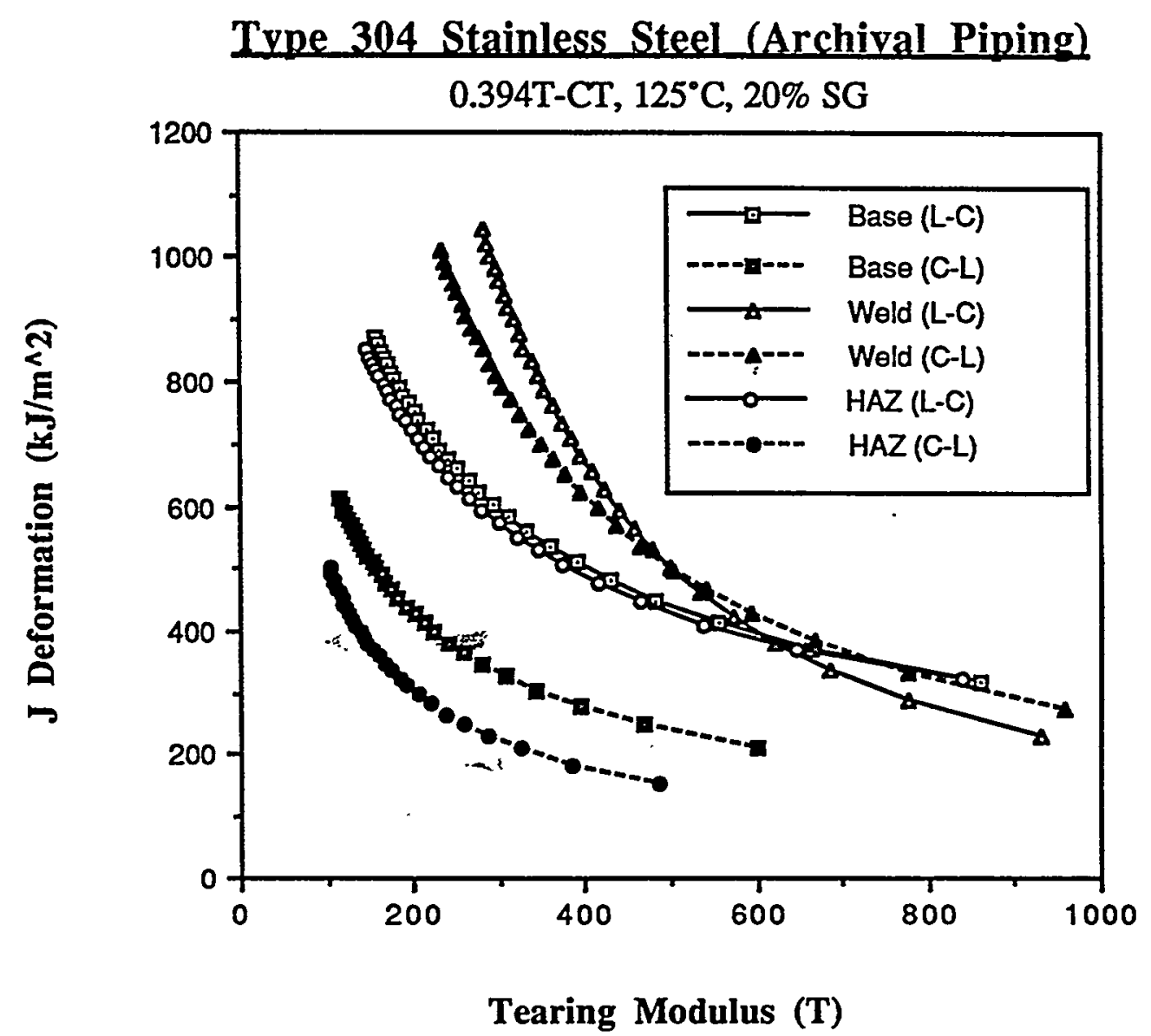

Figure 7-6: Compilation of Mean Material J-T Curves.

HAZ material data bound the data set for each ASTM test direction. 


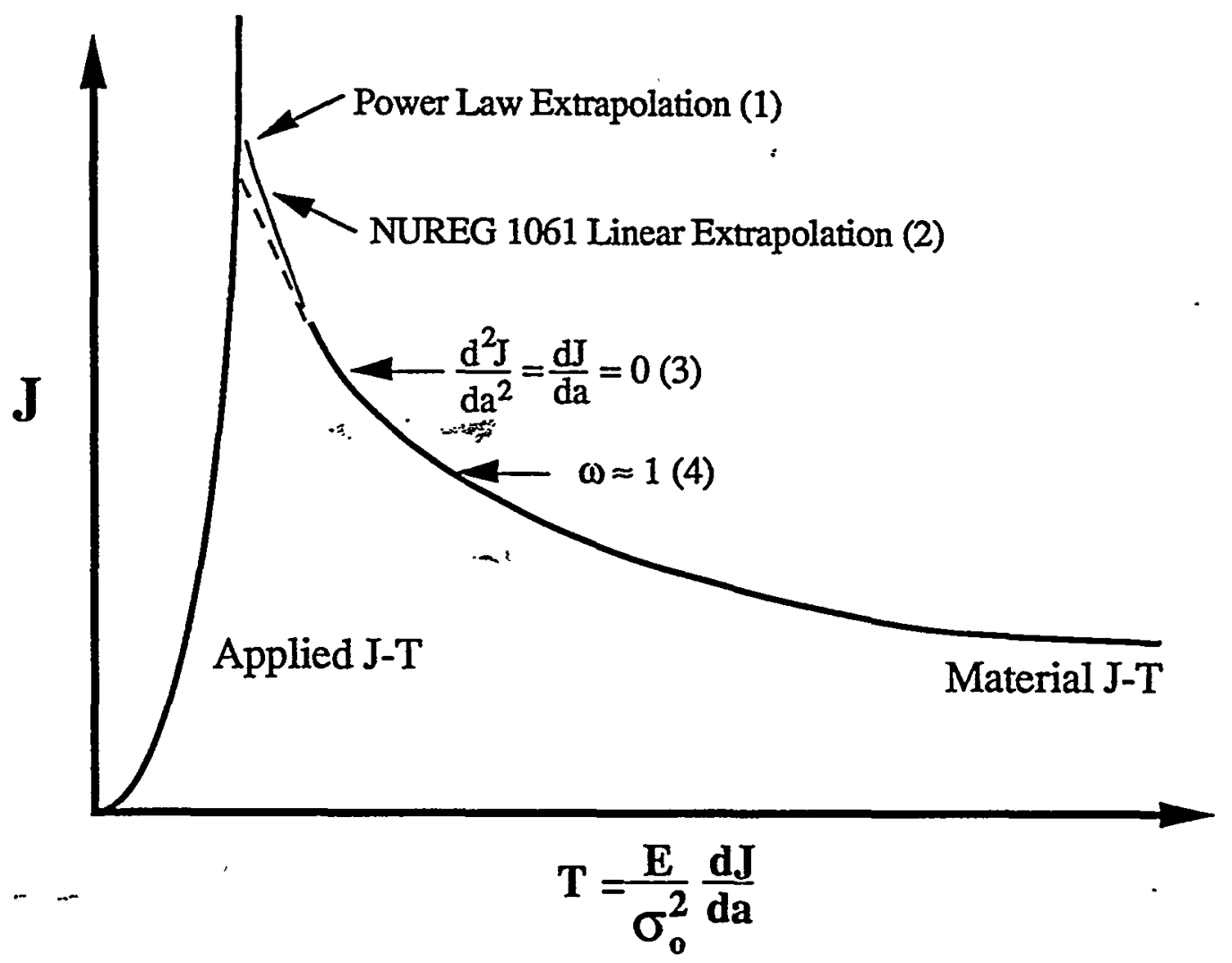

Figure 7-7: J-T Curve "Cut-off" Options to define instability:

(1) Power-law extrapolation of the material J-T curve to intersect the applied J-T curve;

(2) Linear extrapolation of the material J-T curve to intersect the applied J-T curve;

(3) Horizontal cut-off at $d^{2} J /(d a)^{2}=d J / d a=0$; and

- (4) Horizontal cut-off at $\omega=1$ (recommended, see Section 5-5). 


\subsection{CORRELATION OF NOTCH DUCTILITY (CHARPY V-Notch Absorbed Energy) and FRACTURE TOUGHNESS PARAMENTERS}

\subsection{Overview}

For structural safety analysis, evaluation of critical flaw size and stress level relationships requires knowledge of the fracture toughness (KIc or the J-R curve) of the constituent materials. For tough, ductile behavior typical of the SRS stainless steel piping materials, the J-R curve provides an appropriate characterization of the materials' fracture toughness.

Historically, material "toughness" characterization has been accomplished through impact testing of $\mathrm{C}_{\mathrm{v}}$ specimens. However, $\mathrm{C}_{\mathrm{v}}$ tests do not provide information for direct assessment of flaw stability. Recent work by MEA for the Electric Power Research Institute (EPRI) resulted in correlations of J-R curve data versus $C_{V}$ data, specifically the Charpy upper shelf energy $\left(C_{V}\right.$ USE) level metals and weld metals typically used for the pressure vessels of commercial nuclear power reactors (RPV's) [5]. To apply the MEA correlations, the user first establishes a $C_{V}$ USE level. The correlations then provide temperature-dependent equations for the parameters " $\mathrm{C}$ " and " $n$," used in the power-law representation of the J-R curve as described previously in Section 4.1. The correlations are under consideration by the American Society of Mechanical Engineers (ASME) Section XI "Working Group on Flaw Evaluation."

Data for austenitic stainless steels generally are sparse, making a similar correlation attempt more difficult. The present study, however provides several sets of $J-R$ curves with matching $C_{v}$ data. These data sets represent different combinations of steel melt, orientation and test temperature.

\subsection{Results}

The available data appear to describe a trend of increasing $\mathrm{J}_{\mathrm{Ic}}$ with increasing $\mathrm{C}_{\mathrm{v}}$ energy absorption (see Figure 8-1). Figure 8-1 shows this general trend for base, weld and heat-affected-zone materials, with the weld and $\mathrm{HAZ}$ material concentrating in the lower portion of the curve. In Figure $8-2$, the data are grouped by test temperature $\left(25\right.$ or $\left.125^{\circ} \mathrm{C}\right)$. For this arrangement of the data, two trends are observed. The 25 and $125^{\circ} \mathrm{C}$ test data have respectively the following correlations:

$$
\begin{aligned}
& \mathrm{J}_{\mathrm{Ic}}=-6+\mathrm{C}_{\mathrm{V}} \\
& \mathrm{J}_{\mathrm{Ic}}=12+\mathrm{C}_{\mathrm{V}}
\end{aligned}
$$

For the fracture toughness parameter, $\mathrm{T}_{\mathrm{avg}}$, the data again show a trend, with a slight increase in $\mathrm{T}_{\mathrm{avg}}$ with an increase in $\mathrm{C}_{\mathrm{v}}$ energy. This trend, although not as pronounced as the previous correlation, is shown in Figure 8-3.

Additional correlations have been explored by MEA that relate the slope of the J-R curve (dJ/da) to the charpy energy level [5]. The resultant correlations, although limited, do show the expected trend of decreasing $\mathrm{J}$ and $\mathrm{dJ} / \mathrm{da}$ levels with increasing temperature.

- An additional correlation was performed to relate the area under the J-R curve to the $C_{V}$ energy. This study calculated the area under an average J-R curve, using the power-law parameter data from Appendix I. The resultant curve, shown in Figure 8-4, shows reasonable trends for 
weldment components tested in the C-L direction, while little effect of $\mathrm{C}_{\mathrm{v}}$ energy on J-R curve area is observed for L-C test specimens.

\subsection{Conclusions}

The correlations between the Charpy V-notch toughness and J-R curve parameters were developed in this chapter as a preliminary study. Although the results of the above correlations are still preliminary, they do show the expected trend of increasing fracture resistance with increasing $\mathrm{C}_{\mathrm{V}}$ energy level. Additional correlation analyses will be performed with the complete data set of baseline and irradiated mechanical properties from the RMP testing programs [2]. 


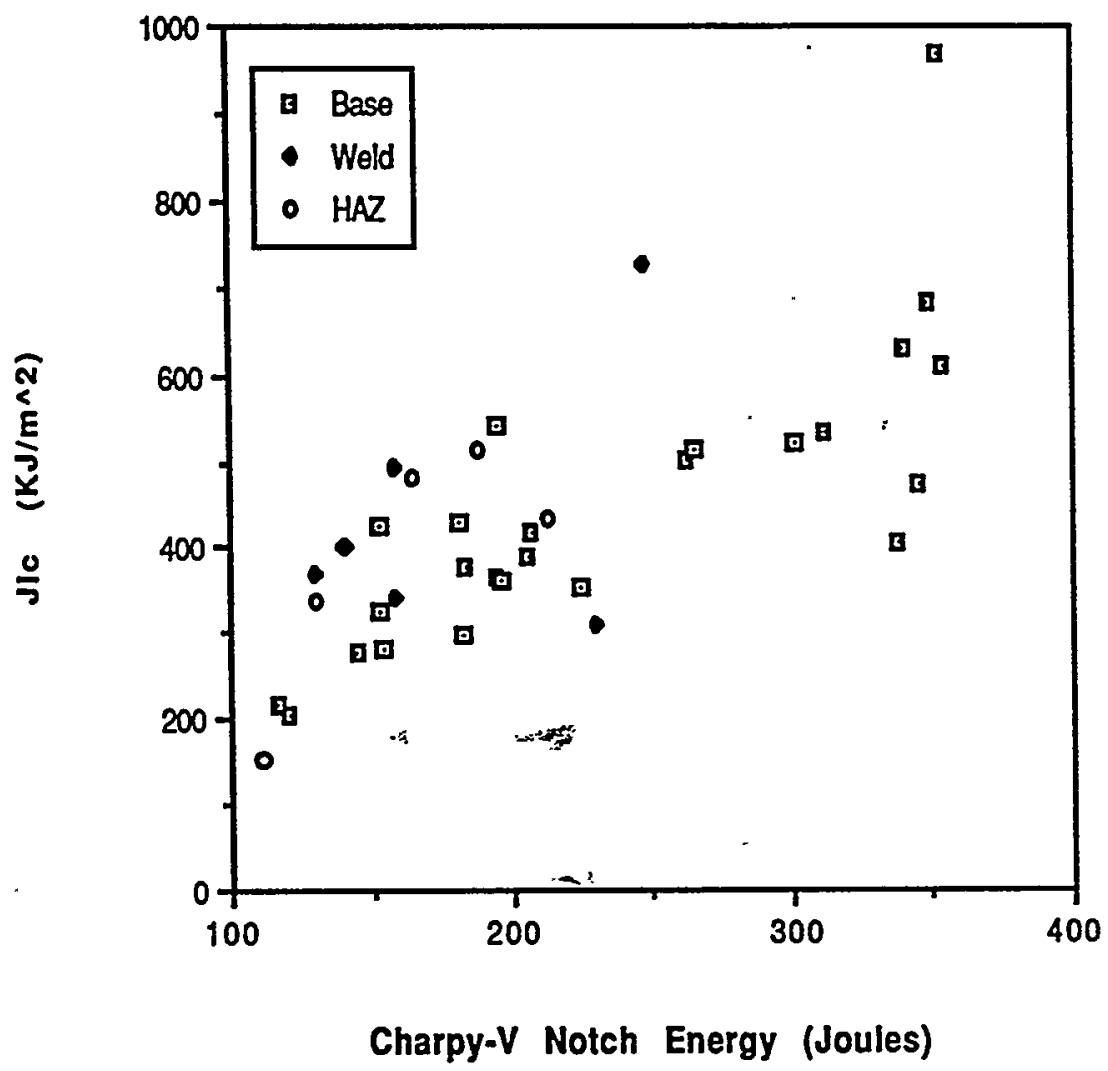

Figure 8-1: Variation of $\mathrm{J}_{\mathrm{Ic}}$ (static tests - Deformation) with $\mathrm{C}_{\mathrm{V}}$ energy for base, weld and HAZ metals. 


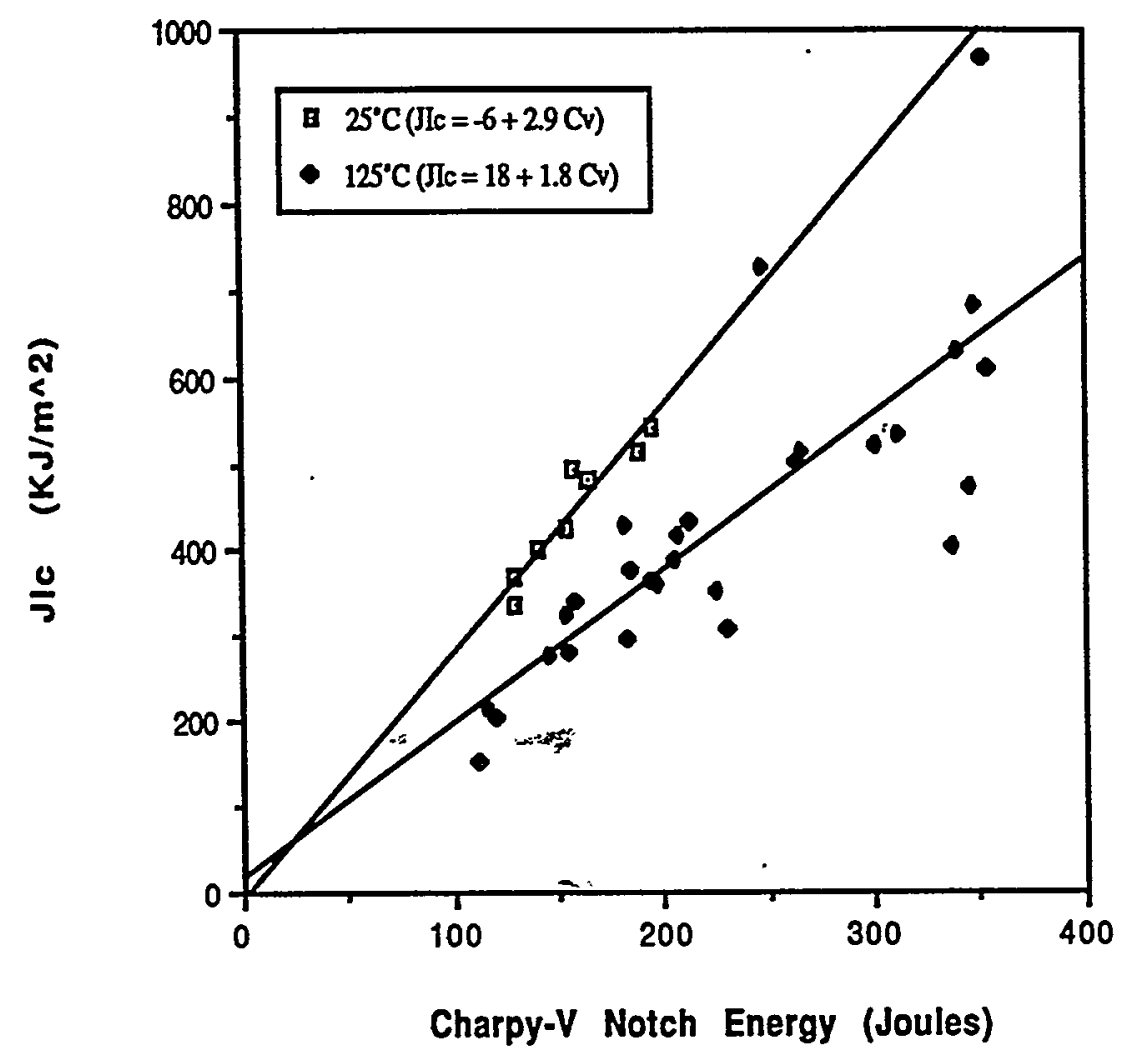

- Figure 8-2: Variation of $\mathrm{J}_{\mathrm{IC}}$ (static tests - Deformation) with $\mathrm{C}_{\mathrm{v}}$ energy for base, weld and HAZ metals, showing effect of test temperature. 


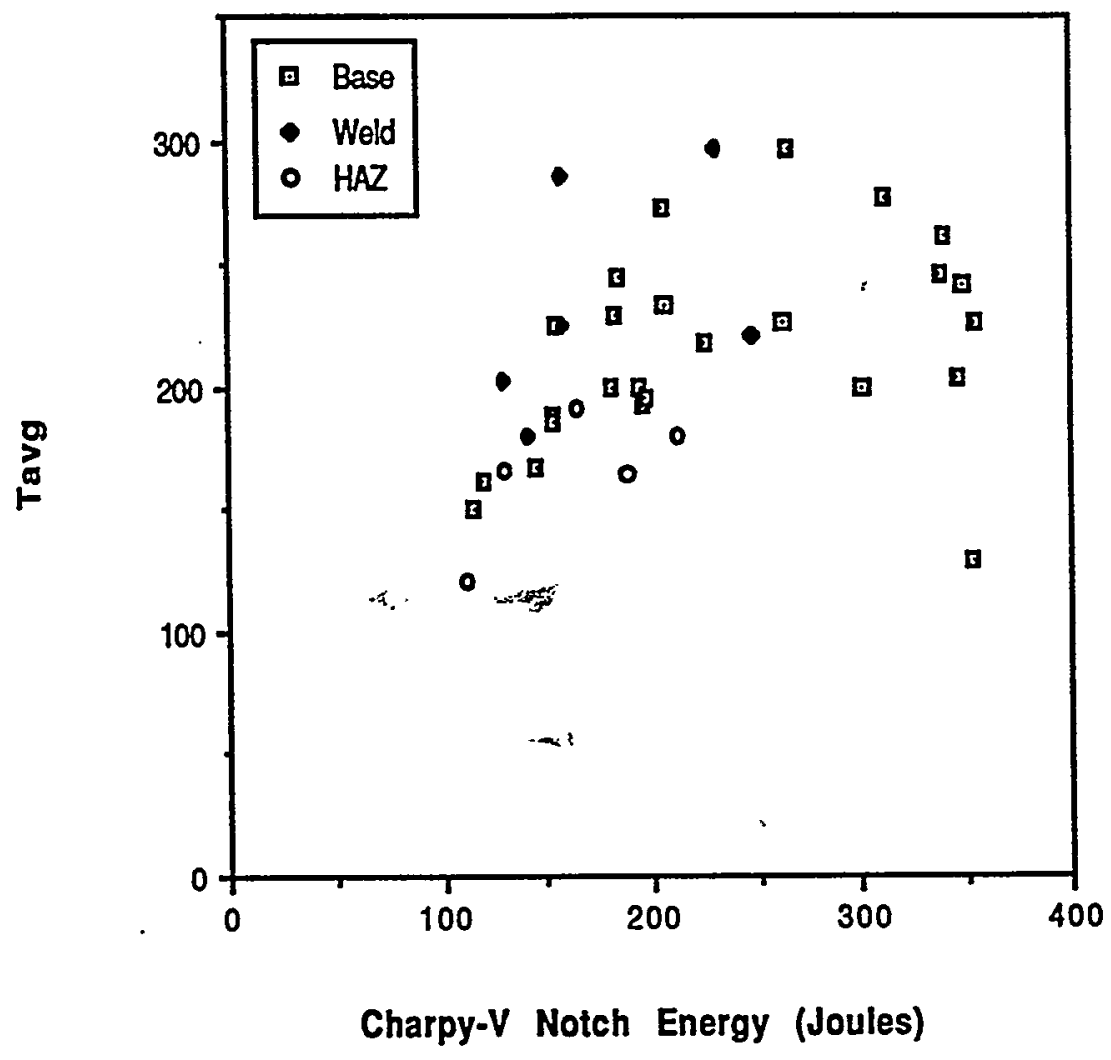

Figure 8-3: Variation of $T_{\text {avg }}$ (static tests - Deformation) with $C_{v}$ energy for base, weld and $\mathrm{HAZ}$ metals. 


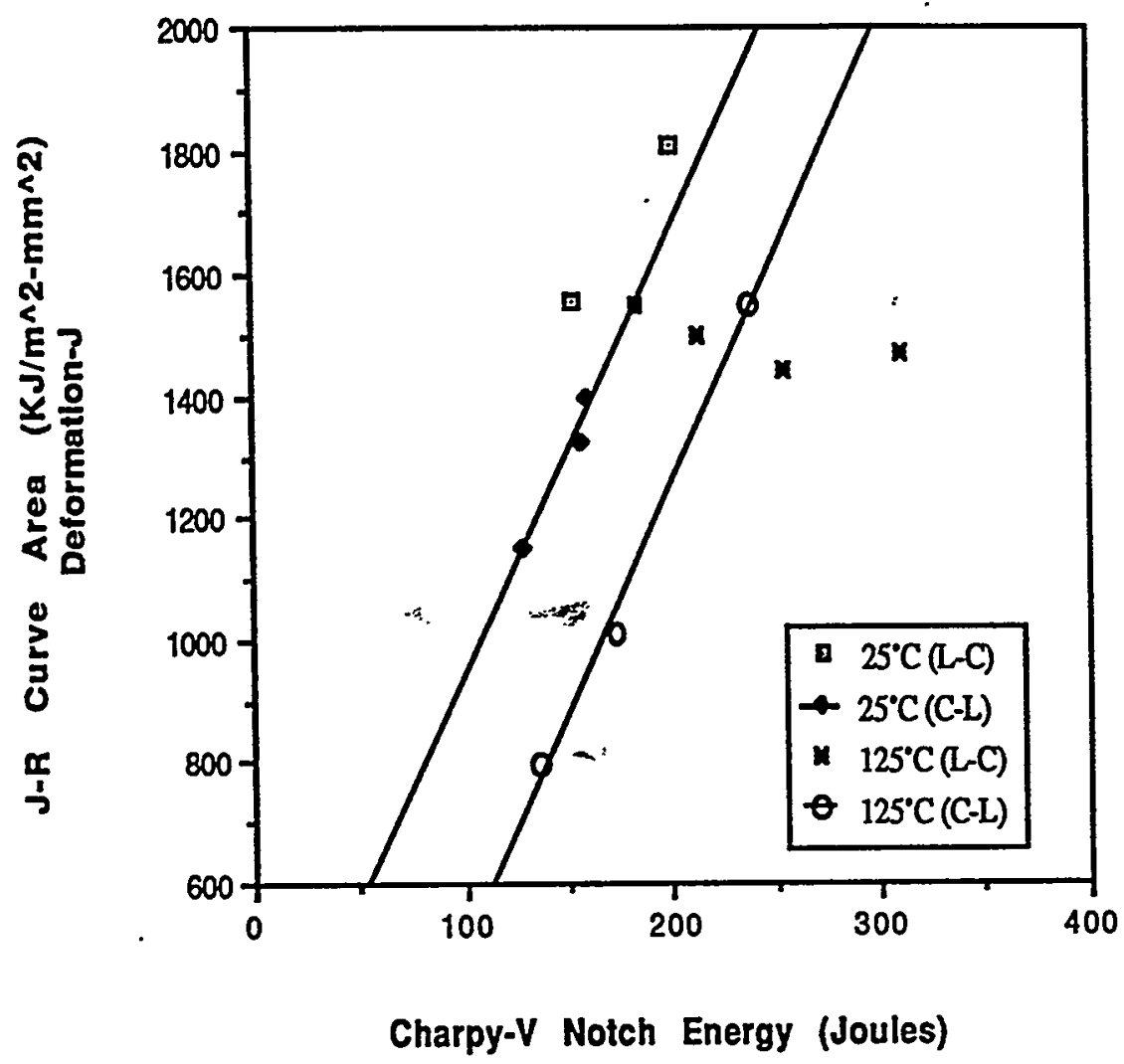

Figure 8-4: Variation in area under J-R curve (static tests - Deformation) with $\mathrm{C}_{\mathrm{V}}$ energy for base, weld and HAZ metals.

) 


\subsection{FUTURE STUDIES}

\section{CONFIRMATORY MECHANICAL TESTING PROGRAM}

Confirmatory testing (tensile and compact tension) of archival cast (CF8) materials will be done in both the static and dynamic loading conditions for comparison to literature cast mechanical results and the archival Type 304 results (see Section 5 and 6) [2].

\section{MICROSTRUCTURAL ANALYSIS AND PROPERTY CORRELATION}

A complete metallographic characterization of all melts and weldment components is planned [2]. This study will macroscopically characterize each of the alloy melts, and identify and quantify any second phase precipitates (inclusions). As discussed above, it is postulated that these inclusions strongly effect the fracture behavior of the material specimens. The results will be applied to further analyze the mechanical property variance observed in both the non-irradiated and irradiated tests. Finally, this study will provide a qualitative picture of the variability of thermomechanical processing techniques used in the 1950's manufacture of Type 304 stainless steel weldment components [2].

\section{FUSION LINE TOUGHNESS EVALEATION}

Fracture toughness testing of compact tension specimens with the notch plane machined bisecting the HAZ / weld fusion line is planned [2]. Several 0.394T-CT's will be tested in the unsidegrooved condition to investigate the weld fusion line toughness [2]. 


\subsection{REFERENCES}

1. N.G. Awadalla, et. al., "Reactor Materials Program," DPST-84-820, December 1984.

2. Savannah River Laboratory, Nuclear Reactor Technology and Scientific Computations Department, Task Technical Plan 89-023-1, Reactor Materials Program Action Plan, December 1990.

3. Reactor Materials Program, "Specification for Sample Preparation, Irradiation and Testing," June 25, 1984.

4. Reactor Materials Program, "Specification for Parametric Study of Fracture Resistance and Welding Variables of Irradiated Type 304 Stainless Steel, Rev. 2," September 1, 1989.

5. J.R. Hawthorne, et. al., "Sample Preparation, Irradiation, and Testing of 304 Stainless Steel Specimens," Materials Engineering Associates Report \# MEA 2221, August 1987.

6. Site Specification 4482, "Process and Service Piping P-Code P45 and P46."

7. R.L. Sindelar, "Reactor Materials" Program - Irradiated Mechanical Properties of Types 304 and 304L Stainless Steel (U)," WSRC-TR-91-11, to be issued.

8. K.J. Stoner, "Reactor Materials Program - Materials Source History for Type 304 Stainless Steel Testing Program," DPST-88-1010, December 1988.

9. W.L. Daugherty, "Process Water System Temperatures and Pressures," SRL-EDG890119, October 13, 1989.

10. ASTM Handbook A813/A813M-88a, Standard Specification for Single- or Double-Welded Austenitic Stainless Steel Pipe, A01.10, 1989.

11. P. Marshall, Austenitic Stainless Steels - Microstructure and Mechanical Properties, Elsevier Publishing Co., 1984.

12. E.F. Nipples, "Metals Handbook, Ninth Edition, Volume 6 - Welding, Brazing, and Soldering," American Society for Metals, 1982.

13. "Specification for Corrosion Resisting Chromium and Chromium-Nickel Steel Bare and Composite Metal Cored and Stranded Welding Electrodes and Welding Rods," ANSI / AWS A5.9-81, American Welding Society Standard, October 1981.

14. Memorandum, K. J. Stoner to J. M. Stone, "Types 308 and 312 Weld Filler Metals," SRL-EDG-90-0142, April 27, 1990.

15. A. Saxena, S. J. Hudak, Jr., "Review and Extension of Compliance Information for Common Crack Growth Specimens," International Journal of Fracture, Vol. 14, No. 5, Oct. 1978, pp. 453-468.

16. F.J. Loss, B.H. Menke and R.A. Gray, Jr., "Development of J-R Curve Procedures," in NRL-EPRI Research Program (RP 886-2), Evaluation and Prediction of Neutron 
Embrittlement in Reactor Pressure Vessel Materials Annual Progress Report for CY 1978, J.R. Hawthorne, Ed., NRL Report 8327, Naval Research Laboratory, Washington, DC, Aug. 1979.

17. H.A. Ernst, "Material Resistance and Instability Beyond J-Controlled Crack Growth," Elastic-Plastic Fracture: Second Symposium, Vol. I: Inelastic Crack Analysis, ASTM STP 803, American Society for Testing and Materials, Philadelphia, PA 1983.

18. ASTM Standard E 399-83, " Standard Test Method for Plane-Strain Fracture Toughness of Metallic Materials."

19. ASTM Standard E 813-81, "Standard Test Method for J $\mathrm{I}_{\text {Ic, }}$ A Measure of Fracture Toughness," (note: current spec. E 813-88).

20. ASTM Standard E 1152-87, "Standard Test Method for Determining J-R Curves."

21. A.L. Hiser, F.J. Loss and N.H. Menke, "J-R Curve Characterization of Irradiated Low Upper Shelf Welds," USNRC Report NUREG / CR-3506, Apr. 1984.

22. H.H. Johnson, "Calibrating the Electric Potential Method for Studying Slow Crack Growth," Materials Research Standards, Vol. 5(9), Sept. 1965, pp. 442-445.

23. G.M. Wilkowski and W.A. Maxey, "Review and Applications of the Electric Potential Method for Measuring Crack Growth in Specimens, Flawed Pipes, and Pressure Vessels," Fracture Mechanics: Fourteenth Symposium -- Vol. II: Testing and Applisations, ASTM STP 791, J. C. Lewis and G. Sines, Eds., American Society for Testing and Materials, 1983.

24. P.W. Bridgman, Trans. Am. Soc. Met., Volume 32, 1944, p. 553.

25. J.R. Hawthorne, "Sample Preparation, Irradiation, and Testing of 304 Stainless Steel Specimen -- Monthly Report for Period Ending May 15, 1986," MEA-2162, May 29, 1986.

26. A.L. Hiser and F.J. Loss, "Alternative Procedures for J-R Curve Determination," USNRC Report NUREG/CR-3402, July 1983.

27. J.E. Freund, "Statistics: A First Course," 2nd Edition, Englewood Cliffs N.J., Prentice Hall, Inc., 1976.

28. W.J. Mills, "Effect of Specimen Size on the Fracture Toughness of Type 304 Stainless Steel - Interim Report," HEDL-TME 81-52, February 1982.

29. J.R. Hawthorne, et. al., "Sample Preparation, Irradiation, and Testing of 304 Stainless Steel Specimens," Materials Engineering Associates Report MEA-85-39.

30. J R. Hawthorne, et. al., "Sample Preparation, Irradiation, and Testing of 304 Stainless Steel Specimens," Materials Engineering Associates Report MEA-86-05.

31. P. Shahinian, Naval Research Laboratory, "Influence of Section Thickness on Fatigue Crack Growth in Type 304 Stainless Steel," Nuclear Technology, Vol. 30, September 1976. 
32. J.B. Elder to K.J. Stoner, "Update of Pipe Replacement Locations for P, K \& L Reactors (U)," EPD-QCM-910032, January 10, 1991.

33. N.G. Awadalla, et. al., "Structural Integrity of-the Process Water System (PWS of the Savannah River Site Production Reactors (U)," WSRC-RP-90-559, June 30, 1990.

34. K.R. O'Kula, "Off-site Irradiation Program in Support of the SRP Reactor Service Life Investigation," DPST-84-551, June 1984.

35. R.L. Sindelar, G.A. Abramczyk and K.R. O'Kula, "Selection of HFIR Specimens for SRP Reactor Materials Program," DPST-86-418, April 1987.

36. D.S. Cramer, "SRP Irradiation Program in Support of:the SRP Reactor Materials Program," DPST-84-811, December 1984.

37. G.A. Abramczyk, "Selection of SRP Surveillance Specimens for Reactor Materials Program," DPST-85-902, December 1985.

38. J.K. Thomas, "Reactor Materials Program - K-Reactor Surveillance Capsule Specimens," SRL-EDG-90-0114, April 1990.

39. V.K. Sikka and M.K. Booker, In "Effects of Melting and Processing Variables on the Mechanical Properties of Steel," ed. by G.V. Smith, MPC-6, New York, ASME, 1977, pp. 256-273.

40. C.R. Brinkman, V.K. Sikka and R.T. King, Nucl. Technology, Vol. 33, 1977.

41. Metal Progress, "1985 Materials Processing Databooked. by D.F. Baxter, Jr., Vol. 128, No. 1, June 1985.

42. ASME B31.1, "American Society of Mechanical Engineers - Power Piping Code," 1989 Edition.

43. ASME B31.3, "American Society of Mechanical Engineers - Power Piping Code," 1990 Edition.

44. S.T. Rolfe and J.M. Barsom, "Fracture and Fatigue Control in Structures - Applications of Fracture Mechanics," Prentice-Hall, Inc.,1977.

45. D.D. Sousa and R.L. Sindelar, "Reactor Materials Program - LOCA Definition Project Response to Review Questions (U), Task Number: 89-036-1," Question ECS-LOCA-03, \#6, WSRC-RP-90-92, November 16, 1990.

46. E.R. Hartman, "Evaluation of LBB Capability of Large Pipe Castings in Reactor Process Water System," DPST-88-571, July 1988.

- 47. D.D. Sousa and R.L. Sindelar, "Reactor Materials Program - LOCA Definition Project Response to Review Qúestions (U), Task Number: 89-036-1,". Question ECS-LOCA-34, \#'s 1, 2 \& 3, WSRC-RP-90-92, November 16, 1990. 
48: J.D. Landes, "Size and Geometry Effects on Elastic Plastic Fracture Characterization," in CSNI Specialist Meeting on Plastic Tearing Instability, NUREG/CP-0010, CSNI Report No. 39 , p. 215.

49: M.F. Kanninen, et. al., "Instability Predictions of Circumferentially Cracked Type 304 Stainless Steel Pipes Under Dynamic Loading," EPRI NP-2347, 1982.

50: Yagawa, et. al., "Theoretical and Experimental Study on Unstable Fracture for Type 304 Stainless Steel Plates with a Soft Tensile Machine," NEUT 81-04.

51: A. Zahoor, et. al., ASME Paper 80-WA/PVP-3, November 1980.

52: M.G. Vassilarus, R.A. Hays, and J.P. Gudas, Volume 4, "Investigation of the Ductile Fracture Properties of Type 304 Plate, Welds, and Four Inch Pipe," NUREG/CP-0058, 1984.

53. N.G. Awadalla, et. al., "Reactor Materials Program - Leak-Before-Break Evaluation of Weldments, Reactor Process Water System," DPST-87-837, Attachment 1, November 1987.

54. K.J. Stoner, "Replacement Criteria for the Savannah River Reactor Process Water System Piping (U)," SRL-EDG-890149;Attachment 2 to WSRC-RP-90-91, February 1990.

55. G.E. Mertz and K.J. Stoner, "Reactor Materials Program Leak-Before-Break Margins for the Process Water System (U)," SRL-EDG-890151, Attachment 4 to WSRC-RP-90-91.

56. A.L. Hiser and J.R. Hawthorne, "Baseline Tests $\left(125^{\circ} \mathrm{C}\right)$ of Type 304 Stainless Steel Piping Materials From Project 1101," MEA-2345, May 1989.

57. "Evaluation of Flaws in Austenitic Piping," Journal of Pressure Vessel Technology, Transactions of the ASME, Vol. 108, August 1986, pp. 352-366.

58. ASME Boiler and Pressure Vessel Code, Section III, "Rules for Construction of Nuclear Power Plant Components; Division 1 - Subsection NB Class 1 Components," through 1987 Addeñdum.

59. "First Topical Report, Stress Corrosion- Fracture Assessment Program, Part II Fracture Assessment, Contract AX-681981," SASR-86-02, Rev. 1, General Electric, March 1986.

60. M.F. Kanninen, et. al., "Toward an Elastic Plastic Fracture Mechanics Predictive Capability for Reactor Piping," Nuclear Engineering and Design, Vol. 48, 1978, pp. 117-134.

61. G.L. Stevens, "SRSCRACK' Computer Program Users Manual," SASR-89-57,Rev. 0, General Electric, November 1989.

62. G.E. Mertz, "Stress Analysis and Load Combinations for the Savannah River Reactor Process Sater System Piping LBB Assessment (U)," SRL-EDG-890148, Attachment 1 to WSRC-RP-90-91, December 1989. 
63. R.L. Sindelar, et. al., "Reactor Materials Program - Leak-Before-Break Analysis of the Reactor Process Water System Piping (U), Task Number: 89-036-1," WSRC-RP-9091, March 1990.

64. S. Ranganath, et. al., "Structural Evaluation of Flaws in Power Plant Piping," Circumferential Cracks in Pressure Vessel Piping, Vol. 1, ASME, 1984, pp. 91-116.

65. P.C. Paris, H. Tada, A. Zahoor, and H. Ernst, "The Theory of Instability of the Tearing Mode of Elastic-Plastic Crack Growth," ASTM STP 668, 1979, pp. 5-36.

66. J. W. Hutchinson and P. C. Paris, "Stability Analysis of J-Controlled Crack Growth," ASTM STP 668, 1979, pp. 37-64.

67. C.F. Shih, Dean and M.D. German, General Electric Company, T13 Report, 1981.

68. V. Kumar, M.D. German, and C.F.Shih, "An Engineering Approach for Elastic-Plastic Fracture Analysis," EPRI Topical Report NP-1831, Electric Power Research Institute, Palo Alto CA, July 1981.

69. K.J. Stoner, et. al., "Mechanical Properties of 1950's Vintage Type 304 Stainless Steel Weldment Components," Fatigue, Degradation, and Fracture, PVP - Vol. 195, 1990.

70. ASME Boiler and Pressure Vessel Code, Section XI, "Rules for Inservice Inspection of Nuclear Power Plant Components; Division 1," through 1987 Addendum.

71. W.L. Daugherty, Savannah River Laboratory - Nuclear Reactor Technology \& Scientific Computations, Task number 88-001-01, Rev. 3, "Qualification of LOCA Definition Project," November 1990.

72. K.A. Crawford, W.L. Daugherty, and D.D. Sousa, "LOCA Definition Project Analysis of Controls Task Number:88-001-1," WSRC-RP-90-1174, November 1990.

73. W.L. Daugherty, "LOCA Definition Project Peer Review Report (U)," WSRC-RP-89. 341, Rev. 1, November 1990.

74. W.L. Daugherty, "Evaluation Team Report on the Qualification of the LOCA Definition Project (U)," WSRC-TR-90-567, December 1990. 
J.D. Spencer

April 1. 1991
WSRC-TR-91-10

Task \# 89-023-A-1

\section{ATTACHMENT I}

\section{BASELINE MECHANICAL PROPERTY TEST RESULTS}

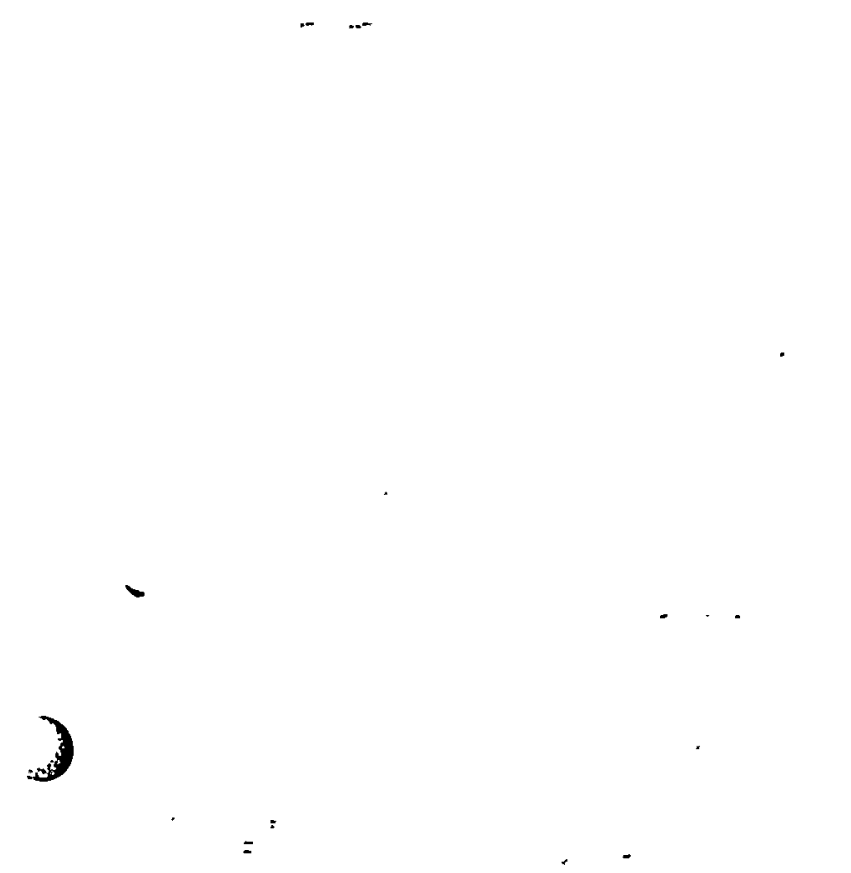

$$
\text { I - } 1
$$




\section{DISCUSSION}

Tables I-1 through I-5 list the test results and details of each of the non-irradiated, baseline, mechanical tests (see Section 4). The results are listed only for the final test configuration, and no design testing results are given. There were three different baseline test matrices. The results of the first are given in MEA-2221 [5]. The additional set of tests were done in support of either the K-Reactor surveillance capsule or the HFIR irradiation capsules [RMP Task 89-023-A-1 files]. These are denoted in the tables by an "S" or a " + " following the specimen designator for each of the surveillance or HFIR support studies respectively. For the dynamic tensile tests, the "second Set" test data are denoted by a "*" following the specimen designator.

Within each table, the data are organized by weldment component (base, HAZ or weld), by test direction (L-C or C-L) and by test temperature $\left(25\right.$ or $\left.125^{\circ} \mathrm{C}\right)$. Following each of these data groupings is the sample average (or mean) and the " $n-1$ " standard deviation. The following table shows a directory of mechanical property data results:

\begin{tabular}{|c|c|c|}
\hline Mechanical Property & Table \# & Page \# \\
\hline Static Tensile & $I-1$ & $I-3$ \\
\hline Charpy Impact Energy & $I-2$ & $I-6$ \\
\hline Static Fracture Toughness - & $I-3$ & $I-11$ \\
\hline Dynamic Tensile & $I-4$ & $I-14$ \\
\hline Dynamic Fracture Toughness & $I-5$ & $I-17$ \\
\hline
\end{tabular}


)

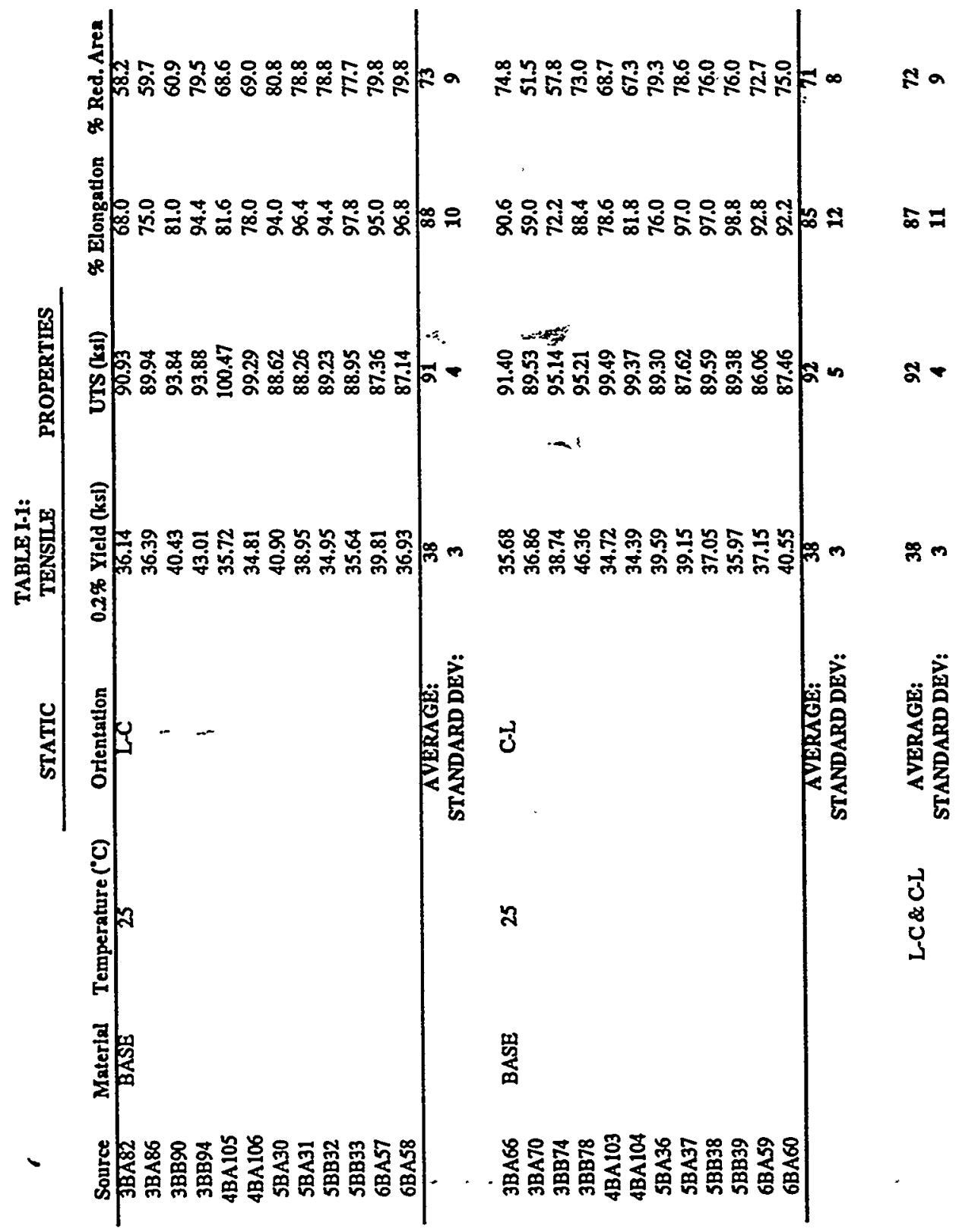

) 


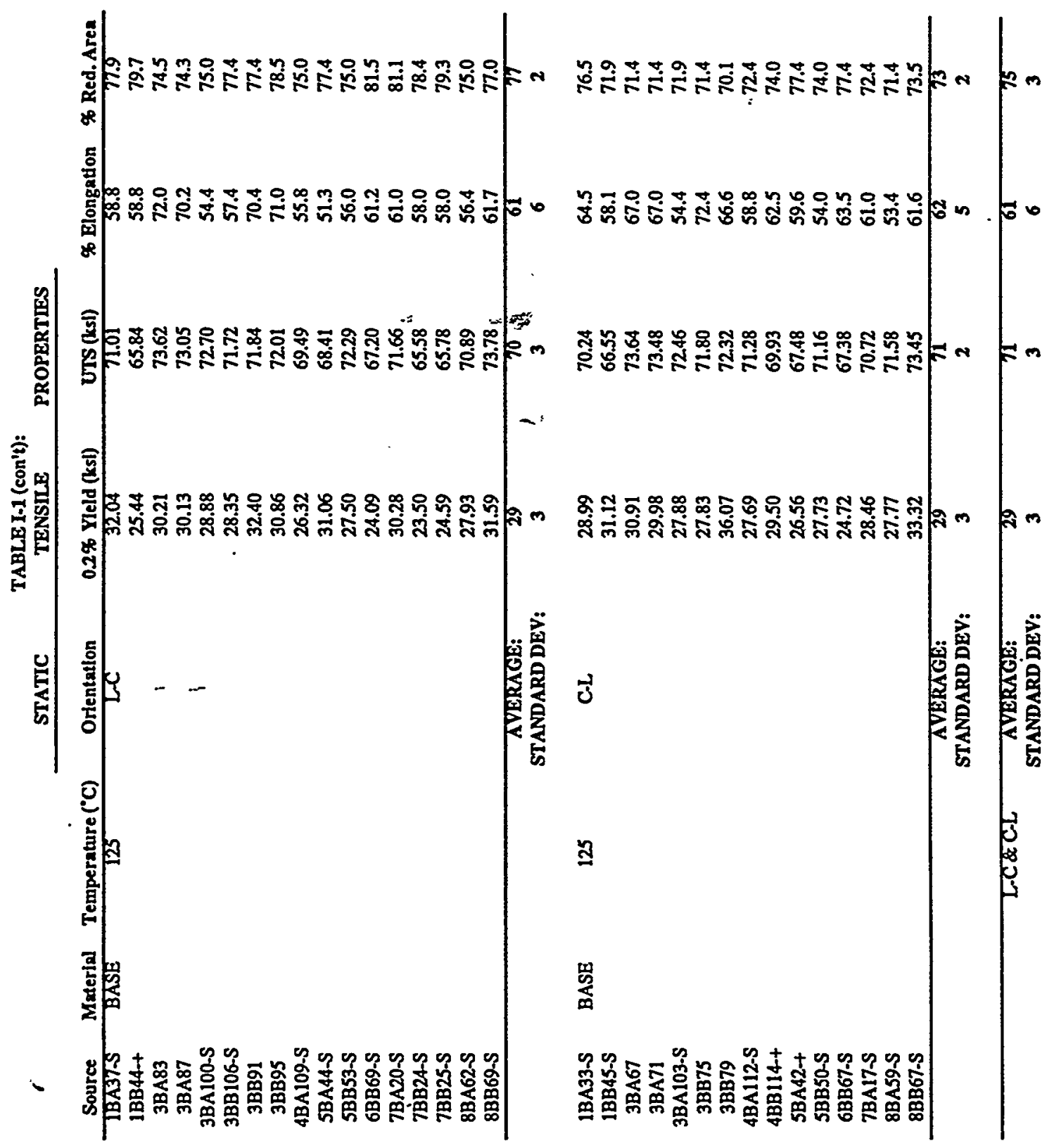

) 


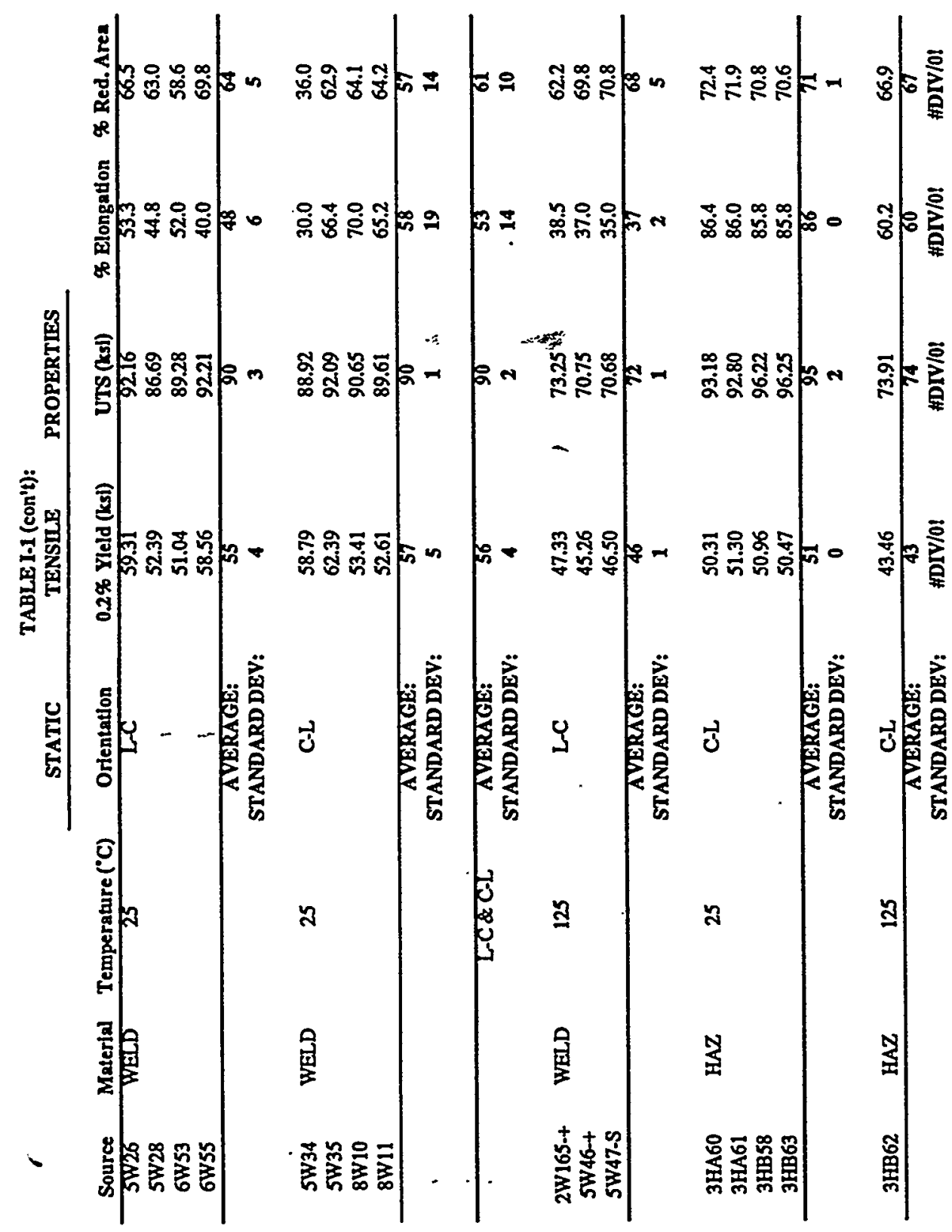

) 
)

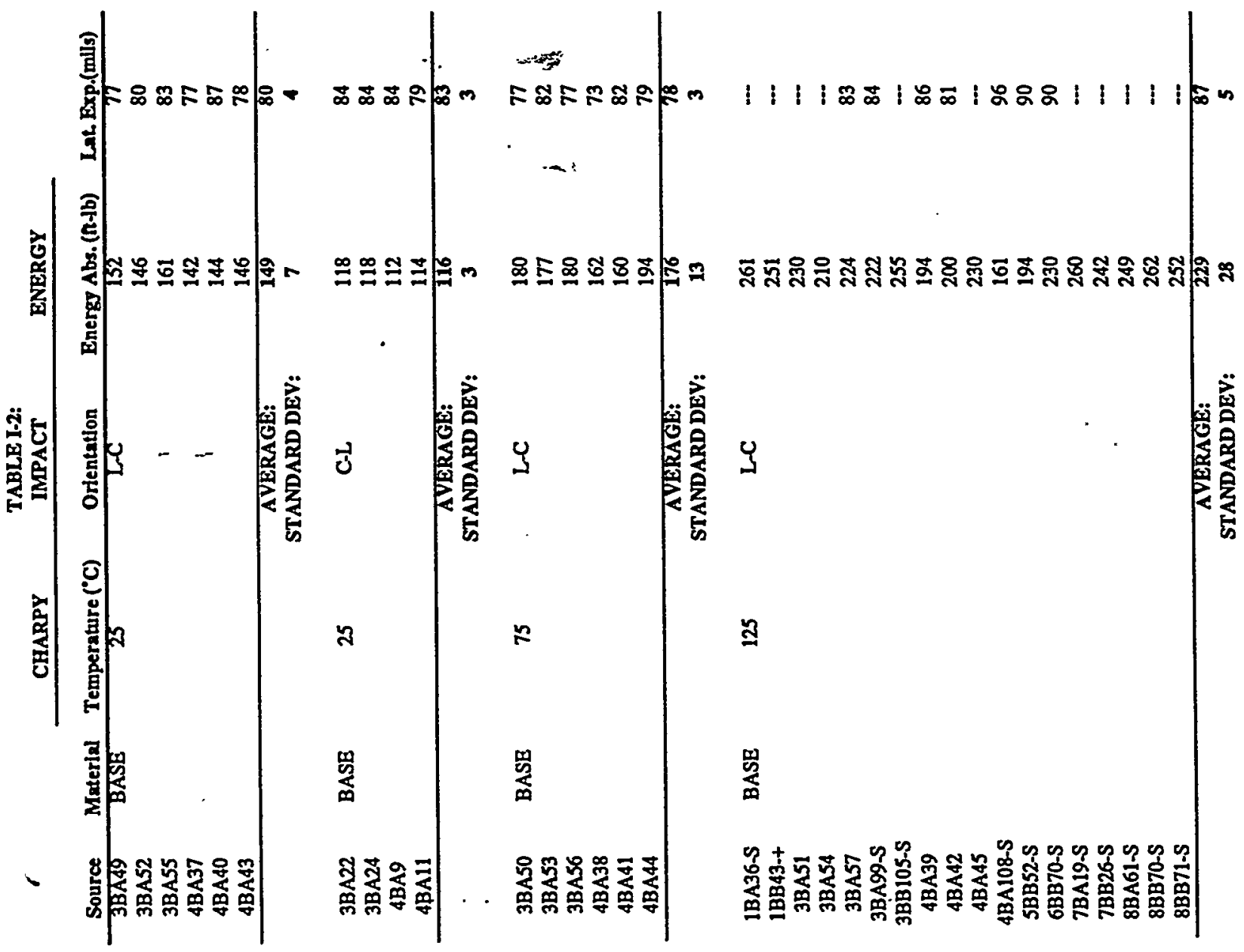

) 


\begin{tabular}{|c|c|c|c|c|c|}
\hline 6 & & CHARPY & $\begin{array}{l}\text { TABLE I-2 (con't): } \\
\text { IMPACT }\end{array}$ & ENERGY & \\
\hline Source & Material & Temperature ( $\left.{ }^{\circ} \mathrm{C}\right)$ & Orientation & EnergJ Abs. (n-lb) & Lat. Exp.(mils) \\
\hline $18 \times 305$ & BASE & 125 & C-L & 143 & 81 \\
\hline 1BB47-S & & & : & 113 & 77 \\
\hline $3 \mathrm{BA} 23$ & & & $i$ & 116 & 81 \\
\hline $3 B A 25$ & & & \} & 111 & 74 \\
\hline 3BA102-S & & & & 116 & 79 \\
\hline $3 \mathrm{BB} 108-\mathrm{S}$ & & & & 86 & 73 \\
\hline 4BA10 & & & & 141 & 73 \\
\hline 4BA12 & & & & 143 & 79 \\
\hline 4BAII1-S & & & & 124 & 70 \\
\hline 4BB115-+ & & & & 166 & 86 \\
\hline 5BB49.S & & & & 145 & 72 \\
\hline $6 B A 61+$ & & & & 135 & 76 \\
\hline 6BB66-S & & & & 153 & 84 \\
\hline 7BAI6.S & & & & 107 & 79 \\
\hline 7BB23-S & & & & 152 & 84 \\
\hline 8BA58-S & & & & 89 & 72 \\
\hline 8BB65-S & & & & 133 & 76 \\
\hline 8BB66-S & & & & 135 & 73 \\
\hline & & & $\begin{array}{c}\text { AVERAGE: } \\
\text { STANDARD DEV: }\end{array}$ & $\begin{array}{l}128 \\
22\end{array}$ & $\begin{array}{l}77 \\
5\end{array}$ \\
\hline 1W7 & WELD & 25 & L-C & 108 & 96 \\
\hline IW11 & & & & 118 & 80 \\
\hline $1 W 14$ & & & & 114 & 80 \\
\hline $2 W 136$ & & & & 98 & 70 \\
\hline $2 W 139$ & & & & 94 & 76 \\
\hline $2 W 141$ & & & & 95 & 73 \\
\hline $3 W 29$ & & & & 112 & 106 \\
\hline $3 \mathrm{~W} 30$ & & & & 109 & 101 \\
\hline $3 W 31$ & & & & 116 & 95 \\
\hline $4 W 16$ & & & & 99 & 63 \\
\hline $4 W 17$ & & & & 104 & 62 \\
\hline $4 W 18$ & & & & 99 & 63 \\
\hline $5 W 4$ & & & & 116 & 84 \\
\hline 5W5 & & & & 128 & 96 \\
\hline $5 W 6$ & & & & 108 & 91 \\
\hline 6W4 & & & & 130 & 87 \\
\hline 6W5 & & & & 136 & 95 \\
\hline 6W6 & & & $\cdot$ & 144 & 86 \\
\hline & & & $\begin{array}{c}\text { AVERAGE: } \\
\text { STANDARD DEV: }\end{array}$ & $\begin{array}{c}113 \\
14\end{array}$ & $\begin{array}{l}84 \\
14\end{array}$ \\
\hline
\end{tabular}

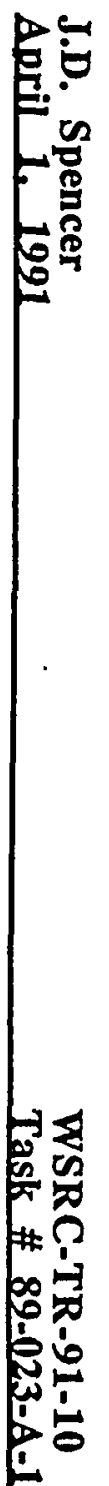


)

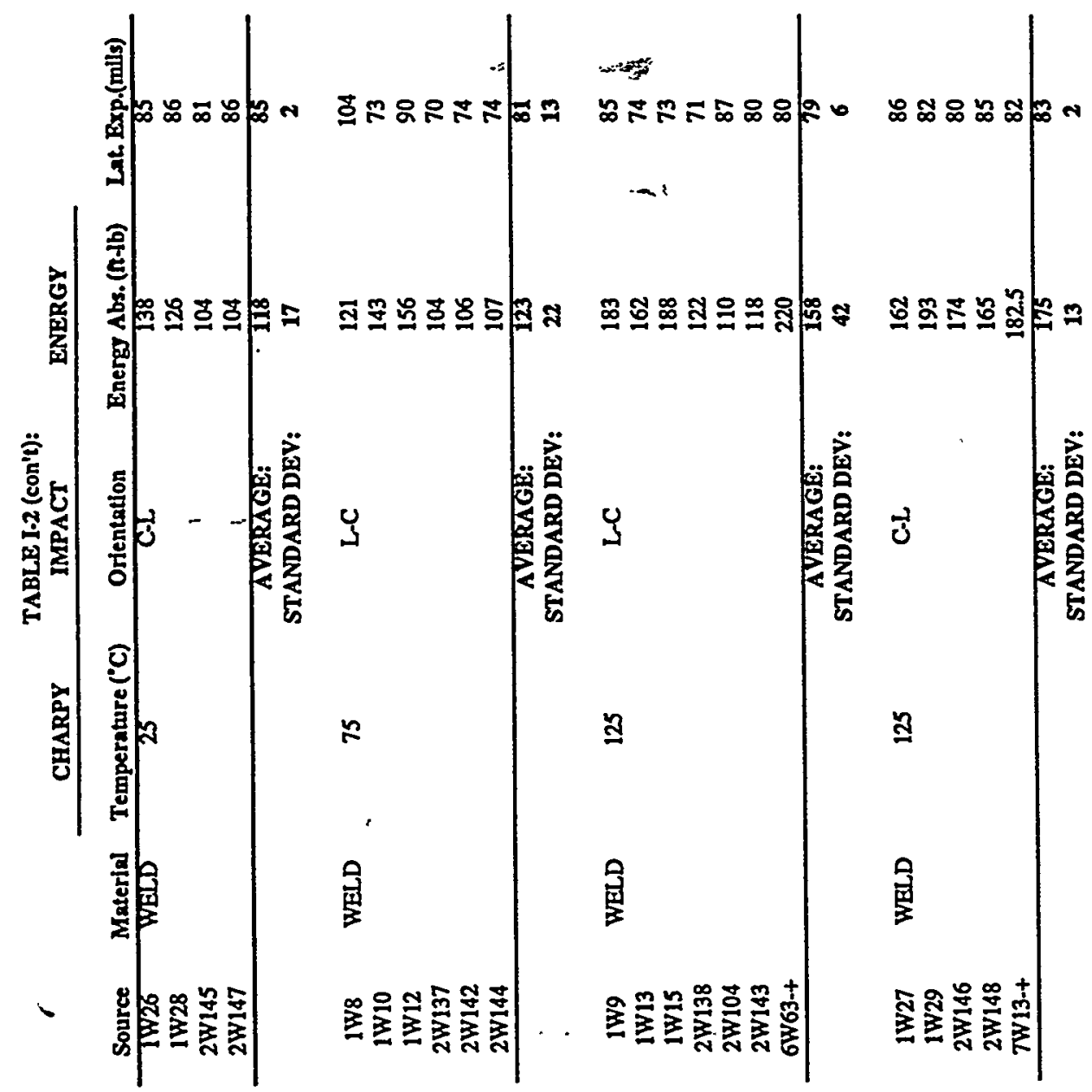

) 
)

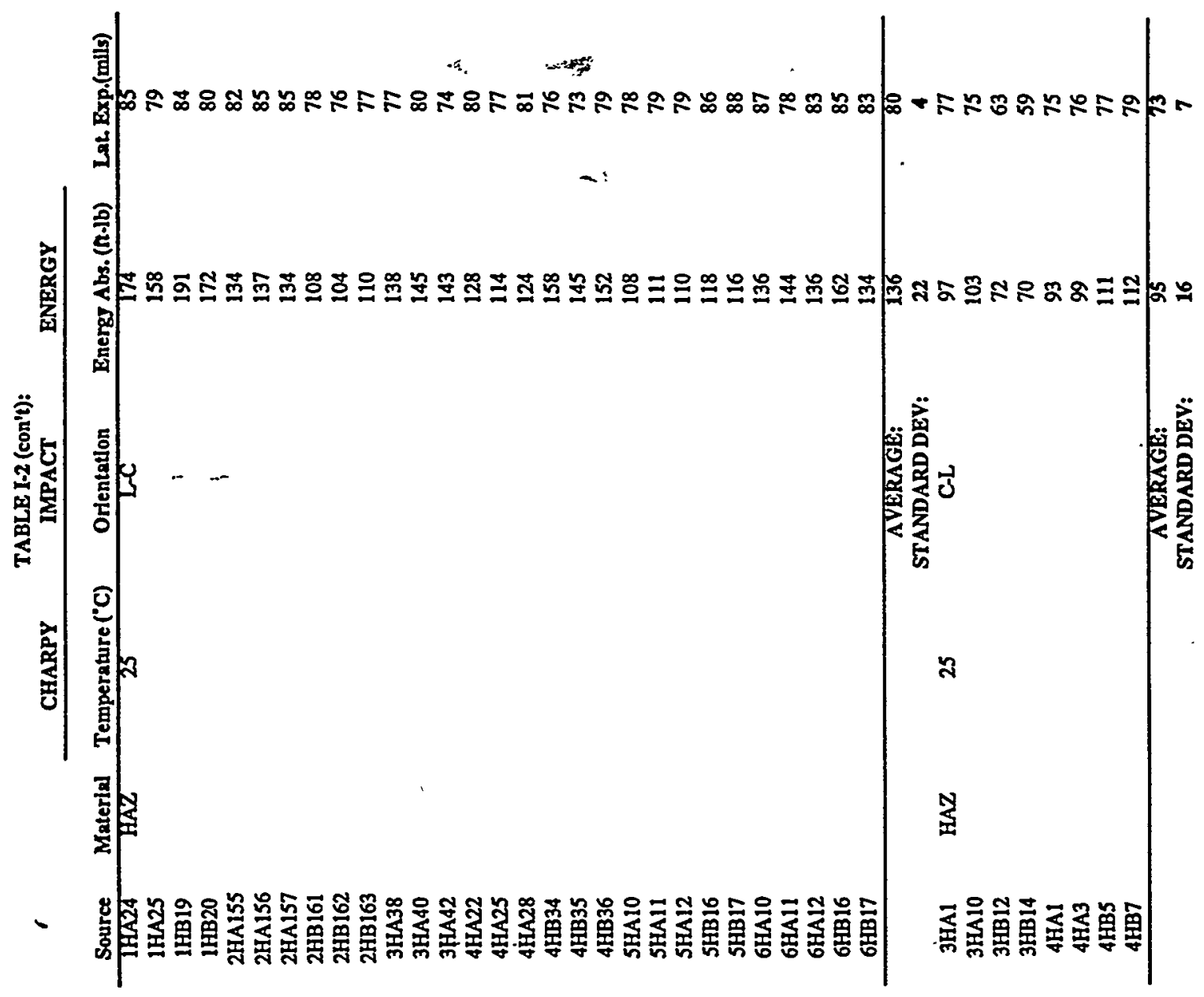

) 


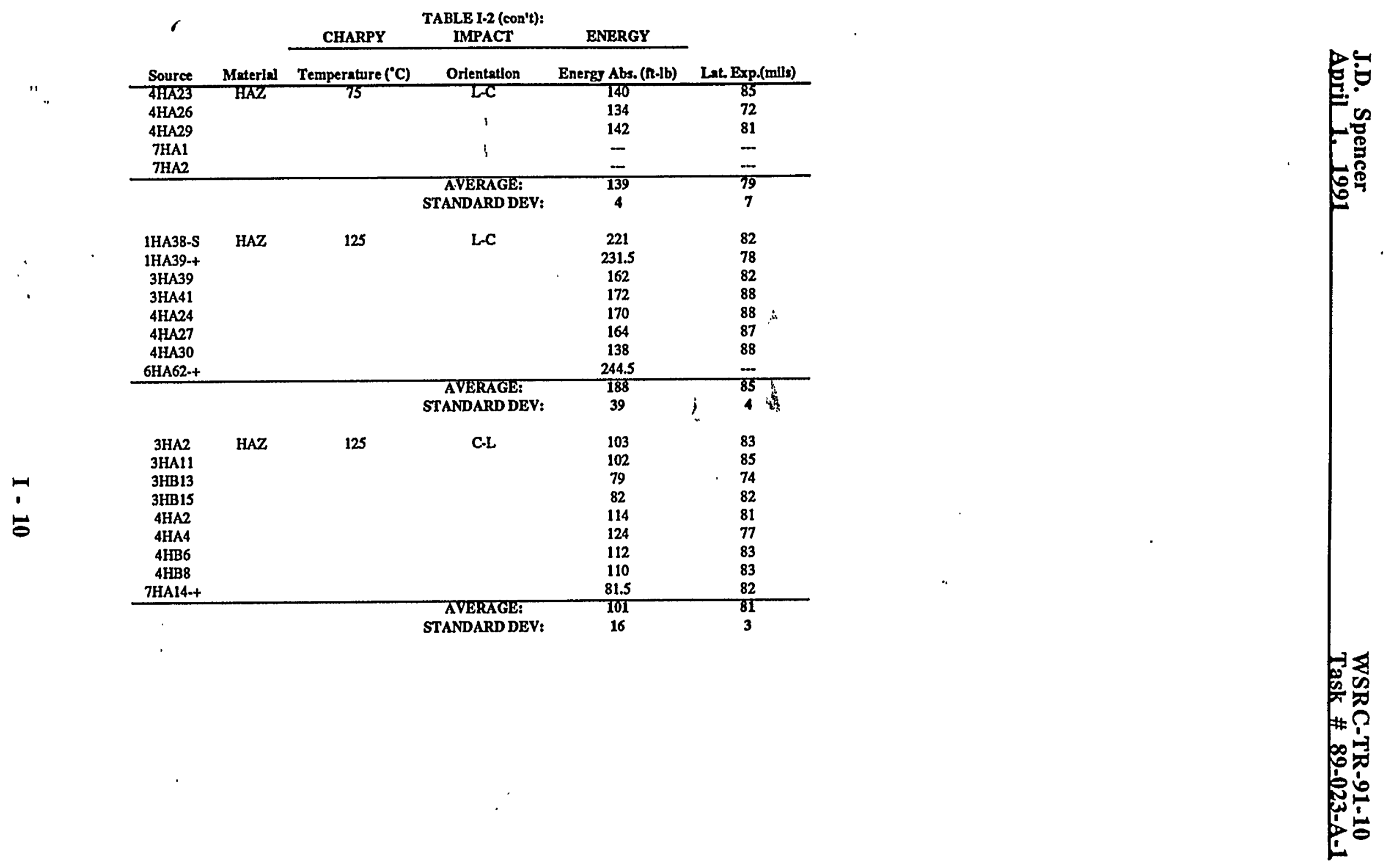




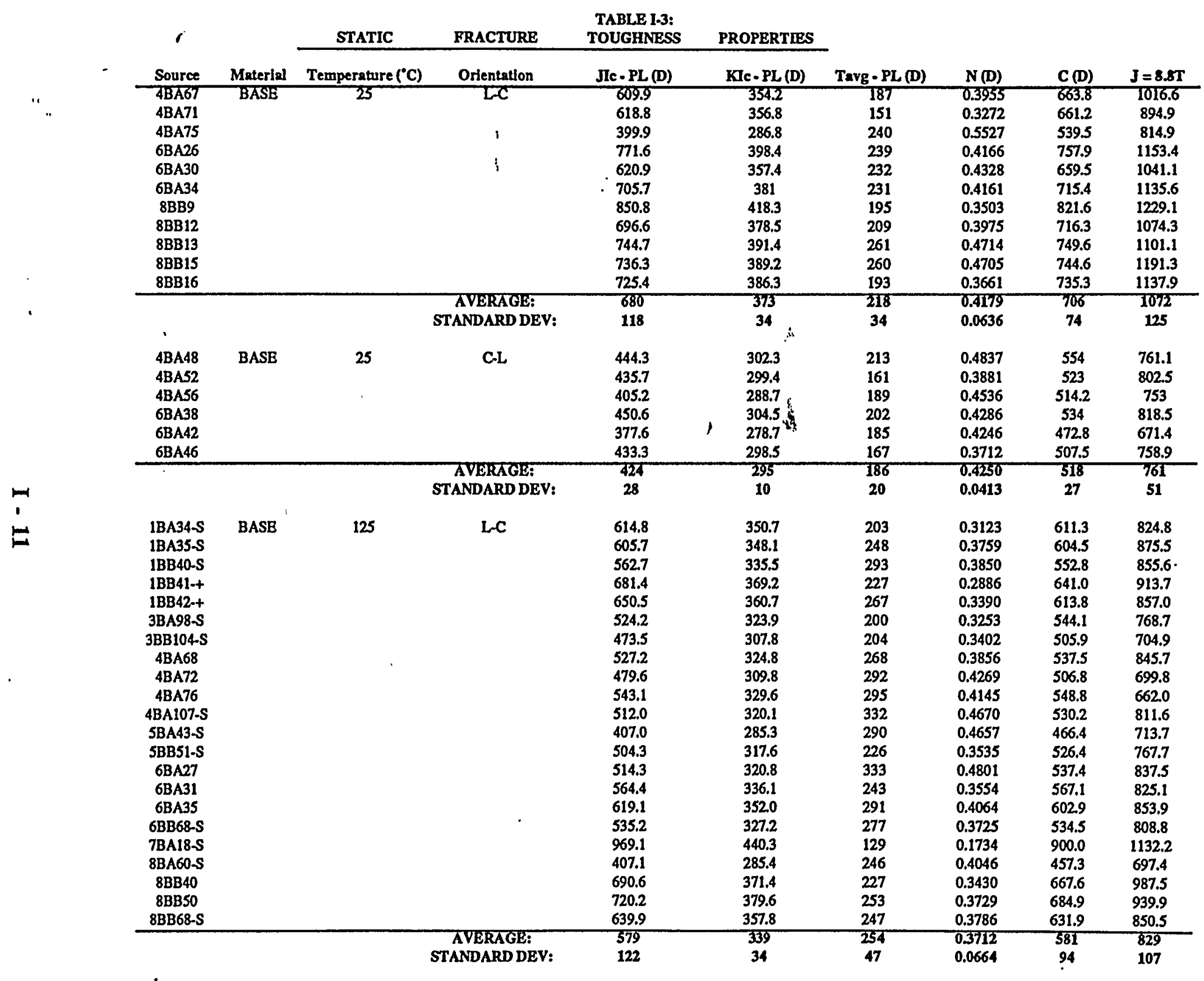




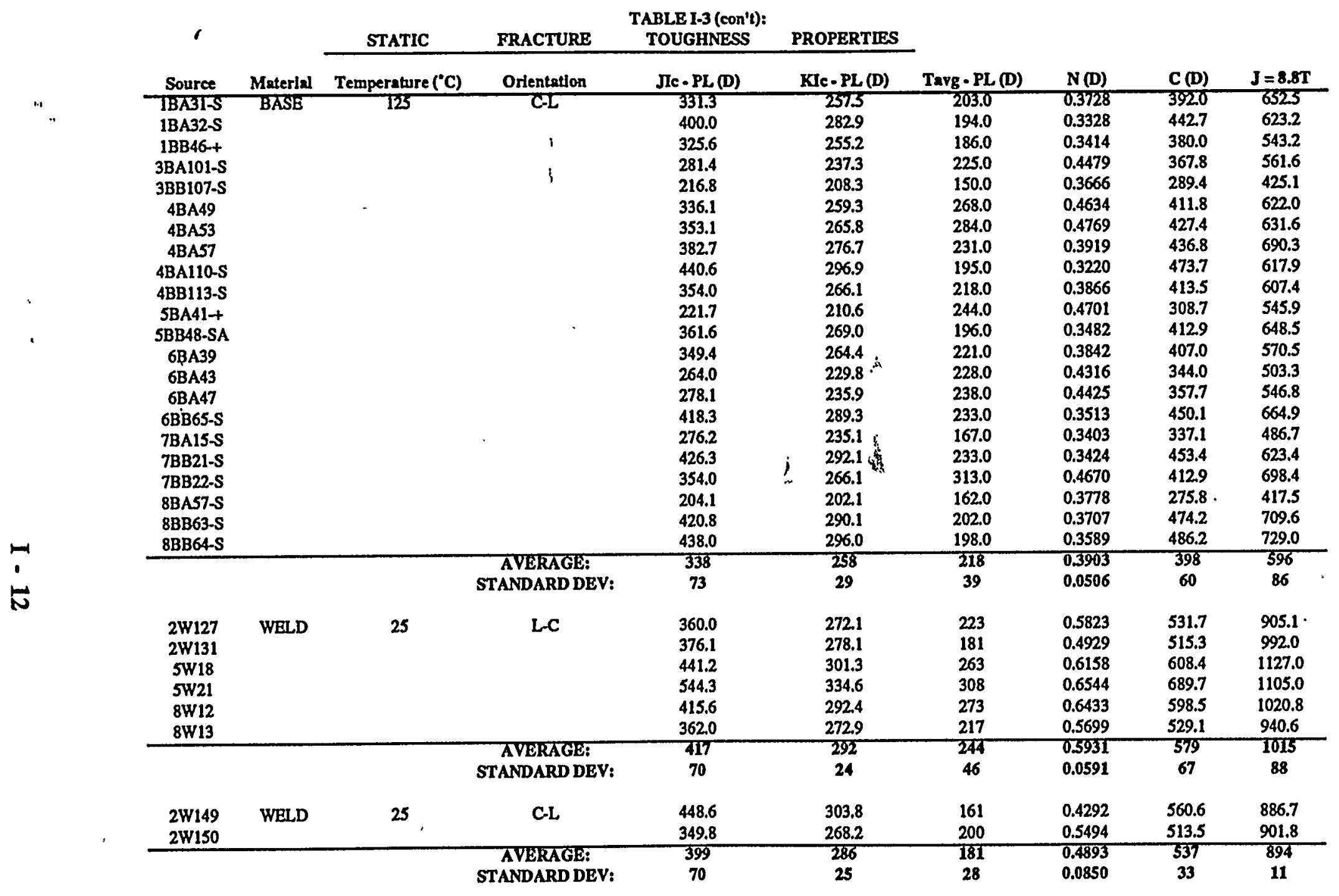


)

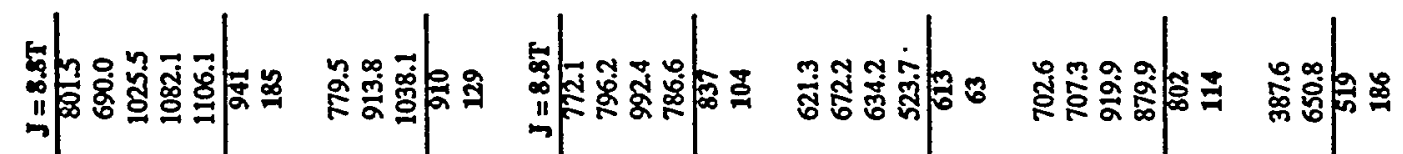

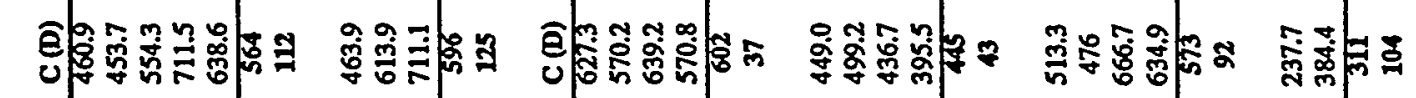

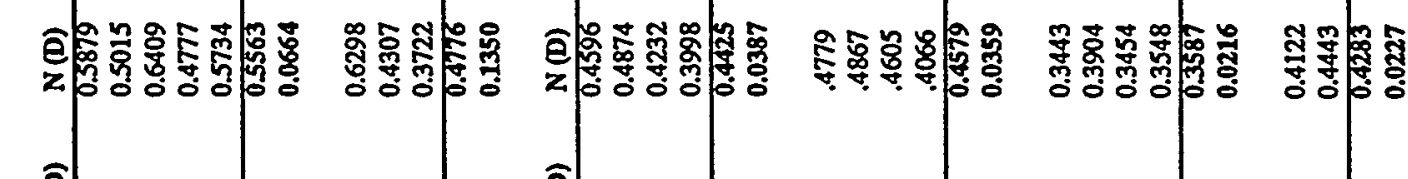

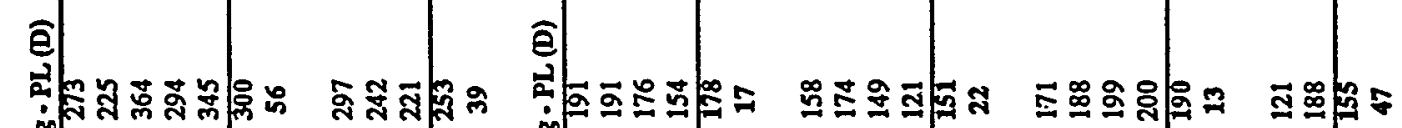
|

) 


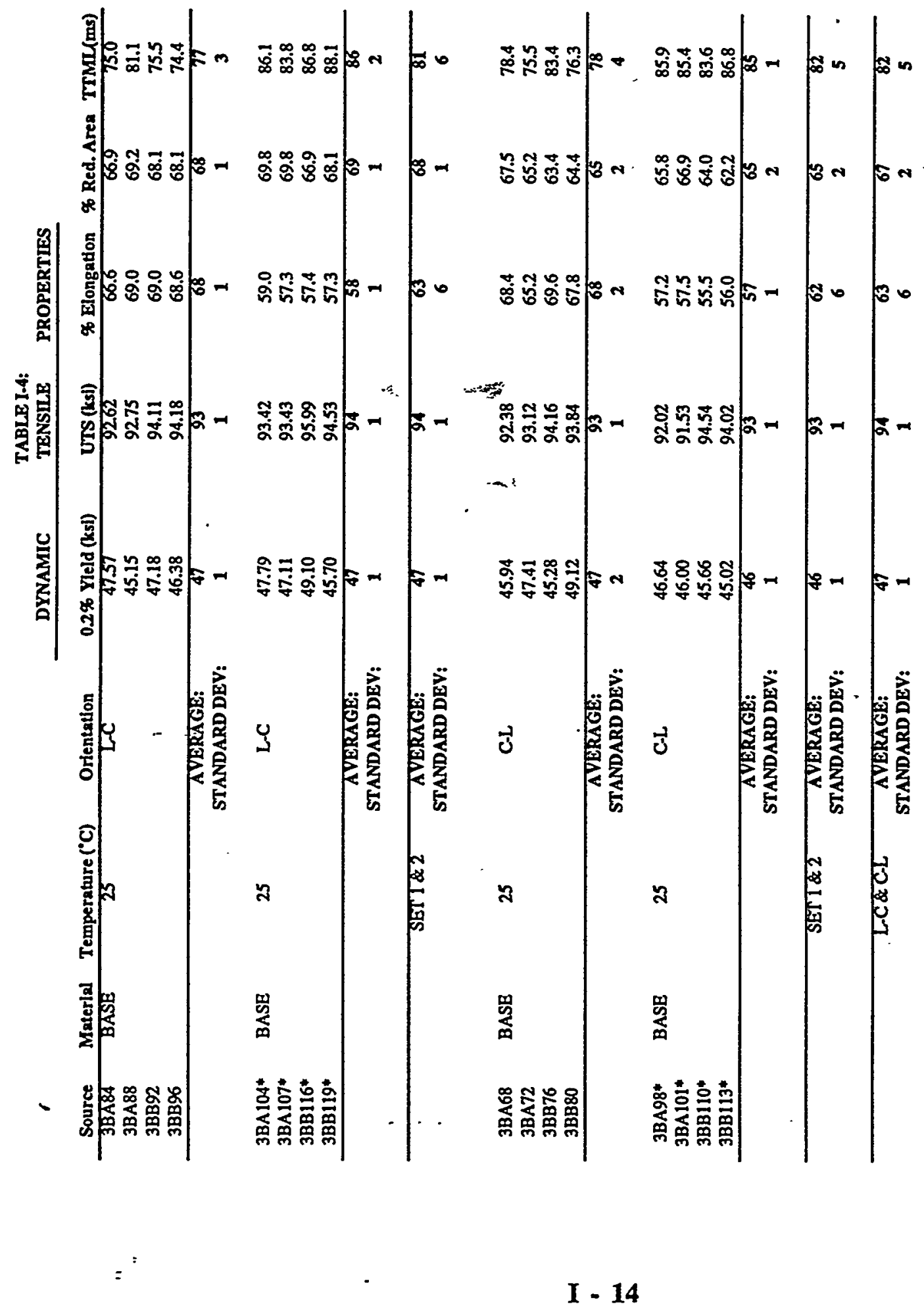


)

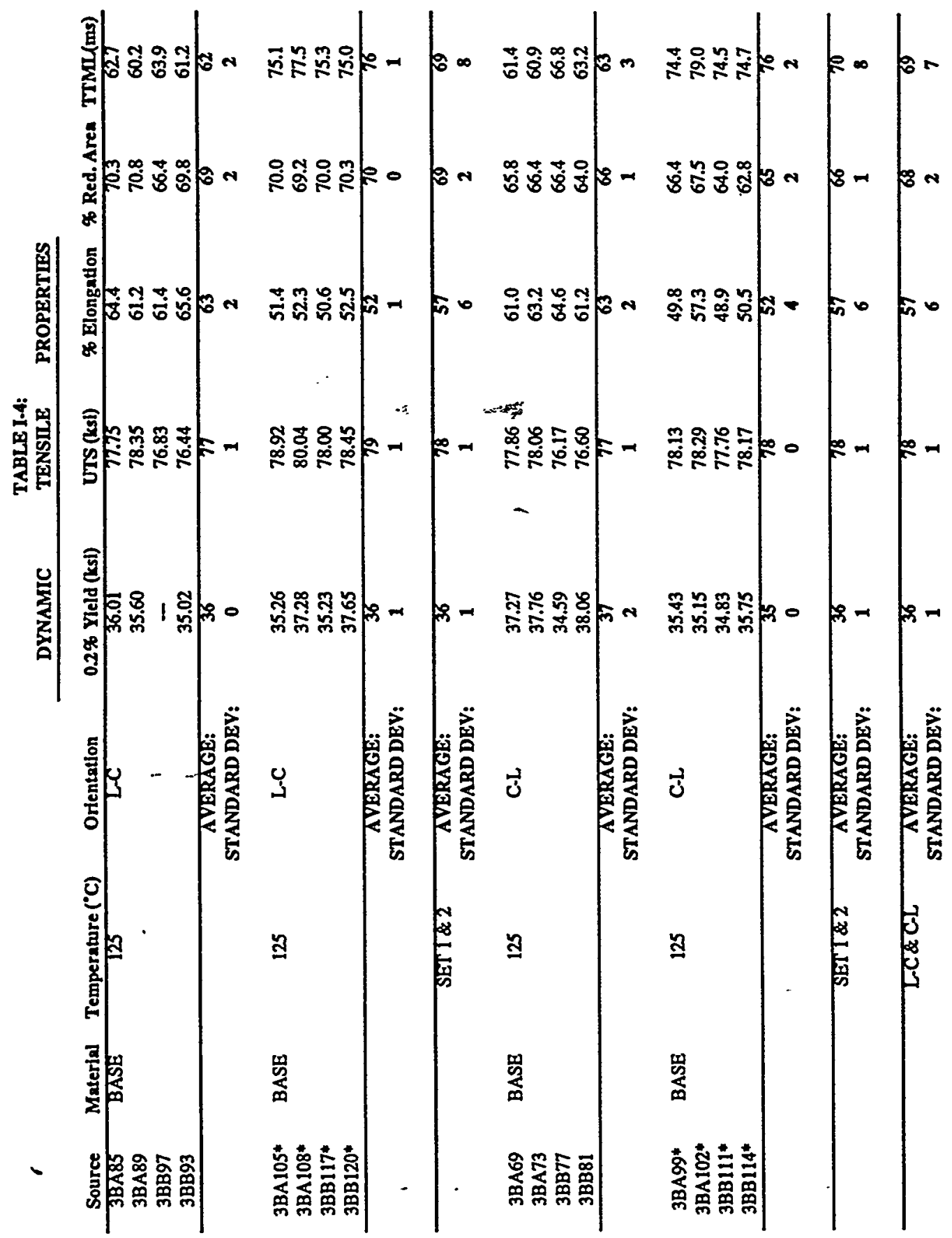

) 
)

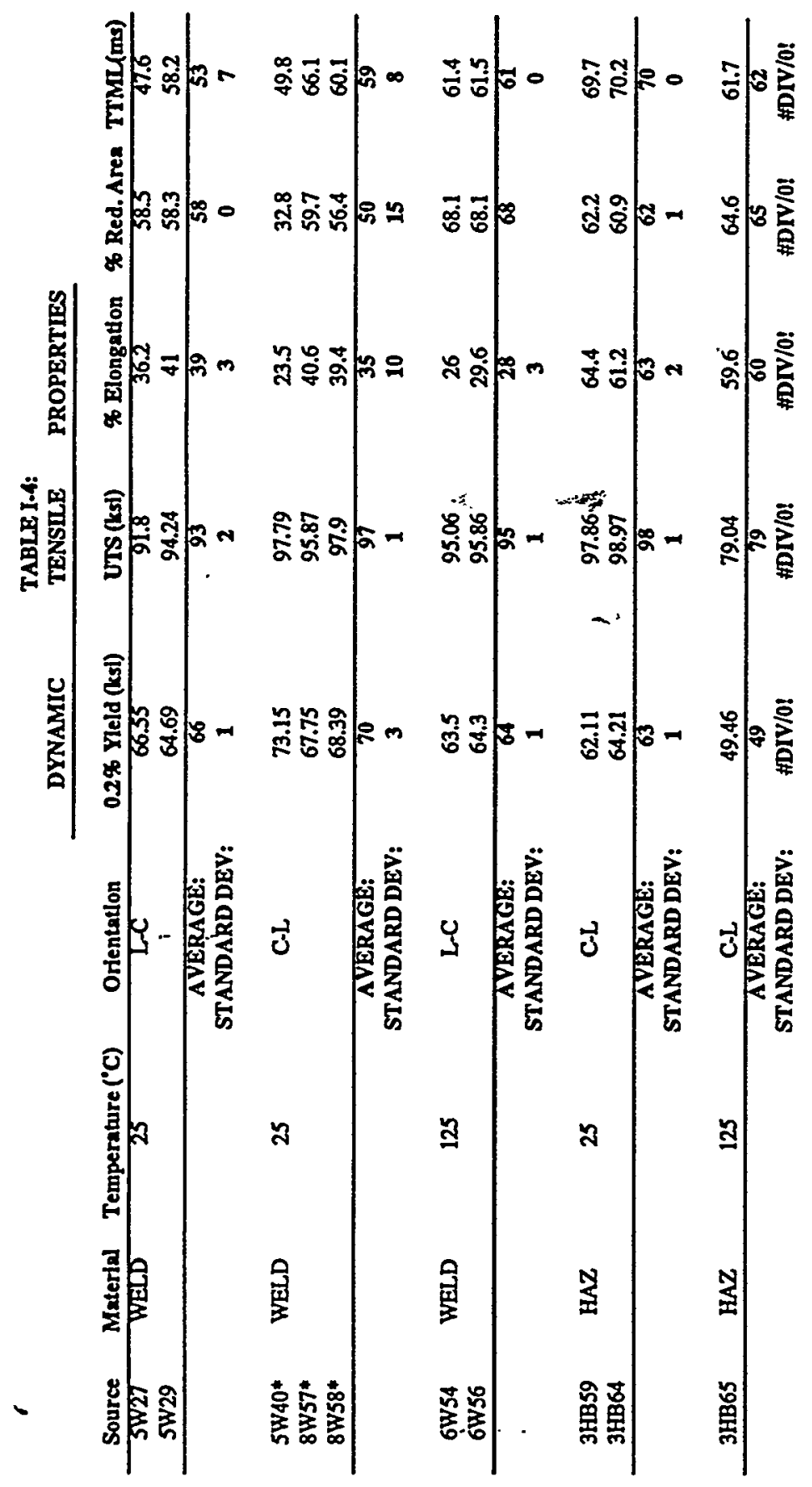

) 
)

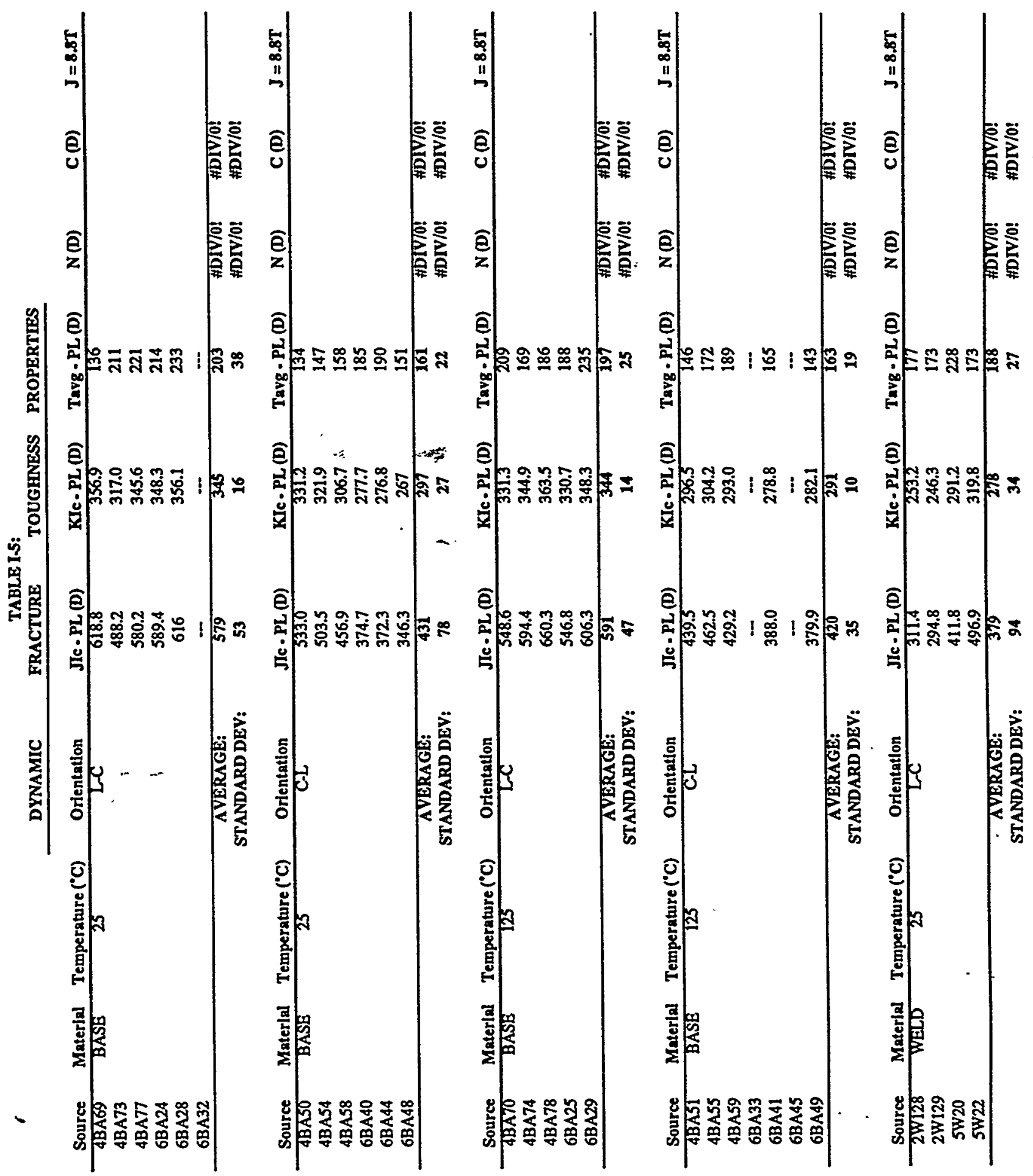

) 
)

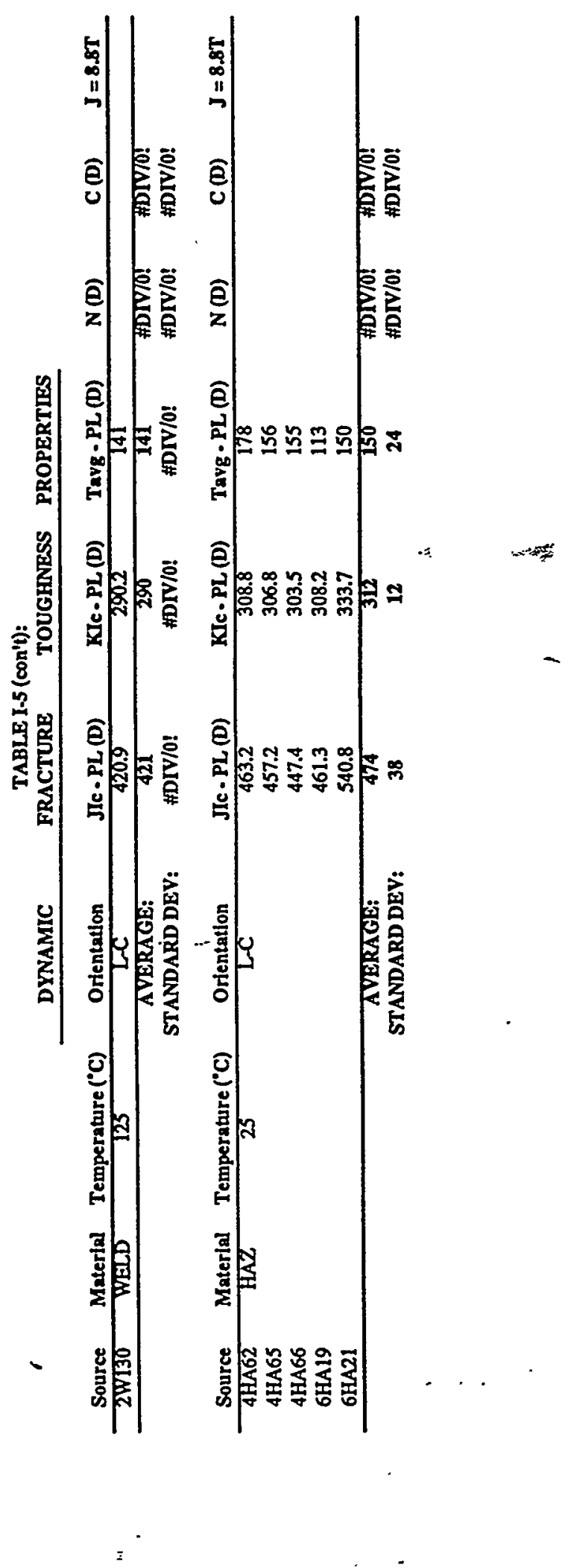




\section{ATTACHMENT II}

MECHANICAL TEST DATA - DIGITIZED PLOTS 


\section{DISCUSSION}

The load, load-line displacement data and the reduced data from the mechanical specimens tested as part of the RMP Baseline are contained on floppy disks and stored in the task files (Task 89023-A-1). Engineering properties from the test data have been listed in Attachment I and summarized in section 5 of the report.

Three subsets of the full test data and materials' property parameters developed from the data are displayed in Figures II-1 to II-3. The lower bound (strength) tensile test data [base material, L-C $\left(=\mathrm{C}-\mathrm{L}\right.$ ), and $125^{\circ} \mathrm{C}$, see Table 5.1] are plotted in Figure II-1a. A single region set of RambergOsgood parameters of $\alpha=2$ and $n=5$ fit the data (as shown in Figure II-1b) and are consistant with the GE estimation scheme for applied J (see RMP Calculation Set \#91-03, Part 3).

Figure II-2a shows the data average (lower bound set $=\mathrm{HAZ}$ material, $125^{\circ} \mathrm{C}, \mathrm{L}-\mathrm{C}$ ) J-R power law curve recommended for elastic-plastic fracture analysis for flaws oriented circumferentially with respect to the piping. Figure II-2b is the $J-T$ curve with the recommended cut-off at $J=850$ $\mathrm{kJ} / \mathrm{m}^{2}$ (corresponding to $\Delta \mathrm{a}=3 \mathrm{~mm}$ ).

Figure II-3a shows the data average (lower bound set $=\mathrm{HAZ}$ material, $125^{\circ} \mathrm{C}, \mathrm{C}-\mathrm{L}$ ) J-R power law curve recommended for elastic-plastic fracture analysis for flaws oriented axially with respect to the piping. Figure $\Pi-3 \mathrm{~b}$ is the J-T curve with the recommended cut-off at $\mathrm{J}=500 \mathrm{~kJ} / \mathrm{m}^{2}$ (corresponding to $\Delta \mathrm{a}=3 \mathrm{~mm}$ ). 


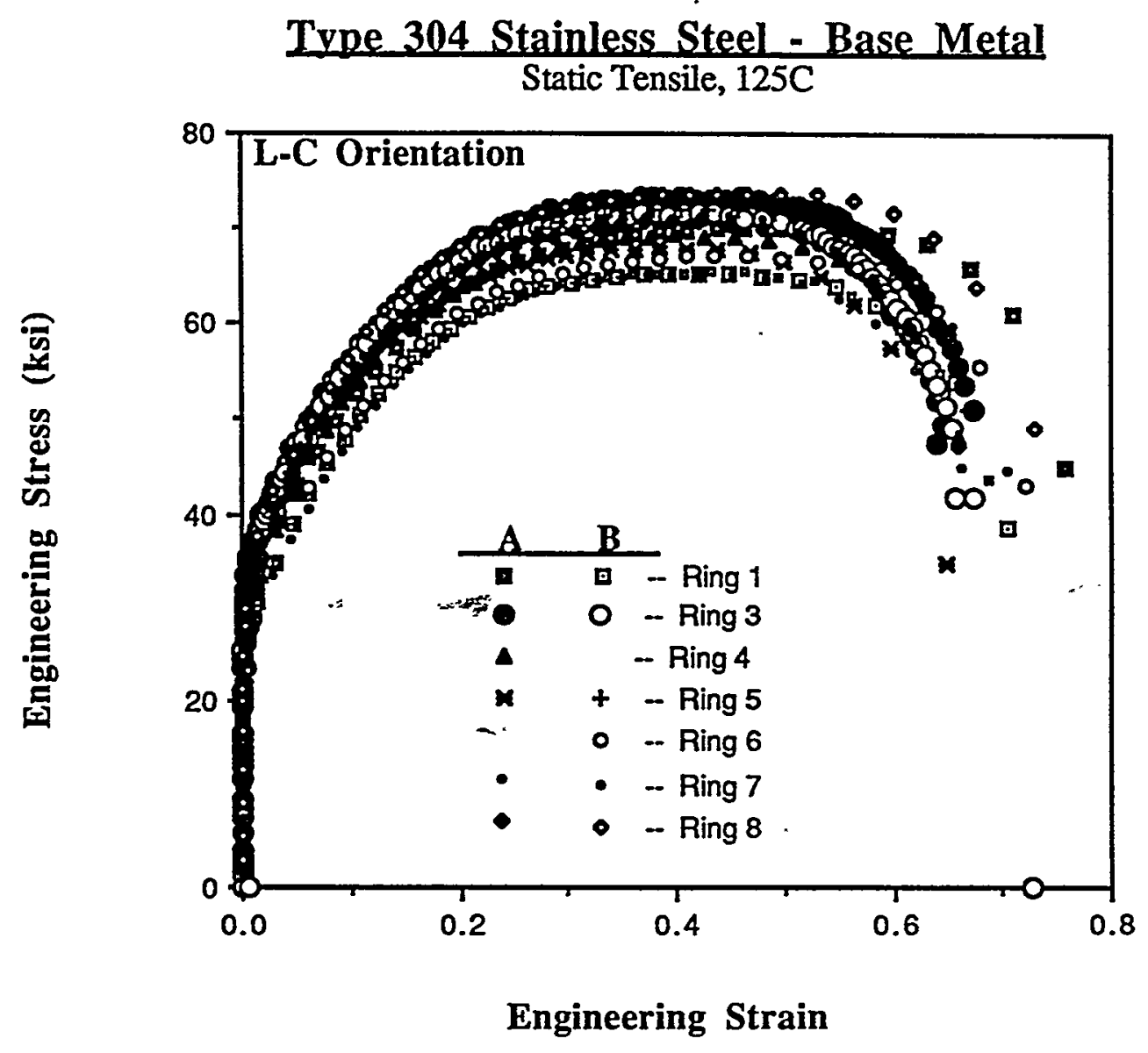

Figure II-1a: Composite tensile data from the lower bound strength conditions (base material, $125^{\circ} \mathrm{C}, \mathrm{L}-\mathrm{C}$ ). 


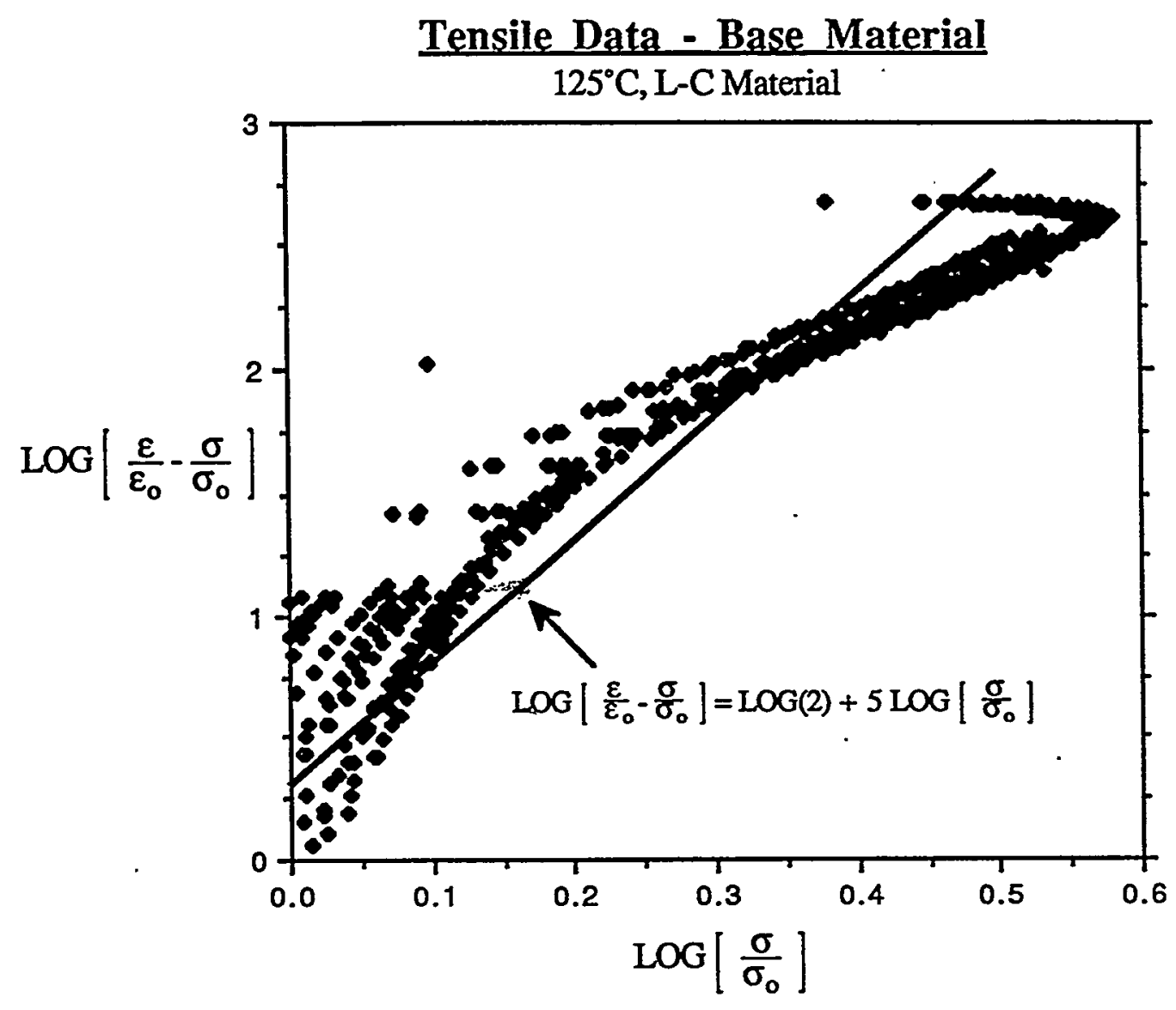

Figure II-1b: Ramberg Osgood formulation of the tensile data (see section 7.2.2). The data is described by a single region, linear fit (parameters of $\alpha=2$ and $n=5$ ).

) 
Type 304 Stainless Steel (Archival Piping) $0.394 \mathrm{~T}-\mathrm{CT}, 125^{\circ} \mathrm{C}, 20 \% \mathrm{SG}$

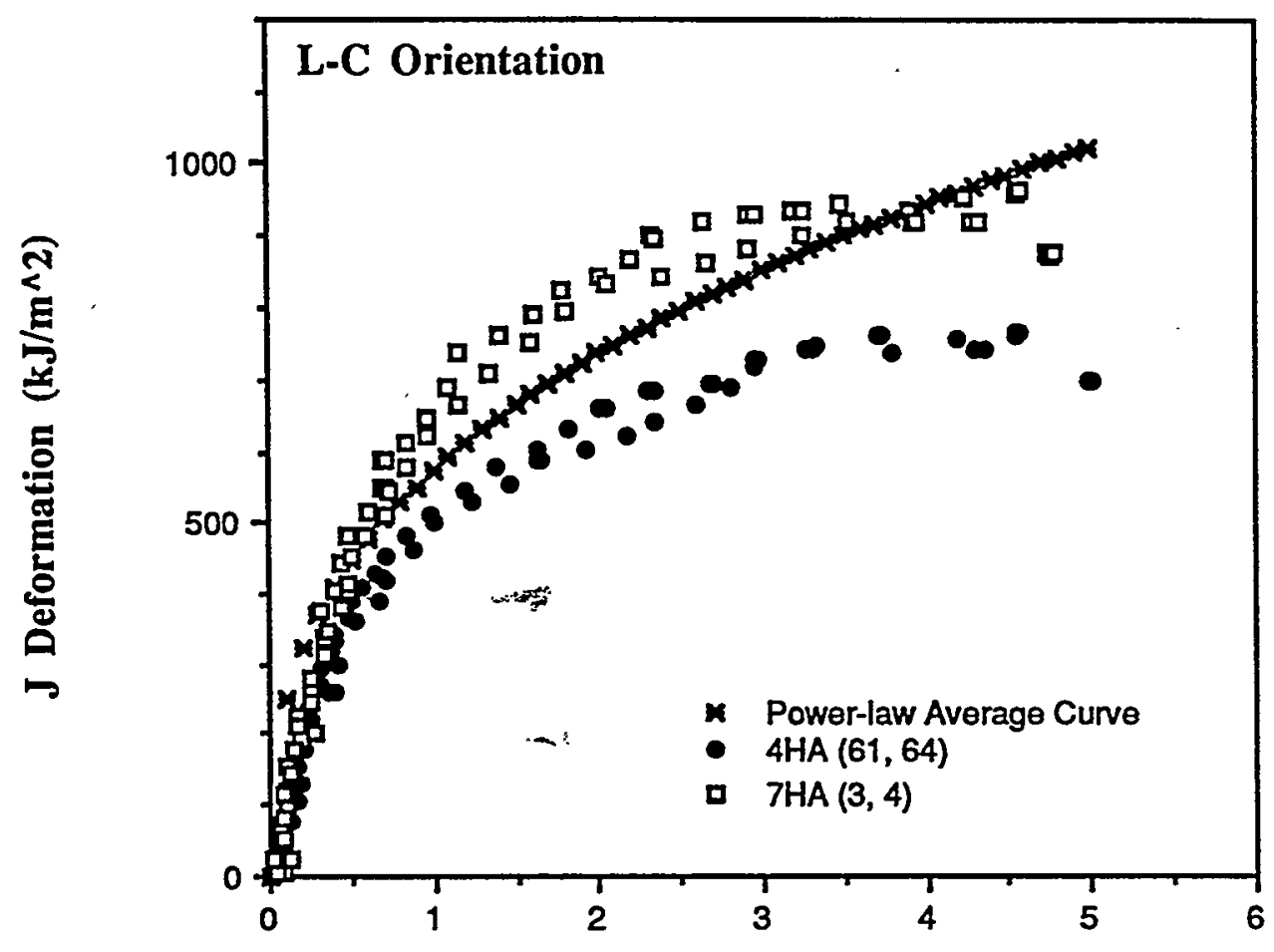

DELTA a (mm)

Figure II-2a: Data average J-R curve, power law formulation $\left(\mathrm{J}\left[\mathrm{kJ} / \mathrm{m}^{2}\right]=573(\Delta \mathrm{a})^{0.36}, \Delta \mathrm{a}\right.$ in $\left.\mathrm{mm}\right)$ for the lower bound data $\left(\mathrm{HAZ}, 125^{\circ} \mathrm{C}, \mathrm{L}-\mathrm{C}\right)$ for flaws oriented circumferentially with respect to the piping. 
)

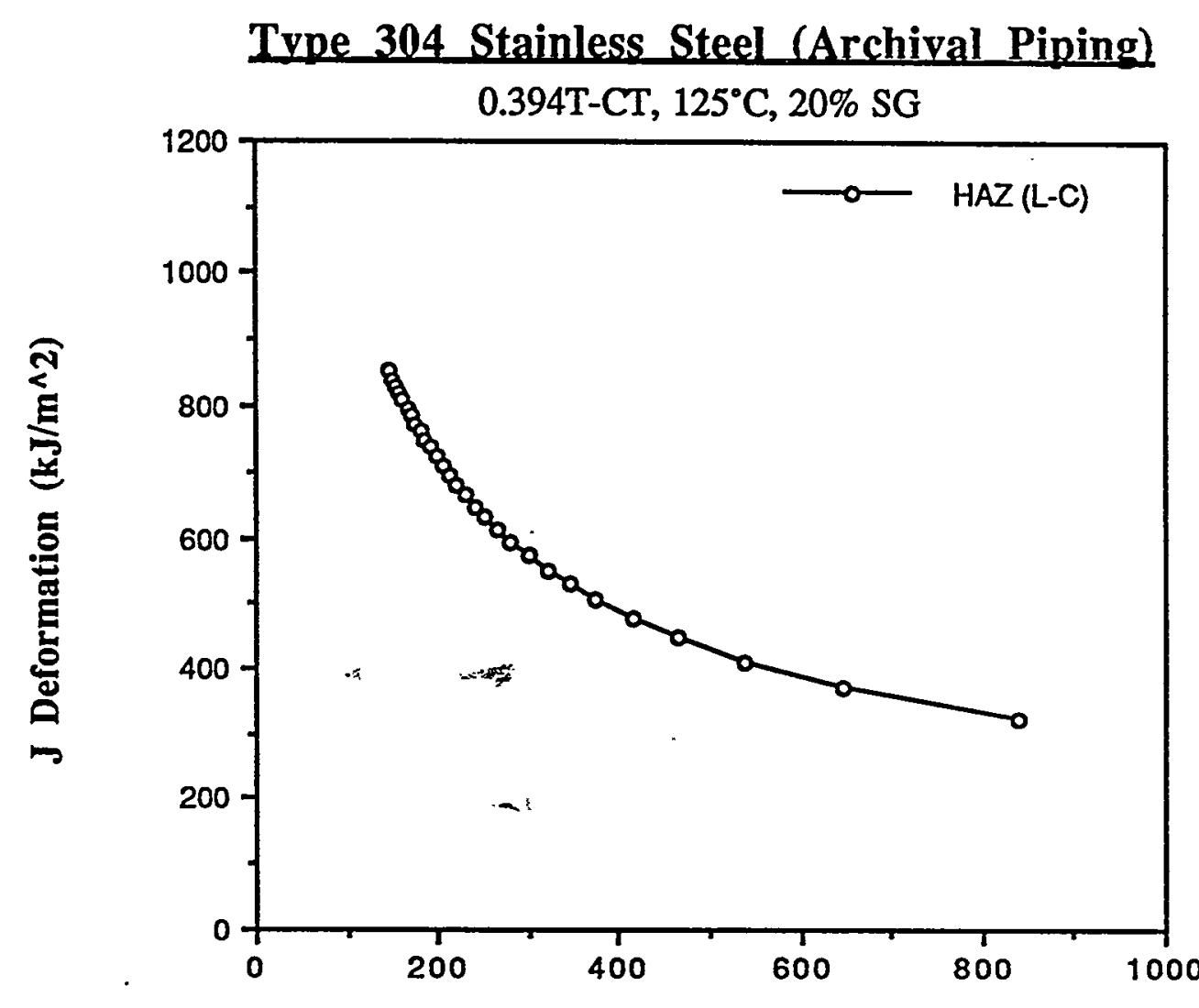

Tearing Modulus (T)

Figure II-2b: Material J-T curve from the power law formulation in Figure II-2a. A cut-off in the materials' curve at $\mathrm{J}=850 \mathrm{~kJ} / \mathrm{m}^{2}$ is shown. 


\section{Type 304 Stainless Steel (Archival Piping)}

$0.394 \mathrm{~T}-\mathrm{CT}, 125^{\circ} \mathrm{C}, 20 \% \mathrm{SG}$

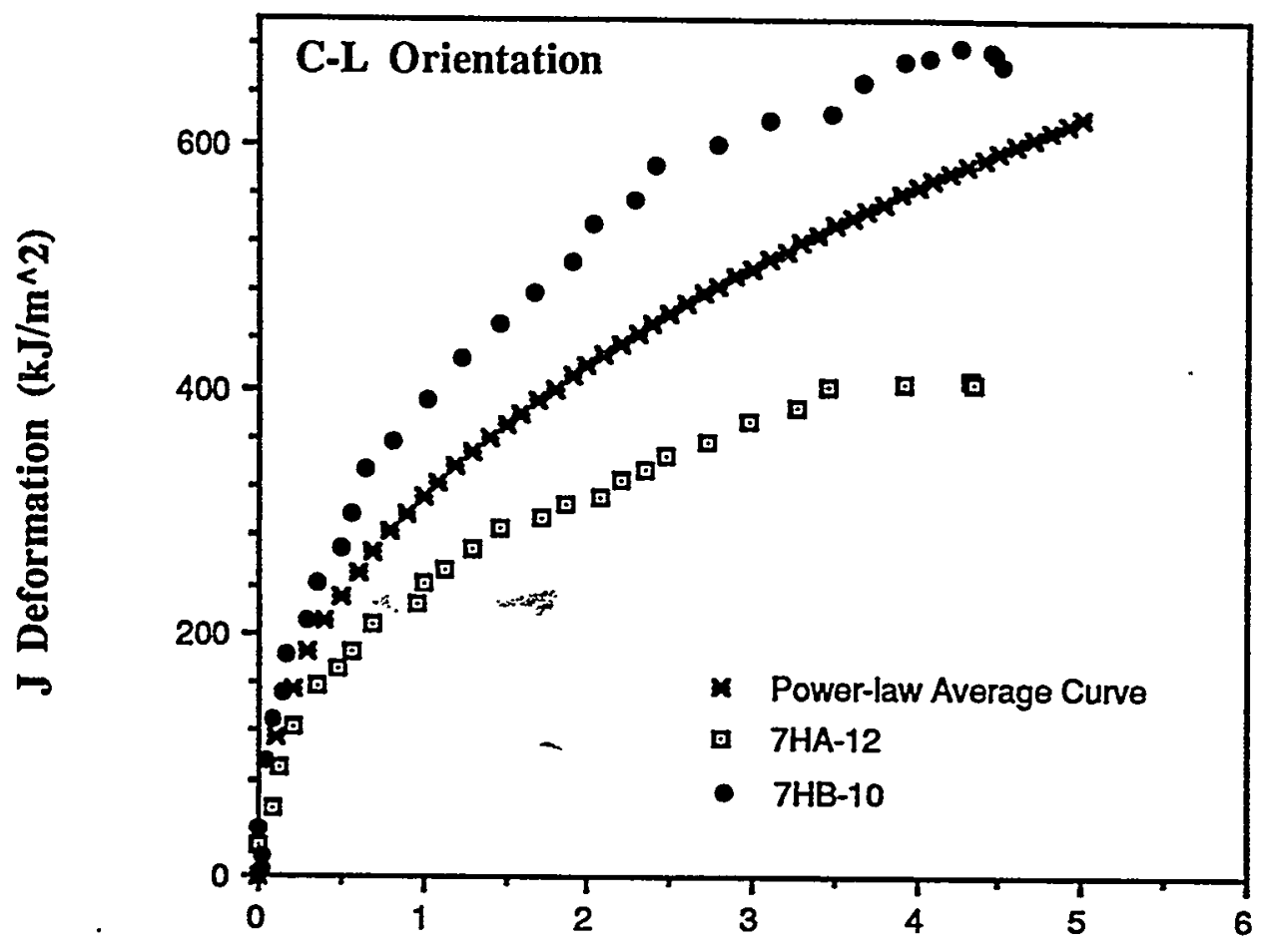

DELTA a (mm)

Figure II-3a. Data average J-R curve, power law formulation $\left(\mathrm{J}\left[\mathrm{kJ} / \mathrm{m}^{2}\right]=311(\Delta \mathrm{a})^{0.43}, \Delta \mathrm{a}\right.$ in $\mathrm{mm}$ ) for the lower bound data $\left(\mathrm{HAZ}, 125^{\circ} \mathrm{C}, \mathrm{C}-\mathrm{L}\right)$ for flaws oriented axially with respect to the piping. 
)

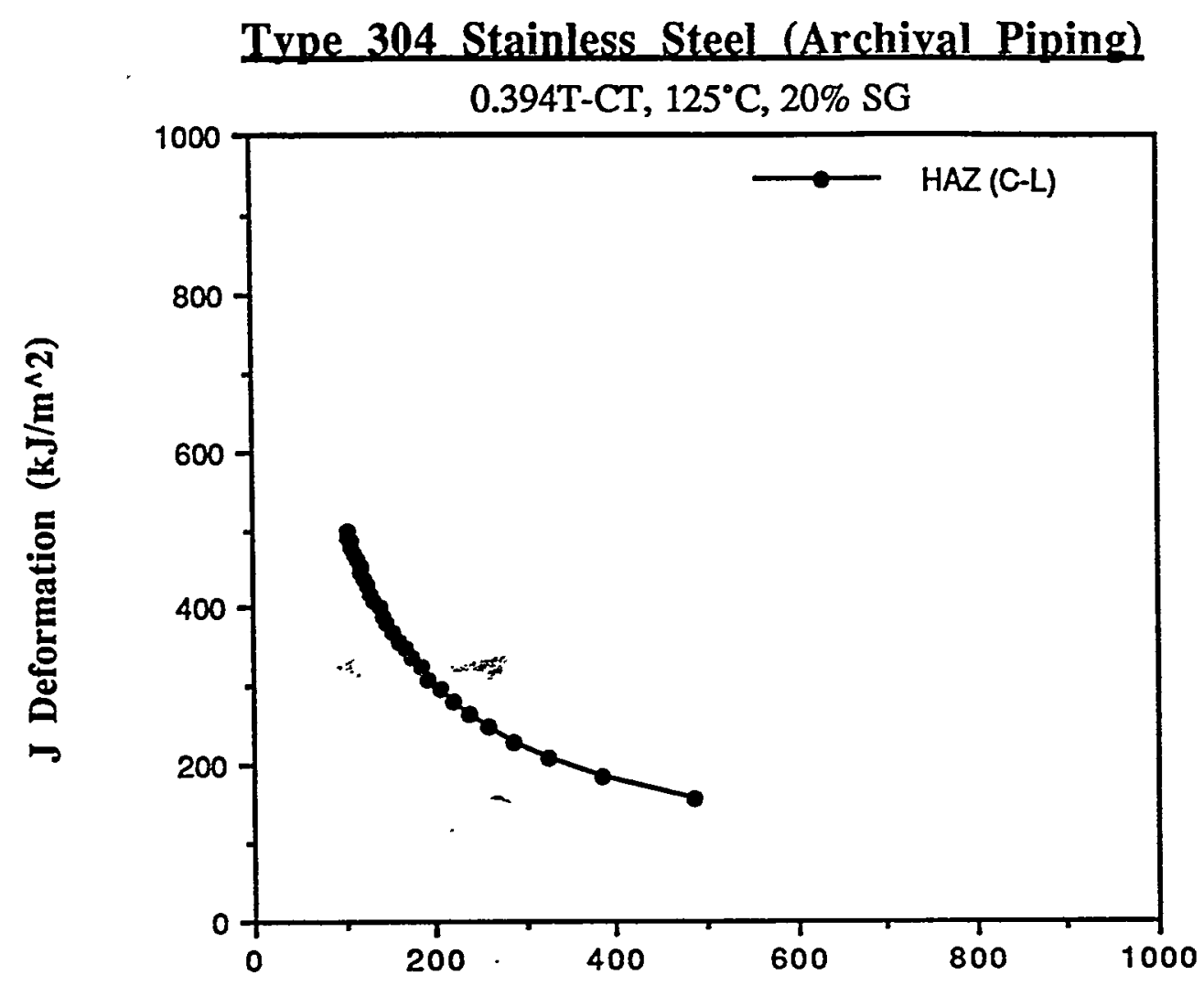

Tearing Modulus (T)

Figure II-3b: Material J-T curve from the power law formulation in Figure II-3a. A cut-off in the materials' curve at $\mathrm{J}=500 \mathrm{~kJ} / \mathrm{m}^{2}$ is shown. 